\title{
IMPLICATIONS OF NON-CARCINOGENIC PAH-FREE EXTENDER OILS IN NATURAL RUBBER BASED TIRE GOMPOUNDS
}

Anida Petchkaew 


\section{IMPLICATIONS OF NON-CARCINOGENIC PAH-FREE EXTENDER OILS IN NATURAL RUBBER BASED TIRE COMPOUNDS}




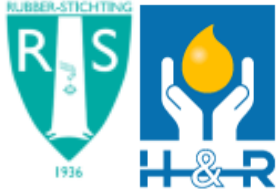

This research is a joint project between the University of Twente and Prince of Songkla University, sponsored by the Netherlands Natural Rubber Foundation and Hansen \& Rosenthal KG (Germany).

\section{Graduation committee}

Chairman: $\quad$ Prof. Dr. G.P.M.R. Dewul

University of Twente, CTW

Secretary:

Prof. Dr. G.P.M.R. Dewulf

University of Twente, CTW

Promoter:

Prof. Dr. Ir. J.W.M. Noordermeer

University of Twente, CTW

Asst. Promoter: Dr. K. Sahakaro

University of Twente, CTW and

Prince of Songkla University,

Science and Technology

Members: $\quad$ Prof. Dr.Ir. R. Akkerman

University of Twente, CTW

Prof. Dr. J.F.J. Engbersen

University of Twente, TNW

Prof. Dr. C. Kummerlöwe

University of Applied Science

Osnabrück, Germany

Prof. Dr. J. Busfield

Queen Mary University of London, UK

Dr. C. Bergmann

Hansen \&Rosenthal KG, Germany

Implications of Non-carcinogenic PAH-free Extender Oils in Natural Rubber Based Tire Compounds

By Anida Petchkaew

Ph.D. Thesis, University of Twente, Enschede, the Netherlands, and Prince of Songkla University, Pattani Campus, Thailand, 2015.

With references - With summary in English and Dutch

Copy right (C) Anida Petchkaew, 2015.

All rights reserved.

Cover design by Subhan Salaeh

Printed at Wöhrmann Print Service, Postbus 92, 7200 AB Zutphen, the Netherlands.

ISBN : 978-90-365-3763-6

DOI: $\quad 10.3990 / 1.9789036537636$

URL: $\quad$ http://dx.doi.org/10.3990/1.9789036537636 


\title{
IMPLICATIONS OF NON-CARCINOGENIC PAH-FREE EXTENDER OILS IN NATURAL RUBBER BASED TIRE COMPOUNDS
}

\author{
DISSERTATION
}

to obtain

the degree of doctor at the University of Twente,

on the authority of the rector magnificus,

Prof. Dr. H. Brinksma,

on account of the decision of the graduation committee,

to be publicly defended

on Thursday, January $15^{\text {th }}, 2015$ at $14: 45$

by

Anida Petchkaew

born on October $11^{\text {th }}, 1977$

in Narathiwat, Thailand 
This dissertation has been approved by :

Promoter $\quad$ : Prof. Dr. Ir. J.W.M. Noordermeer

Assistant Promoter : Dr. K. Sahakaro 
"The one who can stop him/herself each time the mind turns viral is the most fortunate person in the world."

"W. Vajiramedhi"

To my mom and dad 



\section{TABLE OF CONTENTS}

$\begin{array}{lll}\text { Chapter } 1 \quad \text { Introduction } & 1\end{array}$

$\begin{array}{lll}\text { Chapter } 2 & \text { Overview of process oils for extension of rubber } & 7\end{array}$

$\begin{array}{lll}\text { Chapter } 3 & \text { Oil characteristics } & 33\end{array}$

$\begin{array}{lll}\text { Chapter } 4 & \text { Swelling and solubility study of rubbers and process oils } & 47\end{array}$

Chapter $5 \quad$ Effect of oil types and contents on the properties of unfilled 59 rubber compounds

Chapter $6 \quad$ Effect of oil types and contents on the properties of carbon $\quad 79$ black-filled NR compounds

Chapter 7 Effect of oil types and contents on the properties of carbon 111 black-filled NR/SBR blend compounds

Summary

Samenvatting

Symbols and Abbreviations

Bibliography

Acknowledgements

Curriculum vitae 



\section{INTRODUCTION}

\subsection{Introduction}

Rubbers or elastomers are one type of polymers which have been defined according to ASTM D1566 as "a material that is capable of recovering from large deformations quickly and forcibly, and can be, or already is, modified to a state in which it is essentially insoluble (but can swell) in boiling solvents". The rubber technology started with natural rubber which was discovered by the natives from Haiti. They used the milky sap tapped from the rubber tree to make re-bouncing balls and water-proof clothing. The inventions in rubber technology were developed after the Europeans found and brought it to Europe. In 1839, Charles Goodyear and Thomas Hancock discovered that rubber becomes stronger and more elastic by sulfur and heat. The process was later called vulcanization which transforms raw rubber into an elastic rubber material. Hancock was also the pioneer in designing rubber processing machinery ${ }^{1}$. After that, accelerators, fillers, vulcanizing agents and other additives were discovered and developed for use with rubber. Synthetic rubbers were first produced in the 1920s and grew quickly in consumption because the Second World War interrupted the supply of natural rubber. At present, rubbers are widely used as components in cars and appliances such as tires, footwear, foams, belts, seals, hoses, wires, waterproof fabrics, etc. 


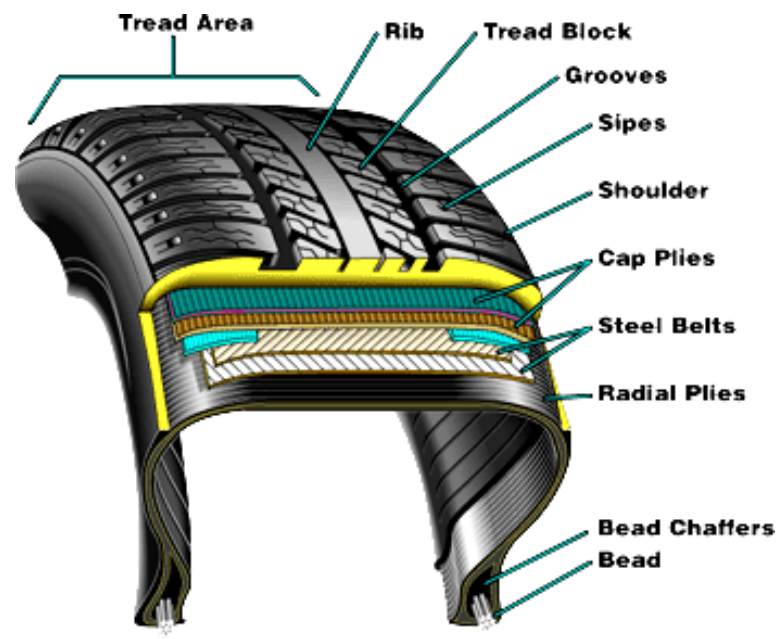

Figure 1.1 Tire components ${ }^{2}$.

For the tire industry, pneumatic tires consist of two basic areas, i.e. the casing and the tread. The tread is designed and compounded to have a good balance of three key properties including abrasion resistance, rolling resistance and wet skid resistance. Rubbers that are commonly used for different parts of tires are Natural Rubber (NR), Styrene Butadiene Rubber (SBR) and Butadiene Rubber (BR). Figure 1.1 shows the tire components. The function of rubber which is the main component is threefold: (1) to provide the contact area between the vehicle and the surface; (2) to provide the cohesive material that holds the tire together such that it acts as an integral unit; and (3) to provide protection for the ultimate strength bearing components ${ }^{3}$. Tire compounds are composed of various ingredients such as carbon black, accelerators, activators, antidegradants, sulfur and process oil. The oils added into rubber compounds are basically petroleum oils which are categorized into three basic types: aromatic, naphthenic and paraffinic. They are generally added in the compounds to improve processing properties, low temperature properties, dispersion of fillers, and to reduce cost. The conventionally widely used oils in tire compounds are Highly Aromatic (HA) oils, because they provide good compatibility with both natural and some synthetic rubbers, as used in tires.

Highly aromatic oils are also referred to as Distillate Aromatic Extract (DAE) which contain a high concentration of Polycyclic Aromatic Hydrocarbons (PAH) or also called Poly Nuclear Aromatics (PNA). PAHs are organic compounds possessing two or more aromatic rings, of which eight types are identified as carcinogens. These are Benzo[a]pyrene, Benzo[e]pyrene, Benzo[a]anthracene, Benzo[b]fluoranthene, Benzo[j]fluoranthene, Benzo[k]fluoranthene, Dibenzo[a,h]anthracene and Chrysene. Many other PAHs are harmful 
to health and environment. PAHs from tires are released to the environment by tire wear. These PAHs are bound to particles which later end up as sediments. Many of the PAH compounds are bioconcentrated in invertebrates in the aquatic environment and are enriched in the food chain ${ }^{4}$.

Due to a driving force from health and environmental risk awareness and an EU legislation ${ }^{5}$, non-carcinogenic oils are in need to replace HA oils in tire compounds. The noncarcinogenic oils which have been proposed to be used in tire compounds are such as Treated Distillate Aromatic Extract (TDAE), Mild Extracted Solvate (MES), Naphthenic oils (NAP) and natural oils. TDAE show better compatibility with SBR than MES because it is more like a HA oil than the MES ${ }^{6}$. The replacement of HA oils by non-carcinogenic oils could reduce the $\mathrm{PAHs}$ emission from tire wear by more than $98 \%{ }^{7}$. However, replacing the $\mathrm{HA}$ oils with these safe process oils has by far not yet fulfilled all technical requirements for rubbers in terms of physical, mechanical and dynamic properties. It has also been reported that some types of natural oils show positive results in some properties such as abrasion resistance in tire compounds ${ }^{8-10}$. Nevertheless, the results from the use of natural oils show inconsistencies and are considered to be far behind the use of petroleum-based TDAE and MES oils. Figure 1.2 shows some of petroleum oils.

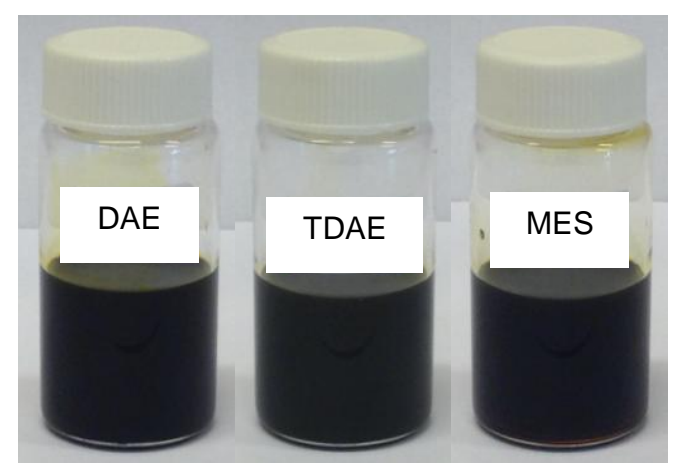

Figure 1.2 The example of petroleum oils.

\section{Aim of this research}

The utilization of PAHs-free extender oils for tire compounds should reduce the harmfulness of PAHs to health and environment and give the tire characteristics to meet the technical requirements for tire treads. This thesis investigates the influences of PAH-free 
petroleum based extender oils, i.e. TDAE and MES, on the properties of NR-based truck tire tread compounds and NR/SBR-based passenger tire tread compounds.

The main objective of this project is to comparatively study the processing properties and tire performance-related properties of the NR and NR/SBR-based tire tread compounds containing PAH-free oils versus conventional HA oil. The oils are characterized with respect to the compound and vulcanizate properties which are related to tire characteristics i.e. wet skid resistance, rolling resistance and wear resistance and other related performance criteria, e.g. hardness, modulus, tensile and tear properties.

\section{Structure of this thesis}

The thesis is divided into eight chapters, and starts with a general introduction in Chapter 1.

Chapter 2 gives an overview of the extender oils which are used in tire compounds. The contents in this chapter include the purposes of extender oils used in rubber compounds, types of extender oils, manufacturing of process oils, characterization of process oils and the non-carcinogenic process oils.

In Chapter 3 the physico-chemical characteristics of the process oils, e.g. density, refractive index, kinematic viscosity, viscosity gravity constant (VGC), aniline point, PAHs content, carbon type analysis data and glass transition temperature, are discussed. In addition, characterization of their thermal properties by Differential Scanning Calorimetry (DSC) and chemical structures by means of Fourier Transform Infrared Spectroscopy (FTIR) and proton Nuclear Magnetic Resonance Spectroscopy ( $\left.{ }^{1} \mathrm{H}-\mathrm{NMR}\right)$ are included in this chapter.

As the oil characteristics are related to the compatibility and mutual solubility of oils and rubbers, the solubility parameters of oils and rubbers are theoretical predicted and discussed in Chapter 4. The solubility aspects are described together with swelling tests of the process oils in lightly crosslinked rubbers.

Chapter 5 reports the findings from a preliminary study which was designed to investigate the effect of oil types and amounts on the properties of unfilled NR, SBR and NR/SBR compounds. Fillers are excluded in order to observe the changes in properties that are influenced by the oils only. Particular attention is paid to the change in glass transition temperature $\left(T_{g}\right)$ and dynamic properties of the rubbers. 
Chapter 6 discusses the effect of oil types and amounts on the properties of carbon black-filled NR truck tire tread compounds. Various properties of the compounds and vulcanizates, i.e. processing properties, filler dispersion, filler-filler and filler-polymer interactions, mechanical properties, dynamic properties, are analyzed and described in this chapter.

In Chapter 7 the effect of oil types and amounts on the properties of carbon blackfilled NR/SBR passenger tire tread compounds is investigated. The processing and vulcanizate properties under investigation are the same as those for the NR truck tire tread compounds in the previous chapter.

Finally, all of the studies discussed in this thesis are summarized in Chapter 8.

\section{References}

1 J.R. White and S.K. De, "Rubber Technologist's Handbook", Rapra Technology Ltd., Shropshire, 2001.

2 Internet page: http://www.offroaders.com/tech/AT-MT-Tires/tire-tech.htm, (August 15, 2013).

3 B. Rodgers, W.H. Waddell, S. Solis and W. Klingensmith, Kirk-Othmer Enc. Chem. Technol., 21, 805 (2004).

4 The Swedish National Chemicals Inspectorate, HA oil in automotives tyres, KEMI Reports No. 5/03, 2003.

5 Directive 2005/69/EC of the European Parliament and of the Council, Official Journal of the European Union, L323, 51 (2005).

6 I. Bowman, M. da Via, M.E. Pattnelli and P. Tortoreto, Kautsch. Gummi Kunstst., 57, 31 (2004).

7 V. Null, Kautsch. Gummi Kunstst., 52, 799 (1999).

8 S. Dasgupta, S.L. Agrawal, S. Bandyopadhyay, S. Chakraborty, R. Mukhopadhyay, R.K. Malkani and S.C. Ameta, Polym. Test., 26, 489 (2007).

9 S. Dasgupta, S.L. Agrawal, S. Bandyopadhyay, S. Chakraborty, R. Mukhopadhyay, R.K. Malkani and S.C. Ameta, Polym. Test., 27, 277 (2008).

10 S. Dasgupta, S.L. Agrawal, S. Bandyopadhyay, R. Mukhopadhyay, R.K. Malkani and S.C. Ameta, Polym. Test., 28, 251 (2009). 


\section{OVERVIEW OF PROCESS OILS FOR EXTENSION OF RUBBER}

Processing aids are chemicals added to elastomers and plastics for improving their processibility and changing the material properties. Processing aids are called with other names depending on their functions and contents, for example: a softener is a chemical that can decrease the hardness of rubber and increase the processibility of the material; a plasticizer is a chemical which increases the flexibility of rubber at low temperature; and an extender is used for increasing the filler loading in rubber ${ }^{1}$. Plasticizers are divided into two groups according to the plasticizing action; primary and secondary plasticizers. Primary plasticizers can dissolve in the rubber and increase the mobility of chain segments. Secondary plasticizers hardly dissolve in the rubber and act as a lubricant between the molecular chains of rubber $^{2}$. The secondary plasticizers can enhance the plasticizing efficiency of the primary plasticizers in the rubber system ${ }^{3}$. Plasticizers that bring about an improvement in flow and processibility are frequently known as process oils ${ }^{2}$. The process oils should be compatible with the rubber. The most widely used process oils in rubber compounds are mineral oils which are made from crude petroleum. This is because they are versatile, effective, tightly controlled for quality, inexpensive and easy to use. Process oils in rubber compounds serve three main purposes ${ }^{4}$ :

- To aid processing of the rubber during milling, mixing, extrusion and injection molding by providing lubrication of the rubber molecules;

- To improve the physical properties of natural and synthetic rubbers such as flex life and low temperature performance; and also aid the dispersion of fillers resulting in improvement in physical and mechanical properties such as tensile strength and abrasion resistance;

- To extend the rubber giving a larger volume of elastomer, thus reducing the cost of rubber compounds and of the finished rubber goods.

The process oils serve as internal lubricant in the rubber compound and allow for the use of higher molecular weight polymers, which have more desirable properties and still give a rubber compound that is acceptable for mixing, milling, and extrusion ${ }^{5}$. Generally, the process oils have high viscosity, low volatility and high solvency for the rubber compounds. 


\subsection{Types of process oils}

The rubber process oils are high boiling petroleum fractions obtained in refining after gasoline, fuel oil, and other low boiling compounds are removed by distillation. Process oils are made up largely of ring structures. The oil molecules typically contain unsaturated rings (aromatic), saturated rings (naphthenic) and saturated side chains (paraffinic) as shown in Figure 2.1.

(a)

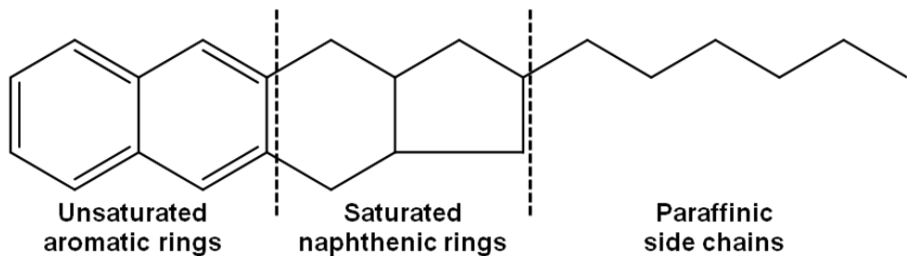

(b)

$\mathrm{CH}_{3} \mathrm{CH}_{2} \mathrm{CH}_{2} \mathrm{CH}_{2} \mathrm{CH}_{2}$ urs

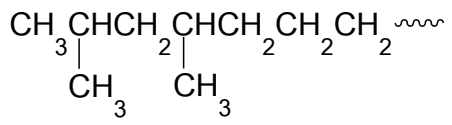

(c)<smiles>CCCCCCCC1CCCCC1</smiles><smiles>C1CCC2CCCCC2C1</smiles>

(d)

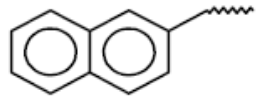

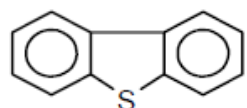

$\mathrm{s}$<smiles>c1ccc2c(c1)[nH]c1ccccc12</smiles>

$\mathrm{H}$

Figure 2.1 Typical molecules in process oils ${ }^{4}(\mathrm{a})$, and examples of various components in process oils (b)-(d): paraffins and isoparaffins (b); derivatives of cyclohexane or decalin (c); derivatives of naphthalene, dibenzothiophene and carbazole (d).

The most widely used process oils are divided into three groups, as follows:

1) Paraffinic oils

Paraffinic oils contain high levels of isoparaffinic molecules. They have less odor and more oxidative stability than naphthenic and aromatic oils. These oils have similar levels of monoaromatics, but much lower levels of multi-ring aromatics compared to aromatic oils.

2) Naphthenic oils

Naphthenic oils contain a higher level of saturated rings than aromatic and paraffinic process oils. They have similar odor to paraffinic oils. 


\section{3) Aromatic oils}

Aromatic oils contain high levels of unsaturated single- and multiple-ring compounds, stronger odor, lower oxidation stability, and higher reactivity compared to paraffinic and naphthenic oils.

Highly aromatic oils are conventionally widely used as process oils for rubber and tire compounds, because they have a good compatibility with both natural and diene-based synthetic elastomers. In addition, they have a low price. Highly aromatic oils are also often referred to as Distillate Aromatic Extracts (DAE). DAE has very high aromatic contents, typically at least $70 \mathrm{wt} \%$, and contains high concentrations of Polycyclic Aromatic Hydrocarbons (PAHs), typically from 10 to $15 \mathrm{wt} \%$. PAHs are also called Polycyclic Aromatics (PCA) as well as Polynuclear aromatics (PNA), of which some are identified as carcinogens.

\subsection{Manufacturing of process oils}

The process oils are manufactured from two general types of crude petroleum, i.e. paraffinic and naphthenic. These paraffinic and naphthenic crudes are complicated mixtures of the same types of molecules. Paraffinic crude petroleum has a higher level of paraffinic or saturated long-chain molecules. It tends to have higher levels of petroleum wax, which consists of straight-chained paraffinic molecules. Naphthenic crude petroleum has higher levels of saturated ring compounds and tends to be low in wax content. There are several methods applied for producing process oils from different crudes, e.g. naphthenic oil is produced from naphthenic feed by a hydrotreating process ${ }^{6-7}$ or by a two stages method involving hydrotreating and solvent extracting steps ${ }^{8-9}$. Process oils have also been made by the hydrotreating process from a mixture of aromatic and paraffinic rich feeds ${ }^{10}$ and a mixture of aromatic extract oil and naphthenic rich feed ${ }^{11}$.

The production of process oils is generally conducted via two different processes ${ }^{5}$. The first process is an extraction - hydrotreating - solvent dewaxing process which is a popular method for producing process oils, as shown in Figure 2.2. Crude petroleum is first distilled into streams according to boiling point, which roughly relates to molecular weight and hydrocarbon type. The heaviest oil stream is first de-asphalted to remove asphaltenes from the oil. The oil streams are next extracted with a solvent such as phenol or furfural to remove the highly aromatic molecules (three or more rings). These highly aromatic oils are used as process oil in rubber compounds. The oil streams are further hydrotreated to improve color and oxidation stability and are then dewaxed to improve the low temperature handling properties and improve compatibility with the rubber ${ }^{5}$. 


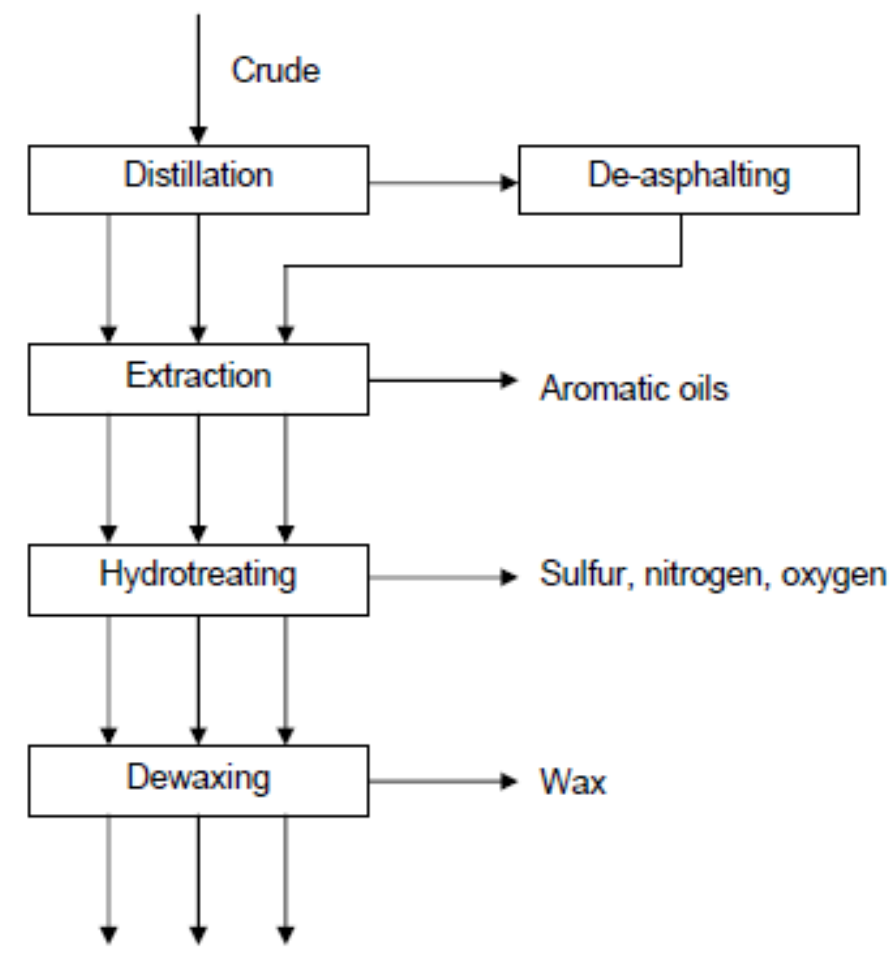

Process oils

Light viscosity, Medium viscosity, Heavy viscosity, Brightstock

Figure 2.2 Manufacture of process oils for rubber adapted from Moneypenny et al. ${ }^{5}$

The second process is a newer hydrocracking - isodewaxing process, as shown in Figure 2.3. The crude petroleum is distilled and then goes into a hydrocracker that breaks up the larger molecules into smaller molecules, opening ring compounds and saturating double bonds with hydrogen. This process converts the aromatic molecules rather that removing them. The oil streams then go to a hydroisomerization processing step, which branches the normal paraffins, making them no longer wax-type molecules. This process has a higher yield of process oil than conventional processing because the aromatic molecules and wax molecules are converted to process oil rather than being removed. This process does not produce the highly aromatic oils used in SBR, wax, or the heaviest process oil. 


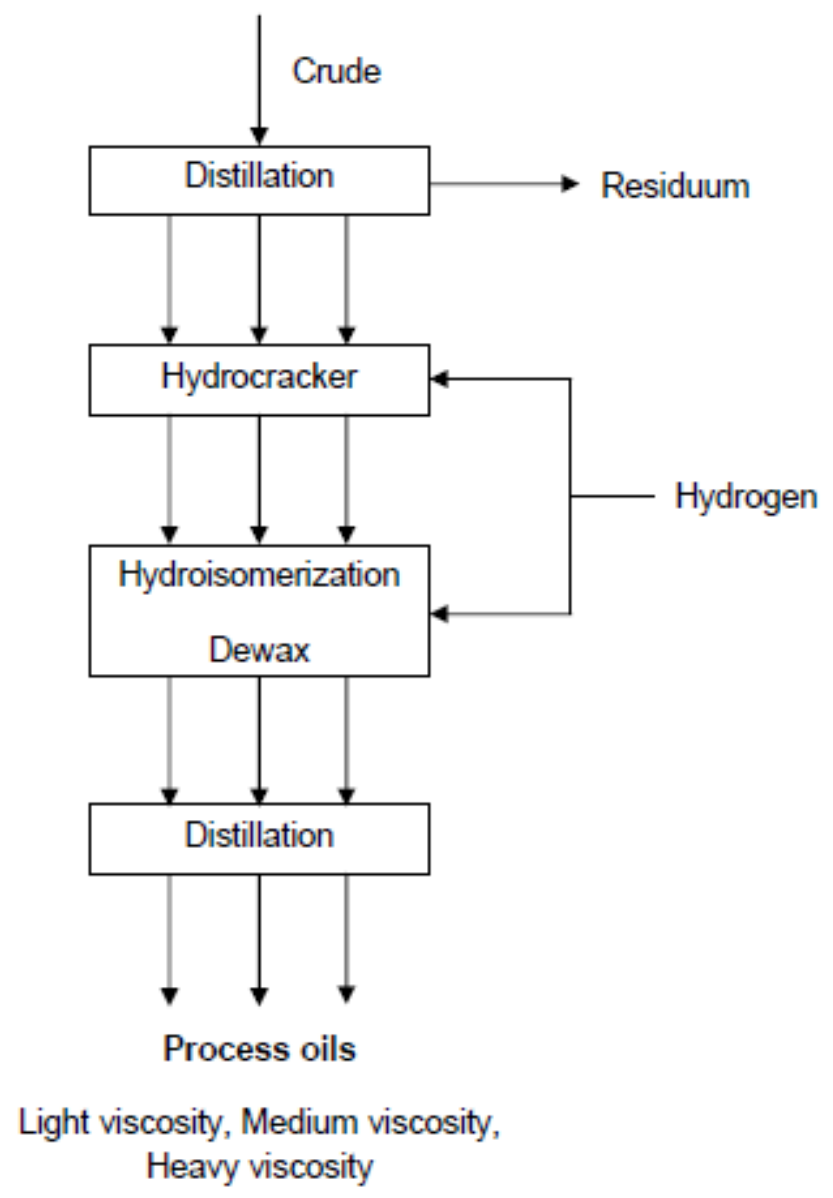

Figure 2.3 Alternative process oil manufacture (adapted from Moneypenny et al. ${ }^{5}$ ).

\subsection{Characterization of process oils}

The properties of rubber compounds depend on the composition and characteristics of the process oils. There are various identification methods for characterizing the process oils as indicated in Table 2.1. 
Table 2.1 Test methods for process oils ${ }^{5}$.

\begin{tabular}{ll}
\hline Inspection & ASTM test method \\
\hline Relative density & D1298 \\
Viscosity & D445 \\
Aniline point & D611 \\
Refractive index & D1218 \\
Color & D1500 or D156 \\
Flash point & D92 or D93 \\
Pour point & D97 \\
Evaporative loss & D972 \\
Composition & \\
$\quad$ Clay-gel analysis & D2007 \\
Carbon type & D2140 \\
Viscosity-gravity constant & D2501 \\
\hline
\end{tabular}

The properties of process oils are described in terms of following subsections ${ }^{5}$.

\subsubsection{Relative density}

Relative density, also known as specific gravity, is a measure of the density of the oil relative to the density of water. Relative density is normally measured and reported at $15.6^{\circ} \mathrm{C}$. Relative density of the oil increases with the aromatic content and molecular weight.

\subsubsection{Viscosity}

The viscosity indicates the ability of oil to flow. If viscosity is high, molecular weight is generally high and compatibility with the rubber is less, so more mixing time is required for the full dispersion of additives ${ }^{12}$. The high viscosity oil needs to be heated to reduce its viscosity before being added to the rubber compound.

There are two different types of viscosity; i.e. dynamic and kinematic viscosities. Dynamic viscosity is a measure of a liquid's resistance to movement and is measured in centipoise (cP). Kinematic viscosity is a measure of the velocity of a liquid and is obtained by measuring the time taken for a certain quantity of liquid to pass through a capillary tube. It is measured in centistokes, where $1 \mathrm{cSt}=1 \mathrm{~mm}^{2} / \mathrm{sec}$. The relationship between the two viscosities can be described as:

Kinematic viscosity $(T)=$ dynamic viscosity $(T) /$ density $(T)$

where $T$ is the temperature at which the viscosity and density are determined. 


\subsubsection{Aniline point}

The aniline point is measured according to ASTM D611 and is based on a measurement of the temperature at which aniline dissolves in the oil. The aniline point is a measure of the solvency of the oil. Low aniline points indicate a high solvency of the oil, and also high aromaticity. It is inversely related to the Viscosity Gravity Constant (VGC) value: see 2.3.9. The aniline point can be used to determine the compatibility of oils with a particular polymer. The aniline point depends on the molecular weight of the oil; oils with higher molecular weights have less solubility for aniline and thus higher aniline points.

\subsubsection{Refractive index}

The refractive index measured according to ASTM D1218 is a measure of the ratio of the velocity of light in air to the velocity of light in the substance being tested. It can be used to measure batch-to-batch consistency. The refractive index indicates the relative composition of the process oils. At a similar molecular weight and density, the refractive index increases with aromatic content ${ }^{13}$. It is also used to calculate the refractive intercept used in the carbon-type composition calculation. The Refractive Intercept (RI) is a relationship between the refractive index of oil at $20^{\circ} \mathrm{C}$ and its density. This parameter is also used to indicate the aromaticity of process oils, and is calculated by the following equation $^{13}$ :

$$
R I=N_{D}^{20}-0.5 d^{20}
$$

where $\mathrm{N}_{\mathrm{D}}^{20}=$ refractive index at $20^{\circ} \mathrm{C}$, and $\mathrm{d}^{20}=$ density at $20^{\circ} \mathrm{C}\left(\mathrm{g} / \mathrm{cm}^{3}\right)$.

\subsubsection{Color}

Aromatic oils are usually dark in color. The color of process oils is affected principally by the presence of heterocyclic polar compounds, generally aromatic groups that include sulfur, nitrogen or oxygen. Polar compounds can reduce the oxidation stability of the oil and therefore cause it to discolor during the action of UV light ${ }^{12}$. Color can be measured by comparing the color of the oil with a preset color chart. Color of the process oil can be important when light colored rubber products are to be produced. Color is generally measured according to either ASTM D156 (Saybolt Color) or D1500.

\subsubsection{Flash point}

The flash point of oil is the temperature at which enough flammable vapors exist above the oil that they will ignite or flash when brought in contact with an open flame. The flash point is measured according to ASTM D92 and D93. The flash point of oil is specified 
for safety reasons and is indicative of the oil's volatility. The lightest few percents of the oil determine the flash point. A correlation exists between the $5 \%$ point in the boiling range and the flash point. The lighter the products, the lower the flash point. Thus two oils with the same viscosity (50\% point) may have different flash points, depending on the amount of light products in the oil.

\subsubsection{Pour point}

Pour point is the lowest temperature at which the oil can flow and is measured according to ASTM D97. The pour point value is indicative of the low temperature flow properties of the oil and is related to the low temperature flexibility of rubber compounds. Paraffinic and aromatic oils tend to have wax pours, in which the oil will not flow owing to the formation of wax crystals. Naphthenic oils, because they generally contain very little wax, tend to have viscosity pours, where they stop flowing because of high viscosity at low temperature. The pour point is important in determining the handling characteristics of the oil at low temperature. It is also related to the wax content of paraffinic and aromatic oils.

\subsubsection{Volatility}

The volatility is determined according to ASTM D972 and is the measure of loss of volatile materials under controlled conditions. This can be important in selecting process oils, especially if the rubber will be subjected to high temperatures. The amount of volatile components from the rubber compound will be influenced by the compatibility of the process oil with the rubber.

\subsubsection{Viscosity gravity constant (VGC)}

The Viscosity Gravity Constant (VGC) is a dimensionless constant that is based on mathematical processing of the viscosity and density values and is measured according to ASTM D2501. The VGC increases as the hydrocarbon distribution changes from paraffinic to naphthenic to aromatic. As a general rule, paraffinic oils have a VGC ranging from 0.79 to 0.85 , naphthenic oils from 0.85 to 0.90 , and aromatic oils above 0.90 . The VGC value can be calculated from equation $(2.3)^{14}$ :

$$
V G C=\frac{G+0.0887-0.776 \log \log (10 \mathrm{~V}-4)}{1.082-0.72 \log \log (10 \mathrm{~V}-4)}
$$

where $\mathrm{G}=$ specific gravity at $15.6^{\circ} \mathrm{C}\left(60^{\circ} \mathrm{F}\right)$, and $\mathrm{V}=$ kinematic viscosity (cSt) at $37.8^{\circ} \mathrm{C}\left(100^{\circ} \mathrm{F}\right)$. 


\subsubsection{Aromatic, naphthenic and paraffinic contents}

There are two major analytical methods used for oil composition analysis:

1) Molecular - type analysis (or Clay - gel analysis)

The procedures are standardized under ASTM D2007. The oil is absorbed in a chromatographic column containing clay and activated silica gel. This method separates the oil into four main component groups ${ }^{4}$ as follows:

- Non-hydrocarbon molecules: These contain nitrogen, sulphur, or oxygen and are also called heterocyclics or polar compounds. They have been shown to be responsible for the degradation of oil-extended polymers in storage and under elevated temperature conditions such as in drying operations. It is also suggested that they have an effect on vulcanization rate.

- Aromatic molecules: These have more influence on rubber properties than any other molecules and are generally present in the two- or three-ring forms. They indicate the compatibility between oil and rubber, depending on the rubber type.

- Saturated molecules: These are highly inert, non-polar, and are not removed by the absorbants or acids. Comprising saturated rings with attached paraffinic side chains, they have very good oxidation stability and give good resistance to discoloration by heat and light.

- Waxes: These should not be present in high-quality oils, but lower grade materials may contain some to cause problems of blooming and sweat-out, because of their insolubility in rubbers. Use of this property is to prevent ozone cracking as an anti-ozonant wax.

This type of analysis has been used to establish a classification system of processing oils under ASTM D2226 that separates oils into four types such as 101, 102, 103 and 104. Types 101 and 102 would be considered aromatic types, 103 naphthenic and 104 paraffinic $^{14}$.

This method has a limitation by the fact that it does not define the degree of aromaticity or naphthenic character very accurately.

2) Carbon - type analysis

Carbon-type analysis provides a means of distinguishing these materials by utilizing the correlations obtained between the physical properties of pure compounds and hydrocarbon oils containing many types of molecules. This analysis depends on the correlation between the viscosity gravity constant (VGC) and the refractive intercept. This method as described by ASTM D2140 calculates the weight percentage of carbon atoms involved in each type of bond - aromatic, naphthenic and paraffinic - from the viscosity gravity constant, refractive index and density ${ }^{5}$. The correlation chart for determining the 
percentages of carbon atom in aromatic rings $\left(\% \mathrm{C}_{\mathrm{A}}\right)$, in naphthenic ring structures $\left(\% \mathrm{C}_{\mathrm{N}}\right)$, and in paraffinic side chains and main chains $\left(\% \mathrm{C}_{\mathrm{P}}\right)$, is shown in Figure 2.4.

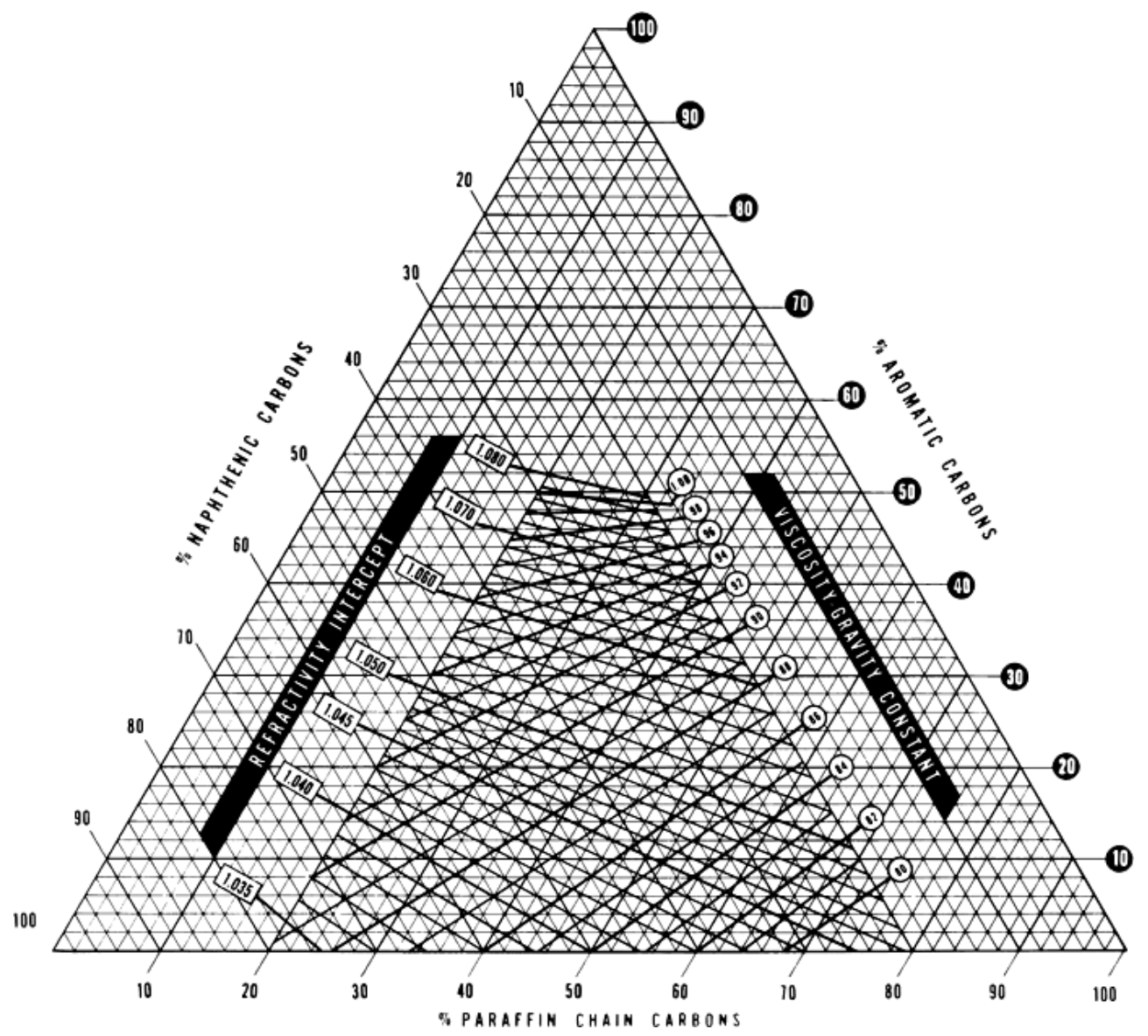

Figure 2.4 Correlation chart for determining $\% \mathrm{C}_{\mathrm{A}}, \% \mathrm{C}_{\mathrm{N}}$, and $\% \mathrm{C}_{\mathrm{P}}{ }^{14}$.

The basic selected properties of the 3 types of process oils are shown in Table 2.2. 
Table 2.2 Properties of oils used in the rubber industry ${ }^{12}$.

\begin{tabular}{|c|c|c|c|c|}
\hline \multirow{2}{*}{ Property } & \multirow{2}{*}{$\begin{array}{l}\text { ASTM } \\
\text { method }\end{array}$} & \multicolumn{3}{|c|}{ Petroleum oils } \\
\hline & & Paraffinic & Naphthenic & Aromatic \\
\hline \multicolumn{5}{|l|}{ Saybolt viscosity } \\
\hline SUS $^{*}, 37.8^{\circ} \mathrm{C}$ & D2161 & $72-3525$ & $103-5830$ & $192-38170$ \\
\hline SUS $^{*}, 98.9^{\circ} \mathrm{C}$ & D2161 & $36-175$ & $36-136$ & $40-300$ \\
\hline Flash point $\mathrm{COC},{ }^{\circ} \mathrm{C}$ & D92 & $174-304$ & $158-257$ & $174-302$ \\
\hline Specific gravity, $15.6^{\circ} \mathrm{C}$ & & $0.847-0.904$ & $0.909-0.959$ & $0.957-1.018$ \\
\hline Pour point, ${ }^{\circ} \mathrm{C}$ & D97 & -23 to -15 & -46 to -4 & -23 to +35 \\
\hline Aniline point, ${ }^{\circ} \mathrm{C}$ & D611 & 92 to 129 & 60 to 89 & 8 to 74 \\
\hline \multicolumn{5}{|l|}{ Clay gel analysis, wt \% } \\
\hline Asphaltenes & & 0 & 0 & 0 \\
\hline Aromatics & D2007 & $9.7-37.0$ & $34.8-48.0$ & $57.9-80.0$ \\
\hline Polar compounds & & $0.2-6.4$ & $0.2-13.0$ & $5.1-24$ \\
\hline Saturates & & $58.0-90$ & $51.1-65.0$ & $11.0-35.3$ \\
\hline \multicolumn{5}{|l|}{ Carbon type analysis, \% } \\
\hline \multicolumn{5}{|l|}{ C-aromatic } \\
\hline C-naphthenic & D3238 & $2-9$ & $15-29$ & $30-57$ \\
\hline \multirow[t]{2}{*}{ C-paraffinic } & & $23-33$ & $32-46$ & $9-40$ \\
\hline & & $62-73$ & $35-46$ & $23-48$ \\
\hline
\end{tabular}

${ }^{*}$ SUS - Saybolt Univeral Seconds

\subsubsection{Quantification of polyaromatic and polycyclic aromatic compounds}

Environmental considerations regarding rubber process oils are related to their polyaromatic content. There are a number of methods to measure the polyaromatic content of the oil; e.g. IP346 (an analytical method essentially measuring the level of certain polyaromatic compounds through selective extraction with a solvent), high pressure liquid chromatography (HPLC), and gas chromatography $(G C)^{5}$. The results of the various methods differ significantly because they measure different things. The IP346 method is used for deciding which oils have to be labelled under European Community (EU) legislation. It measures the content of substances that are soluble in dimethyl Sulfoxide (DMSO). DMSO dissolves all polyaromatics and a number of single aromatics and naphthenes, especially if they contain a heteroatom. It has been shown, using skin painting on mice, that there is a correlation between the IP 346 test results and possible physiological effects ${ }^{5}$. Oils with a value of $3 \%$ (by weight) and above have to be labelled in 
Europe. Values obtained by IP346 are significantly higher than the true polyaromatic contents of interest, and this is especially true for naphthenic oils ${ }^{5}$.

The IP346 test method can measure the proportion of the polycyclic aromatic compounds, but can not separate between carcinogenic and non - carcinogenic species. High-field proton nuclear magnetic resonance $\left({ }^{1} \mathrm{H}-\mathrm{NMR}\right)$ was proposed to analyse polycyclic aromatic hydrocarbons (PAHs) in petroleum products, which is an extension of the IP346 test method ${ }^{15}$. This method is used to measure the level of bay region protons within polycyclic aromatic molecules that show discrimination between carcinogenic and non carcinogenic materials. There are certain structures within the molecule which are considered to be directly associated with their carcinogenic potential. The method uses the bay region proton measurement as a marker for carcinogenicity. Proton types in PAHs are expressed in Figure 2.5 and Table 2.3. A determination of the aromaticity of oil in vulcanized rubber compounds by ${ }^{1} \mathrm{H}$ NMR is also standardized according to ISO 21461 : $2006(E)^{16}$ in order to check the types of oils used in e.g. ready tires put on the market.

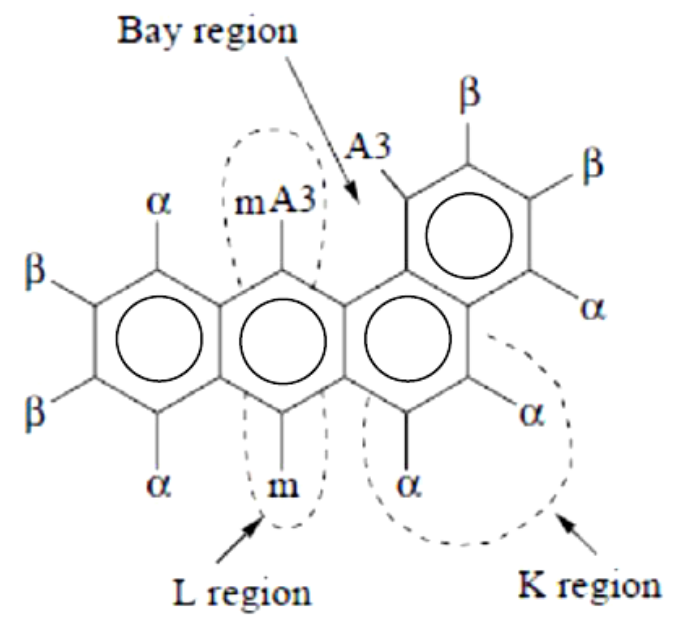

Figure 2.5 Proton types in PAHs molecules (Benzo[a]anthracene example) ${ }^{15}$. 
Table 2.3 PAH protons in the ${ }^{1} \mathrm{H}-\mathrm{NMR}$ spectrum ${ }^{15}$.

\begin{tabular}{|c|c|c|}
\hline Type & Position, ppm & Location of protons in PAH molecules \\
\hline & 0 to 4 & On side chain \\
\hline$\beta$ & up to 7.9 & $\beta$ to a ring in a 2-ring or greater $\mathrm{PAH}$ \\
\hline$\alpha$ & up to 8.3 & $\begin{array}{l}\alpha \text { to a ring in a 2-ring or greater } \mathrm{PAH} \text {, but not in a bay } \\
\text { location }\end{array}$ \\
\hline $\mathrm{m}$ & 8.2 to 8.5 & $\alpha, \alpha$ to 2 rings in a 3-ring or greater $\mathrm{PAH}$ \\
\hline A3 & 8.1 to 9.0 & On a 3-sided bay region \\
\hline mA3 & 8.9 to 9.4 & On a 3-sided bay region and $\alpha, \alpha$ to 2 rin \\
\hline \multicolumn{3}{|c|}{ Other types of bay region protons not shown in Figure 2.5} \\
\hline A4 & 8.6 to 9.3 & On a 4-sided bay region \\
\hline A5 & 8.5 & On a 5 -sided bay region \\
\hline
\end{tabular}

Gas chromatography - mass spectroscopy (GC - MS) is also applied to determine more specifically the quantity of carcinogenic PAHs in petroleum products. A normal phase high pressure liquid chromatography-gas chromatography (LC-GC) has been developed to provide quantitative analysis of PAHs in petroleum fuel, diesel exhaust particulates, coal liquids and urban air particulates ${ }^{17}$. Solid-phase extraction columns are employed for the quantitative extraction of a range of $\mathrm{PAHs}$ from transformer oils, which are subsequently analyzed by gas chromatography ${ }^{18}$. The determination of aromatics and PAHs in gasoline samples is performed by using a sensitive method that employs a programmed temperature vaporizer inlet followed by capillary gas chromatography coupled to mass spectrometry in the ion monitoring acquisition mode (PTV-GC-MS (SIM) $)^{19}$. The PAHs in diesel, residue and soot samples collected during each burn, are quantitatively characterized by GC-MS and a new pyrogenic index was proposed as a quantitative indicator for identification of pyrogenic $\mathrm{PAHs}$ and for differentiating pyrogenic and petrogenic PAHs ${ }^{20}$. GC-MS is often used for characterizing PAHs content in petroleum products, but it has the limitation to determine the sulfur-containing PAHs in petroleum and other geochemical substances, so a $\mathrm{Pd}(\mathrm{II})$ containing stationary phase, which allows the polycyclic aromatic sulfur heterocycles (PASHs) to be collected in a separate fraction, was proposed to solve this problem ${ }^{21}$. Furthermore, fluidized - bed extraction was proposed to determine PAHs in carbon black, cured rubber compounds and tire treads. This method involves fluidized - bed extraction prior to clean up and analysis of PAHs by GC - MS applying the isotope dilution principle ${ }^{22}$. 


\subsection{Plasticization mechanism of process oils in rubber}

Process oils are added into rubber compounds to improve processability and rheological, physical and mechanical properties of rubbers. Process oils act as plasticizers in rubber compounds and they have varying degrees of solvation action on rubber. The plasticization is the softening action of plasticizer that is attributed to its ability to reduce the intermolecular attractive forces between chains in the polymer system ${ }^{23}$. The softening effect of plasticizer improves processing through easier filler incorporation and dispersion, lower processing temperatures and better flow properties ${ }^{2}$. There are four main theories that describe the plasticization of plasticizers in polymer systems, i.e. the lubricity theory, the gel theory, the free volume theory and the mechanistic theory ${ }^{2,24-25}$.

\subsubsection{The lubricity theory}

A plasticizer acts as a lubricant and reduces intermolecular friction between the polymer molecules. It can lubricate the movement of the molecules and reduce their internal resistance to sliding. Dissolving and swelling occur first in the plasticized systems, polymers are dissolved when all bonds between the chains are completely broken, while they are swollen if the bonds between the chains are partly broken and partly intact. In polymer bulk, the large voids in the molecular space lattice lead to the formation of planes of easy gliding. A plasticizer fills the voids between the gliding planes, acts as a lubricant, so one plane can glide over another. Marcilla and Beltran ${ }^{25}$ show two possibilities of gliding which could explain the mechanism of softening by plasticizers.

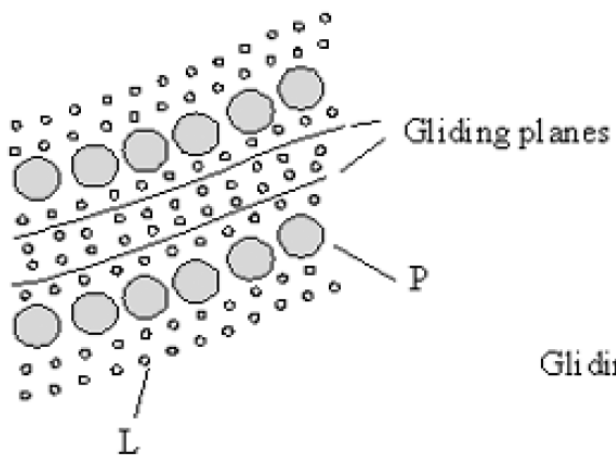

(a)

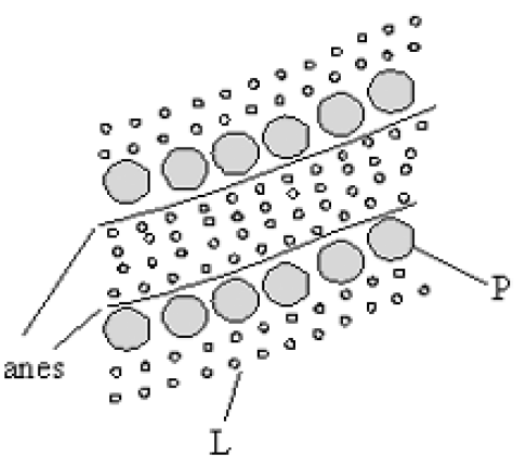

(b)

Figure. 2.6 Two possibilities for gliding ${ }^{25} . P$ is polymer and $L$ is lubricant. (a): the gliding planes are in the bulk of the plasticizers; and (b): the gliding planes are at the polymer lubricant interphase surface. 


\subsubsection{The gel theory}

The gel theory can be explained by a model of polymers in three-dimensional honey comb structure or gel, which is formed by attachment of the polymer molecules. This structure is the cause of rigidity of polymers, while the weak attachment of polymer molecules leads to the gel. The points of attachment are close together and so reduce the molecular movement. Plasticizers move to solvate the polymer-polymer union or the points of attachment, therefore the rigidity of polymer is reduced. Free plasticizer that is not solvating the polymer attachment can also swell the polymer providing further flexibility ${ }^{24}$. Figure 2.7 shows the gel theory of plasticization.

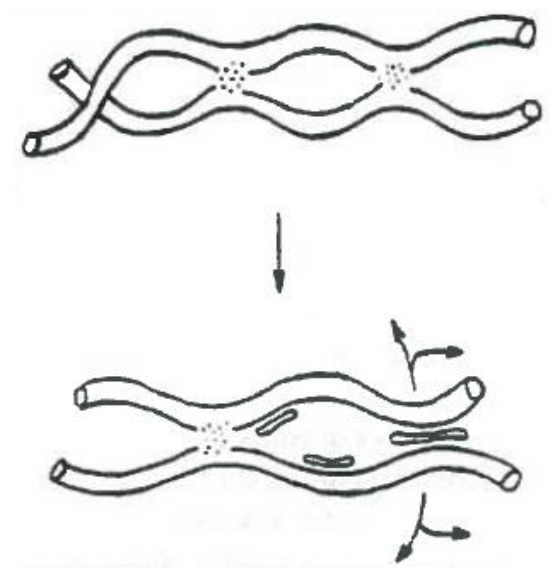

Figure 2.7 The gel theory of plasticization ${ }^{24}$.

\subsubsection{The free volume theory}

The free volume theory was later proposed, after the lubricity and the gel theory. This theory is used to explain the movement of polymer molecules and the glass transition temperature change of plasticized polymer. Free volume is the space between atoms and molecules and is the difference of the specific volume above the transition temperature and the solid specific volume extrapolated to the same temperature above the transition temperature. Free volume is increased when the specific volume increases and temperature causes to increase the specific volume. Marcilla and Beltran ${ }^{25}$ referred to the work of Fox and Flory in which the specific volume versus temperature curve for a polystyrene fraction was reported ${ }^{26}$. Therein, the specific volume increased with temperature, attributed to an increase of the space between atoms and molecules as well as the molecules had enough energy to move, rotate or bend above the glass transition temperature ${ }^{25}$. Figure 2.8 shows the sources of free volume for plasticization. 

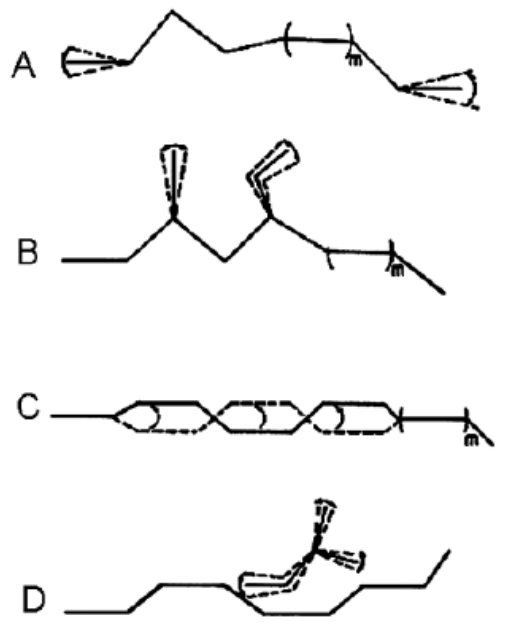

Figure 2.8 The sources of free volume for plasticization ${ }^{25}$. $(A)$ : chain end motion; $(B)$ : side chain motion; $(C)$ : main chain movement; (D): external plasticizer motion.

The introduction of a plasticizer, which has a lower molecular weight than the polymer, can impart a greater free volume per volume of material since (1) there is an increase in the proportion of end groups, and (2) it has a lower glass transition temperature than the polymer ${ }^{3}$. Therefore, addition of plasticizer into the polymer system not only changes the glass transition temperature of the polymer, but also raises the free volume for the polymer system. The plasticizer efficiency is affected by the molecule weight and structure of the plasticizer.

\subsubsection{The mechanistic theory}

The mechanistic theory relates to the solvation - desolvation equilibrium and is closest to the gel theory in which a plasticizer selectively solvates the point of attachment along the polymer chain. In the gel theory, plasticizer attaches to the polymer chain, whereas in the mechanistic theory plasticizer can exchange with other plasticizer molecules. In this theory, plasticizer is not bound permanently to the polymer, but an exchange in an equilibrium mechanism between solvation and desolvation of the polymer ${ }^{3,24}$.

\subsection{Non-carcinogenic process oils}

Extender oils that are generally used for rubber and tire compounds are aromatic oils because they give good compatibility with the typical rubbers used for tires: NR, SBR and BR. However, they have PAHs or PNAs greater than $3 \mathrm{wt} \%$ (according to the IP346 test method) and are classified as carcinogenic substances according to the European 
legislation ${ }^{27-30}$. The aromatic oils must be labelled with the risk phrase "R45" (may cause cancer) and the label "T" (toxic, skull and crossbones) in Europe. There are eight types of $\mathrm{PAHs}$ that have been identified as carcinogens, i.e. Benzo[a]pyrene (BaP), Benzo[e]pyrene (BeP), Benzo[a]anthracene (BaA), Chrysene (CHR), Benzo[b]fluoranthene (BbFA), Benzo[j]fluoranthene (BjFA), Benzo[k]fluoranthene (BkFA), and Dibenzo[a,h]anthracene (DBahA). Their chemical structures are shown in Figure 2.9. PAHs from tires are released to the environment by tire wear and PAHs are bound to particles as sediments at the end. According to a KEMI report ${ }^{31}$, $\mathrm{PAH}$ compounds are bio-concentrated in invertebrates in the aquatic environment and are enriched in the food chain. The International Agency for Research on Cancer (IARC) also reported that the PAHs in mineral oils provide a risk on the health of experimental animals ${ }^{32}$. Due to the impulse from the health and environmental risk awareness which lead to the issuance of EU legislations, non - carcinogenic oils are needed to replace aromatic oils in tire compounds.<smiles>c1ccc2c(c1)cc1ccc3cccc4ccc2c1c34</smiles>

$\mathrm{BaP}$<smiles></smiles>

BbFA<smiles>c1cc2c3c-2cccc3ccc2cccc3c2=c2c(c1)cccc23</smiles>

BeP<smiles>c1cc2ccc3c(cc2c1)c1cccc2cccc3c21</smiles>

BjFA<smiles>c1ccc2cc3c(ccc4ccccc43)cc2c1</smiles>

BaA<smiles>c1ccc2cc3c(cc2c1)-c1cccc2cccc-3c12</smiles>

BkFA<smiles>c1ccc2c(c1)ccc1c3ccccc3ccc21</smiles>

CHR<smiles>c1ccc2c(c1)ccc1cc3c(ccc4ccccc43)cc12</smiles>

DBahA

Figure 2.9 Eight types of PAHs are identified as carcinogens.

Various processes have been proposed to produce process oils with low PAHs content $^{33-42}$, i.e. less than 3 wt\% by the IP346 method. For example, lube oil distillate and deasphalted oil are selected as raw material oils to be extracted with a solvent having a selective affinity for aromatic hydrocarbons under the condition such that the extraction yield complies with the PAHs content of the lube fraction ${ }^{34-35}$. The process oil from this method contains less than $3 \%$ by weight of PAHs content (IP346), which has an aniline point of $80^{\circ} \mathrm{C}$ or less, and $\% \mathrm{C}_{\mathrm{A}}$ value of 20 to $50 \%$. Kaimai et al. ${ }^{38}$ also used the lube oil distillate and deasphalted oil as feedstock, extracted with the solvent having selective affinity for aromatic hydrocarbons. 
A novel process for the production of an extract useful as a process oil and a raffinate useful as a high-viscosity base oil by solvent refining was reported by Morishima and Fujino ${ }^{39}$. They carried out a reduced pressure distillation under the condition that the end point of the distillate is $580^{\circ} \mathrm{C}$ or higher. Then, the resulting residual oil was deasphalted and the resulting deasphalted oil was subjected to solvent refining. They claimed that this is a novel and economic process for preparing a rubber process oil having a high safety and PAHs content less than 3 wt $\%$. Takasaki et al. ${ }^{40}$ reported a process for efficiently producing a process oil using residual oil as feedstock. Herein, the residual oil was mixed with lubricant base oil and the mixture was extracted with a solvent to obtain a process oil with a low PAHs content. They claimed that the viscosity of ordinary oil from this process was maintained and the compatibility with SBR was excellent. Other inventors report solvent extraction methods with polar solvents for producing rubber process oils ${ }^{41-42}$.

Treated Distillate Aromatic Extract (TDAE) and Mild Extracted Solvate (MES) are used as extender oils to replace high aromatic oils for rubber compounds. TDAE is manufactured from DAE by further severe processing, such as hydrotreating or solvent extraction, to lower the concentration of PAH's to below the threshold of $3 \mathrm{wt} \%$ (IP346). MES is a paraffinic vacuum distillate fraction, wherein the aromatic content is kept as high as possible, but the PAH-content is below the threshold of $3 \mathrm{wt} \%{ }^{43}$. The manufacture of these oils is schematically displayed in Figure 2.10. RAE (residual aromatic extract) with low $\mathrm{PAH}$ concentration is also produced from the extraction of the heaviest stream, but RAE has a viscosity $3-4$ times higher than the DAE and there may not be enough supply to meet the demand.

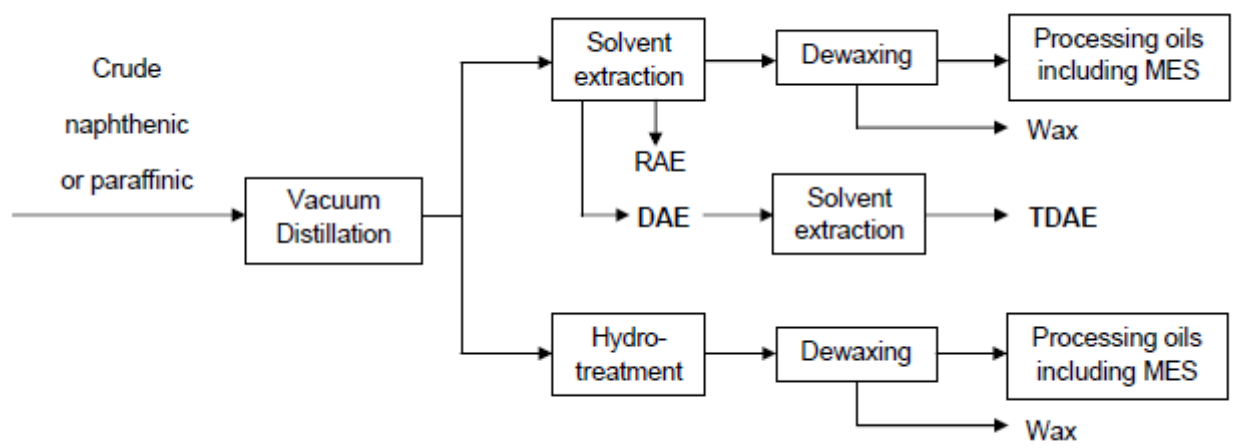

Figure 2.10 General refining technologies (adapted from Joona ${ }^{44}$ )

The risk of $\mathrm{PAH}$ in tire wear particles lead to a search for alternative PAH-tree oils to replace the DAE in tire tread compounds. The structure-property relationships of process 
oils and interactions between the oils and rubber have been studied by Schneider et al. ${ }^{45}$ Their investigation was based on SBR based carbon black reinforced tire tread compounds using 4 types of process oils with contents of aromatic carbon ranging from $38 \mathrm{wt} \%$ to $4 \mathrm{wt} \%$ by the IP346 method. The properties of the oils were related to the aromatic carbon content, and the change of glass transition temperature $\left(T_{g}\right)$ of the oil-extended rubber was correlated with the $T_{g}$ of the oils. It was demonstrated that the $T_{g}$ of oils clearly affected the vulcanizate properties.

$\mathrm{Null}^{46}$ investigated the use of TDAE, MES and naphthenic oils in carbon black filled E-SBR/NR/BR compounds and silica filled S-SBR/BR compounds, where E-SBR, S-SBR and $\mathrm{BR}$ are emulsion styrene-butadiene rubber, solution styrene-butadiene rubber and butadiene rubber, respectively. The replacement of DAE by the PAH-free oils (i.e. TDAE, MES and NAP oils) could reduce the PAH emission from tires by more than $98 \%$. The Mooney viscosity of a carbon black compound with MES was decreased to the greatest extent. All PAH-free oils show significant improvement in DIN abrasion resistance for both SBR rubber types, while other properties such as tensile strength, elongation at break, modulus at $300 \%$ elongation and hardness are comparable when compared with DAE. The changes of properties affected by the oil types are more pronounced in carbon black compounds when compared with those of silica compounds. All PAH-free oils show an improvement of rolling resistance especially in carbon black compounds, but deterioration in the wet grip property.

TDAE and MES oils are similar in their basic physical properties but different in the chemical nature because of the different proportions of aromatics and saturates. Bowman et al. ${ }^{47}$ reported the use of TDAE and MES as extender oils in oil-extended types of E-SBR and S-SBR for replacement of highly aromatic oil. In E-SBR 1712, MES oil shows a lower compatibility than TDAE. Both E-SBR and S-SBR rubbers with TDAE and MES show an uncertainty trend in the mechanical properties after aging, but both types of oils show small differences in properties compared to DAE oil. In SBR compounds, the replacement of highly aromatic oil with TDAE oil would require some changes in compound formulations, but the replacement with MES would also require an appropriate microstructure change of the S-SBR. This work concluded that a satisfactory result could be achieved by simply changing the oil from highly aromatic to TDAE, but the introduction of MES would be much more difficult.

Naphthenic oil is also used as safe extender oil in rubber compounds since it is non-carcinogenic and is a good plasticizer alternative for very non-polar elastomers such as Ethylene Propylene Diene (EPDM) rubber. Naphthenic oils show good characteristics in SBR despite their low aromatic content, and are one of the best alternatives to aromatic 
extracts as far as solvent properties, compatibility, performance and availability are concerned $^{44}$. Joona ${ }^{48}$ investigated the effect of 4 naphthenic and DAE oils in solution-SBR based silica compounds. The results show that the vulcanization characteristics are comparable for all compounds, but the mechanical properties of each compound are slightly different. This work demonstrates that naphthenic oil has a good compatibility with a solution-SBR based-silica compound, and shows slightly better wet grip property with very similar rolling resistance compared to DAE.

Neau et al. $^{49}$ employed naphthenic oils as extender oil in two tire rubber formulations, one based on emulsion-SBR with carbon black and the other based on solution-SBR/BR with silica. In this work, three naphthenic oils were compared to DAE and TDAE. All three naphthenic oils need longer cure time than DAE because they contain a lower amount of sulfur compounds in the oil compared to DAE. The naphthenic and TDAE oils give very similar $T_{g}$ of the final compounds and the same tan $\delta$ (hysteretic properties) at $0^{\circ} \mathrm{C}$ in S-SBR/BR indicating similar wet grip properties of tires made thereof. The tan $\delta$ in the range between 0 to approx. $+30^{\circ} \mathrm{C}$, may be taken as an indication of tire skid behaviour, and the range between +30 to approx. $+70{ }^{\circ} \mathrm{C}$ comprises the normal running temperature of a tire, so that under these temperature conditions tan $\delta$ essentially determines the degree of rolling resistance ${ }^{50}$. However, the compound with TDAE shows a higher $\tan \delta$ at $60^{\circ} \mathrm{C}$ which indicates higher rolling resistance. In E-SBR, only small differences in $T_{g}$ of compounds were observed when changing the oils, while all naphthenic and TDAE oils show similar $\tan \delta$ at $60^{\circ} \mathrm{C}$ but lower than that obtained with DAE. The tan $\delta$ at $0^{\circ} \mathrm{C}$ are comparable for naphthenic and DAE oils in E-SBR, but slightly higher than TDAE. The performance of these naphthenic oils in the compounds based on E-SBR and S-SBR/BR is different. Nevertheless, this study shows that naphthenic oils are good alternatives, matching very well to those of TDAE for the replacement of the labelled DAE.

Dynamic mechanical properties of the rubber compounds with oils having a low content of PAHs compared to those having the same composition but aromatic oil (DAE) were reported by Kuta et al. ${ }^{51}$ They studied the influence of oils that were used as extender oils in SBR and as process oils in tire compounds based on NR and/or SBR and/or BR. The oils with low PAHs content used in this work were TDAE, MES, RAE and naphthenic oils. The low PAHs content oils show a slight difference in viscoelastic properties of oil extended SBR when compared with those of rubber with aromatic oils, while the dynamic properties of laboratory prepared standard vulcanizates of tire rubbers are minimally influenced. The performance of six new eco-friendly oils and standard aromatic oil in rubber compounds such as NR, SBR, NR/SBR and BIIR/NR blends was studied by Öter et al. ${ }^{52}$. They found 
that the use of eco-friendly oils such as TDAE, MES and NAP give a small change in rheological, physical and mechanical properties for unaged vulcanizates. Furthermore, these eco-friendly oils result in some improvement in tensile strength for aged vulcanizates. Based on their study of various rubber compounds, it seems possible to adjust the rubber formulations to have very similar properties to that of traditional aromatic oil containing compounds.

Not only petroleum-based TDAE, MES and naphthenic safe process oils have been tested in tire tread compounds, but there are also attempts to apply natural oils in such compounds. Natural oils (e.g. rubber seed, neem, dolma, soybean, alsi, kurunj, sesamum, mustard, ground nut and castor oils) show a lower aromatic content, specific gravity, pour point, VGC and aniline point than the HA oil. Dasgupta et al. ${ }^{53-55}$ have published a series of works based on natural oils. For a NR-based truck tire tread cap compound, some natural oils show better processing properties (lower Mooney viscosity, lower activation energy of the flow process and faster curing), better polymer-filler interaction and filler dispersion than the petroleum oils ${ }^{53}$. Petroleum oils show higher crosslink density and $300 \%$ modulus than natural oils, while tensile strength and elongation at break of all compounds are comparable. Compounds with some natural oils display higher abrasion loss, heat build up and fatigue to failure, as well as better traction properties but poorer rolling resistance than those of compounds containing $\mathrm{HA}$ oil ${ }^{54}$. Even though the results are quite fluctuating among different types of compounds, natural oils may act as alternative processing oils for rubber compounds. Natural oils (i.e. neem and kurunj oils), which were mixed with a NR compound, NR/BR-based bias truck tire tread cap compound, NR/BR-based rip type tire tread cap compound, and S-SBR/NR/BR-based radial passenger tire tread compound, yield better modulus and hardness retention but poorer tensile strength retention after ageing when compared with the compounds containing aromatic oil. All compounds mixed with natural oils show better abrasion properties which are supported by their better polymer-filler interaction and filler dispersion ${ }^{55}$. The performance of epoxidized natural oils such as Epoxidized Palm Oil (EPO) and Epoxidized Soybean Oil (ESBO) in NR, SBR and NR/SBR blend compounds has been investigated ${ }^{56}$, compared with conventional aromatic oil (DAE). The results show that all compounds with EPO and DAE oils have similar cure characteristics and processing properties, but the use of ESBO oil retards the curing reaction. The mechanical properties of the compounds having EPO and DAE oil are comparable and better than those of the compound with ESBO. 


\subsection{Concept of this thesis}

The present work in this thesis investigates the characteristics of conventional aromatic oil (DAE) and two types of petroleum-based safe process oils, i.e. TDAE and MES oils. The physico-chemical characteristics of the process oils are analyzed. In addition, characterization of the chemical structure of the process oils by means of FTIR and NMR spectroscopic techniques is performed. As the compatibility of oils and rubbers has an influence on rubber compounds and affects the dispersion of fillers, the solubility of the oils and rubbers is studied both by theoretical calculation of solubility parameters and as well as by swelling measurements. Then, a preliminary study based on unfilled compounds is carried out to investigate the effect of oil types and amounts on the properties of NR, SBR and their blend compounds, where particular attention is paid to the changes in glass transition temperature $\left(T_{g}\right)$ and dynamic properties. Lateron, NR truck tire tread and NR/SBR passenger tire tread compounds containing DAE, TDAE and MES oils are prepared and the processing and vulcanizate properties, i.e. Mooney viscosity, cure characteristics, filler dispersion, filler-filler and filler-polymer interactions, mechanical and dynamic properties are comparatively investigated.

\subsection{References}

1 B. Rodgers, W.H. Waddell, S. Solis and W. Klingensmith, Kirk-Othmer Enc. Chem. Technol., 21, 805 (2004).

2 H.W. Engels, H.J. Weidenhaupt, M. Pieroth, W. Hofmann, K.H. Menting, T. Mergenhagen, R. Schmoll and S. Uhrlandt, in: ULLMANN'S Encyclopedia of Industrial Chemistry, Rubber, Chapter 9: Chemicals and Additives, Wiley-VCH Verlag GmbH \& Co. KGaA, Weinheim, 2011.

3 D.F. Cadogan and C.J. Howick, ULLMANN'S Enc. Ind. Chem., 27, 599 (2000).

4 G. Morris, in: Developments in Rubber Technology-1 Improving Product Performance, Chapter 6: Plasticizers, Eds.: A Whelan and K.S. Lee, Applied Science Publishers Ltd., Essex, 1979.

5 H.G. Moneypenny, K.H. Menting and F.M. Gragg, in: Rubber Compounding Chemistry and Applications, Chapter 8: General compounding, Eds.: B. Rodgers, Marcel Dekker Inc., New York, 2004.

6 B.G. Corman, P.F.Korbach and K.M. Webber (to Exxon Research and Engineering Company), US Patent 4801373, January 31, 1989.

7 K.K. Aldous, J.B. Angelo and J.P. Boyle (to Exxon Research and Engineering Company), US Patent 6110358, August 29, 2000. 
8 K.K. Aldous, J.B. Angelo, J.P. Boyle, B.M. Jarnot and W.E. Hanson (to Exxon Research and Engineering Company), US Patent 5846405, December 8, 1998.

9 K.K. Aldous, J.B. Angelo and J.P. Boyle (to Exxon Research and Engineering Company), US Patent 5853569, December 29, 1998.

10 K.K. Aldous, J.B. Angelo, J.P. Boyle, B.M. Jarnot and W.E. Hanson (to Exxon Research and Engineering Company), US Patent 6024864, February 15, 2000.

11 K.K. Aldous, J.B. Angelo and J.P. Boyle (to Exxon Research and Engineering Company), US Patent 5840175, November 24, 1998.

12 F.W. Barlow, "Rubber Compounding: Principles, Materials, and Techniques", Marcel Dekker Inc., New York, 1988.

13 W.A. Schneider, F. Huybrechts and K.H. Nordsiek, Kautsch. Gummi Kunstst., 44, 528 (1991).

14 ASTM D-2140, "Standard Test Method for Carbon-type Composition of Insulating Oils of Petroleum Origin", 2003.

15 D.T. Coker, A.G. King, D.L. Mumford and C.S. Nessel, Anal. Commun., 34, 137 (1997).

16 ISO 21461:2006 (E), "Rubber-Determination of the Aromaticity of Oil in Vulcanized Rubber Compounds", 2006.

17 A.C. Lewis, S.A. Askey, K.M. Holden, K.D. Bartle and M.J. Pilling, J. High Resol. Chromatogr., 20, 109 (1997).

18 I. Pillai, L. Ritchie, R. Heywood, G. Wilson, B. Pahlavanpour, S. Setford and S. Saini, J. Chromatogr. A, 1064, 205 (2005).

19 J.L.P. Pavon, M.N. Sanchez, M.E.F. Laespada and B.M. Cordero, J.Chromatogr. A, 1202, 196 (2008).

20 Z. Wang, M. Fingas, Y.Y. Shu, L. Sigouin, M. Landriault and P. Lambert, Environ. Sci. Technol., 33, 3100 (1999).

21 A.H. Hegazi and J.T. Andersson, Energ. Fuel., 21, 3375 (2007).

22 C. Bergmann, J. Trimbach, M. Haase-Held and A. Seidel, Kautsch. Gummi Kunstst., 65, 24 (2011).

23 L.B. Weisfeld, In: Polymer Modifiers and Additives: Plasticizers, Eds.: J. T. Lutz Jr. and R.F. Grossman, Marcel Dekker, Inc., New York, 2001.

24 S.E. O'Rourke, Rubber Technol. Int., 60 (1996).

25 A. Macilla and M. Beltran, in: Handbook of Plasticizers, Chapter 5: Mechanisms of Plasticizers Action, Eds.: G. Wypych, ChemTec Publishing, Toronto, 2004.

26 T.G. Fox and P.J. Flory, J. Appl. Phys., 21, 581 (1950).

27 European Union, Directive 67/548/EEC of the European Parliament and of the Council, Official Journal of the European Union, 196/1, 234 (1967). 
28 European Union, Directive 2005/69/EC of the European Parliament and of the Council, Official Journal of the European Union, L323, 51 (2005).

29 European Union, Regulation (EC) No 1907/2006 of the European Parliament and of the Council, Official Journal of the European Union, L396, 439 (2006).

30 European Union, Commission Regulation (EC) No 552/2009 of the European Parliament and of the Council, Official Journal of the European Union, L164, 25 (2009).

31 The Swedish National Chemicals Inspectorate, HA oil in automotives tyres, KEMI Rep. 5/03, 2003.

32 International Agency for Research on Cancer, Polynuclear aromatic hydrocarbons: Part 2 Carbon blacks, Mineral oils (Lubricant base oils and derived products) and some nitroarenes, Report vol. 33 in IARC Monographs on the Evaluation of Carcinogenic Risks to Humans, (1998).

33 E. Ardrizzi and R. Vivirito (to Exxon Research and Engineering Company), US Patent 5504135, April 2, 1996.

34 T. Kamai, K. Fujihara and Y. Morishima (to Japan Energy Corporation), EP Patent 0933418 B1, August 4, 1999.

35 T. Kamai, K. Fujihara and Y. Morishima (to Japan Energy Corporation), EP Patent 0933418 A2, August 4, 1999.

36 M. Takasaki and M. Tanaka (to Idemitsu Petrochemical Co., Ltd.), EP Patent 0950703 A2, October 20, 1999.

37 T. Hashimoto (to Bridgestone Corporation), US Patent 6103808, August 15, 2000.

38 T. Kaimai, K. Fujihara and Y. Morishima (to Japan Energy Corporation), US Patent 6248929 B1, June 19, 2001.

39 Y. Morishima and K. Fujino (to Sughrue, Mion, Zinn, Macpeak \& Seas, PLLC), US Patent 2001/0045377 A1, November 29, 2001.

40 M. Takasaki, M. Tanaka, H. Anzai and M. Nakamura (to Idemitsu Kosan Co., Ltd.), US Patent 6399697 B1, June 4, 2002.

41 J.P. Davies and K.P. Grace (to BP Oil International Ltd. And BP Refinery (Kwinana) Pty Ltd.), US Patent 6802960 B1, October 12, 2004.

42 M.R.S. Manton and M.A.H. Marie (to Shell Oil Company), US Patent 7186876 B2, US 7186876 B2, March 6, 2007.

43 Y.H. Jois, M.P. Smith and J.R. Powers (to Shell Oil Co., Houston, Texas), US Patent 2005/0272850 A1, December 8, 2005.

44 M. Joona, presented at RubberChem 2004: the $4^{\text {th }}$ international rubber chemicals, compounding and mixing conference, November 2004, Birmingham (UK). 
45 W.A. Schneider, F. Huybrechts, K.H. Nordsiek and Marl, Kautsch. Gummi Kunstst., 44, 528 (1991).

46 V. Null, Kautsch. Gummi Kunstst., 52, 799 (1999).

47 I. Bowman, M. da Via, M.E. Pattnelli and P. Tortoreto, Kautsch. Gummi Kunstst., 57, 31 (2004).

48 M. Joona, Rubber World, 235, 15 (2007).

49 A. Neau, K. Alavi and M. Rangstedt, Rubber Fibers Plast. Int., 4, 126 (2009).

50 K.H. Nordsiek, Kautsch. Gummi Kunstst., 38, 178 (1985).

51 A. Kuta, Z. Hrdlička, J. Voldánová, J. Brejcha, J. Pokorný and J. Plitz, Kautsch. Gummi Kunstst., 64, 120 (2010).

52 M. Öter, B. Karaağac and V. Deniz, Kautsch. Gummi Kunstst., 65, 48 (2011).

53 S. Dasgupta, S.L. Agrawal, S. Bandyopadhyay, S. Chakraborty, R. Mukhopadhyay, R.K. Malkani and S.C. Ameta, Polym. Test., 26, 489 (2007).

54 S. Dasgupta, S.L. Agrawal, S. Bandyopadhyay, S. Chakraborty, R. Mukhopadhyay, R.K. Malkani and S.C. Ameta, Polym. Test., 27, 277 (2008).

55 S. Dasgupta, S.L. Agrawal, S. Bandyopadhyay, R. Mukhopadhyay, R.K. Malkani and S.C. Ameta, Polym. Test., 28, 251 (2009).

56 K. Sahakaro and A. Beraheng, Rubber Chem. Technol., 84, 200 (2011). 


\section{OIL CHARACTERISTICS}

The potential and commercially available petroleum-based Polycyclic Aromatic Hydrocarbons (PAHs)-free safe process oils for replacement of toxic Distillate Aromatic Extract (DAE) are: Treated Distillate Aromatic Extract (TDAE), Mild Extracted Solvate (MES) and Naphthenics (NAP). In this chapter, the physico-chemical characteristics of DAE, TDAE and MES oils, which possess different aromatic carbon $\left(C_{A}\right)$ contents, are investigated. Various oil characteristics: density, viscosity, aniline point, Viscosity Gravity Constant (VGC), carbon distribution, PAHs content by DMSO extract, and glass transition temperature $\left(T_{g}\right)$ are analyzed. The VGC, aniline point, carbon distribution and DMSO extract indicate a higher aromatic content in DAE compared to TDAE and MES oils, respectively. Correlations between aromatic carbon $\left(\mathrm{C}_{\mathrm{A}}\right)$ contents with oil density, refractive index, kinematic viscosity and $\mathrm{Tg}$ are illustrated. Herein, increasing $\mathrm{C}_{\mathrm{A}}$ content clearly increases such properties. Chemical compositions of the oils are characterized by Fourier Transforms Infrared Spectroscopy (FT-IR) and Nuclear Magnetic Resonance spectroscopy (NMR). IR spectra of DAE and TDAE oils clearly show an absorption band at $1603 \mathrm{~cm}^{-1}$ assigned to $\mathrm{C}=\mathrm{C}$ stretching vibration of aromatic rings, and an aromatic region in the range of $877-746 \mathrm{~cm}^{-1}$, while the ${ }^{1} \mathrm{H}$-NMR spectrum of DAE oil shows bay region protons in a chemical shift range of 8.3-9.5 ppm, which indicates the presence of non-linear PAHs with 3 or more fused rings in the molecular structure. 


\subsection{INTRODUCTION}

Mineral oils are generally used as process oils for rubber compounds to improve processing properties, low temperature properties, dispersion of fillers, and to reduce cost. There are three main types of mineral oils which are added to rubber compounds. These are aromatic, naphthenic and paraffinic oils. Each type of process oil has different physicochemical characteristics which have an influence on the properties of rubber compounds. The physico-chemical characteristics of process oils are influenced by the chemical compositions of the process oils. The structure-property relationships of process oils and interactions between the oils and rubber have been studied by Schneider et al. ${ }^{1}$. Their investigation was based on Styrene Butadiene Rubber (SBR)-based carbon black reinforced tire tread compounds using four types of process oils with contents of aromatic carbon ranging from $38 \%$ to $4 \%$. The properties of the oils were related to the aromatic carbon content, and the change of glass transition temperature $\left(T_{g}\right)$ of oil extended rubber was correlated with the $T_{g}$ of the oils. It was demonstrated that the $T_{g}$ of the oils clearly affected the vulcanizate properties. The use of more naphthenic oils lowered viscosity and increased resilience but deteriorated the wet skid resistance of tires, as reported by Nordsiek ${ }^{2}$. A study of six mineral and ten natural oils ${ }^{3}$ revealed that all mineral oils showed higher aniline points than the natural oils which indicates that the mineral oils have a good compatibility with rubbers such as Natural Rubber (NR), SBR and Butadiene Rubber (BR).

The conventionally and widely used oils in tire compounds are Highly Aromatic oils (HA oils), because they provide good compatibility with both natural and synthetic rubbers. Highly aromatic oils are also referred to as Distillate Aromatic Extract (DAE) which contains a high concentration of Polycyclic Aromatic Hydrocarbons (PAHs), also called Polycyclic Aromatics (PCAs) and Polynuclear Aromatics (PNAs). PAHs are organic compounds possessing two or more aromatic rings, of which eight types are identified as carcinogens ${ }^{4}$. According to European legislation ${ }^{5-6}$, from 1 January 2010 extender oils shall not be used for the production of tires or parts of tires if they contain more than $1 \mathrm{mg} / \mathrm{kg}(0.0001 \%$ by weight $)$ of Benzo[a]pyrene, and more than $10 \mathrm{mg} / \mathrm{kg}(0.001 \%$ by weight $)$ of the sum of all listed PAHs. These limits shall be regarded as kept, if the polycyclic aromatics extract is less than $3 w t \%$ in the Dimethyl Sulfoxide (DMSO) extract (according to the IP346 test method). Several methods have been developed for analyzing PAHs-content in mineral oils, especially aromatic oil. The quantification of carcinogenic PAHs in transformer oils was analyzed by a solvent extraction method with subsequent determination by Gas Chromatography $(\mathrm{GC})^{7}$. This method used commercially available solid-phase extraction columns and milliliter volumes of relatively non-hazardous solvents. By using this method, it was reported that the extraction efficiencies for PAHs were more than $74 \%$, with a relative 
standard deviation value of less than $20 \%$. Solvent extraction with DSMO (according to IP 346) and gas chromatography-mass spectrometry (GC-MS) were used together for analyzing the PAHs contents in process oils ${ }^{8}$. In addition, the PAHs content was also determined by the ${ }^{1} \mathrm{H}$-NMR technique. This method was used to measure the level of bay region hydrogens within polycyclic aromatic molecules ${ }^{9}$ that appears in the chemical shift range of 8.3 to $9.2 \mathrm{ppm}$.

This chapter presents the physico-chemical characteristics of DAE, TDAE and MES oils. The glass transition temperature of the oils from Differential Scanning Calorimetry (DSC) analysis, and their FT-IR and ${ }^{1} \mathrm{H}-\mathrm{NMR}$ fingerprints are also discussed.

\subsection{EXPERIMENTAL}

\subsubsection{Materials}

Three types of process oils were used in this work: DAE (Tudalen 65), TDAE (Vivatec 500) and MES (Vivatec 200). All oils were supplied by Hansen\&Rosenthal KG (Hamburg, Germany).

\subsubsection{Oils characterizations}

\subsubsection{Physico-chemical characterizations}

The physico-chemical characteristics of the DAE, TDAE and MES oils, e.g. color, specific gravity, flash point, pour point, viscosities at $40^{\circ} \mathrm{C}$ and $100{ }^{\circ} \mathrm{C}, \mathrm{VGC}$, aniline point, carbon distribution, PAHs content, sulfur content, volatility, glass transition temperature, were supplied by Hansen\&Rosenthal KG $(H \& R)$, Hamburg, the manufacturer of the oils. The characteristics of the process oils were mostly analyzed according to ASTM standards as in the list shown in Table 3.1, except the PAHs content that was analyzed by DMSO extraction (IP346 test method) and glass transition temperature (Tg) of the process oils which was characterized by using the DSC technique.

\subsubsection{Thermal analysis by differential scanning calorimetry (DSC)}

DSC analysis of the process oils was performed between -100 and $50^{\circ} \mathrm{C}$ at a heating or cooling rate of $5^{\circ} \mathrm{C} /$ min using a Perkin Elmer DSC7.

\subsubsection{Molecular structural analysis by spectroscopic techniques}

All process oils were characterized for their molecular structures by using Fourier Transform Infrared (FT-IR) spectrophotometry (Brucker EQUINOX55), and Proton Nuclear Magnetic Resonance ( $\left.{ }^{1} \mathrm{H}-\mathrm{NMR}\right)$ (Varian Unity Inova $500 \mathrm{MHz}$ ). For ${ }^{1} \mathrm{H}-\mathrm{NMR}$ characterization, deuterated chloroform $\left(\mathrm{CDCl}_{3}\right)$ was used as solvent. The FT-IR and ${ }^{1} \mathrm{H}$ NMR spectra of TDAE and MES oils are compared to those of DAE oil. 


\subsection{RESULTS AND DISCUSSION}

\subsubsection{Physico-chemical characteristics of the oils}

The physico-chemical characteristics of the DAE, TDAE and MES oils, as analyzed and supplied by H\&R (Hamburg), are shown in Table 3.1.

Aromatic oils are normally dark in color because they contain heterocyclic compounds which consist of nitrogen and sulfur in their ring structure. These polar compounds reduce the oxidation stability of the oils and therefore cause a discoloration after exposition to UV-light ${ }^{10}$. The less aromatic and more paraffinic structure of MES oil should result in lighter color. However, according to the color test results as shown in Table 3.1, all three oil types display the same level of color, as their physical appearance is shown in Figure 3.1.

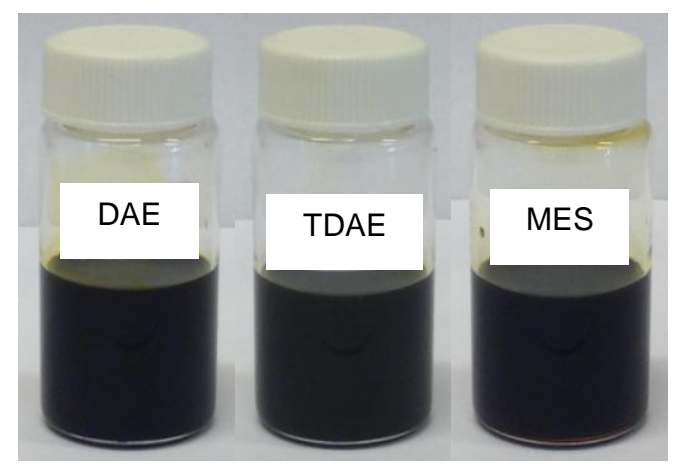

Figure 3.1 Physical appearances of DAE, TDAE and MES oils. 
Table 3.1 Characteristics of the DAE, TDAE and MES oils

\begin{tabular}{|c|c|c|c|c|}
\hline Properties & $\begin{array}{c}\text { Standard } \\
\text { test method }\end{array}$ & $\begin{array}{c}\text { DAE } \\
\text { (Tudalen 65) }\end{array}$ & $\begin{array}{c}\text { TDAE } \\
\text { (VivaTec 500) }\end{array}$ & $\begin{array}{c}\text { MES } \\
\text { (VivaTec 200) }\end{array}$ \\
\hline Color ASTM & ASTM D156 & $8.0 \mathrm{D}$ & $8.0 \mathrm{D}$ & $8.0 \mathrm{D}$ \\
\hline Density at $15^{\circ} \mathrm{C}, \mathrm{kg} / \mathrm{m}^{3}$ & ASTM D1298 & 990 & 950 & 915 \\
\hline Density at $20^{\circ} \mathrm{C}, \mathrm{kg} / \mathrm{m}^{3}$ & & 987 & 947 & 912 \\
\hline Refractive index at $20^{\circ} \mathrm{C}$ & ASTM D1218 & 1.56 & 1.53 & 1.51 \\
\hline Kin. Viscosity at $40^{\circ} \mathrm{C}, \mathrm{mm}^{2} / \mathrm{s}$ & ASTM D445 & 1240 & 410 & 210 \\
\hline Kin. Viscosity at $100^{\circ} \mathrm{C}, \mathrm{mm}^{2} / \mathrm{s}$ & & 26.0 & 18.8 & 16.0 \\
\hline Flash point $\mathrm{COC},{ }^{\circ} \mathrm{C}$ & $\begin{array}{l}\text { ASTM D92 or } \\
\text { D93 }\end{array}$ & 260 & 272 & 270 \\
\hline Pour point, ${ }^{\circ} \mathrm{C}$ & ASTM D97 & 20 & 27 & -6 \\
\hline Sulfur, wt\% & & 1.2 & 0.8 & 0.5 \\
\hline Aniline point, ${ }^{\circ} \mathrm{C}$ & ASTM D611 & 41 & 68 & 97 \\
\hline VGC & ASTM D2501 & 0.94 & 0.89 & 0.84 \\
\hline Carbon distribution, wt\%: & ASTM D2140 & & & \\
\hline $\mathrm{C}_{\mathrm{A}}$ & & 40 & 25 & 15 \\
\hline $\mathrm{C}_{\mathrm{N}}$ & & 25 & 30 & 27 \\
\hline$C_{P}$ & & 35 & 45 & 58 \\
\hline DMSO extract, wt $\%$ & IP346 & 20 & $<2.9$ & $<2$ \\
\hline $\begin{array}{l}\text { Glass transition temperature, } \\
{ }^{\circ} \mathrm{C}\end{array}$ & & -37 & -48 & -58 \\
\hline
\end{tabular}

The oil density and refractive index are affected by the chemical composition of the process oil and increase with increasing aromatic content. The relationships between the content of aromatic carbons $\left(\mathrm{C}_{\mathrm{A}}\right)$ and density as well as refractive index at $20^{\circ} \mathrm{C}$ are shown in Figure 3.2. Herein, the data are compared with the data reported by Schneider et al. ${ }^{1}$. It is seen that the density and refractive index of the oils linearly increase with increasing content of aromatic carbon, $\mathrm{C}_{\mathrm{A}}$. The kinematic viscosity, which determines the flow properties and the handling characteristics at various temperatures of the oils, also increases with increase of aromatic carbon, as shown in Figure 3.3. DAE has a distinctly higher viscosity especially at $40^{\circ} \mathrm{C}$ compared to TDAE and MES oils, respectively. The different oil viscosities can have an effect on the rubber properties, in particular on processability, low-temperature performance and weight loss at high temperature. It is known that the viscosity is related to molecular weight and at equal molecular weight the aromatic compounds have a higher viscosity than the saturated compounds ${ }^{1}$. Higher aromatic oil, i.e. DAE therefore has the highest viscosity. In addition to the fact that the 
viscosity is influenced by the oil composition, the oil viscosity changes with temperature ${ }^{1,11}$. Schneider et al. ${ }^{1}$ reported that aromatic oils have the greatest change of viscosity with temperature, whereas paraffinic oils show the least change of viscosity with temperature. This implies that DAE will have the greatest change while MES has the least change with temperature. The different compositions of the process oils also affect their $\mathrm{T}_{\mathrm{g}}$ 's as depicted in Figure 3.3. It is clearly seen that the $T_{g}$ 's of the process oils strongly depend on the content of aromatic carbons $\mathrm{C}_{\mathrm{A}}$. The difference in $\mathrm{T}_{\mathrm{g}}$ of the process oils is expected to have an influence on the $T_{g}$ of the rubber compounds, and so on the dynamic mechanical properties of vulcanizates.

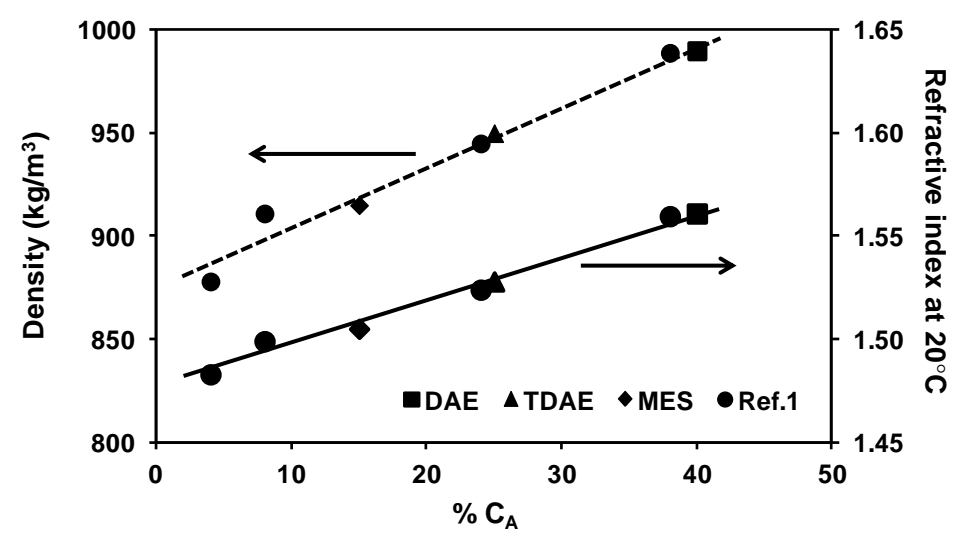

Figure 3.2 Correlation between density and refractive index with aromatic carbon $\left(C_{A}\right)$ content of the process oils.

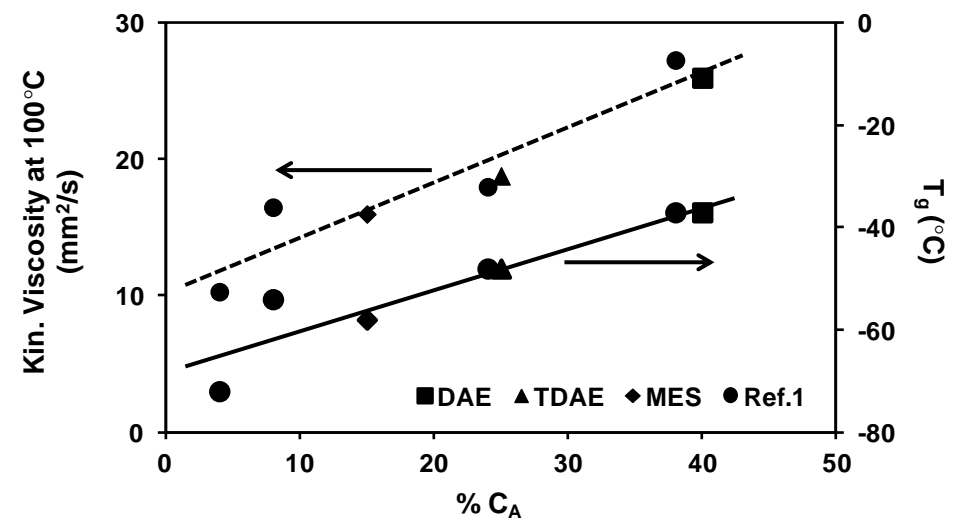

Figure 3.3 Correlation between kinematic viscosity and glass transition temperature $\left(T_{g}\right)$ with aromatic carbon $\left(\mathrm{C}_{\mathrm{A}}\right)$ content of the process oils. 
In addition to the kinematic viscosity, the flowability of the oils is determined by the pour point value, as it indicates the lowest temperature at which the oil still can flow. This value is therefore important for handling characteristics, and will have an effect on low temperature flexibility of the rubber compounds. Among the oil types studied, MES has the lowest pour point at $-6^{\circ} \mathrm{C}$ whereas DAE has a slightly lower pour point than TDAE close to room temperature. This property is influenced by the wax content as well as the viscosity of the oil. The flash points of all types of oil used in this work are slightly different and higher than $250^{\circ} \mathrm{C}$. This flash point value tells the temperature at which enough flammable vapors exist above the oil that they will ignite or flash when presented with an open flame. So, it is an important characteristic to determine the processing safety during production of rubber compounds.

The values of VGC, aniline point, carbon distribution and DMSO-extract clearly show that the DAE oil contains a substantially higher aromatic content than the TDAE and MES, respectively. The VGC increases as the hydrocarbon distribution changes from paraffinic to naphthenic to aromatic. The highest aniline point of the MES oil indicates the lowest compatibility with aniline which may also imply that it has the lowest compatibility with rubber. It can be seen that the aniline point is inversely related to the VGC value. The oil characteristics as shown in Table 3.2 and Figures 3.2 - 3.3 clearly reveal a dependence of oil properties on their chemical compositions.

\subsubsection{DSC - thermograms of the oils}

The DSC thermograms of DAE, TDAE and MES oils are shown in Figure 3.4. The DAE oil displays a transition in the temperature range of -46 to $-33^{\circ} \mathrm{C}$, whereas the TDAE oil exhibits a transition between -60 to $-46^{\circ} \mathrm{C}$, and MES in the range of -68 to $-60^{\circ} \mathrm{C}$. The transition regions of the DAE, TDAE and MES oils are in accordance with the glass transition temperatures as reported by the oil manufacturer in Table 3.2. According to the DSC results in Figure 3.4, the DAE oil shows the highest $T_{g}$ at $-43^{\circ} \mathrm{C}$, followed by the TDAE and MES oils that have $T_{g}$-values at $-51^{\circ} \mathrm{C}$ and $-65^{\circ} \mathrm{C}$, respectively. Herein, the $T_{g}$-values are taken as the temperature at which one-half of the shift has occurred, i.e. mid-point temperature. It should be noted that the characterization of $T_{g}$ by DSC analysis is sensitive to experimental conditions and the specific equipment, so the $T_{g}$-values analyzed by using different instruments and/or under different conditions may vary. Even though the $T_{\mathrm{g}}$-values as provided in Table 3.2 and as obtained by the DSC thermograms in Figure 3.4 are different, they are ranked in the same order. The $T_{g}$ 's of the oils decrease with decreasing aromatic content. 


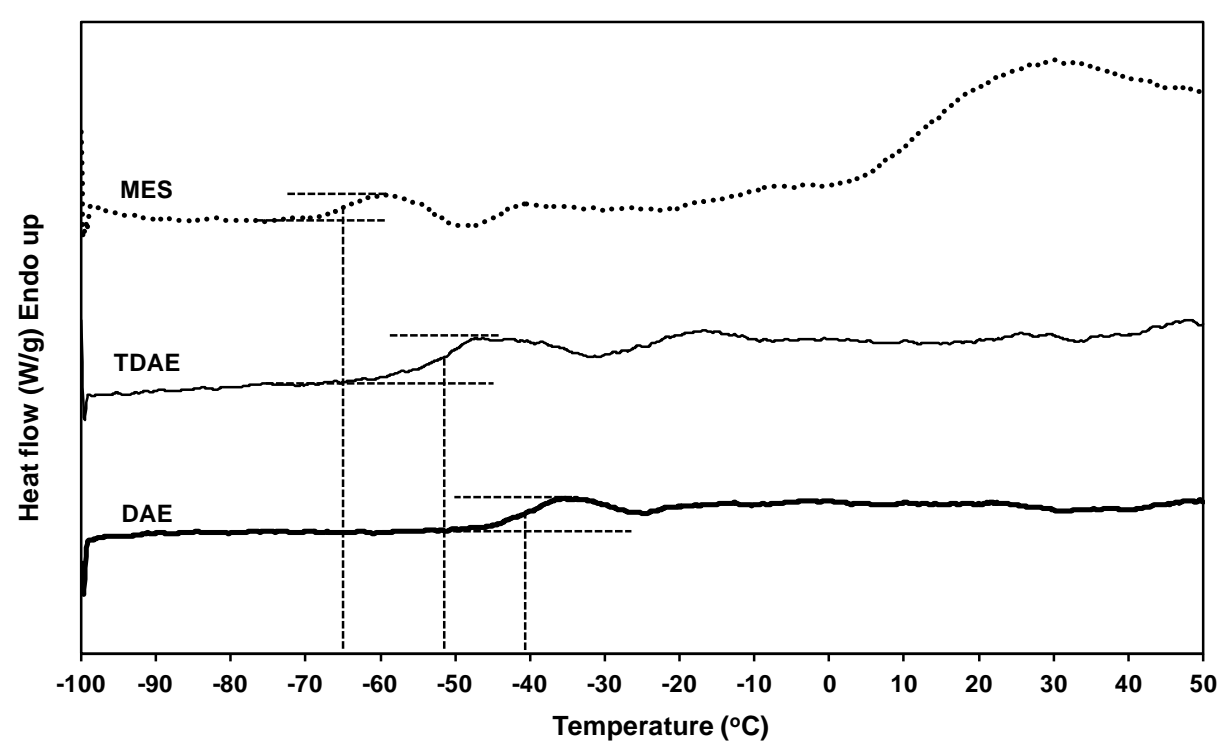

Figure 3.4 DSC curves of DAE, TDAE and MES oils upon heating at a heating rate of $5^{\circ} \mathrm{C} / \mathrm{min}$.

Schneider et al. ${ }^{1}$ related the $\mathrm{T}_{\mathrm{g}}$-value to the composition of the process oils, providing that the proportions of each of the different structural groups present in the materials are known, following the concept proposed to calculate $T_{g}$ of polymers by Weyland et al. $^{12}$. With regard to the process oils, three different structural groups, i.e. methylene, cyclohexane and benzene are taken to represent paraffinic, naphthenic and aromatic moieties, respectively. By using these hypothetical structures, the $T_{g}$ of the process oils could be calculated from Equation (3.1).

$$
T_{g}=W_{A} T_{g A}+W_{N} T_{g N}+W_{P} T_{g P}
$$

Where $W_{A}, W_{N}$ and $W_{P}$ are the mole fraction of aromatic, naphthenic and paraffinic structures, respectively. $T_{g A}, T_{g N}$ and $T_{g P}$ were calculated as follows ${ }^{1}$ :

$$
\mathrm{T}_{\mathrm{gi}}=\frac{\mathrm{Y}_{\mathrm{gi}}}{\mathrm{M}_{\mathrm{i}}}
$$

Where $i$ is the given group, $Y_{g}$ is the molar glass transition values and $M_{i}$ is the molecular weight of group i.

The calculated $T_{g}$-values according to Equation (3.1) for DAE, TDAE and MES oils are $-39,-53$ and $-63{ }^{\circ} \mathrm{C}$, respectively. Table 3.2 shows the $T_{g}$-values of the oils obtained from the calculation and experimental DSC analysis, compared to the values supplied by the oil manufacturer. 
Table 3.2 Glass transition temperatures of the DAE, TDAE and MES oils

\begin{tabular}{cccc}
\hline \multirow{2}{*}{ Source of data } & \multicolumn{3}{c}{ Glass transition temperature, ${ }^{\circ} \mathrm{C}$} \\
\cline { 2 - 4 } & DAE & TDAE & MES \\
\hline H\&R technical data & -37 & -48 & -58 \\
DSC analysis (Exp) & -43 & -51 & -65 \\
Calculation & -39 & -52 & -63 \\
\hline
\end{tabular}

The calculated $T_{g}$ are close to the experimental $T_{g}$ by DSC for the case of TDAE and MES, while the calculated $T_{g}$ for DAE is closer to the value supplied by $H \& R$. Variation of $T_{g}$-values indicates a complication of molecular structures present in the process oils. This also reflects in the DSC thermograms of the oils, as seen in Figure 3.4. The thermograms of all the process oils show small exothermic peaks above the $\mathrm{Tg}$. This crystallization upon cooling below the melting temperature but above the $T_{g}$ is called "cold crystallization"1, leading to the occurrence of small crystallites. Based on the DSC experimental conditions employed, MES oil shows a pronounced tendency to cold crystallization. In addition, MES oil shows a broad endothermic melting signal above $5^{\circ} \mathrm{C}$, which may be assumed to originate from crystallizable paraffinic structure and waxes. This cold crystallization and melting behavior of the process oils has also been reported by Schneider et al. ${ }^{1}$.

\subsubsection{FT-IR and ${ }^{1} \mathrm{H}-\mathrm{NMR}$ spectra of the oils}

The FT-IR spectra of DAE, TDAE and MES oils are shown in Figure 3.5. 


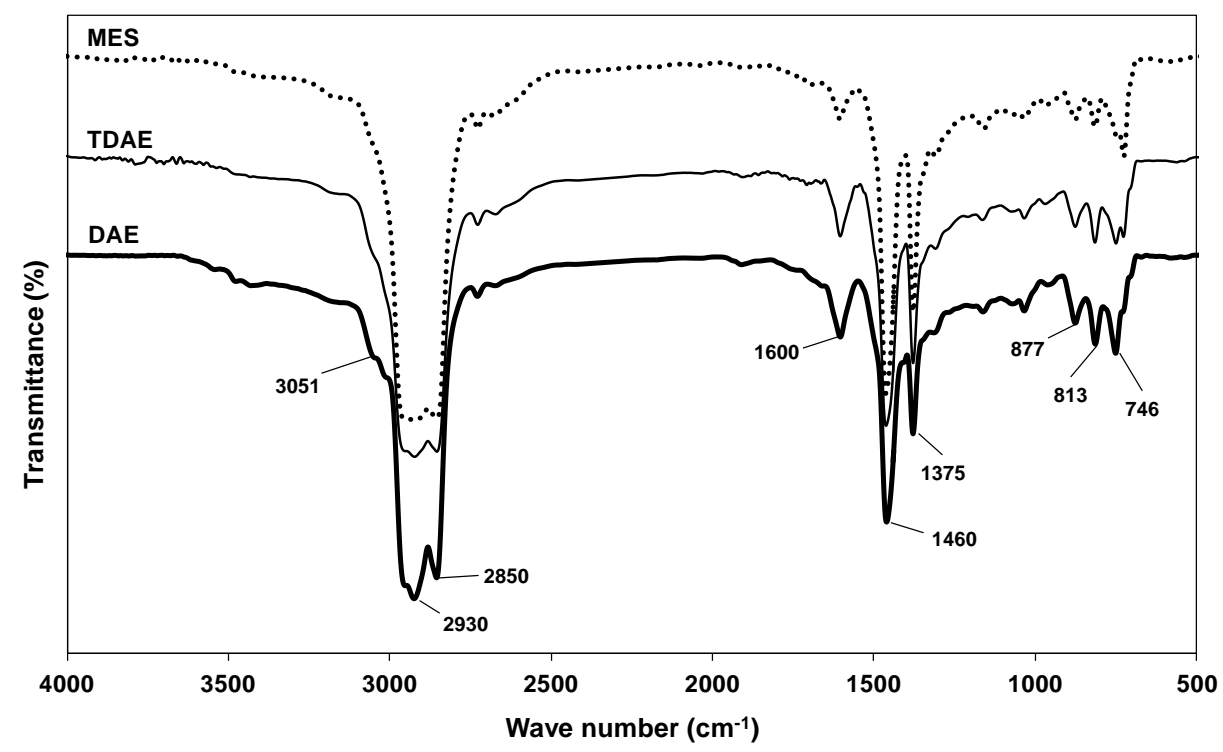

Figure 3.5 FT-IR spectra of DAE, TDAE and MES oils.

All FT-IR spectra show similar infrared absorption peaks associated with the vibrations of $\mathrm{C}-\mathrm{H}$ in both aliphatic and aromatic structures. The strong absorption bands at the wavenumber of 2930 and $2850 \mathrm{~cm}^{-1}$ are due to $\mathrm{C}-\mathrm{H}$ asymmetric and symmetric stretching vibrations, respectively. The absorption peaks at 1460 and $1375 \mathrm{~cm}^{-1}$ are the characteristic peaks of $\mathrm{C}-\mathrm{H}$ bending in alkyl chains. The aromatic structures contained in the process oils display their characteristic peaks at a few different regions ${ }^{13}$. By considering the spectrum of DAE which contains the highest aromatic content, a shoulder peak at 3051 $\mathrm{cm}^{-1}$, assigned to $\mathrm{C}-\mathrm{H}$ stretch in aromatic ring structures, is observed. This shoulder peak is weaker in TDAE and almost diminished in the spectrum of MES oil. The peak at $1600 \mathrm{~cm}^{-1}$ is assigned to the $\mathrm{C}=\mathrm{C}$ stretching vibration in aromatic rings. The peak intensities of $\mathrm{DAE}$ and TDAE are similar, but that of MES is weaker, indicating a lower content of aromatic structures in MES oil. The aromatic region of the oils is also clearly visible in the wavenumber range of $877-746 \mathrm{~cm}^{-1}$ which is assigned to $\mathrm{C}-\mathrm{H}$ out of plane bending in different patterns of substituted benzene. The peaks at 877 and $813 \mathrm{~cm}^{-1}$ are due to $\mathrm{C}-\mathrm{H}$ out of plane bending in para- and meta-disubstituted benzene, respectively, while the peak at $746 \mathrm{~cm}^{-1}$ is due to $=\mathrm{C}-\mathrm{H}$ out of plane bending in monosubstituted benzene. The lower content of aromatic structures in MES oil also reflects in weaker absorption peaks in this aromatic region, especially the peak of wavenumber $813 \mathrm{~cm}^{-1}$ assigned to $\mathrm{C}-\mathrm{H}$ out of plane in meta-disubstituted benzene. 
The ${ }^{1} \mathrm{H}-\mathrm{NMR}$ spectra of the DAE, TDAE and MES oils are displayed in Figure 3.6. The DAE oil clearly displays the absorption peaks of aromatic protons in the chemical shift range of 6.6 to $9.0 \mathrm{ppm}$, indicating the presence of substantial amounts of aromatic structures. The broad peak indicates a variety of aromatic compounds that are present in this oil. The aromatic protons in TDAE and MES oils mostly disappear indicating a much lower aromatic content in these two types of oil when compared with DAE.

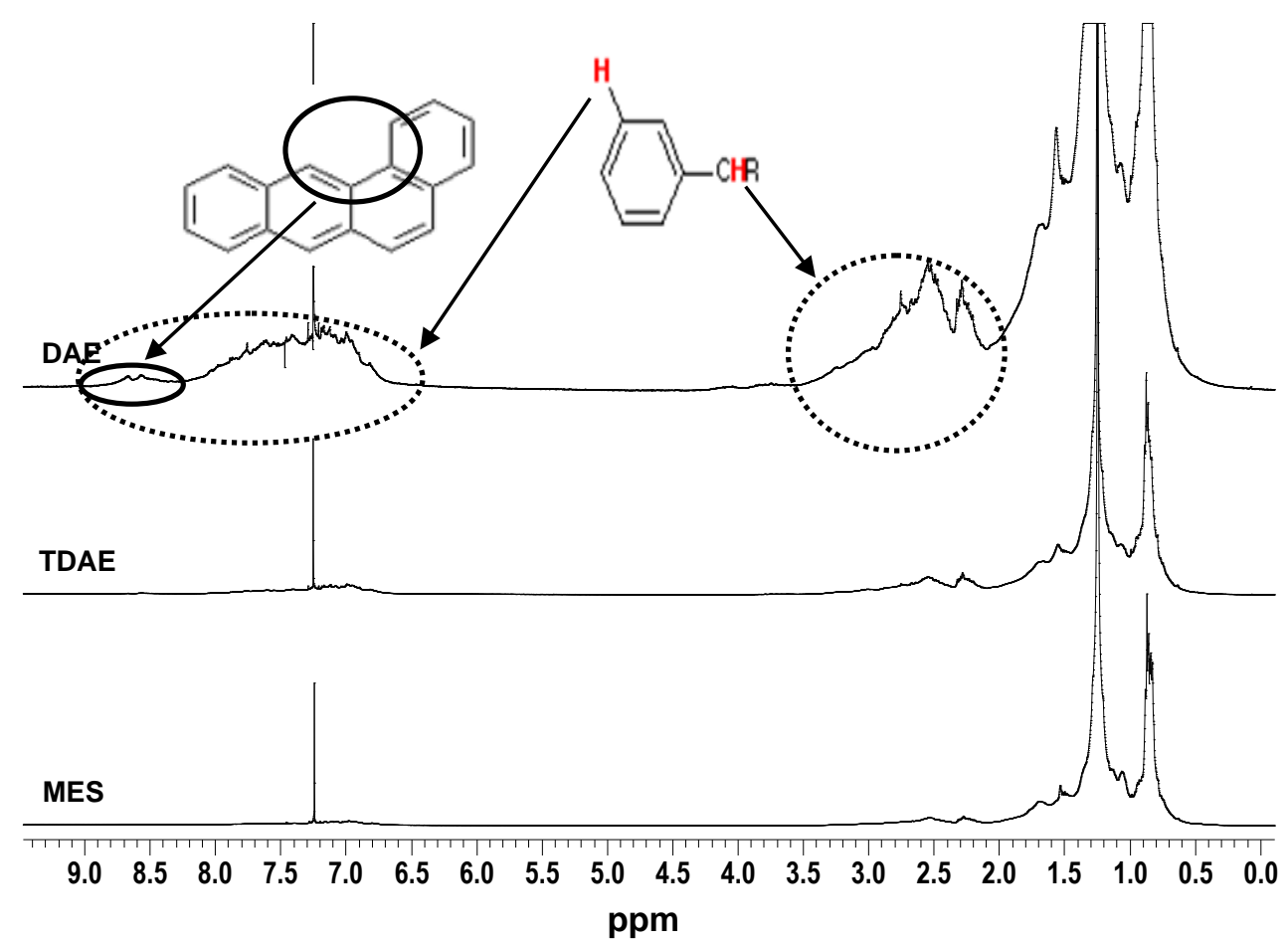

Figure 3.6 ${ }^{1} \mathrm{H}-\mathrm{NMR}$ spectra of the DAE, TDAE and MES oils.

The absorption bands in a range of 2.1 to $4.0 \mathrm{ppm}$ are assigned to protons in substituted groups on aromatic rings. The signals that appear between 7.9 to $8.2 \mathrm{ppm}$ are assigned to protons attached to a ring structure with 1,2 or more rings of $\mathrm{PAH}$-molecules. For the latter case, the a proton of the $\mathrm{PAH}$ molecule as shown in Figure 3.7 will appear in this chemical shift range. The absorption bands between 8.30 to $9.20 \mathrm{ppm}$ are assigned to so-called bay region protons in $\mathrm{PAH}$-molecules. A bay proton is defined as a $\mathrm{H}$-atom that is located at the periphery of a molecule that has the molecular structure of non-linear PAHs with 3 or more fused rings which contain a characteristics three sided concave area ${ }^{9,14}$. Examples of bay protons in a PAH molecule are given in Figure 3.7 as A3 and mA3. 


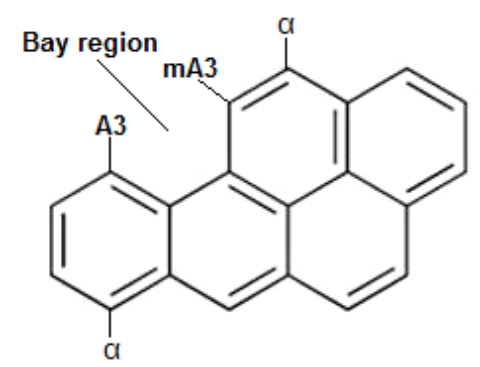

Figure 3.7 Proton types in PAH molecules (benzo[a]pyrene as example) ${ }^{9}$.

${ }^{1} \mathrm{H}$-NMR spectroscopy has been applied to identify and selectively quantify hydrogen atoms in the bay region, which are characteristic of aromatic oils according to ISO 21461. The higher the percentage of bay region protons, the higher the aromaticity.

The percentage of bay region protons $\left(\% \mathrm{H}_{\text {Bay }}\right)$ can be calculated using the following equation:

$$
\% \mathrm{H}_{\text {Bay }}=\frac{\mathrm{I}_{2}}{\mathrm{l}_{1}+\mathrm{I}_{3}} \times 100
$$

Where $\mathrm{I}_{1}$ is the pure aromatic area from 6.0 to $9.5 \mathrm{ppm}$ (excluding the $\mathrm{CHCl}_{3}$ signal); $I_{2}$ is the area of the bay region from 8.3 to $9.5 \mathrm{ppm}$, and $\mathrm{I}_{3}$ is the area of the aliphatic and ethylenic regions from 0.2 to $5.8 \mathrm{ppm}$. Based on the integral values of the different peaks appearing in the spectra shown in Figure 3.6, the percentages of bay region protons are equal to $0.73,0.22$ and 0.14 for the DAE, TDAE and MES oils, respectively.

\subsection{CONCLUSIONS}

TDAE and MES oils as alternatives for conventional DAE oil possess different characteristics. The viscosity gravity constant (VGC), aniline point, carbon distribution and DMSO extract indicate a higher aromatic content in DAE compared to TDAE and MES oils, respectively, as also evidenced in FT-IR and ${ }^{1} \mathrm{H}-\mathrm{NMR}$ spectra. The higher aromatic carbon content results in higher density, refractive index, kinematic viscosity and glass transition temperature. The glass transition temperature of MES oil is lower than that of TDAE and DAE oil, respectively, as proved by DSC analysis and theoretical prediction, in addition to the data supplied by the oil manufacturer. The highest aniline point of MES oil implies the lowest compatibility with rubber. The infrared absorption peaks of the three oils are similar, but MES oil shows weaker characteristic peaks of aromatic structures, compared to those of TDAE and DAE, in accordance with its lowest aromatic content. The ${ }^{1} \mathrm{H}-\mathrm{NMR}$ spectrum of DAE oil not only shows a substantially high aromatic content, as reflected by absorption bands of aromatic protons that are attached to ring structures, but also displays peaks 
between 8.3 to $9.2 \mathrm{ppm}$ which are assigned to bay region protons in $\mathrm{PAH}$-molecules, of which some are classified as carcinogenic substances. The ${ }^{1} \mathrm{H}-\mathrm{NMR}$ spectra of TDAE and MES oils confirm the presence of much less aromatic molecular structures, compared to conventional DAE oil.

\subsection{REFERENCES}

1 W.A. Schneider, F. Huybrechts and K.H. Nordsiek, Kautsch. Gummi Kunstst., 44, 528 (1991).

2 K.H. Nordsiek, Kautsch. Gummi Kunstst., 39, 599 (1986).

3 S. Dasgupta, S.L. Agrawal, S. Bandyopadhyay, S. Chakraborty, R. Mukhopadhyay, R.K. Malkani and S.C. Ameta, Polym. Test., 26, 489 (2007).

4 European Union, Regulation (EC) No 1907/2006 of the European Parliament and of the Council, Official Journal of the European Union, L396, 439 (2006).

5 European Union, Directive 2005/69/EC of the European Parliament and of the Council, Official Journal of the European Union, L323, 51 (2005).

6 European Union, Commission Regulation (EC) No 552/2009 of the European Parliament and of the Council, Official Journal of the European Union, L164, 25 (2009).

7 I. Pillai, L. Ritchie, R. Heywood, G. Wilson, B. Pahlavanpour, S. Setford and S. Saini, J. Chromatogr A, 1064, 205 (2005).

8 C. Bergmann, J. Trimbach, M. Haase-Held and A. Seidel, Kautsch. Gummi Kunstst., 65, 24 (2011).

9 D. T. Coker, A. G. King, D. L. Mumford and C. S. Nessel, Anal. Coms., 34, 137 (1997).

10 F.W. Barlow, "Rubber Compounding: Principles, Materials, and Techniques", Marcel Dekker Inc., New York, 1988.

11 G. Morris, in: Developments in Rubber Technology-1 Improving Product Performance, Chapter 6: Plasticizers, Eds.: A Whelan and K.S. Lee, Applied Science Publishers Ltd., Essex, 1979.

12 H.G. Weyland, P.J. Hoftyzer and D.W. van Krevelen, Polymer, 11, 79 (1970).

13 B. H. Stuart, "Infrared Spectroscopy: Fundamentals and Applications", John Wiley \& Sons Ltd., West Sussex, 2004.

14 ISO 21461:2006 (E), "Rubber-Determination of the Aromaticity of Oil in Vulcanized Rubber Compounds", 2006. 
Chapter 3 


\section{SWELLING AND SOLUBILITY STUDY OF RUBBERS AND PROCESS OILS}

One of the main criteria to select a type of compounding ingredient including process oils is the compatibility between rubbers and that component. With respect to process oils, the solubility parameters $(\delta)$ of rubbers and process oils are of importance as the $\Delta \delta$ values determine the compatibility between both components. The petroleum-based, non-carcinogenic safe process oils for replacement of toxic Distillate Aromatic Extract (DAE) under investigation in this work, are Treated Distillate Aromatic Extract (TDAE) and Mild Extracted Solvate (MES). The solubilities of DAE, TDAE and MES oils are investigated in Natural Rubber (NR), Styrene Butadiene Rubber (SBR) and their blend at 50/50 weight ratio. The solubility parameters $(\delta)$ are calculated based on the group contribution method, and the $\Delta \delta$ values between oils and rubbers are correlated with the mass swelling of lightly crosslinked NR and SBR at different temperatures. A smaller $\Delta \delta$ means better solubility of oil in the rubber which is confirmed by the higher level of oil uptake in the rubber. At high temperature in the range of mixing temperatures, MES oil shows less compatibility with NR and SBR compared to TDAE and DAE, respectively. 


\subsection{INTRODUCTION}

The different characteristics of the process oils as described in Chapter 3 affect the properties of rubber compounds. An important parameter of the process oils that will have an influence on the rubber properties is the compatibility between the oils and rubbers. The compatibility and solubility of process oils in a rubber matrix can be related to their solubility parameters $(\delta)$ as materials with similar $\delta$ will mutually dissolve in each other. The concept of the solubility parameter was developed by Hildebrand and Scatchard ${ }^{1}$. The Hildebrand solubility parameter is widely accepted as a good indication of solubility for non-polar materials. It provides a numerical estimation of the degree of interaction between the materials and indicates solvency behavior. The $\delta$ can be calculated from the square root of the Cohesive Energy Density (CED), which is equal to the heat of vaporization, divided by the molar volume. Basically, the Cohesive Energy $\left(E_{c o h}\right)$ can be predicted by means of additive functions in which the contribution of structural groups is taken into account. There is a variation of values of $E_{c o h}$ given by different researchers, e.g. by Hoftijzer and van Krevelen (1970) and Fedors $(1974)^{1}$. To calculate $\delta$, molar attraction constants (F) have also been used, such as by Small (1953), van Krevelen (1965) and Hoy (1970). The different set of values of $E_{\text {coh }}$ and $F$ are summarized by van Krevelen and te Nijenhuis ${ }^{1}$. In addition to the Hildebrand solubility parameter, the Hansen solubility parameter (HSP) ${ }^{2}$ has been proposed particularly for polar molecules, and has been widely used in paints and coating materials. This is a more complicated three dimensional solubility parameter based on 3 parameters: $\delta_{d}, \delta_{p}$, and $\delta_{h}$ which are defined as the energy from dispersive forces, intermolecular forces, and hydrogen bonds between molecules, respectively. Experimentally, the solubility parameter can be analyzed by the use of inverse gas chromatography (IGC). With this IGC technique, the solubility parameters of e.g. soybean oil as a function of temperature was investigated, and such parameters were found to decrease with decreasing temperature ${ }^{3}$.

The solubility parameters are used to indicate the compatibility between rubbers and chemicals or compounding ingredients. The diffusion and solubility of sulfur and accelerators in various rubbers were studied ${ }^{4-8}$. The diffusion of sulfur in natural rubber ${ }^{4}$ and synthetic rubbers ${ }^{5}$ at different temperatures, and its influence on the vulcanization was reported. The solubility of accelerators in rubber blends particularly under the vulcanization temperature was studied and its influence on the properties of the vulcanizates was discussed based on their compatibility and distribution ${ }^{7}$. The solubility of the curatives was increased with rising temperature and the degree of mastication. Guo et al. ${ }^{9}$ investigated the solubility of curatives in synthetic rubbers, in which the solubility parameter of sulfur and several accelerators were calculated in accordance with the method of Hoftijzer and van Krevelen ${ }^{1}$, and the solubility of these additives was experimentally investigated by 
measuring the weight increase of the rubber packed on all sides in fine powders of the curatives. The experimental results and the calculated solubility parameters were correlated, and the absolute $\delta$ differences between rubbers and curatives were used to judge the solubility of the curatives in the rubbers.

Swelling can be applied to quantify the mutual solubilities of polymer/rubbers and solvents. Swelling of rubber should reach a maximum when the solvent has the same solubility parameter as the rubber ${ }^{10}$. There are several factors affecting the swelling of rubber in liquid media such as test temperature, molecular weight of the liquid medium, and the crosslink density of the rubber. A study of the swelling behavior of a SBR membrane in various solvents showed that the solvent uptake increased with increasing test temperature, because of an increase in free volume and a favorable chain conformation during the temperature rise ${ }^{11}$. An increase of crosslink density gives rise to a decrease of the equilibrium swelling of rubbers ${ }^{12-13}$.

This chapter reports the solubility parameters of DAE, TDAE and MES oils. The solubility parameters of the oils are theoretically calculated and the solubility behavior of the various oils in lightly crosslinked NR, SBR and their blend at 50/50 weight ratio is quantified based on swelling tests at different temperatures. This is to estimate the compatibilization level of these oils with rubbers prior to application in practical filled rubber compounds.

\subsection{EXPERIMENTAL}

\subsubsection{Materials}

Natural rubber (Ribbed Smoked Sheet 3, RSS3) locally produced in Pattani (Thailand) and emulsion-polymerized Styrene Butadiene Rubber (SBR1502) produced by BST Elastomers (Thailand) were used as rubber materials. Three types of oil, i.e. DAE (Tudalen 65), TDAE (Vivatec 500) and MES (Vivatec 200), were supplied by Hansen\&Rosenthal KG (Hamburg, Germany). The chemicals for preparing rubber compounds were stearic acid (Imperial Chemical, Thailand), ZnO (Global Chemical, Thailand) and dicumyl peroxide (DCP, Akzo Nobel Polymer Chemical, the Netherlands). DCP was used to lightly crosslink the rubber for the swelling study. All elastomers and compounding ingredients were used as received.

\subsubsection{Methods}

\subsubsection{Solubility parameter calculations}

Compatibility between oils and rubbers depends on their solubility parameters $(\delta)$. The closer the values of the solubility parameters of oils and rubbers, i.e. the smaller $\Delta \delta$, the better the compatibility. The solubility parameter can be determined from the square root of 
the CED, i.e. the cohesive energy ( $\left.E_{\text {coh }}\right)$ per unit volume $(V)$, as shown in Equation (4.1), and the solubility parameter of polymers at $298 \mathrm{~K}$ can be estimated using group contribution methods $^{1,14}$.

$$
\delta=(\mathrm{CED})^{1 / 2}=\left(\frac{\mathrm{E}_{\mathrm{coh}}}{\mathrm{V}}\right)^{1 / 2}
$$

In addition, Small ${ }^{15}$ defined the molar attraction constant $(F)$ and applied the sum of $F$ for group $j\left(F_{j}\right)$ to calculate the total solubility parameters following Equation (4.2):

$$
\delta=\frac{\Sigma_{\mathrm{j}} \mathrm{F}_{\mathrm{j}}}{\mathrm{V}}
$$

The present work calculates the solubility parameters of the oils and rubbers using the molar attraction constants given by Small, as summarized by Van Krevelen and te Nijenhuis ${ }^{1}$. Based on the molar attraction constants, the solubility parameters at $298 \mathrm{~K}$ $\left(25^{\circ} \mathrm{C}\right)$ are calculated. For DAE, TDAE and MES oils, the solubility parameters are estimated based on the molar percentages of different structural groups, e.g. methylene, cyclohexane and benzene, representing paraffinic, naphthenic and aromatic groups, respectively ${ }^{16}$. The solubility parameter of oil can be calculated from Equations (4.3) and (4.4):

$$
\begin{aligned}
& \delta_{\text {oil }}=W_{A} \delta_{A}+W_{N} \delta_{N}+W_{P} \delta_{P} \\
& \delta_{\text {oil }}=W_{A}\left(\frac{\Sigma_{A} F_{A}}{V_{A}}\right)+W_{N}\left(\frac{\Sigma_{N} F_{N}}{V_{N}}\right)+W_{P}\left(\frac{\Sigma_{P} F_{P}}{V_{P}}\right)
\end{aligned}
$$

When $\delta_{\text {oil }}$ is the solubility parameter of the oil, $W_{A}, W_{N}$ and $W_{P}$ are the mole fraction of aromatic, naphthenic and paraffinic structures, respectively. $\delta_{A}, \delta_{N}$ and $\delta_{P}$ are the solubility parameters of the aromatic, naphthenic and paraffinic structures, respectively.

In addition, in order to calculate the solubility parameters at higher temperature, Equations (4.5) and (4.6) are used to calculate the parameters for the oils (at the liquid state) ${ }^{17}$ and rubbers (above the glass transition temperature $\left.T_{g}\right)^{18}$, respectively.

$$
\begin{aligned}
& \ln \delta_{\mathrm{T}}=\ln \delta_{298}-1.25 \alpha(T-298) \\
& \ln \delta_{\mathrm{T}}=\ln \delta_{298}-\alpha(T-298)
\end{aligned}
$$

Where $\alpha$ is the coefficient of linear thermal expansion of the oils and rubbers. The $\alpha$ values for the oils were estimated from their density change in a range of 15 to $120^{\circ} \mathrm{C}$ : $6.55 \times 10^{-4} \mathrm{~K}^{-1}$ for DAE; $6.94 \times 10^{-4} \mathrm{~K}^{-1}$ for TDAE and $7.73 \times 10^{-4} \mathrm{~K}^{-1}$ for MES. The linear thermal expansion coefficients of NR and SBR were estimated to be equal to a value of $4.80 \times 10^{-4} \mathrm{~K}^{-119}$.

\subsubsection{Sample preparation and swelling measurements}

Swelling measurements of the oils in rubber samples slightly crosslinked by peroxide were carried out using the method adapted by Guo et al. ${ }^{9,20} \mathrm{NR}$, SBR and their 
blend at 50/50 weight ratio were compounded on a two-roll mill using the formulation as given in Table 4.1. For the NR-based compounds, the rubber was masticated for 2 mins prior to adding SBR and the other ingredients. Total mixing time was kept constant at 5 mins. Vulcanization with dicumyl peroxide (DCP) was carried out at $150{ }^{\circ} \mathrm{C}$ for 40 mins. The gel contents were measured after extraction with toluene in a Soxhlet extractor for two days. In this work, two different levels of gel contents in NR, SBR and their NR/SBR blend were obtained by using different concentrations of DCP, as shown in Table 4.1. The levels of crosslinking in each rubber type at the same DCP content were kept in the similar range to exclude the influence of crosslink density on solubility. The vulcanized samples were then cut into sheets with a size of $10 \times 10 \times 2 \mathrm{~mm}^{3}$. These sheets were extracted with acetone in a Soxhlet extractor for two days to remove the non-rubber parts. Finally, all the samples were dried for $24 \mathrm{~h}$ at room temperature prior to the solubility test. The samples were then immersed in the oils, and the increases in sample weight measured and plotted against time.

The percentage of swelling of the samples was calculated according to Equation (4.7):

$$
\text { Sw elling }(\%)=\frac{\left(W_{1}-W_{0}\right)}{W_{0}} \times 100
$$

where $W_{0}$ and $W_{1}$ are the weights of dried and swollen samples, respectively.

Table 4.1 Formulations and gel contents in the vulcanizates for the swelling study

\begin{tabular}{lcccccc}
\hline \multicolumn{1}{c}{ Component } & \multicolumn{2}{c}{ Formulation 1 $(\mathrm{F} 1)$} & \multicolumn{3}{c}{ Formulation 2 (F2) } \\
\hline NR & 100 & - & 50 & 100 & - & 50 \\
SBR & - & 100 & 50 & - & 100 & 50 \\
ZnO & 3 & 3 & 3 & 3 & 3 & 3 \\
Stearic acid & 1 & 1 & 1 & 1 & 1 & 1 \\
DCP & 0.3 & 0.3 & 0.3 & 1.7 & 1.7 & 1.7 \\
\hline Gel content (\%) & $\mathbf{6 9 . 4}$ & $\mathbf{6 8 . 0}$ & $\mathbf{6 6 . 7}$ & $\mathbf{9 0 . 5}$ & $\mathbf{8 6 . 6}$ & $\mathbf{8 6 . 6}$ \\
\hline
\end{tabular}

\subsection{RESULTS AND DISCUSSION}

The process oils are complex combinations of a large variety of molecular species, so the solubility of the oils depends on their molecular structure and chemical compositions, i.e. paraffinic-, naphthenic- and paraffinic-contents. The solubility parameters of NR, SBR and process oils, calculated according to Small's group contribution method for the 
temperatures of $25,60,100$ and $140^{\circ} \mathrm{C}$, are shown in Table 4.2. The solubility parameters of the oils may only be taken as estimated values because they were calculated from only three components, i.e. aromatic, naphthenic and paraffinic carbons. In fact, the oils consist of a variety of different components such as heterocyclic or polar compounds. The solubility parameter of SBR is slightly higher than that of NR due to the presence of the styrene component along with the butadiene part. Among the three types of oils, the solubility parameter of DAE is higher than of TDAE and MES, respectively. This indicates that DAE has the highest polarity. A removal of PAHs leads to less polar aromatic groups and MES contains the highest amount of paraffinic moieties, so MES oils has the lowest solubility parameter.

Table 4.2 Calculated solubility parameters $(\delta)$ of rubbers and process oils $\left(\mathrm{J}^{1 / 2} / \mathrm{cm}^{3 / 2}\right)$ based on molar attraction constants.

\begin{tabular}{ccccc}
\hline \multirow{2}{*}{ Rubber and oil type } & \multicolumn{4}{c}{$\delta\left(\mathrm{J}^{1 / 2} / \mathrm{cm}^{3 / 2}\right)$} \\
\cline { 2 - 5 } & $25^{\circ} \mathrm{C}$ & $60^{\circ} \mathrm{C}$ & $100^{\circ} \mathrm{C}$ & $140^{\circ} \mathrm{C}$ \\
\hline NR & 16.9 & 16.6 & 16.3 & 16.0 \\
SBR & 17.5 & 17.2 & 16.8 & 16.5 \\
DAE & 17.5 & 17.0 & 16.5 & 15.9 \\
TDAE & 17.2 & 16.7 & 16.1 & 15.6 \\
MES & 17.1 & 16.5 & 15.9 & 15.3 \\
\hline
\end{tabular}

Table 4.3 Calculated absolute $\Delta \delta$ of rubbers and process oils $\left(\mathrm{J}^{1 / 2} / \mathrm{cm}^{3 / 2}\right)$

\begin{tabular}{cccccccccc}
\hline \multirow{2}{*}{ Oil } & \multicolumn{2}{c}{$25^{\circ} \mathrm{C}$} & \multicolumn{2}{c}{$60^{\circ} \mathrm{C}$} & \multicolumn{2}{c}{$100^{\circ} \mathrm{C}$} & \multicolumn{2}{c}{$140^{\circ} \mathrm{C}$} \\
\cline { 2 - 9 } type & NR & SBR & NR & SBR & NR & SBR & NR & SBR \\
\hline DAE & 0.6 & 0 & 0.4 & 0.2 & 0.2 & 0.3 & 0.1 & 0.6 \\
TDAE & 0.3 & 0.3 & 0.1 & 0.5 & 0.2 & 0.7 & 0.4 & 0.9 \\
MES & 0.2 & 0.4 & 0.1 & 0.7 & 0.4 & 0.9 & 0.7 & 1.2 \\
\hline
\end{tabular}

The difference in solubility parameters $(\Delta \delta)$ predicts the mutual solubility between oils and rubbers. For a good solubility of a polymer in an organic liquid, $\Delta \delta$ must be small ${ }^{1}$ : 
$\leq 5 \mathrm{~J}^{1 / 2} / \mathrm{cm}^{3 / 2}$. The calculated results shown in Table 4.3 in principle imply that all of the three process oils are well soluble in NR and SBR. For NR, the absolute values of $\Delta \delta$ of rubber and oils are ranked differently at different temperatures. At $25^{\circ} \mathrm{C}, \Delta \delta$ of $\mathrm{DAE}>\mathrm{TDAE}>\mathrm{MES}$, while at $60^{\circ} \mathrm{C} \Delta \delta$ of $\mathrm{DAE}>\mathrm{TDAE} \approx \mathrm{MES}$, and at $100^{\circ} \mathrm{C}$ and $140^{\circ} \mathrm{C}$, MES>TDAE $\approx D A E$. This can be interpreted such that NR and MES oil are less compatible at higher temperature, e.g. at a temperature during mixing, whilst NR and DAE become more compatible. This correlates with the results of swelling tested at 25,60 and $100^{\circ} \mathrm{C}$, as shown in Figure 4.1. The situation is different for the values of $\Delta \delta$ of SBR and the oils. In this case, at every temperature $\triangle \delta$ of MES>TDAE>DAE, SBR is best compatible with DAE, followed by TDAE and MES, respectively. Increase of temperature increases the \%swelling due to the greater mobility of both rubber chains and oil molecules. At higher temperature, the difference of \%swelling between oil types becomes larger, and the DAE oil clearly shows better compatibility with both NR and SBR, as reflected in the higher \%swelling. As shown in Table 4.3, the absolute values of $\Delta \delta$ between NR-DAE and SBR-DAE at 100 and $140^{\circ} \mathrm{C}$ are generally smaller than those of rubber-TDAE and rubber-MES, respectively. The oil with closer value of solubility parameter to rubber should dissolve and distribute better in the compound, resulting in more homogeneous properties and better chain flexibility. The mixing of this oil type into the rubber will also be easier as the oil can distribute faster into the matrix. The addition of process oil or plasticizer increases polymer chain mobility and the longitudinal relaxation time $\left(T_{1}\right)$ in NMR relaxation experiments. If the plasticizer has a strong interaction with polymer segments then it reduces both polymer mobility and $T_{1}$ times $^{21}$. Diekman et al. ${ }^{22}$ studied the dynamics of polymer chains with ${ }^{1} \mathrm{H}$ NMR relaxation in SBR containing DAE, TDAE and MES oils in which the relaxation times were ranked as MES > TDAE > DAE. This implies that DAE has the strongest interaction with SBR which correlates with the swelling observation. Furthermore, as expected, an increase of the gel content of the rubbers used for the \%swelling test, i.e. an increase of crosslink density, reduces the percentage of swelling of rubbers due to restriction by the rubber network, but does not change the overall picture. 

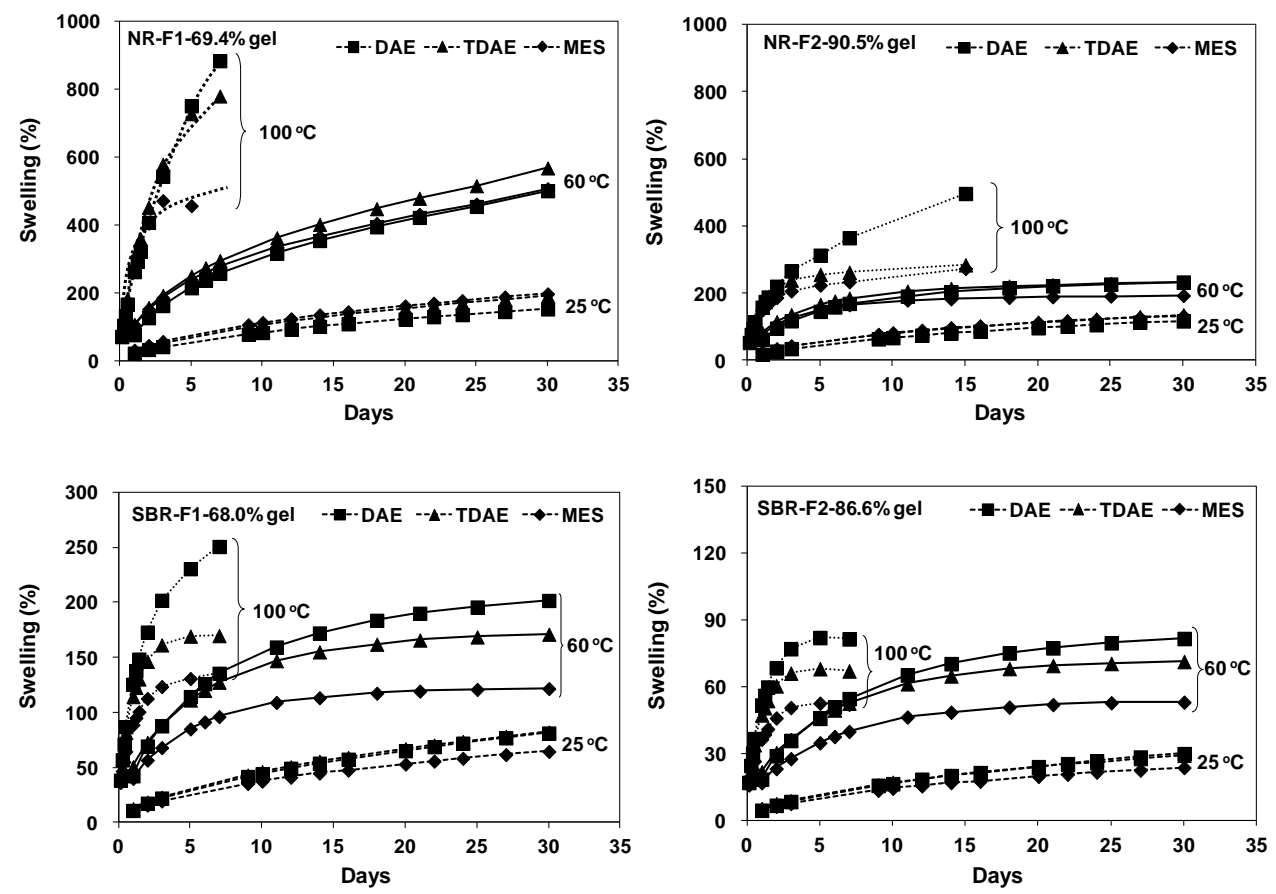

Figure 4.1 Percentages of swelling of NR and SBR in different oils at 25,60 and $100^{\circ} \mathrm{C}$.

With regard to the swelling of oils in the different rubber types as shown in Figure 4.2, it is clear that the oil uptake in NR is higher than in the NR/SBR blend and SBR, respectively. At $60^{\circ} \mathrm{C}$, the percentages of swelling of DAE and TDAE in the rubbers are quite similar and higher than that of MES. However, at $100^{\circ} \mathrm{C}$ the solubility of the oils in the rubbers is most differentiated, especially for the NR case in which DAE shows a significantly higher \%swelling than TDAE and MES. 

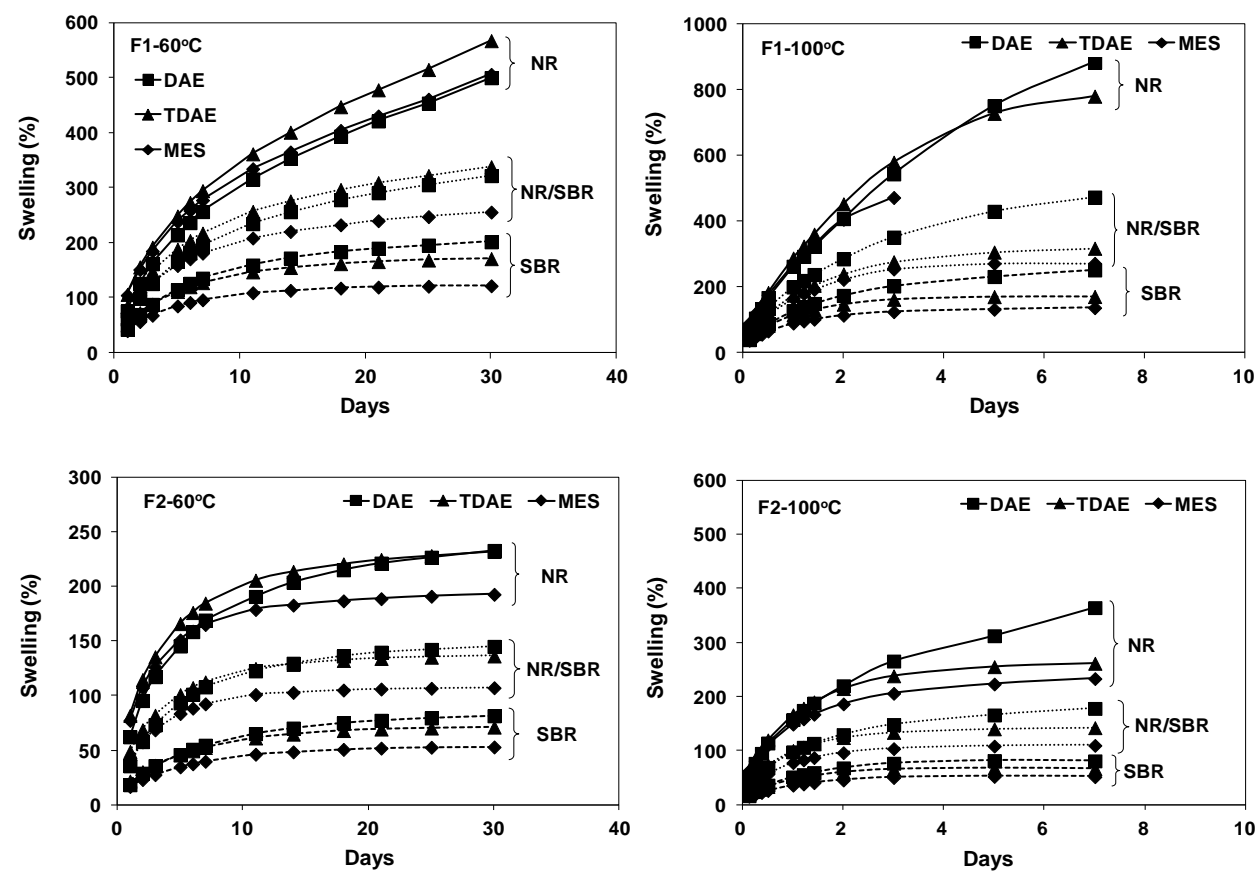

Figure 4.2 Percentages of swelling of NR, NR/SBR blend, and SBR in different oils at 60 and $100^{\circ} \mathrm{C}$. Gel contents of $\mathrm{F} 1 \sim 70 \%$ and $\mathrm{F} 2 \sim 90 \%$.

The relationship between the solubility parameters of the three process oil types in lightly crosslinked NR, the NR/SBR blend and SBR of a gel content of approximate $70 \%$, and the equilibrium swelling ratio $(Q)$ as calculated by using Equation $(4.8)^{10}$, are shown in Figure 4.3.

$$
\mathrm{Q}=1+\frac{\left(\mathrm{m}_{\mathrm{s}} / \mathrm{m}_{0}-1\right) \rho_{\text {rubber }}}{\rho_{\text {oil }}}
$$

Where $Q$ is the equilibrium swelling ratio of the lightly crosslinked rubbers, $m_{0}$ is the mass of the crosslinked rubber before swelling, $m_{s}$ is the mass of the crosslinked rubber at equilibrium swelling, and $\rho_{\text {rubber }}$ and $\rho_{\text {oil }}$ are the densities of the rubber and oil, respectively. 

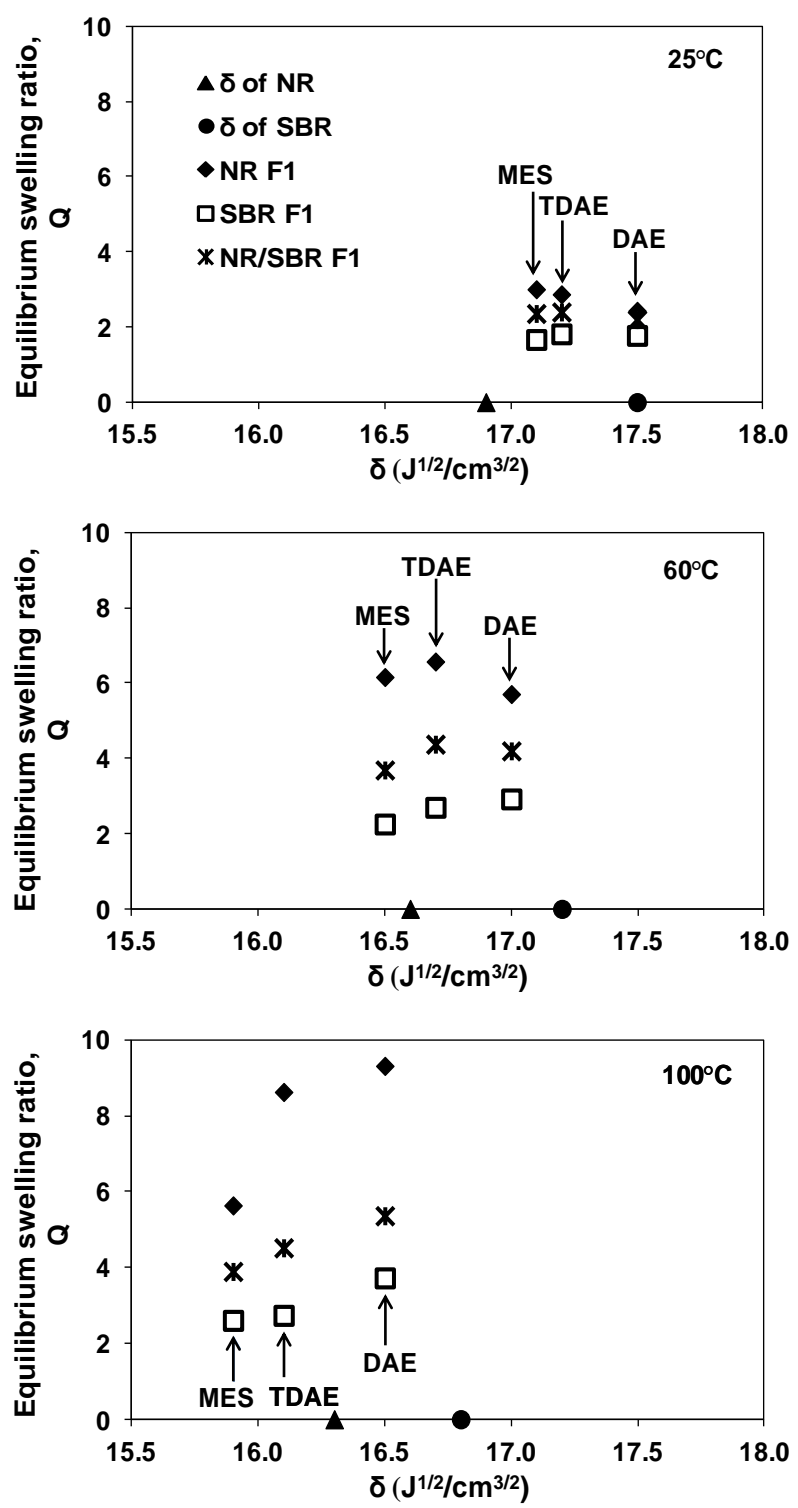

Figure 4.3 Relationship between the equilibrium swelling ratios of NR, SBR and the NR/SBR blend and the solubility parameters of the process oils.

Figure 4.3 shows the changes of the equilibrium swelling ratios of the lightly crosslinked rubbers or $Q$ value, versus the solubility parameters at different temperatures. With increasing temperatures the $Q$ values remarkably increase and the solubility parameters of both oils and rubbers are shifted to lower values. At low temperature of $25^{\circ} \mathrm{C}$, NR is swollen more in MES compared to TDAE and DAE, respectively, in accordance with 
the closer $\delta$ values of MES and NR, as indicated in Figure 4.3, and the $\Delta \delta$ values shown in Table 4.3. At $25^{\circ} \mathrm{C}$, the $\mathrm{Q}$-values of the three rubber types are quite similar. Increase of the temperature to $60^{\circ} \mathrm{C}$ causes a shift of $\delta$ - values of TDAE and MES oils close to the $\delta$ of NR, resulting in a higher equilibrium swelling ratio of $N R$ in TDAE and MES, compared to DAE. On the opposite site, at this temperature the $\delta$ - value of SBR is closer to that of DAE compared to TDAE and MES. This reflects in the ranking of $Q$-values of the lightly crosslinked SBR in those oils, wherein the equilibrium swelling ratio of SBR is highest in DAE. At high temperature of $100^{\circ} \mathrm{C}$, both $\mathrm{NR}$ and SBR have higher equilibrium swelling ratios in DAE oil compared to those in TDAE and MES oils. At this temperature, NR has a $\delta$ value that lies almost in the middle between the values of DAE and TDAE oils, as marked in Figure 4.3, and so the Q-values of NR in both oils are similar. As previously discussed for the calculated $\Delta \delta$-values: Table 4.3 , that the MES oil becomes less compatible with rubber at higher temperature, it is clearly evidenced in Figure 4.3 that the Q-values for NR, SBR and their blend are all lower in MES oil.

The present results clearly demonstrate the good compatibility of DAE will both types of rubbers NR and SBR over a very broad temperature range from low to high (vulcanization) temperature of $140-160{ }^{\circ} \mathrm{C}$. As the solubility parameters of the oils shift much quicker to lower values with increase of temperature than those of the rubbers, it is clear that MES is the first to reach practical limits of solubility at high loadings and high temperatures, higher even than mixing temperatures, such as vulcanization at $140-160{ }^{\circ} \mathrm{C}$ and/or ageing conditions at elevated temperatures.

\subsection{CONCLUSIONS}

DAE, TDAE and MES oils possess different characteristics and so differ in their solubility and compatibility with NR and SBR rubbers. The compatibility of NR, SBR and their $50 / 50$ blend with the three types of oils is studied by a theoretical prediction based on the difference in solubility parameters $(\Delta \delta)$ and an experimental swelling study. The calculated solubility parameters based on group contribution methods using molar attraction constants reveal that all of the three oils have a good solubility in both NR and SBR as the $\Delta \delta$ are small $\left(\leq 5 \mathrm{~J}^{1 / 2} / \mathrm{cm}^{3 / 2}\right)$. However, at high temperature in the range of mixing temperatures, MES oil shows significantly less compatibility compared to TDAE and DAE. The theoretical predictions correlate well with the results of swelling. 


\subsection{REFERENCES}

1 D.W. Van Krevelen and K. Te Nijenhuis, in: Properties of Polymer, Chapter 7: Cohesive Properties and Solubility, 4th Edition, Elsevier, Amsterdam, 2009.

2 C.M. Hansen, Prog. Org. Coat., 51, 109 (2004).

3 J.W. King, Lebensm. Wiss. U. Technol., 28, 190 (1995).

4 A.R. Kemp, F.S. Malm, G.G. Winspear and B. Stiratelli, Ind. Eng. Chem., 32, 1075 (1940).

5 A.R. Kemp, F.S. Malm and B. Stiratelli, Ind. Eng. Chem., 36, 109 (1944).

6 J. B. Gardiner, Rubber Chem. Technol., 41, 1312 (1968).

7 F.X. Guillaumond, Rubber Chem. Technol., 49, 105 (1976).

8 M.D. Morris, Rubber Chem. Technol., 68, 794 (1995).

9 R. Guo, A. G. Talma, R. N. Datta, W. K. Dierkes and J.W.M. Noordermeer, Macromol. Mater. Eng., 294, 330 (2009).

10 T. Caykara, J. Macromol Sci. A, A41, 971 (2004).

11 S.C. George, M. Knorgen and S. Thomas, J. Membrane Sci., 163, 1 (1999).

12 H. Westlinning and G. Butenuth, Rubber Chem. Technol., 35, 274 (1962).

13 C. Kamnuantip and N. Sombatsompop, Mater. Lett., 57, 3167 (2003).

14 A.F.M. Braton, "Handbook of Solubility Parameters and Other Cohesion Parameters", CRC Press, Boca Raton, 1985.

15 P.A. Small, J. Appl. Chem., 3, 71 (1953).

16 H.G. Weyland, P.J. Hoftyzer and D.W. van Krevelen, Polymer, 11, 79 (1970).

17 J.H. Hildebrand and R.L. Scott, "The Solubility of Non-electrolytes", Dover Publications, New York, 1964.

18 S. Krause, in Polymer Blends Vol. 1, Polymer-Polymer Compatibility, Eds.: D.R. Paul and S.Newman, Academic Press, New York, 1978.

19 A.N. Gent, "Engineering with Rubber: How to Design Rubber Components", HanserVerlag, Munich, 2001.

20 R. Guo, A. G. Talma, R. N. Datta, W. K. Dierkes and J.W.M. Noordermeer, Eur. Polym. J., 44, 3890 (2008).

21 G. Wypych, in: Handbook of Plasticizer, Chapter 15: Specialized Analytical Methods in Plasticizers Testing, ChemTech Publishing, Toronto, 2004.

22 A. Diekmann, I. Homeier and U. Giese, Kautsch. Gummi Kunstst., 64, 36 (2011). 


\section{EFFECT OF OIL TYPES AND CONTENTS ON THE PROPERTIES OF UNFILLED RUBBER COMPOUNDS}

This chapter covers the performance of Distillate Aromatic Extract (DAE), Treated Distillate Aromatic Extract (TDAE) and Mild Extracted Solvate (MES) oils in natural rubber (NR), styrene butadiene rubber (SBR) and their blend at 50/50 weight ratio. The unfilled compounds are primarily used in order to observe the influence of oil types on the properties of the rubbers without interference from fillers. The processing and mechanical properties of the compounds containing DAE, TDAE and MES oils reveal that they have only minor effects on Mooney viscosity and cure rate of all the compound types, except for NR compounds in which MES shows a lower cure rate index compared to TDAE and DAE oils. The incorporation of DAE which has a higher $T_{g}$ than the oil-free rubbers increases the $T_{g}$ of the rubber compounds, while the use of MES oil with the lowest $T_{g}$ has no effect on the $T_{g}$ of NR but decreases the $T_{g}$ of SBR slightly. The different oil types show only a slight change in loss tangent values at 0 and $60{ }^{\circ} \mathrm{C}$, except for MES oil in NR that results in higher loss tangent at $60^{\circ} \mathrm{C}$, compared to that of DAE and TDAE. The use of TDAE and MES oils instead of DAE in SBR and in the NR/SBR blend yields compounds with similar mechanical properties, while the use of MES oil in NR results in lower modulus and tensile strength. When considering the overall changes in properties, NR is most sensitive to a change of oil type. 


\subsection{INTRODUCTION}

Distillate Aromatic Extract (DAE), Treated Distillate Aromatic Extract (TDAE) and Mild Extracted Solvate (MES) differ in chemical nature because of the different proportions of aromatics and saturated hydrocarbons. The solubility parameters $(\delta)$ and the absolute $\Delta \delta$ values between the process oils and rubbers, as discussed in Chapter 4, are indicative of their compatibility. Furthermore, the difference in the physico-chemical characteristics of the process oils, as reported in Chapter 3 , is also expected to have an influence on the properties of compounds and vulcanizates. The structure-property relationships of process oils and interactions between the oils and rubber were studied by Schneider et al. ${ }^{1}$. Their investigation was based on styrene butadiene rubber (SBR) based carbon black reinforced tire tread compounds using 4 types of process oils with contents of aromatic carbon ranging from $38 \%$ to $4 \%$. The properties of the oils were related to the aromatic carbon content, and the change of glass transition temperature $\left(T_{g}\right)$ of oil extended rubber was correlated with the $T_{g}$ of the oils. The reduction of aromatic compounds in the oils reduced the $T_{g}$ of the oils and hence the $T_{g}$ of the compounds. It was demonstrated that the $T_{g}$ of the oils clearly affected the vulcanizate properties. The use of more naphthenic oils lowered viscosity and increased resilience, but deteriorated the wet skid resistance of tires, as monitored by Nordsiek ${ }^{2}$.

The influence of non-toxic mineral oils on the vulcanizate properties has been investigated before in comparison with the use of conventional aromatic oil. The properties of carbon black- and silica-filled SBR based-tire tread compounds were investigated by Null ${ }^{3}$ when TDAE, MES and Naphthenic (NAP) oils were used to replace DAE process oil. The use of TDAE, MES and NAP-oils resulted in similar tensile strength, modulus and hardness, lower tire rolling resistance, but poorer wet grip when compared with the DAE compound. These results are in agreement with the work reported by Bowman et al. ${ }^{4}$ on emulsion- $(E-$ SBR) and solution-SBR (S-SBR) compounds plasticized with TDAE and MES oils. The use of TDAE resulted in vulcanizates with similar properties to that of DAE oil, whereas MES resulted in inferior mechanical properties due to its lower compatibility with SBR rubber and a much lower viscosity. The reduction of aromatic compounds in the oils affected the $T_{g}$ of the oils and hence the $T_{g}$ of the compounds.

A study on naphthenic oils with different aromatic contents ${ }^{5}$ in a S-SBR compound filled with silica demonstrated that the vulcanizates had similar hardness, modulus, tensile strength and dynamic properties compared with the compound containing DAE oil. The use of NAP as an alternative to TDAE in the replacement of DAE as extender oil in rubber generally used in the tire industry, has also been reported recently ${ }^{6}$. Further, a study on dynamic mechanical properties of SBR compounds containing several types of oils with low 
content of PAHs (i.e. TDAE, MES, RAE (Residual Aromatic Extract) and NAP) reported only small differences in dynamic modulus values and glass transition temperatures ${ }^{7}$, supporting that the oil replacement in tire rubbers is feasible. In addition to petroleum-based safe process oils, some vegetable oils have also been investigated for the replacement of DAE, aiming to promote the use of more sustainable resources ${ }^{8-11}$. However, the results have not yet fully met the technical requirements especially for high performance products such as tires.

Despite the fact that the use of petroleum-based process oils such as TDAE and NAP in the replacement of DAE oil has been reported to offer high performance matching, well to that of the labeled DAE, especially in terms of physical and mechanical properties, their contribution to the dynamic mechanical properties is still not optimal. This is especially true for MES. Even though these non-labeled oils have been implemented in various tire manufacturing companies, a truly good understanding of the influence of these oils on the rubber performance is still limited, due to only little open literature available. In addition, as most studies were done using SBR-based compounds, it is therefore interesting to investigate the influence of these safe process oils in NR compounds as well, generally formulated for truck tires, in addition to SBR and their blends.

This chapter presents the properties of oil-extended unfilled compounds of those rubber types. Influences of oil types and amounts on the processing properties of rubber compounds, $\mathrm{T}_{\mathrm{g}}$ of vulcanizates, dynamic mechanical properties and some mechanical properties are investigated and discussed in comparison with the use of conventional DAE oil. This is to create a basic understanding prior to application in practical carbon black or silica filled tire-tread compounds in the following chapter.

\subsection{EXPERIMENTAL}

\subsubsection{Materials}

Natural rubber (Ribbed smoked sheet 3, RSS3) locally produced in Pattani (Thailand) and emulsion-polymerized styrene butadiene rubber (SBR1502) produced by BST Elastomers (Thailand) were used as rubber materials. Three types of oils, i.e. DAE (Tudalen 65), TDAE (Vivatec 500) and MES (Vivatec 200), were supplied by Hansen\& Rosenthal KG (Hamburg, Germany). The other compounding ingredients were stearic acid (Imperial Chemical, Thailand), ZnO (Global Chemical, Thailand), N-cyclohexyl-2benzothiazolesulfenamide (CBS) and diphenyl guanidine (DPG) (Flexsys, Belgium), and sulfur (Siam Chemicals, Thailand). All elastomers and compounding ingredients were used as received. 


\subsubsection{Methods}

\subsubsection{Preparation of rubber compounds}

Mixing of all compounds was carried out using an internal mixer with a chamber volume of $500 \mathrm{~cm}^{3}$ (Chareon Tut Co., Ltd., Thailand), an initial temperature setting of $60^{\circ} \mathrm{C}$ and a rotor speed of $60 \mathrm{rpm}$ using the formulations as given in Table 5.1. Three different types of process oils, i.e. DAE, TDAE and MES were employed and the oil contents were varied from $0,5,10,15$ to $20 \mathrm{phr}$, respectively.

Table 5.1 Formulations for the compound study

\begin{tabular}{lccc}
\hline Ingredients & \multicolumn{3}{c}{ Amount (phr) } \\
\hline NR (RSS 3) & 100.0 & 50.0 & - \\
SBR 1502 & - & 50.0 & 100.0 \\
Oil & & Varying types and loadings \\
Zinc oxide & 3.0 & 3.0 & 3.0 \\
Stearic acid & 1.0 & 1.0 & 1.0 \\
CBS & 1.2 & 1.2 & 1.2 \\
DPG & 0.3 & 0.3 & 0.3 \\
Sulfur & 1.5 & 1.5 & 1.5 \\
\hline
\end{tabular}

In order to eliminate a possible effect of mastication of the natural rubber on the oilresults, it was pre-masticated for 3 mins, using a kneader, prior to being used for each NR and NR/SBR compound. The mixing procedures in the internal mixer started with a remastication of the rubbers for 2 mins. Stearic acid, zinc oxide and 1/3 process oil were then added and mixed for 3 mins. Next, DPG and $1 / 3$ process oil were added and mixed for another 3 mins. After that, CBS and the remaining process oil were added and mixed for 3 mins and the compound was subsequently dumped. The compounds were finally mixed with sulfur on a two-roll mill and sheeted to a thickness of approximately $3 \mathrm{~mm}$.

\subsubsection{Testing of Mooney viscosity, cure characteristics and vulcanizate properties}

Mooney viscosity and Mooney stress relaxation were determined using a Mooney viscometer (TechPro, USA) at $100^{\circ} \mathrm{C}$ and a large rotor according to ASTM D1646. Mooney viscosities at various rotor speeds (i.e. at 1, 2, 4 and $8 \mathrm{rpm}$ ) were studied at $100^{\circ} \mathrm{C}$ using a Mooney viscometer (Alpha Technologies, USA) in order to analyze the rheological behavior of the compounds. Log-log plots of viscosity and shear rate are applied to obtain a pseudoplasticity index (n), following the method reported by White and Tokita ${ }^{12}$ and Nakajima and Collins ${ }^{13}$. 
Cure characteristics were determined using a moving die rheometer MDR2000 (TechPro, USA) according to ASTM D5289 at $150^{\circ} \mathrm{C}$ for 30 mins for the NR and NR/SBR compounds, and 45 mins for the SBR compound. The cure rate index equal to [100/(90\% optimum cure time - scorch time)] was calculated.

The rubber compounds were cured to their $90 \%$ optimum cure times by compression molding at $150^{\circ} \mathrm{C}$. The resulting vulcanizates were left to condition at room temperature for at least $16 \mathrm{~h}$ prior to being tested. Thin sheets of rubber vulcanizates with dimensions of $10 \times 24 \times 1 \mathrm{~mm}^{3}$ were tested for their dynamic mechanical properties using a dynamic mechanical thermal analyzer (Rheometric Scientific DMTA V, USA) in the tension mode. The instrument was operated at a strain of $0.08 \%$, frequency $1 \mathrm{~Hz}$, heating rate 5 ${ }^{\circ} \mathrm{C} /$ min over a temperature range of $-150{ }^{\circ} \mathrm{C}$ to $+100{ }^{\circ} \mathrm{C}$. Tensile properties of the vulcanizates were tested using type $C$ dumb-bell test pieces according to ASTM D412 with a H10KS tensile testing machine (Hounsfield Test Equipment, England) at a constant crosshead speed of $500 \mathrm{~mm} / \mathrm{min}$. Indentation hardness was measured using a Shore $A$ durometer (Brevetti Affri, O.M.A.G. Induno, Italy) according to ASTM D1415.

\subsection{RESULTS AND DISCUSSION}

\subsubsection{Viscosities and cure characteristics of the compounds}

The difference of Mooney viscosities of the compounds with each type of oil in the same rubber is small, and increasing the oil-contents gradually decreases the compound viscosities: Figure 5.1, where the NR compounds have lower viscosities than those of the SBR compounds as a result of the mixing process in which the NR molecules were shortened by the pre-mastication and mixing conditions. 


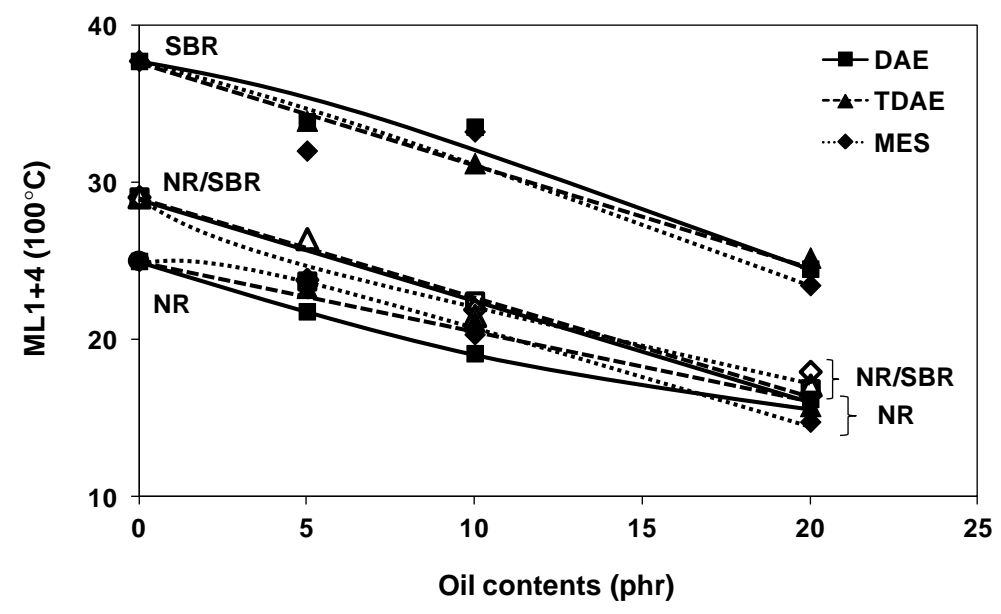

Figure 5.1 Mooney viscosities of the compounds with varying amounts of DAE, TDAE and MES oils.

Mooney stress relaxation is commonly well described as $\mathrm{M}=\mathrm{Kt}^{\mathrm{a}}$, where $\mathrm{K}$ is a constant equal to the torque in Mooney units $1 \mathrm{sec}$. after the rotor has stopped, $a$ is an exponent that measures the rate of stress relaxation (i.e. the slope of the relaxation function), and $t$ is relaxation time (sec.). This equation can be converted into a log-log plot as follows.

$$
\log M=a \log t+\log K
$$

From the log-log plot, $a$ is the slope of the plot and is a measure of uncured rubber elasticity, though not totally independent of the viscous Mooney value itself. A steeper slope, i.e. a faster rate of decay, indicates that the polymer has a higher (viscous/elastic) ratio and a less uncured elasticity ${ }^{14,15}$, at least for polymers with the same Mooney values to start with. Herein, a lower uncured elasticity can mean better processability. 


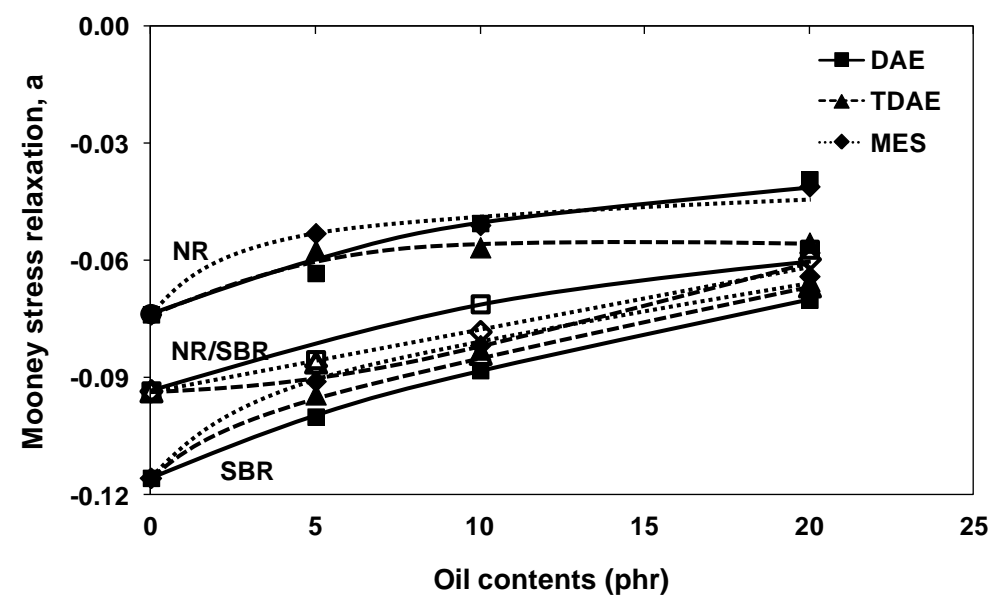

Figure 5.2 Mooney stress relaxation rate of the compounds with varying amounts of DAE,

TDAE and MES oils.

As displayed in Figure 5.2, increasing oil contents decrease the rate of decay, i.e. the number becomes less negative or the slope $a$ is flatter, indicating a lower viscous/elasticity ratio for all the uncured compounds. This may partly be attributed to the lower Mooney viscosities. But this means also that the oils increase the elastic vs. viscous response of the materials which could be attributed to more chain mobility and flexibility on the presence of oil between the rubber molecules. Three types of oils give similar Mooney stress relaxation rates at the same oil contents, except NR compounds with TDAE oil that have a higher decay rate than the compounds with DAE and MES oils at 20 phr. The faster decay rates of SBR and NR/SBR blend compounds when compared to NR indicate less uncured elasticity. This is due to the presence of the styrene component in the copolymer which introduces damping behavior.

The rubber compounds are non-Newtonian materials that have pseudoplastic behavior, i.e. their viscosities decrease with increasing shear rates. Even though the range of shear rates in the Mooney test is lower than practical processing shear rates, the results should provide an indication of flow behavior of the rubber compounds. By varying rotor speeds, Mooney viscosities were recorded and calculated into real shear viscosities ${ }^{13}$. The shear viscosity and shear rate are related through a power law function via the following equation:

$$
\eta=k \gamma^{n-1}
$$

where: $\eta$ is the shear viscosity, $k$ is a constant, $\gamma$ is shear rate and $n$ is the power law index. For Newtonian behavior, $\mathrm{n}$ is equal to 1 . If $\mathrm{n}$ is less than 1 , the material shows 
shear thinning or pseudoplastic behavior; if it is greater than 1, the material shows shear thickening behavior.
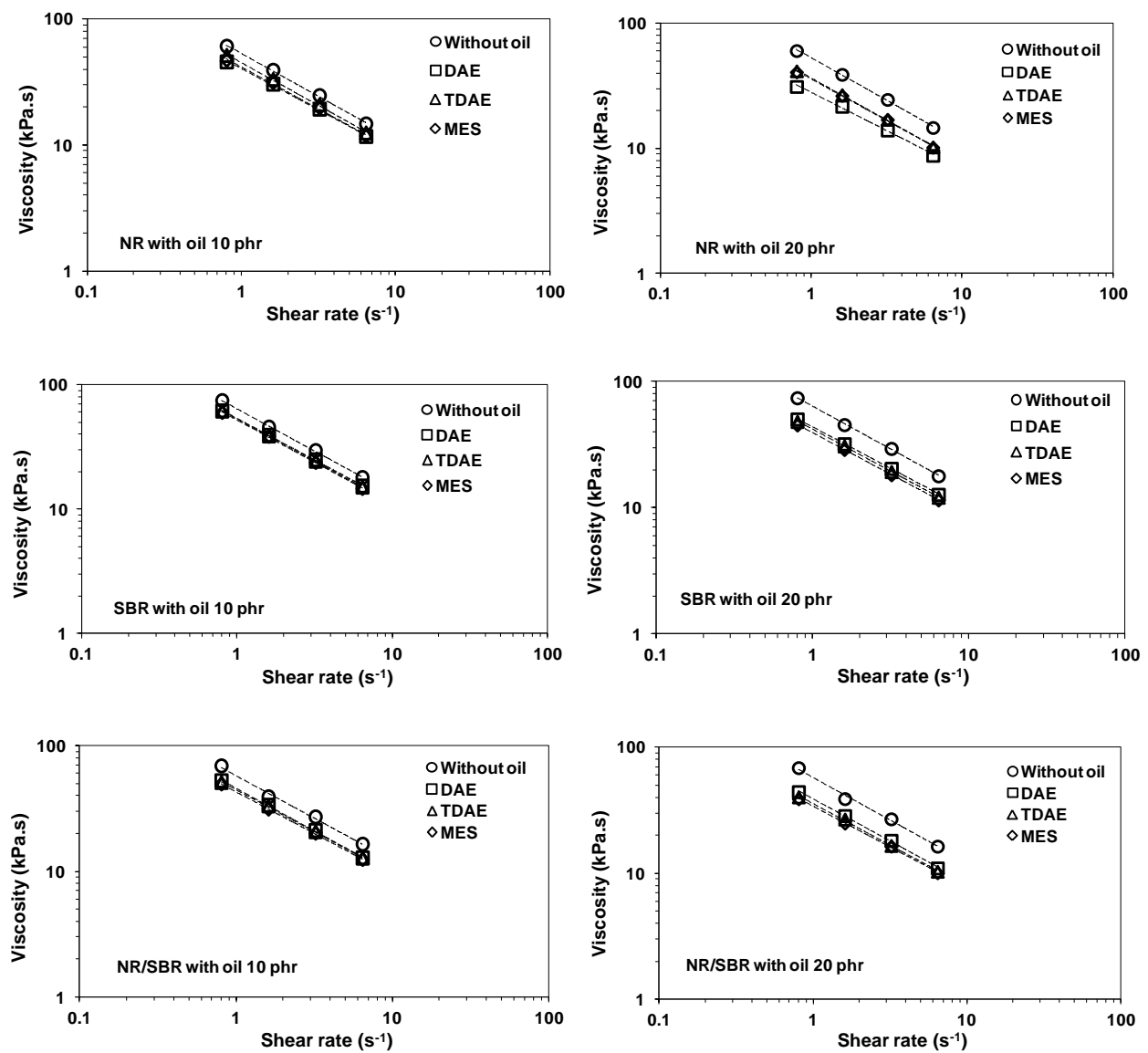

Figure 5.3 Correlation between viscosity and shear rate of NR, SBR and NR/SBR blend compounds with DAE, TDAE and MES oils at 10 and 20 phr.

Figure 5.3 shows the log-log plots of viscosities versus shear rates of NR, SBR and NR/SBR blend compounds with the three types of oils at 10 and 20 phr. The viscosities of the compounds decrease with increasing shear rate and further decrease with higher oil contents. At the same oil content, all 3 types of process oils give similar shear viscosities, except the case of the 20 phr DAE-extended NR compound which shows the lowest value and differentiates from the other two compound types. The greater extent of viscosity reduction may be attributed to the better oil-rubber compatibility, as previously discussed in terms of $\Delta \delta$ in Chapter 4 (Table 4.3). The addition of oils increases the power law index (n) 
of the compounds compared to the unplasticized one as shown in Table 5.2, indicating a slight tendency in the direction of more Newtonian behavior. The increase of oil content from 10 to 20 phr tends to increase $n$ slightly, and mostly there is no significant difference in nvalues between the oil-types, as shown in Table 5.2. However, the NR compound with 20 phr of DAE clearly shows the highest $n$-value which implies more Newtonian behavior or better compatibility than the others.

Table 5.2 The power law index of NR, SBR and NR/SBR blends compounds with varying oil types and contents.

\begin{tabular}{cccccc}
\hline \multirow{2}{*}{ Compounds } & Oil content & \multicolumn{3}{c}{$\mathrm{n}=$ power law index } \\
\cline { 3 - 6 } & & Without oil & DAE & TDAE & MES \\
\hline NR & 0 & 0.32 & & 0.32 & 0.33 \\
& 10 & & 0.34 & 0.33 & 0.34 \\
& 20 & & 0.39 & & \\
SBR & 0 & 0.32 & & 0.32 & 0.32 \\
& 10 & & 0.33 & 0.33 & 0.34 \\
\hline NR/SBR & 20 & & 0.34 & & \\
& 0 & 0.33 & 0.32 & 0.33 & 0.34 \\
& 10 & & 0.33 & 0.34 & 0.35 \\
\hline
\end{tabular}

Addition of different oil types affects the cure characteristics of the NR compounds in particular, as shown in Figure 5.4. The addition of low contents of DAE and TDAE-oils (i.e. $5 \mathrm{phr}$ ) shortens the scorch and cure times, whereas the use of MES-oil slightly prolongs the cure when compared to the non-oil extended compound. However, increasing oil contents increase scorch and cure times, while they decreases the torque differences $\left(\mathrm{M}_{\mathrm{H}}-\mathrm{M}_{\mathrm{L}}\right)$ as a result of the plasticization effect, as typically demonstrated in Figure 5.4, comparing the oil contents at 5 and 20 phr. The addition of oils to both the NR/SBR blend and SBR only prolongs the cure when compared to the non-oil extended compounds. The addition of DAE and TDAE gives very similar scorch and cure times whereas the use of MES oil gives slightly longer values, as typically shown in the cure curves of the NR/SBR blend in Figure 5.5 . 

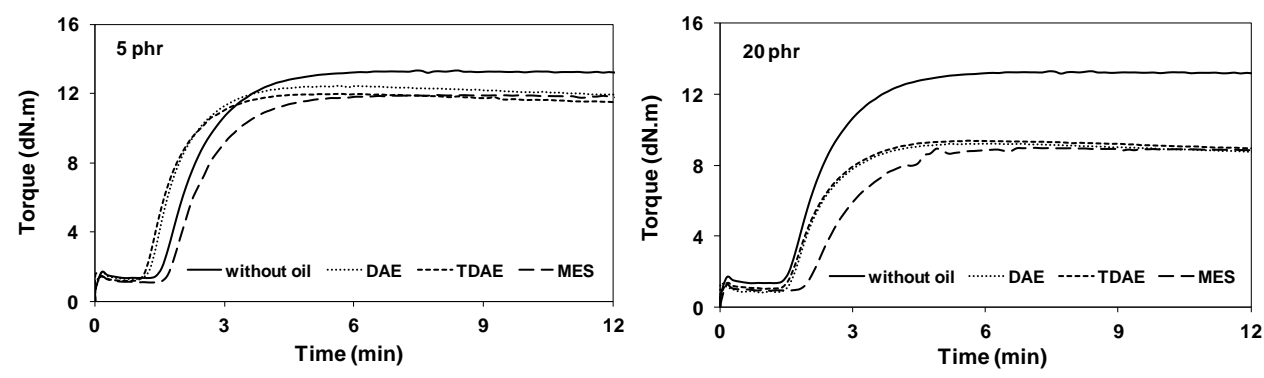

Figure 5.4 Typical cure curves of NR compounds with DAE, TDAE and MES -oils at 5 and $20 \mathrm{phr}$, measured at $150^{\circ} \mathrm{C}$.
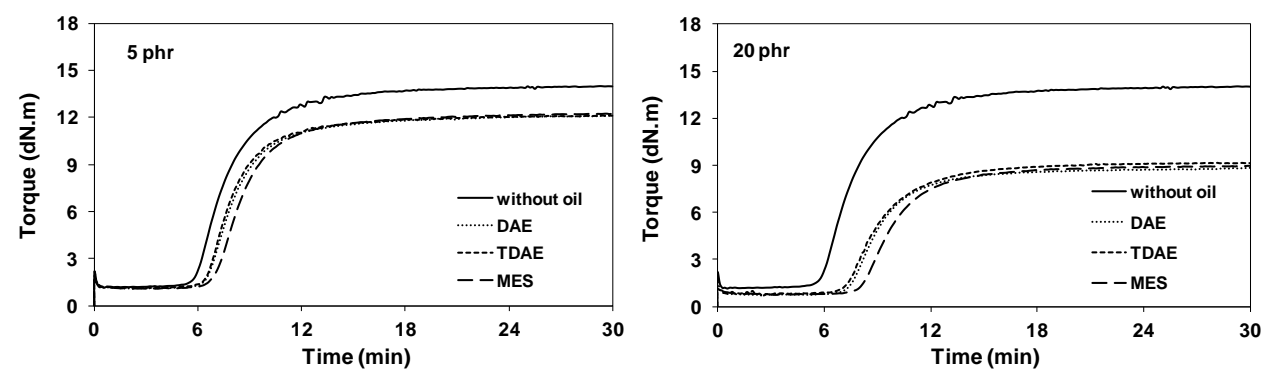

Figure 5.5 Typical cure curves of NR/SBR compounds with DAE, TDAE and MES-oils at 5 and $20 \mathrm{phr}$, measured at $150^{\circ} \mathrm{C}$.

The influence of DAE and TDAE on the scorch and cure times of NR compounds is reflected also in their higher cure rate indices, compared to the compounds with MES and without oil, as displayed in Figure 5.6. The types and amounts of oils have no influence on the cure rate indices of the SBR and NR/SBR-blend compounds. DAE and TDAE-oils can accelerate the curing reaction in NR which contains more reactive double bonds compared to SBR. It can also be attributed to the presence of nitrogen- and sulfur-containing heterocyclic compounds in the DAE and TDAE-oils which can cause cure acceleration, in addition to the accelerators. The TDAE-oil contains less heterocyclic compounds compared to DAE, whereas MES is the most inert type. The cure rate indices for the SBR and NR/SBR-compounds remain more or less constant with increase of oil content, even though the plasticization effect becomes more pronounced at higher oil contents. In the oil-extended compounds, the oils may also interfere with other additives, especially the highly polar accelerators. Apparently, all these various factors more or less balance each other. 


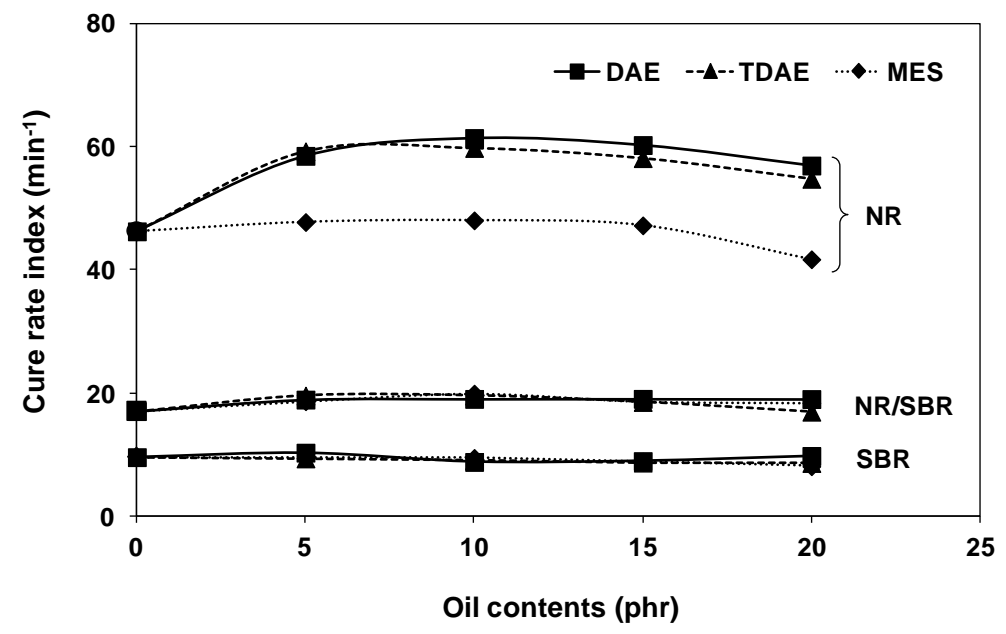

Figure 5.6 Cure rate indices of NR, SBR and NR/SBR compounds with varying amounts of DAE, TDAE and MES-oils at $150^{\circ} \mathrm{C}$.

\subsubsection{Influence of oil types on $\mathrm{T}_{\mathrm{g}}$ of vulcanizates}

The three different types of process oils have different glass transition temperatures $\left(T_{g}\right)$, so the $T_{g}$ 's of the rubber compounds are also affected. In this work, the $\mathrm{T}_{\mathrm{g}}$-values are taken as the temperature for the peak of the loss tangent plotted against temperature as analyzed using the DMTA technique. The $\Delta T_{g}$, i.e. the difference of $T_{g^{-}}$ values between those of the rubbers without oil and those with different oil types/contents, is plotted in Figure 5.7. The overall effects are restricted to a few degrees $\mathrm{C}$. 

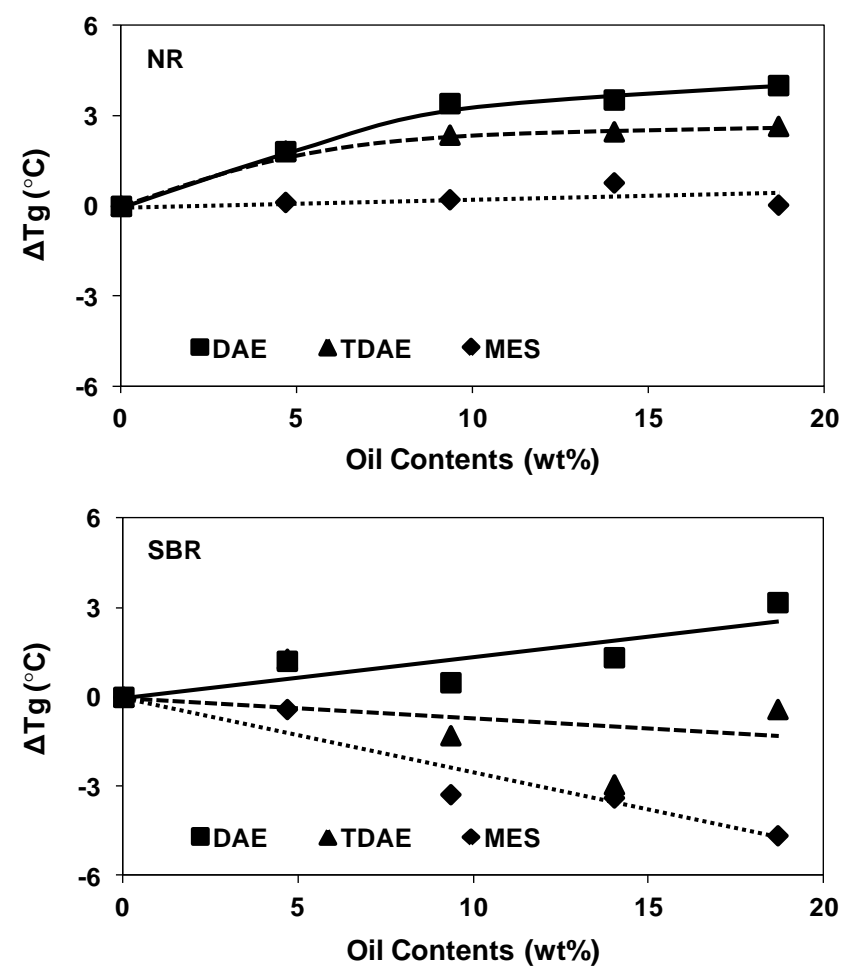

Figure 5.7 $\Delta T_{g}$ of NR and SBR with three different types of oils at different oil-contents. (Experimental values with trend lines)

The addition of DAE and TDAE-oils in NR increases the $T_{g}$ of the corresponding compounds as the $\mathrm{T}_{\mathrm{g}}$ 's of the oils are higher than that of the rubber. The increase in $\mathrm{T}_{\mathrm{g}^{-}}$ values tends to level off with the DAE and TDAE-contents. Meanwhile, adding of MES-oil which has a similar $T_{g}$ to that of $N R$ results in more or less the same $T_{g}$-values at varying oil contents. The addition of DAE into SBR also increases the $T_{g}$ of the resulting compound, but the use of TDAE and MES-oils which have lower $T_{g}$ 's than that of SBR decreases the $T_{g}$ of the corresponding compounds. The results reveal that the $T_{g}$ 's of the NR and SBR vulcanizates are in correspondence with the $T_{g}$ 's of the oils.

The glass transition temperatures of miscible mixtures can be predicted by the simple rule of mixtures based on the composition dependence ${ }^{16}$. The first approximation of the $T_{g}$ variation of oil-extended rubber can be expressed by the simple equation (5.3) ${ }^{1}$ : 


$$
\mathrm{T}_{\mathrm{g}}^{\mathrm{OE}-\mathrm{R}}=\mathrm{W}_{\mathrm{oil}} \times \mathrm{T}_{\mathrm{g}}^{\mathrm{oil}}+\left(1-\mathrm{W}_{\mathrm{oil}}\right) \times \mathrm{T}_{\mathrm{g}}^{\mathrm{R}}
$$

Where $\mathrm{T}_{\mathrm{g}}^{\mathrm{OE}-\mathrm{R}}$ is the glass temperature of oil-extended rubber; $\mathrm{W}_{\text {oil }}$ is the weight fraction of oil; $T_{g}^{\text {oil }}$ and $T_{g}^{R}$ are the $T_{g}$-values of pure oil and oil-free rubber, respectively.

However, as the polymer and process oils are not entirely miscible, so the more advanced of Fox equation is also used to calculated the $T_{g}$ of oil-extended rubber which is calculated from the weighted average of the $T_{g}$ of its components using the inverse rule of mixtures, according to the Fox equation as shown in Equation (5.4) ${ }^{17}$ :

$$
\frac{1}{T_{g}^{O E-R}}=\frac{W_{\text {oil }}}{T_{g}^{\text {oil }}}+\frac{W_{R}}{T_{g}^{R}}
$$

Where $W_{R}$ is the weight\% of oil-free rubber.

The simple equation (5.3) can be differentiated to render equation (5.5), which predicts a linear relation:

$$
\frac{\Delta \mathrm{T}_{\mathrm{g}}^{\mathrm{OE}-\mathrm{R}}}{\Delta \mathrm{W}_{\text {oil }}}=\mathrm{T}_{\mathrm{g}}^{\text {oil }}-\mathrm{T}_{\mathrm{g}}^{\mathrm{R}}
$$

The equation (5.5) can be used to define a measure for the plasticizer efficiency of the process oil. The data obtained for the oils and rubbers under investigations are plotted in Figure 5.8. It can be seen that the plasticizer effect increases with increasing aromatic content in either rubber. The $\mathrm{T}_{\mathrm{g}}^{\mathrm{oil}}-\mathrm{T}_{\mathrm{g}}^{\mathrm{R}}$ of $\mathrm{DAE}$ and TDAE in NR is positive, so these oils increase the $T_{g}$ of the rubber. The $T_{g}^{\text {oil }}-T_{g}^{R}$ values of DAE in SBR and MES in NR are negative but close to zero, so they are expected to have only little effect on $T_{g}$. Regarding the use of TDAE and MES in SBR, both of these oils act as plasticizers in SBR and reduce the $T_{g}$ of the SBR compounds. However, the plots are not linear as two curved lines are observed in Figure 5.8. So, the simple rule of mixtures is apparently too simple and the Fox equation after all is a better approximation. 

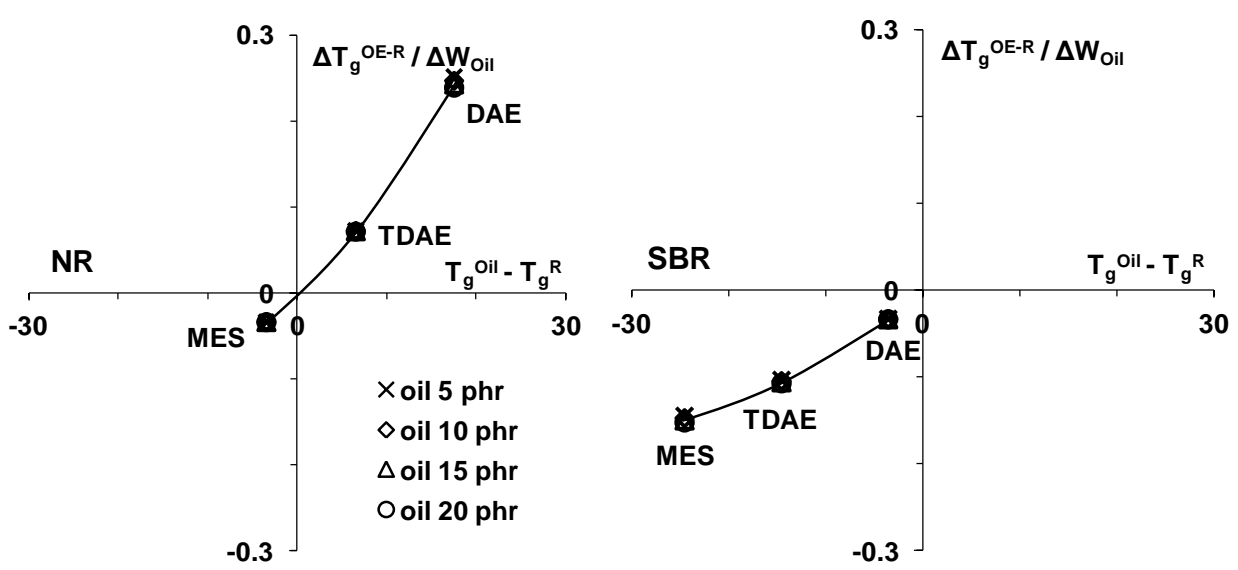

Figure 5.8 Shift by weight of the $T_{g}$ of oil-extended NR and SBR versus the differences in $T_{g}$ of the pure components.

\subsubsection{Dynamic mechanical properties of the vulcanizates}

Two of the key properties for tire performance are the wet grip and rolling resistance which are often characterized by the dynamic mechanical loss tangent at $0^{\circ} \mathrm{C}$ and $60^{\circ} \mathrm{C}$, respectively. A higher loss tangent at $0^{\circ} \mathrm{C}$ indicates better wet grip and a lower loss tangent at $60^{\circ} \mathrm{C}$ indicates lower rolling resistance. Although the present investigation was executed using unfilled compounds and their loss tangents cannot be related to the practical application of filled compounds in tires, it is still worth to analyze their dynamic properties. The replacement of DAE with TDAE and MES-oils affects the glass transition temperatures of the compounds, and hence should play a role in their viscoelastic properties. The DMTAanalysis of the vulcanizates without filler reveals an influence of oil types on the loss tangents of the rubbers at 0 and $60^{\circ} \mathrm{C}$, as shown in Figure 5.9. 

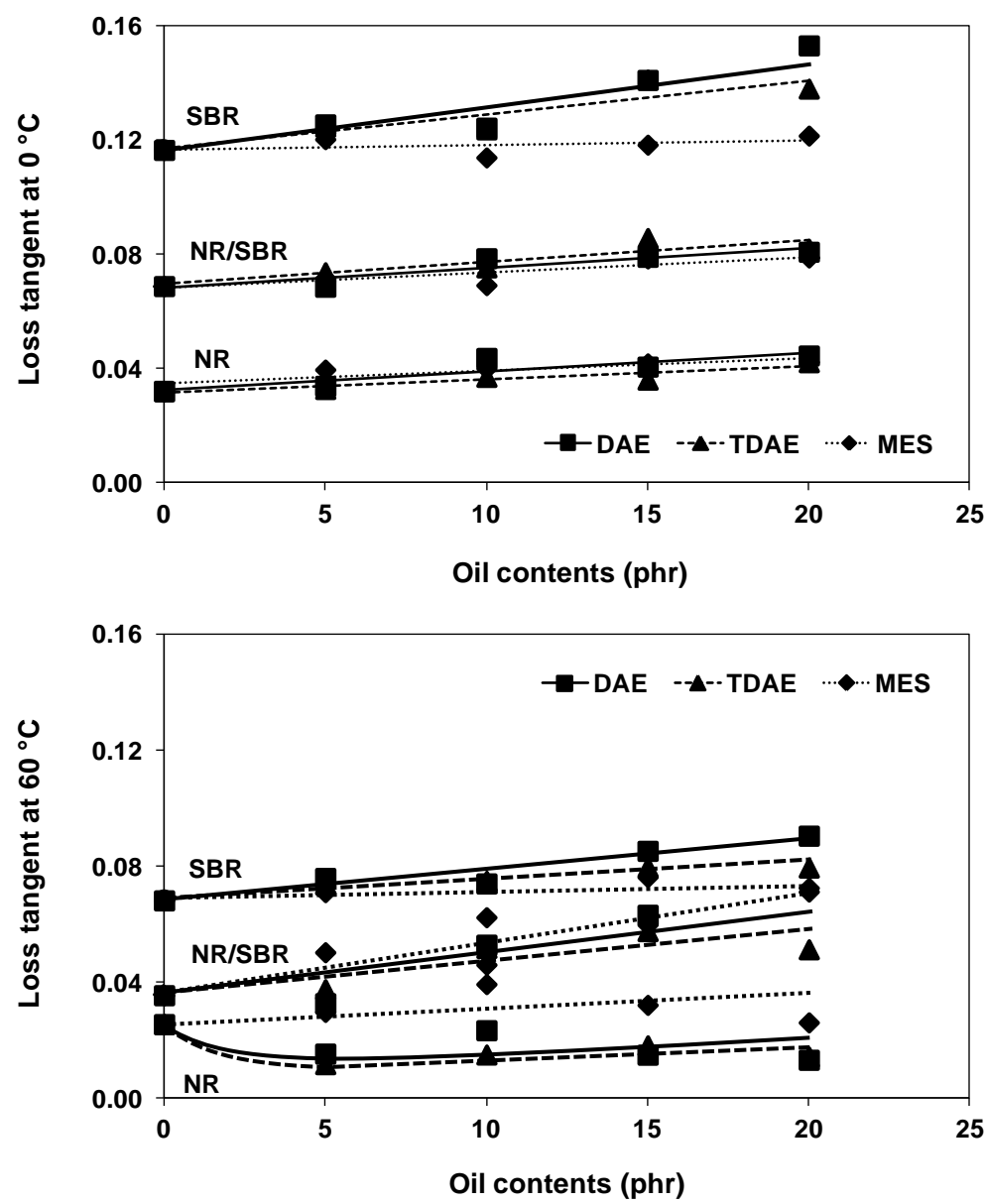

Figure 5.9 Loss tangent at 0 and $60^{\circ} \mathrm{C}$ of $\mathrm{NR}, \mathrm{SBR}$ and NR/SBR vulcanizates with varying amounts of DAE, TDAE and MES-oils.

Adding oils to the rubber increases in general the loss tangent, as expected because the oils do not contribute to elasticity but damping instead. The NR and NR/SBR vulcanizates with different oil types show similar loss tangents at $0^{\circ} \mathrm{C}$ for equal oil-loading, while the SBR-vulcanizates with DAE and TDAE-oils show higher loss tangent at $0^{\circ} \mathrm{C}$ compared to that of SBR with MES. NR and SBR clearly display different dynamic properties amongst themselves as a result of their molecular structures. The more elastic NR looses much less energy during sinusoidal deformation and hence has a distinctively lower loss tangent, when compared with SBR, in which the styrene-content enhances the damping properties. The NR/SBR blends show loss tangent values in between the parent polymers. 
The loss tangent values at $60^{\circ} \mathrm{C}$ of all the compounds are more influenced by the process oil-types used. For NR-vulcanizates, both DAE and TDAE give similar results primarily, indicating that the replacement of DAE by TDAE in NR would have little adverse effect on rolling resistance. Both DAE and TDAE-extended NR display even a lower loss tangent compared to oil-free $\mathrm{NR}$, in accordance with the increased $\Delta \mathrm{T}_{\mathrm{g}}$ in Figure 5.7, and the calculated results in Figure 5.8, which predicts that these oils may act as "hardener" instead of plasticizer ${ }^{1}$. The use of MES in NR leads to a slight increase in loss tangent at $60^{\circ} \mathrm{C}$, even though the $\Delta T_{g}$-value of the MES added to NR remains more or less unchanged with oil content, but its acts still as a plasticizer according to the results shown in Figure 5.8. For the SBR-vulcanizates, in which all types of oils act as a plasticizer and the plasticizer effect of MES>TDAE>DAE, the vulcanizates with MES-oil therefore show lower loss tangent at $60^{\circ} \mathrm{C}$ when compared with TDAE and DAE-oils. The NR/SBR blends show loss tangent values at $60^{\circ} \mathrm{C}$ again in between the parent polymers.

The results of dynamic mechanical properties of the vulcanizates indicate that the two types of rubber behave differently with regard to the oil-types used for processing. The different responses towards the change of oil-type in these unfilled compounds suggest that the dynamic mechanical properties of filled compounds, especially those related to tire performance, need to be critically analyzed and adjusted.

\subsubsection{Mechanical Properties of the vulcanizates}

The NR, SBR and NR/SBR-blend vulcanizates containing the three different types of process oils were tested for hardness and tensile properties. The results are shown in Figures 5.10 - 5.12. As expected, an increase of oil-contents reduces the hardness and $100 \%$-modulus of the vulcanizates (Figure 5.10) since the rubber molecules can deform easier due to an increase of the free volume and the lubrication effect of the oils. At the same oil-content, NR/SBR blends display the same levels of hardness and modulus irrespective of the oil types. However, for the NR and SBR-cases, the DAE-containing vulcanizates tend to have a higher $100 \%$-modulus than those with TDAE and MES, respectively. This can be correlated with the change of glass transition temperature of the rubbers which clearly increased with the addition of DAE oil, as shown in Figure 5.7. 

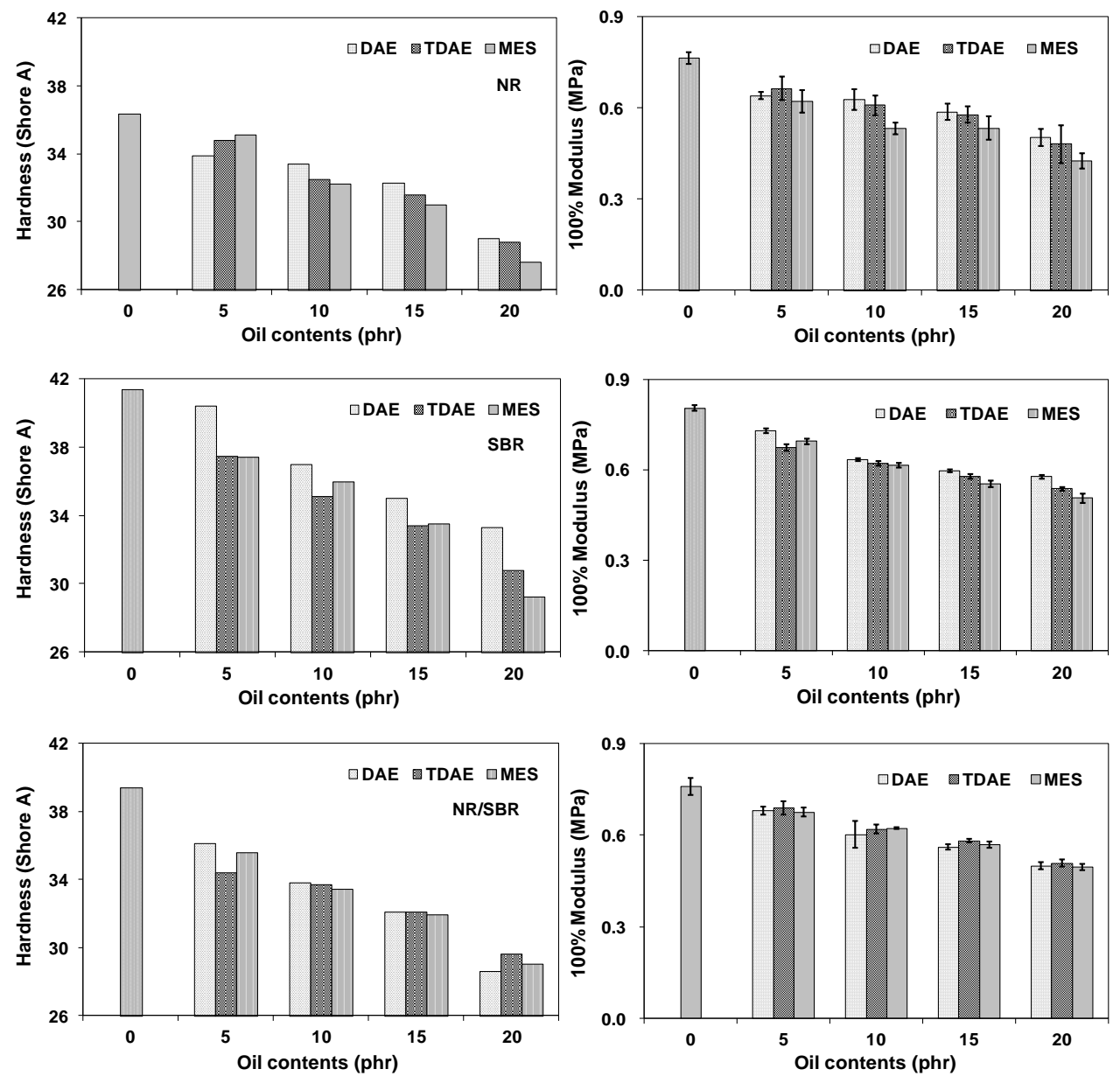

Figure 5.10 Hardness and 100\%-modulus of NR, SBR and NR/SBR vulcanizates with varying amounts of DAE, TDAE and MES-oils.

The lower apparent extent of crosslinking as implied by the lower cure rate index: Figure 5.6, when MES oil is used in comparison with the TDAE and DAE oils in NR compounds, has an effect on tensile strength, as shown in Figure 5.11. The NR vulcanizates with DAE and TDAE -oil have similar tensile strengths which are higher than those for MES. A lower tensile strength is not unequivocally related to a lower crosslink density, because over-crosslinking may also cause a decrease. However, as a closer look at the $100 \%$ modulus data in Figure 5.10 also indicates consistently lower values for MES than for DAE and TDAE, most so for NR, it seems acceptable to relate the lower tensile strength for the MES-NR combinations indeed to a lower degree of crosslinking. However, the oil-types have no strong influence on the tensile strengths of the unfilled NR/SBR blend and SBR 
vulcanizates. Comparing among the rubber types, NR shows a distinctly higher tensile strength than the blends and SBR, respectively, due to its strain-crystallization behavior. The un-reinforced SBR simply has no strength and badly needs reinforcement for practical applications.

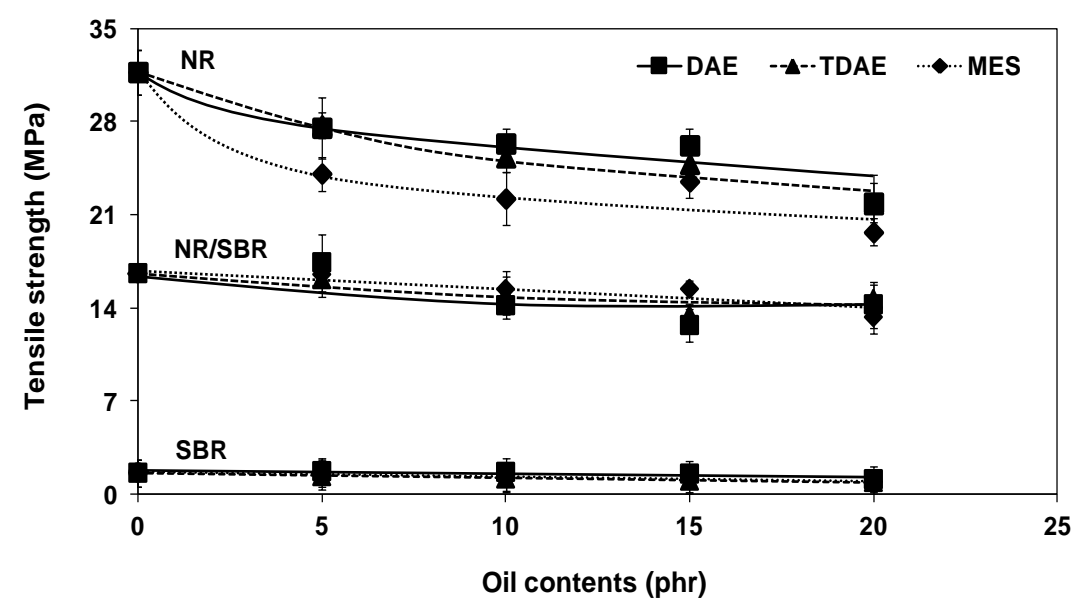

Figure 5.11 Tensile strength of NR, SBR and NR/SBR-vulcanizates with varying amounts of DAE, TDAE and MES-oils.

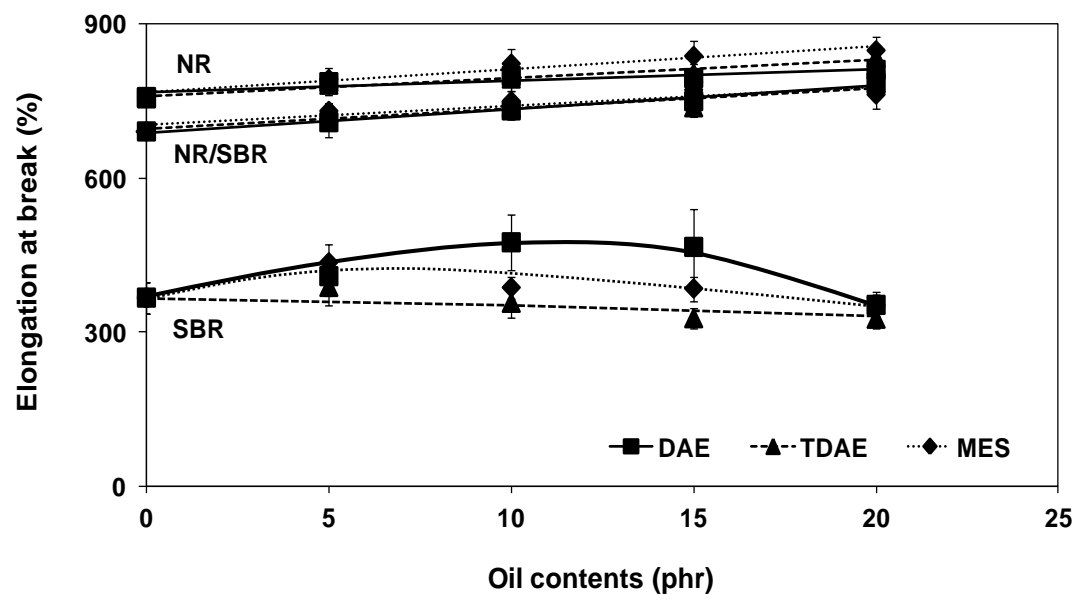

Figure 5.12 Elongation at break of NR, SBR and NR/SBR-vulcanizates with varying amounts of DAE, TDAE and MES-oils.

Increasing oil-contents of every oil-type in NR and NR/SBR blend vulcanizates increase their elongations at break since the materials become softer and therefore easier to 
be deformed. The SBR-vulcanizates with DAE-oil also show an increase of elongation at break, but the TDAE and MES-oils give similar elongations at break as that of the non-oil extended SBR.

\subsection{CONCLUSIONS}

Petroleum-based TDAE and MES-oils as alternatives for labeled DAE-oils possess different characteristics and so differ their influences on the properties of NR and SBRrubber compounds. The investigation with unfilled NR, SBR and the NR/SBR blend at 50/50 weight ratio using DAE, TDAE and MES as process oils reveals that the oil-types have only minor effects on Mooney viscosity and cure rate of all the compound types, except for the NR- compounds in which DAE and TDAE-oils give a higher cure rate index compared to MES. Different glass transition temperatures of the process oils affect the $T_{g}$ of the rubber compounds. The incorporation of DAE which has a higher $\mathrm{T}_{g}$ than the oil-free rubbers increases the $T_{g}$ of the rubber compounds, while the use of MES-oil with the lowest $T_{g}$ has no effect on $T_{g}$ of NR but decreases the $T_{g}$ of SBR. The SBR with MES-oil shows lower loss tangent values at both 0 and $60^{\circ} \mathrm{C}$, while the use of MES-oil in NR results in higher loss tangent at $60^{\circ} \mathrm{C}$, relative to that of DAE and TDAE. The replacement of DAE with TDAE and MES-oils in SBR and in the NR/SBR blend shows only small changes in their mechanical properties, but the use of MES-oil in NR results in lower hardness, 100\%-modulus and tensile strength when compared to the ones extended with TDAE or DAE. When considering the overall changes in properties, NR shows to be most sensitive to the change of oil type.

\subsection{REFERENCES}

1 W.A. Schneider, F. Huybrechts and K.H. Nordsiek, Kautsch. Gummi Kunstst., 44, 528 (1991).

2 K.H. Nordsiek, Kautsch. Gummi Kunstst., 39, 599 (1986).

3 V. Null, Kautsch. Gummi Kunstst., 52, 799 (1999).

4 I. Bowman, M. da Via, M. E. Pattnelli, and P. Tortoreto, Kautsch. Gummi Kunstst., 57, 31 (2004).

5 M. Joona, Rubber World, 235, 15 (2007).

6 A. Neau, K. Alavi, and M. Rangstedt, Rubber Fibers Plastics International, 4, 126 (2009).

7 A. Kuta, Z. Hrdlicka, J. Voldanova, J. Brejcha, J. Pokorny, and J. Plitz, Kautsch. Gummi Kunstst., 63, 120 (2010).

8 S. Dasgupta, S. L. Agrawal, S. Bandyopadhyay, S. Chakraborty, R. Mukhopadhyay, R. K. Malkani, and S. C. Ameta, Polym. Test., 26, 489 (2007). 
9 S. Dasgupta, S. L. Agrawal, S. Bandyopadhyay, S. Chakraborty, R. Mukhopadhyay, R. K. Malkani, and S. C. Ameta, Polym. Test., 27, 277 (2008).

10 S. Dasgupta, S. L. Agrawal, S. Bandyopadhyay, S. Chakraborty, R. Mukhopadhyay, R. K. Malkani, and S. C. Ameta, Polym. Test., 28, 251 (2009).

11 K.Sahakaro and A. Beraheng, Rubber Chem. Technol., 84, 200 (2011).

12 J.L. White and N. Tokita, J. Appl. Polym. Sci., 9(5), 1929 (1965).

13 N. Nakajima and E.A. Collins, Rubber Chem. Technol., 47, 333 (1974).

14 J.S. Dick, Compound Processing Characteristics and Testing, Chapter 2, in "Rubber Technology: Compounding and Testing for Performance", Carl Hanser Verlag, Munich, pp.31-32 (2001).

15 J. Malac, The Open Macromolecules Journal, 3, 41 (2009).

16 P.R. Couchmann, Macromolecules, 11, 1156 (1978).

17 J.R. Fried, "Polymer Science and Technology", Pearson Education Inc., New Jersey, (2003). 


\section{EFFECT OF OIL TYPES AND CONTENTS ON THE PROPERTIES OF CARBON BLACK-FILLED NR COMPOUNDS}

This chapter reports the investigations on the influence of DAE-, TDAE- and MESoils at different loadings on the properties of practical HAF-black filled NR compounds. Various properties of uncured compounds and rubber vulcanizates were examined. The compounds with different oil types show similar mixing torques at the same oil contents, but the ones with DAE oil have lower Mooney viscosity with higher complex viscosity when compared to the mixes with TDAE- and MES-oils. The filled compounds containing different oil types show similar cure characteristics, while the DAE-plasticized compounds show the highest Payne effect and lowest bound rubber content compared with the mixes with TDAEand MES-oils. The filler dispersion is characterized by SEM microscopy and the results reveal that carbon black is finely dispersed in all of the compounds. The use of DAE, TDAE and MES gives vulcanizates with similar mechanical properties (i.e., hardness, tensile and tear strength, and elongation at break), but different in the properties which are related to changes of the glass transition temperature and viscoelastic behavior (i.e. abrasion resistance, fatigue life, resilience, heat build-up and loss tangent). The vulcanizates with the highest $T_{g} D A E$ oil show the lowest abrasion resistance, fatigue life, rebound resilience and highest heat build-up. On the contrary, the use of MES with the lowest $\mathrm{T}_{g}$ gives the best elastic response. The incorporation of oil increases the loss tangent at both $0^{\circ} \mathrm{C}$ and $60^{\circ} \mathrm{C}$ of the vulcanizates, and the loss tangent values at $0^{\circ} \mathrm{C}$ of the vulcanizates are not influenced by the oil types. A difference is observed for the loss tangent at $60^{\circ} \mathrm{C}$, where the rubber with MES oil is lower than those with TDAE and DAE, respectively. The results clearly show that the replacement of DAE- with TDAE- and MES-oils has little effect on the mechanical properties, but does influence the dynamic mechanical properties which are related to the different $T_{g}$ 's of the oils. 


\subsection{INTRODUCTION}

The previous chapters described the influence of oil types and contents on the properties of unfilled compounds, in order to understand the changes of the material characteristics in relation to the process oils only without any interference from fillers. However, the rubber compounds are practically reinforced by reinforcing fillers to achieve the desired properties. Carbon black is the most commonly used reinforcing filler for rubber products including tires, while silica is increasingly used for tread compounds to produce low rolling resistance tires. The incorporation of carbon black into rubber compounds improves various properties such as modulus, tensile and tear strength, fatigue life and abrasion resistance. To achieve the desired performance, carbon black must be sufficiently dispersed in the rubber, as poor dispersion leads to detrimental effects, e.g. reduced product life, poor processing characteristics and poor performance ${ }^{1}$. The methodology for determining the dispersion of carbon black and the factors which affect the kinetics of dispersion in NR compounds were reported by Coran et al. ${ }^{1}$. The incorporation of carbon black into rubber increases both the dynamic storage modulus and the phase angle, that is why these dynamic properties are dependent on strain amplitude ${ }^{2}$. The filled-rubber compounds are highly complex systems in which various solid and liquid ingredients are dispersed in a rubber matrix ${ }^{3}$. In such a system, the reinforcing filler develops strong interactions that lead to the development of a structural material and the associated specific flow properties ${ }^{3}$. Filler-rubber interactions give rise to additional crosslinks in the network structure, and the immobilized elastomeric layers on the filler surface have an influence on the dynamic response of the material ${ }^{4}$.

The use of process oil allows the addition of filler at higher loading while maintaining the same hardness. The incorporation of oil reduces the compound viscosity, improves processing characteristics and helps with filler dispersion. It also helps to reduce the price of the compounds and resulting products. Fillers in combination with process oil are essential ingredients for rubber compounds based on both natural rubber and synthetic rubbers. Natural rubber (NR) is a unique material with special characters derived from its strain-induced crystallization ${ }^{5,6}$. For the tire industry, NR is needed for production of truck and aviation tires. It is also employed as a blend component for different parts of passenger tires, e.g. tread and sidewall. NR provides very good tensile and tear strength, flexing and fatigue resistance, and elastic properties ${ }^{7}$. Some benefits resulting from the use of NR for tire applications are such as reduced rolling resistance, low temperature flexibility, enhanced adhesion between components, good tear strength, etc. ${ }^{8}$. Even though NR already has excellent strength and elastic properties, fillers are practically added into NR compounds to enhance properties, such as stiffness, abrasion and wet skid resistance for tire performance. 
Carbon black was conventionally used in combination with highly aromatic oil or Distillate Aromatic Extract (DAE) for tire compounds due to its good compatibility. However, as a result of the toxicity of PAHs in DAE oil, the replacement of DAE with safe process oils has taken place. This Chapter reports on the influence of oil types, comparing DAE, Treated Distillate Aromatic Extract (TDAE) and Mild Extracted Solvate (MES), at varying contents on the properties of High Abrasion Furnace (HAF) or N330 carbon black filled NR compounds.

\subsection{EXPERIMENTAL}

\subsubsection{Materials}

Natural rubber (Ribbed smoked sheet 3, RSS3) used for the filled compound preparation was locally produced in Vietnam. Three types of oils, i.e. DAE (Tudalen 65), TDAE (Vivatec 500) and MES (Vivatec 200), were supplied by Hansen\&Rosenthal KG (Hamburg, Germany). Carbon black N330 or HAF $\left(V_{U L C A N}{ }^{\circledR}\right.$ ) was obtained from Cabot Corporation, United States. N-cyclohexyl-2-benzothiazolesulfenamide (CBS) and diphenyl guanidine (DPG) were obtained from Flexsys B.V., Belgium. Sulfur was obtained from Sigma Aldrich, the Netherlands. The other compounding ingredients including stearic acid, zinc oxide, polymerized 2,2,4-trimethyl-1,2-dihydroquinoline (TMQ), N-(1,3-dimethylbutyl)$\mathrm{N}$ '-phenyl-p-phenylenediamine (6PPD) and microcrystalline wax, were commercial grades for industry. All elastomers and compounding ingredients were used as received.

\subsubsection{Methods}

\subsubsection{Preparation of rubber compounds}

The compound preparation was carried out by using a two step-mixing procedure. In the first step, a rubber masterbatch was prepared by using an internal mixer with a chamber volume of 5 liters and intermeshing rotor system (Werner \& Pfleiderer GK5E, Germany), a mixer temperature setting of $50^{\circ} \mathrm{C}$, a fill factor of 0.70 and a rotor speed of 40 rpm. The formulations are given in Table 6.1. The three different types of process oils, i.e. DAE, TDAE and MES were employed and the oil contents were varied between $0,5,10$ and 15 phr. 
Table 6.1 Formulations for the carbon black-filled NR compound study.

\begin{tabular}{lc}
\hline Ingredients & Amount (phr) \\
\hline NR (RSS 3) & 100.0 \\
Carbon black (HAF) & 60.0 \\
Oil & Varying types and loadings \\
Zinc oxide & 3.0 \\
Stearic acid & 1.0 \\
6PPD & 1.5 \\
TMQ & 2.0 \\
Microcrystalline wax & 0.5 \\
CBS & 1.2 \\
DPG & 0.3 \\
Sulfur & 1.5 \\
\hline
\end{tabular}

To minimize variation due to the mastication effect of NR and to homogenize the rubber after storage prior to being used, NR was pre-masticated for 3 mins on a two-roll mill with setting of the nip gap at $3 \mathrm{~mm}$, and kept at room temperature overnight. The mixing procedures in the internal mixer started with a re-mastication of the rubber for $1 \mathrm{~min}$, followed by the addition of stearic acid, zinc oxide, 6PPD, TMQ, microcrystalline wax and 2/3 carbon black, and mixed for 3 mins. Subsequently, 1/3 carbon black and process oil were added and mixed for another 4 mins. After that, the masterbatch was dumped and made into a sheet on the two-roll mill.

The second mixing step was to add the curatives, i.e. CBS, DPG and sulfur into the masterbatch by using a two-roll mill. The final compounds were sheeted to a thickness of approximately $3 \mathrm{~mm}$.

\subsubsection{Compound viscosities, cure characteristics and vulcanization}

Mooney viscosity and Mooney stress relaxation were determined using a Mooney viscometer (MV2000vs, Alpha Technologies, USA) at $100^{\circ} \mathrm{C}$ and large rotor according to ASTM D1646. The complex viscosity of the uncured compounds was also tested in the frequency sweep mode from 0.1 to $30 \mathrm{~Hz}$ by using a Rubber Process Analyzer (RPA2000, Alpha Technologies) at $100^{\circ} \mathrm{C}$ and a strain of $7 \%$. Cure characteristics were tested at $150^{\circ} \mathrm{C}$ for 30 mins. using the RPA2000 according to ASTM D5289, and the cure rate index equal to [100/(90\% optimum cure time - scorch time)], was calculated. The rubber compounds were cured to their $90 \%$ optimum cure times by compression molding at $150^{\circ} \mathrm{C}$. 
6.2.2.3 Characterization of filler dispersion, filler-filler and filler-rubber interactions

Filler dispersion was analyzed by Scanning Electron Microscopy (SEM) FEI Quanta 400. The rubber vulcanizates were cryogenically cracked after immersing in liquid nitrogen, and the newly cracked surface was coated with gold prior to analysis.

Filler-filler and filler-rubber interactions were characterized by strain sweep measurements and bound rubber content, respectively. For strain sweep measurements, the change of storage modulus $\left(G^{\prime}\right)$ as a function of deformation or strain of uncured compounds was measured using the RPA2000 at $100^{\circ} \mathrm{C}$ and a frequency of $0.5 \mathrm{~Hz}$. The strains were varied in the range of $0.56 \%-100 \%$. The so-called Payne effect was determined from the difference of $G^{\prime}$ at $0.56 \%$ and $100 \%$, i.e. $G^{\prime}(0.56 \%)-G^{\prime}(100 \%)$.

Bound rubber content (BRC) is a parameter that is widely used to indicate fillerrubber interactions. The experiments were performed by putting $0.2 \mathrm{~g}$ of uncured compound without curatives which were cut into small pieces in a metal cage, and then immersing in 20 $\mathrm{ml}$ of toluene for $144 \mathrm{hrs}$ at room temperature. Toluene was renewed every $24 \mathrm{hrs}$. The sample was then removed from the toluene, dried for $24 \mathrm{hrs}$ at $105^{\circ} \mathrm{C}$ and weighed.

The BRC was calculated according to equation $(6.1)^{9,10}$ :

$$
\operatorname{BRC}(\%)=\frac{W_{f g}-W_{f}}{W_{p}} \times 100
$$

Where $W_{f g}$ is the weight of filler with the bound rubber attached; $W_{f}$ is the weight of the filler in the specimen and $W_{p}$ is the weight of rubber in the specimen.

\subsubsection{Testing of the vulcanizate properties}

Tensile properties - The vulcanizates were tested for their tensile properties according to ISO 37 by using a Zwick Z1.0 tensile testing machine operated at a constant crosshead speed of $500 \mathrm{~mm} / \mathrm{min}$. The dumb-bell test pieces (type 2) were tested both before and after aging at $70^{\circ} \mathrm{C}$ for $168 \mathrm{hrs}$. For aged specimens, the percent changes of tensile strength and elongation at break was calculated following equation (6.2) according to ASTM D573-99:

$$
\text { Change }(\%)=\frac{(\mathrm{A}-\mathrm{O})}{\mathrm{O}} \times 100
$$

Where $O$ is the origin value and $A$ is the value after aging.

Hardness - Indentation hardness was measured using a Zwick hardness tester, Shore A type, according to ASTM D2240-02.

Tear resistance - Tear tests were carried out on angle test pieces (Die C) according to ASTM D624-00 with a Zwick Z1.0 tensile testing machine operated at a constant crosshead speed of $500 \mathrm{~mm} / \mathrm{min}$. 
Abrasion resistance - A DIN abrasion tester was employed to determine the volume loss of abraded rubber vulcanizates. The test was performed in accordance with DIN53516 and ISO 4649.

Fatigue to failure - Fatigue life of the specimens was tested using a Monsanto fatigue-to-failure tester as described in ASTM D4482-99. Dumbbell shape specimens were stretched at an extension ratio of 2.0 and subjected to a tensile strain cycle at $1.7 \mathrm{~Hz}$. The number of cycles required to cause failure was recorded.

Rebound resilience - A Dunlop tripsometer (Wallace Test Equipment, England) was used for measuring rebound resilience of NR vulcanizates according to BS 903: Part A8: 1990 . Specimens with $4 \mathrm{~mm}$ thickness and $44.6 \mathrm{~mm}$ diameter were tested at $60^{\circ} \mathrm{C}$, and resilience was calculated in percent according to equation (6.3):

$$
\% \text { Resilience }=\frac{1-\cos B}{1-\cos A} \times 100
$$

Where $A$ is the angle at which the plunger was released (45 degrees), and $B$ is the angle which the plunger bounced back to after hitting the specimen.

Heat build-up (HBU) - The test was performed by using a Goodrich Flexometer (Ferry Industry, USA) according to ISO 4666/3-1982(E). A cylindrical shaped sample having a height of $25 \mathrm{~mm}$ and a diameter of $17.5 \mathrm{~mm}$ was tested at $100^{\circ} \mathrm{C}$ for $25 \mathrm{~min}$ by applying a weight of $11 \mathrm{~kg}$, stroke $4.45 \mathrm{~mm}$ and frequency of $30 \mathrm{~Hz}$. The increase in temperature $(\Delta T)$ from the beginning of the test $\left(T_{0}\right)$ to 25 mins test time $\left(T_{25}\right)$ was recorded.

Dynamic mechanical properties - Thin sheets of rubber vulcanizates with dimensions of $10 \times 24 \times 1 \mathrm{~mm}^{3}$ were tested for their dynamic mechanical properties using a dynamic mechanical thermal analyzer (Rheometric Scientific DMTA V, USA) in the tension mode. The measurement was performed with a frequency of $10 \mathrm{~Hz}$, a heating rate of 5 ${ }^{\circ} \mathrm{C} /$ min over a temperature range of $-130{ }^{\circ} \mathrm{C}$ to $+100{ }^{\circ} \mathrm{C}$. In the range of $-130{ }^{\circ} \mathrm{C}$ to $-20^{\circ} \mathrm{C}$, the strain was set at $0.002 \%$, and in the temperature range of $-20^{\circ} \mathrm{C}$ to $+100{ }^{\circ} \mathrm{C}$, a strain of $0.02 \%$ was applied.

\subsection{RESULTS AND DISCUSSION}

\subsubsection{Mixing torque}

The mixing torques of the carbon black-filled NR masterbatches with respectively 5 and $10 \mathrm{phr}$ of the different oil types are shown in Figures 6.1, and with different loadings of TDAE and MES in Figure 6.2. In these figures, the mixing torque of the masterbatch without oil is not included due to some errors while capturing the torque data during mixing. As shown in Figure 6.1(a), the mixing curves can be divided into three zones. NR was masticated and mixing torques were decreased in zone I due to the break-down of the 
rubber molecules. Mixing torques increased in zone II after the addition of 2/3 of carbon black and other chemicals to the rubber, mainly due to the incorporation of solid particles into the rubber. The rubber chains come in contact with the carbon black surface and interactions between both phases take place. This causes the increase in mixing torque and formation of bound rubber that results in an immobilized rubber layer on the filler surface. During mixing, the rubber chains are forced into the interstices between agglomerates/aggregates, and the presence of process oil helps to improve chain mobility and wetting on the filler surface. As the mixing proceeds, the mixing torques progressively decrease due to dispersion of the carbon black accompanied by an increase of the compound temperature due to viscous heating. The addition of the remaining $1 / 3$ carbon black and oils further increases the mixing torque in zone III due to the incorporation of more solid particles. Herein, the mixing torque curves do not show a clear second peak which indicates a black incorporation time (BIT). This may be due to the fact that the carbon black was divided into two parts to be added into the mixer, in order to prevent excessive shear forces generated by high mixing torques at the first filler loading. Only a small increase of torques can be observed at the end of zone II. After the complete addition of carbon black and process oil, the masterbatch with $5 \mathrm{phr}$ of DAE oil shows a slightly higher mixing torque compared to the mixes containing TDAE and MES, but at higher loading of oil at $10 \mathrm{phr}$, there is no difference between the oil types. Increasing the oil contents decreases the mixing torque of the masterbatches as typically shown in zone III in Figure 6.2. As bound rubber is formed during the mixing of carbon black into the rubber, it has been reported by Cotten ${ }^{11}$ that at a given carbon black activity, the effective thickness of the immobilized polymer layer is independent of the oil loading, while oil loading has no effect other than that associated with lowering of the bound rubber content. 

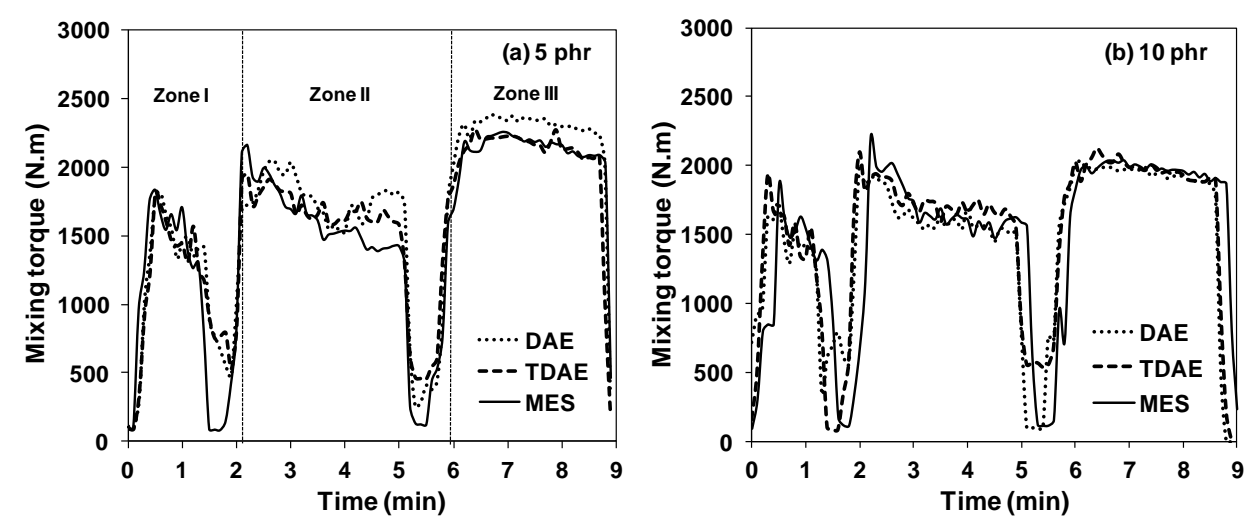

Figure 6.1 Mixing torques of HAF-filled NR masterbatches with (a) $5 \mathrm{phr}$ and (b) $10 \mathrm{phr}$ of various oil types.
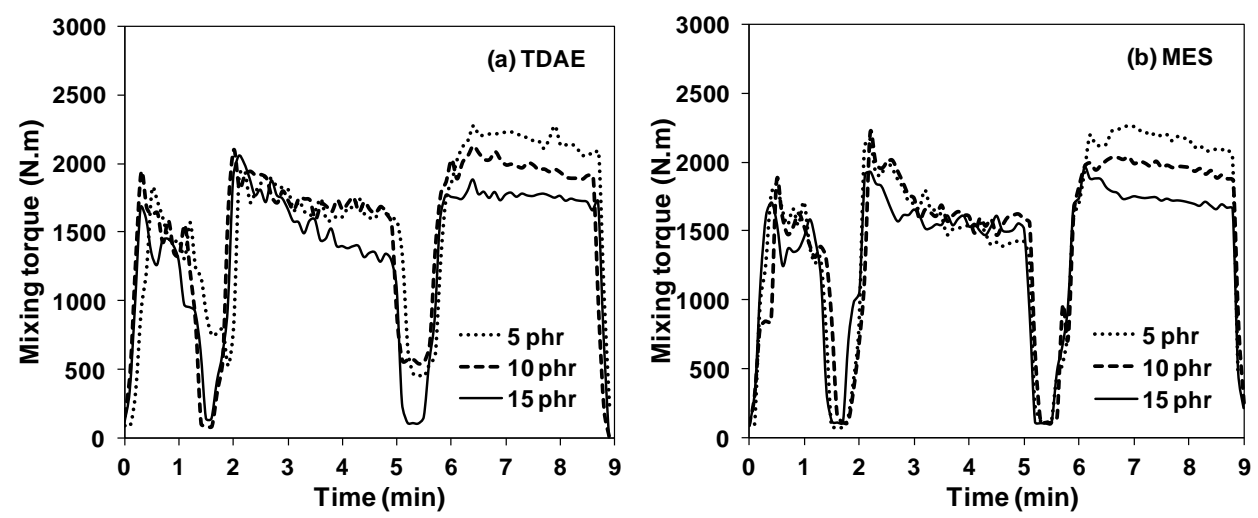

Figure 6.2 Mixing torques of HAF-filled NR masterbatches with varying contents of (a)

TDAE oil and (b) MES oil.

The final discharge temperatures or dump temperatures of the masterbatches are summarized in Table 6.2. The mixes with low content of TDAE and MES oils at 5 phr show similar dump temperatures when compared to the mix without oil, but the compound with 5 phr of DAE shows the highest dump temperature. The increase of oil loadings to 10 and 15 phr decreases the dump temperatures due to the plastization effect of oil in the mixer which causes lower shearing forces and heat generation. When comparing between the oil types, the mixes with DAE oil show the highest dump temperature, while there is no clear trend among TDAE and MES oils. 
Table 6.2 Dump temperatures of NR masterbatches.

\begin{tabular}{ccccc}
\hline \multirow{2}{*}{$\begin{array}{c}\text { Oil contents } \\
(\mathrm{phr})\end{array}$} & without oil & DAE & TDAE & MES \\
\cline { 2 - 5 } & 145 & - & - & - \\
\hline 0 & - & 155 & 145 & 145 \\
5 & - & 142 & 135 & 139 \\
10 & - & 132 & 130 & 128 \\
\hline
\end{tabular}

\subsubsection{Viscosities and cure characteristics of the compounds}

Oil content clearly has an effect on compound viscosity and among the oil types, the NR filled-compounds with DAE oil show the lowest Mooney viscosities, as shown in Figure 6.3. It is interesting to note, that the first $5 \mathrm{phr}$ of all oil types gives a rise in Mooney viscosity relative to the compound without oil added. In the filled compounds, the cause of different viscosities may be related to the level of filler dispersion, interactions between filler and rubber, and the mutual solubility between oils and rubber. A better rubber-oil compatibility and filler dispersion results in lower compound viscosities ${ }^{12}$. The dump temperatures of the NR masterbatches are higher than $100^{\circ} \mathrm{C}$, as shown in Table 6.2. As previously reported in Table 4.3 , the difference in solubility parameters $(\Delta \bar{\delta})$ of NR and DAE is smallest at $140^{\circ} \mathrm{C}$, while the $\Delta \delta$ value of $N R$ and MES is the largest. The better compatibility between DAE oil and rubber leads to a more homogeneous mixture and helps the filler dispersion. In this case, the use of DAE oil is expected to result in better filler dispersion than the use of the other oils, and so to decrease the Mooney viscosity of the compound. However, as observed in Figure 6.3 the Mooney viscosity of the compound without oil is lower than those of the compounds with $5 \mathrm{phr}$ of the oils. This can be attributed to the mastication effect of NR. Without oil, higher shear forces were generated during mixing and the molecular chains were more broken down, as NR is well-known for its sensitivity to mastication due to its reactive double bonds in the polymer backbone. As the molecular weight is strongly related to viscosity ${ }^{3}$ and shorter chains have better mobility, so the viscosity of this compound is lower when compared to the compound with small amounts of oil, at 5 phr. The use of $5 \mathrm{phr}$ of oil helps to lubricate the rubber chains and carbon black particles/aggregates, so the shear forces generated during mixing were lower than for the un-plasticized compound. Further increase of the oil contents to 10 and 15 phr decreases the Mooney viscosity of the compounds, mainly owing to the lubrication effect which is in accordance with the decrease of mixing torque. Furthermore, it has been reported that the increased loading of oil also reduces bound rubber $^{11}$ which also reduced the compound 
viscosity. The results of bound rubber contents as function of oil loadings in this work are later presented in Figure 6.11.

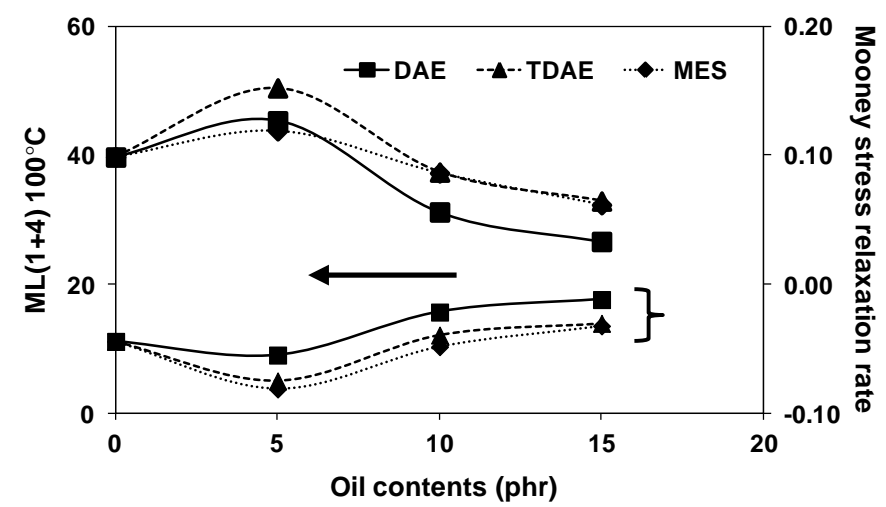

Figure 6.3 Mooney viscosities and Mooney stress relaxation rate of HAF-filled NR compounds with varying amounts of DAE-, TDAE- and MES-oils.

As mentioned previously in section 5.3.1, from the Mooney stress relaxation can be described by the equation $M=K t^{a}$, where $M$ is the torque in Mooney units, $t$ is the time after stopping the rotor, and $K$ is a constant equal to the torque in Mooney units $1 \mathrm{sec}$. after the rotor has stopped, $a$ is an exponent that measures the rate of stress relaxation. A higher decay rate means a higher ratio of the viscous over elastic properties, and a lower uncured rubber elasticity ${ }^{13,14}$. As displayed in Figure 6.3, increasing oil contents result in a flatter slope, i.e. a lower rate of decay, of the NR compounds except for the ones with 5 phr of oils. This indicates that the oils increase the relative uncured rubber elastic response which could be attributed to chain flexibility in the presence of oil in between the rubber molecules. The DAE oil gives the smallest decay rate (i.e. the number is less negative) at the same oil contents due to its good compatibility with NR, which makes it easier to facilitate the rubber chain movement. The use of DAE oil therefore provides a larger elastic/viscous ratio of the uncured compounds.

The complex viscosities $\left(\eta^{\star}\right)$ of the compounds were tested under varied frequency, and a change of $\eta^{*}$ as a function of frequency is typically shown in Figure 6.4(a) for the compounds containing 15 phr of oils. Under shear deformation, the increase of frequency or shear rate decreases the complex viscosities, showing shear-thinning behavior of the rubber compounds. All the compounds show only small differences in their complex viscosities. The complex viscosity values at frequency of $0.5 \mathrm{~Hz}$ of the compounds with different oil loadings are plotted in Figure 6.4(b). Herein, the compounds with DAE oil show 
the highest complex viscosities, while the TDAE and MES plasticized compounds show almost the same values. The filled-NR compound without oil shows a lower complex viscosity when compared to the one with oil $5 \mathrm{phr}$, but further increase of oil loading thereafter reduces the complex viscosities. The shape of the complex viscosity curves: an increase at low oil loadings vs. a decrease at higher oil loadings, looks similar to the Mooney viscosity curves in Figure 6.3. However, it is quite conspicuous that in the complex viscosity case DAE gives the highest viscosities, vs. the lowest in the Mooney case.
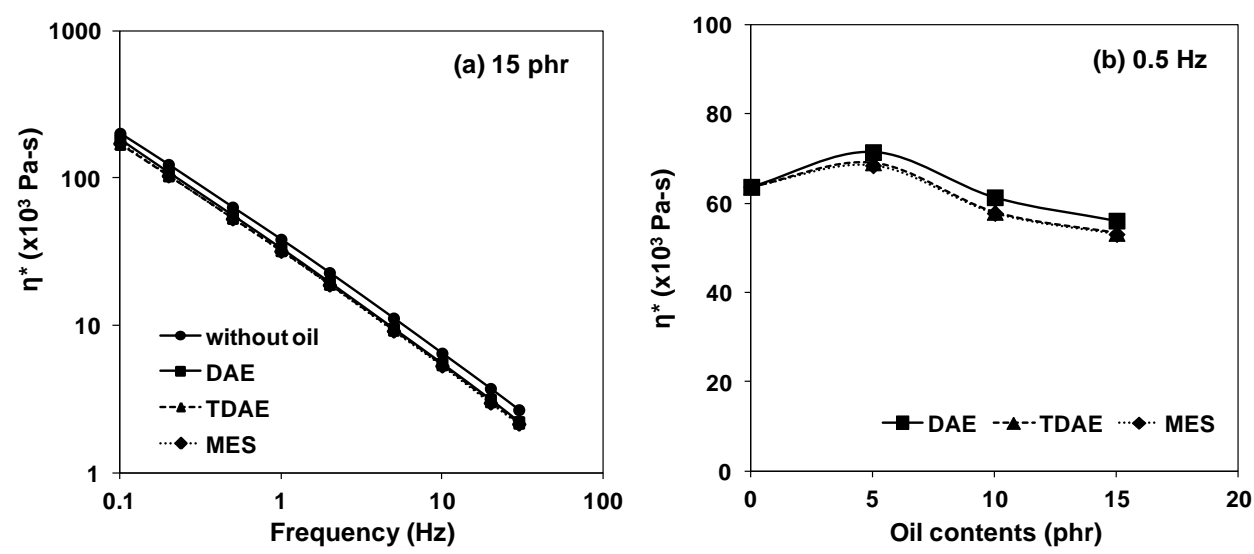

Figure 6.4 Complex viscosities of HAF-filled NR compounds with different oil types: (a) at varying frequencies with $15 \mathrm{phr}$ of oil; (b) with different oil contents at $0.5 \mathrm{~Hz}$, both at $7 \%$ strain and $100^{\circ} \mathrm{C}$.
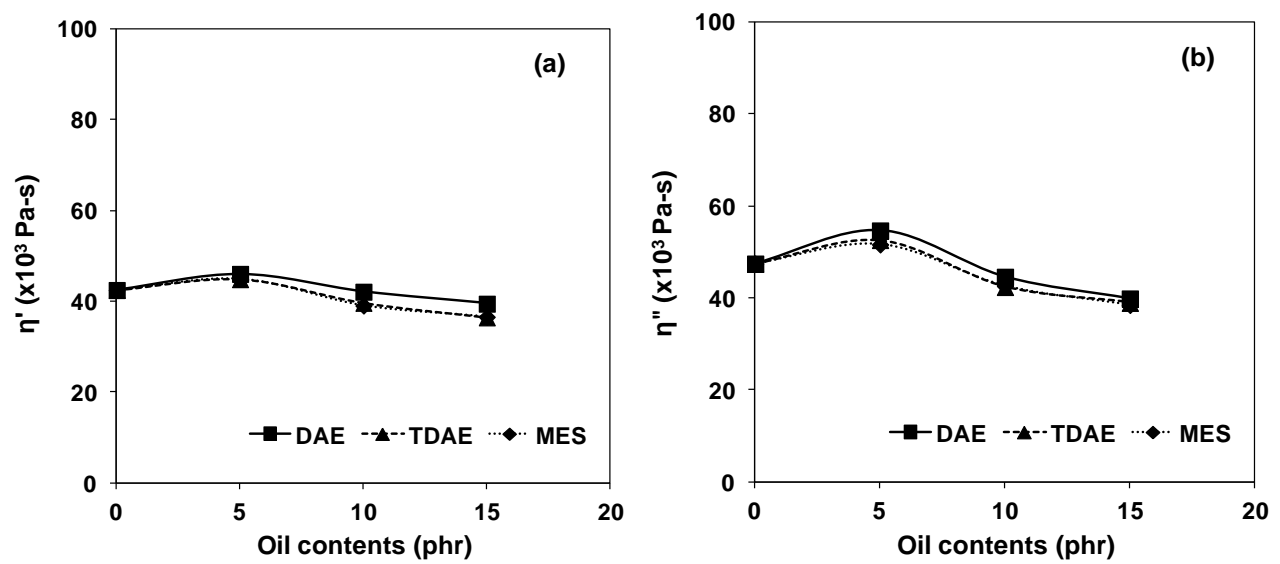

Figure 6.5 Real (a) and imaginary (b) parts of complex viscosities at $0.5 \mathrm{~Hz}$ of HAF-filled NR compounds with different oil types and contents. 
As the complex viscosity of the materials consists of the real $\left(\eta^{\prime}\right)$ and imaginary $\left(\eta^{\prime \prime}\right)$ parts, Figure 6.5 displays the contribution from each part to the complex viscosity of the HAF-filled NR compounds. The real or dynamic viscosity is related to the steady state viscosity that measures the rate of energy dissipation, while the imaginary part measures the elasticity or stored energy ${ }^{15-16}$, i.e. $\eta^{\prime}$ represents the viscous behavior and $\eta^{\prime \prime}$ corresponds to the elastic behavior. The results in Figure 6.5 clearly show that the addition of oils into the rubber compounds contributes more to the elastic component due to the better chain mobility and flexibility. The relationship of $\eta "$ at different oil contents: Figure 6.5 (b) resembles the plot of $\eta *$ in Figure 6.4 (b). For all cases, the filled NR compounds with DAE-oil show slightly higher viscosities over the compounds with TDAE and MES, indicating that apparently the higher elasticity of DAE-plasticized compounds prevails over the viscous dissipation.
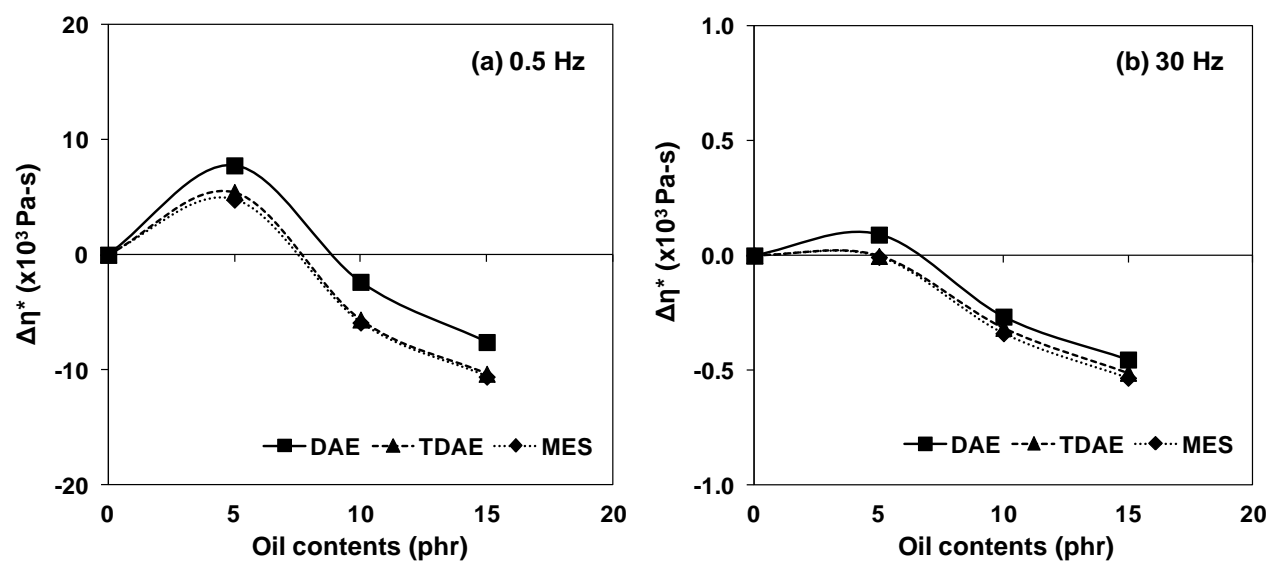

Figure 6.6 Differential complex viscosities of HAF-filled NR compounds with different oil types at (a) $0.5 \mathrm{~Hz}$ and (b) $30 \mathrm{~Hz}$, at $7 \%$ strain and $100^{\circ} \mathrm{C}$ as functions of oil contents.

By calculating the difference in complex viscosities $\left(\Delta \eta^{*}\right)$ of the plasticized compounds vs. the value of the unplasticized one, the results are shown in Figure 6.6 at two different frequencies, i.e. at $0.5 \mathrm{~Hz}$ and $30 \mathrm{~Hz}$. The difference of complex viscosities becomes smaller at higher frequency. The results again show that the filled-NR compounds with 5 phr of every oil type have higher viscosities than the one without oil, which can be attributed again to the increased mastication effect of NR in the absence of the lubricating effect of the oil, as previously discussed for the result of the Mooney viscosity (Figure 6.3). The addition of 10 and 15 phr of oils then results in lower complex viscosities in relation to 
the compound without oil as the result of increased chain mobility, increased free volume and decreased molecular forces between the molecules.

For rubber processing, the Mooney viscosity test is still the most commonly employed method to determine the flow behavior of the compounds. However, rubber compounds with the same viscosity can often be found to process differently ${ }^{17}$. Mooney viscosity is tested under large deformation as the rotor embedded in the rubber is rotated at a constant speed of $2 \mathrm{rpm}$, imparting a shear rate of only $\pm 1 \mathrm{~s}^{-1}{ }^{18}$. So, the Mooney viscosity is measured at a very low shear rate. Under large deformation, contact points and temporary network structures in the system decrease causing softening of the compound. The DAE which can better dissolve in NR than the other types of oils, therefore results in lower Mooney viscosity. On the other hand, testing at low strain at varying frequencies for the complex viscosity, the materials are more prominently influenced by the elastic response from the filler network and interactions between the various components. This might explain why DAE plasticized NR compounds with good oil-rubber compatibility therefore exhibit the highest complex viscosity.

The minimum torque $\left(\mathrm{M}_{\mathrm{L}}\right)$ from the cure curve also indicates the compound viscosity. As shown in Figure 6.7, the change of minimum torque with oil content is in agreement with the Mooney viscosity (Figure 6.3) and complex viscosity (Figure 6.4b), but the difference between the oil types again shows a different trend. Herein, the compounds with TDAE oil tend to show a slightly higher minimum torque than the compounds with DAEand MES-oils.

When considering the torque difference $\left(M_{H}-M_{L}\right)$ which is generally related to the level of cure or crosslink density, increasing oil contents to 10 and 15 phr results in a decrease of the torque difference (Figure 6.7). Higher loading of oil has a dilution and plastization effects on the rubber and its components, which affects the reduced crosslink density of the NR vulcanizates ${ }^{12}$. The plastization effect also has an influence on stiffness of the vulcanizates which results in a lower maximum torque $\left(M_{H}\right)$. The typical cure curves of the compounds containing 5 and 15 phr of oils are displayed in Figure 6.8. The use of only a small amount of oil at $5 \mathrm{phr}$ has no influence on the cure behavior, while increased loading of oil to $15 \mathrm{phr}$ results in a slight increase of scorch and cure times of the compounds, and the maximum torque is clearly decreased, compared to the compound without oil. This is due to the dilution effect of the oils. The change of oil types in NR-filled compounds has only a minor effect on cure rate indices as shown in Figure 6.9. DAE oil gives a slightly higher cure rate index when compared to TDAE and MES at the same oil content, and increases with increasing oil contents. This means that DAE oil can accelerate the curing reaction slightly because of the presence of nitrogen- and sulfur-heterocyclic species in this oil, as 
previously seen for its effect in unfilled compounds in Chapter 5 (Figure 5.6). The cure rate indices of the compounds with TDAE oil are further marginally higher than those for the compound with MES oil, as the MES is the most inert type due to its highest paraffinic content.

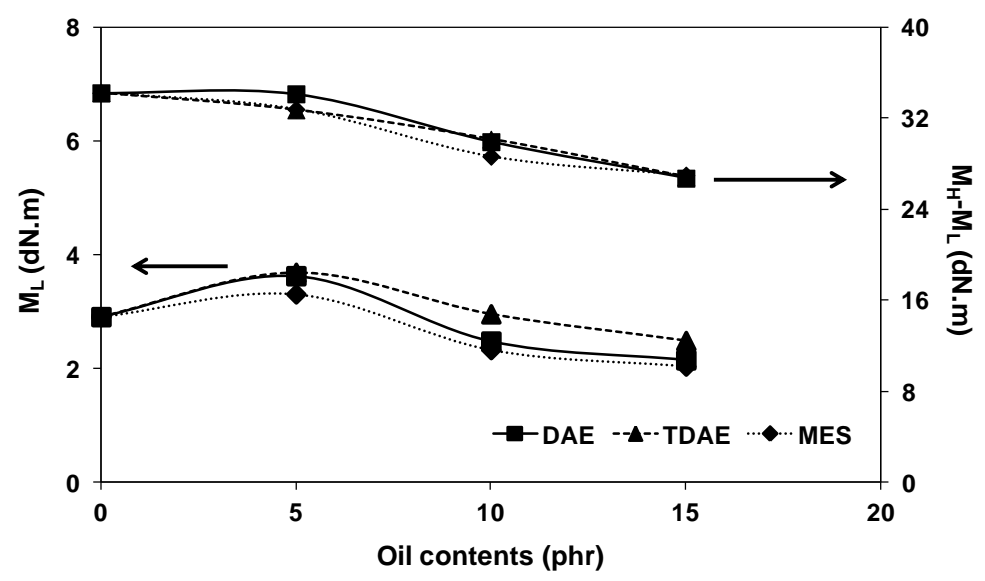

Figure 6.7 Minimum torque and torque difference of HAF-filled NR compounds with varying amounts of DAE-, TDAE- and MES-oils.
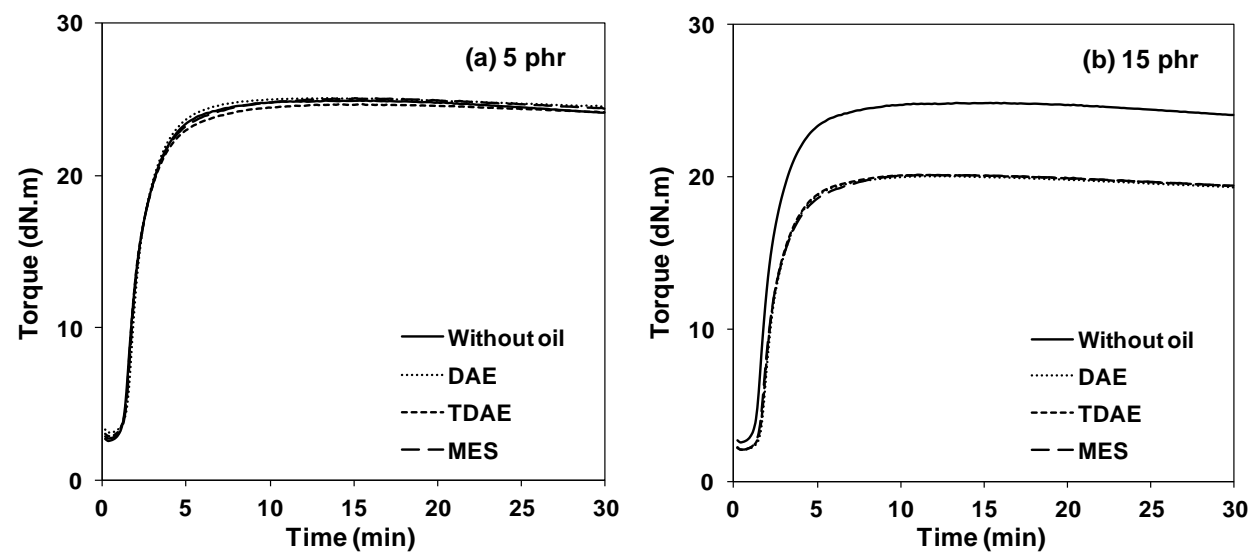

Figure 6.8 Typical cure curves of HAF-filled NR compounds with DAE-, TDAE- and MESoils at (a) $5 \mathrm{phr}$, and (b) $15 \mathrm{phr}$. 


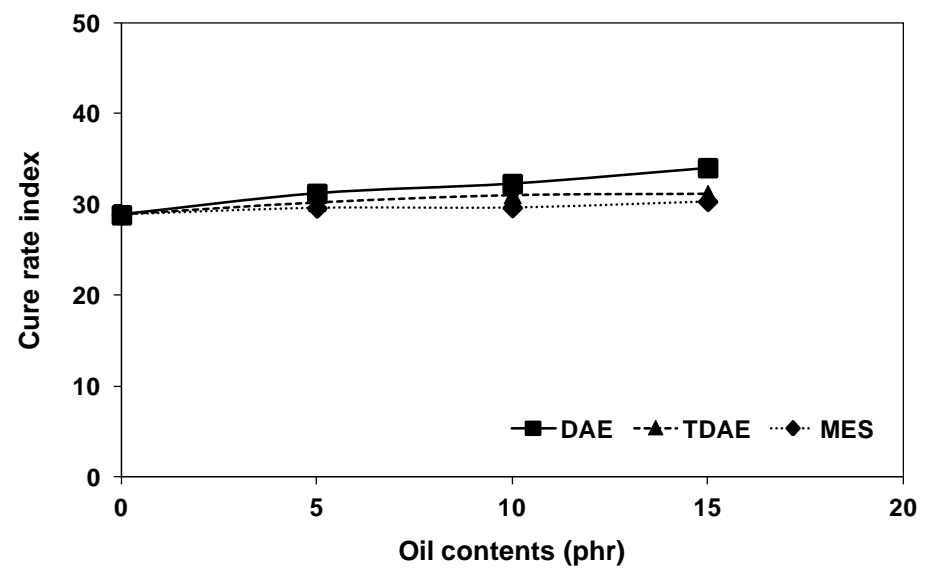

Figure 6.9 Cure rate indices of HAF-filled NR compounds with varying amounts of DAE-,

TDAE- and MES-oils.

\subsubsection{Filler - filler interaction, bound rubber and filler dispersion}

The addition of fillers to rubber compounds has an influence on both static and dynamic properties. Besides the strain-independent contributions of the hydrodynamic effect, the filler-to-rubber interaction and the crosslink network of the rubber matrix, the dynamic modulus $\left(G^{*}\right)$ shows also a strain dependency which is attributed to filler-filler interactions. This stress softening that is known as the Payne effect, plays an important role in the understanding of the reinforcement mechanisms of filled-rubber compounds and can be attributed to the breakdown of the filler-filler network ${ }^{19,20}$. The decrease of storage modulus $\left(\Delta G^{\prime}\right)$ with increasing strain of the filled masterbatches without curatives with 5 and $15 \mathrm{phr}$ are displayed in Figure 6.10. The incorporation of $15 \mathrm{phr}$ of oil clearly results in lower $\mathrm{G}^{\prime}$ in the low strain region due to the softening effect of the process oils. 

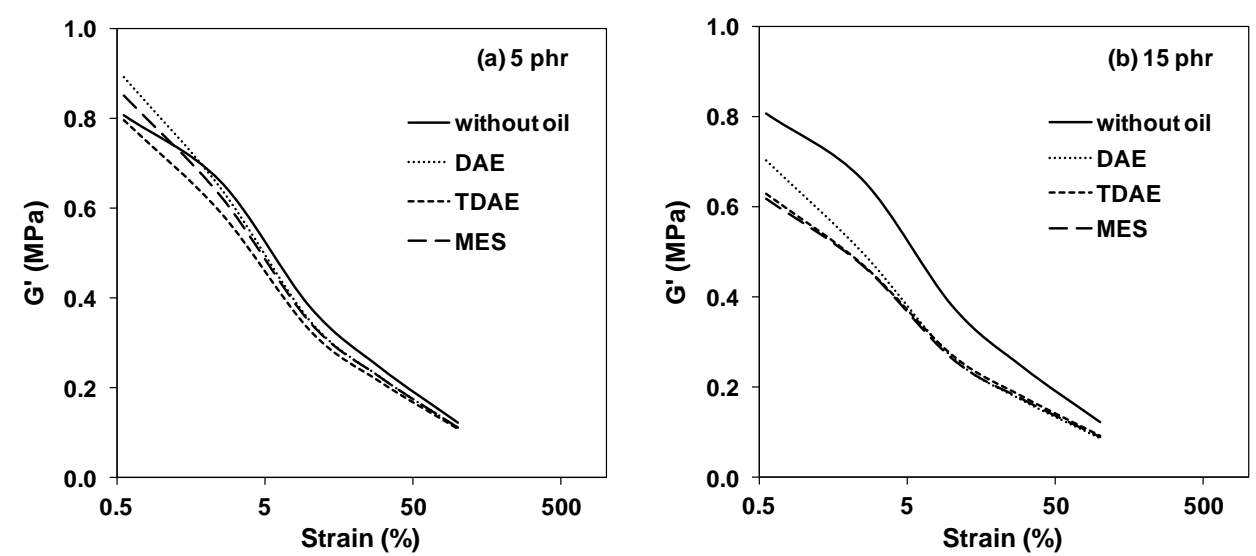

Figure 6.10 Storage moduli as a function of strain for HAF-filled NR masterbatches with (a) $5 \mathrm{phr}$, and (b) 15 phr of various oil types.

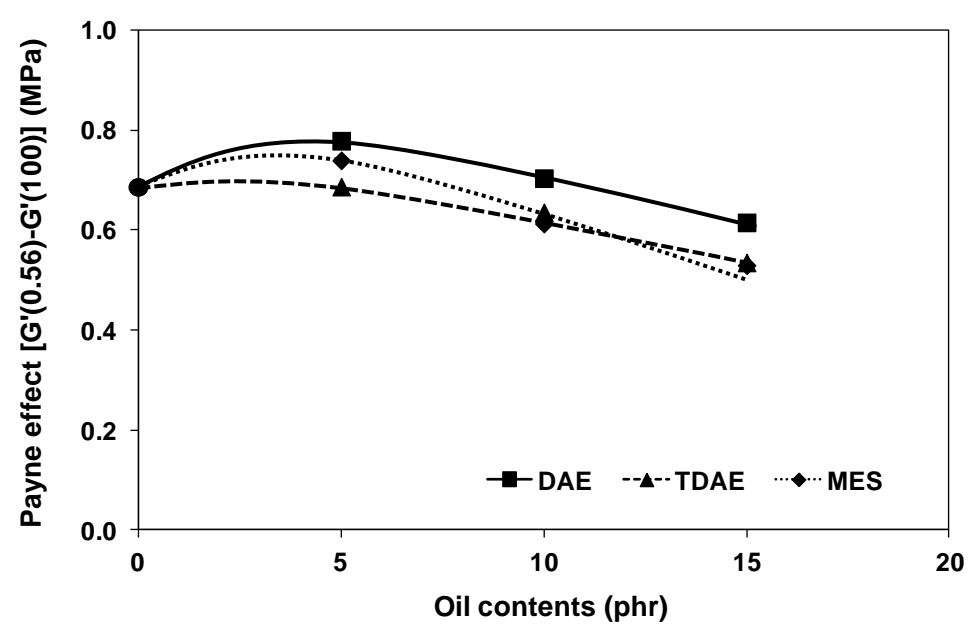

Figure 6.11 Payne effects of HAF-filled NR masterbatches with various oil types and amounts.

The degree of the filler-filler interaction can be derived from the difference in storage moduli $\left(\Delta G^{\prime}\right)$ at low and high strains, i.e. $G^{\prime}(0.56 \%)-G^{\prime}(100 \%)$. As shown in Figure 6.11, DAE oil gives a higher Payne effect than the other two oils at every oil content, while TDAE and MES plasticized masterbatches show similar $\Delta G^{\prime}$, except at 5 phr of oil. A higher Payne effect generally indicates that the masterbatch has a higher filler-filler interaction. The Payne effects of these masterbatches are decreased with increasing oil content, which correlates with decreasing filler-filler interactions due to the presence of oils in between the rubber molecules and carbon black particles/aggregates. The masterbatches with oil $5 \mathrm{phr}$ 
again show a peculiar higher Payne effect when compared to the masterbatch without oil. As discussed above for the viscosities, the addition of $5 \mathrm{phr}$ of oil lubricates the filled system and lowers the shear forces generated during mixing, when compared to the masterbatch without oil. So, the break-up of filler agglomerates into aggregates may happen to a lesser extent, resulting in a slightly poorer dispersion and higher filler-filler interactions. However, when higher amount of oils penetrate into the interstices between rubber and filler, the interactions between the filler particles become weaker.

Another important parameter that influences the reinforcement efficiency of fillers in rubber compounds is filler-rubber interaction, which is commonly analyzed by measuring the bound rubber content. Before vulcanization, bound rubber is the rubber portion bound to filler particles/aggregates, which cannot be extracted by a good solvent and is left in a form of highly swollen rubber gel on the filler ${ }^{3,9,21}$. Figure 6.12 shows the bound rubber contents of HAF-filled NR compounds with various oil types and contents. A filler-rubber interface model was proposed by Fukahori ${ }^{22,23}$ to explain bound rubber in carbon black-filled rubbers. In this model, the bound rubber has a double layer structure with different molecular mobility: an inner glassy hard layer and an outer gelly layer. In the inner layer, molecules are strongly adhered to the carbon black surface and molecular mobility is restricted, while in the outer layer the molecular motion is less but still considerably constrained. The gelly or sticky layer is reported to play an important role at large extension through structural stress hardening ${ }^{23}$.

The bound rubber contents are slightly decreased with increasing oil contents, while the oil types do not show a significant effect on bound rubber content, except for the compounds with DAE oil that show slightly lower values than those of the compounds with MES- and TDAE-oils at 10 and 15 phr. The better compatibility between NR and DAE oil may interfere with the filler-rubber interactions as the oils insert in between the rubber and filler interstices and so result in a reduction of filler-rubber interactions in the compounds. This is in accordance with the Payne effect results in Figure 6.11 where the compounds with DAE oil show the highest values. 


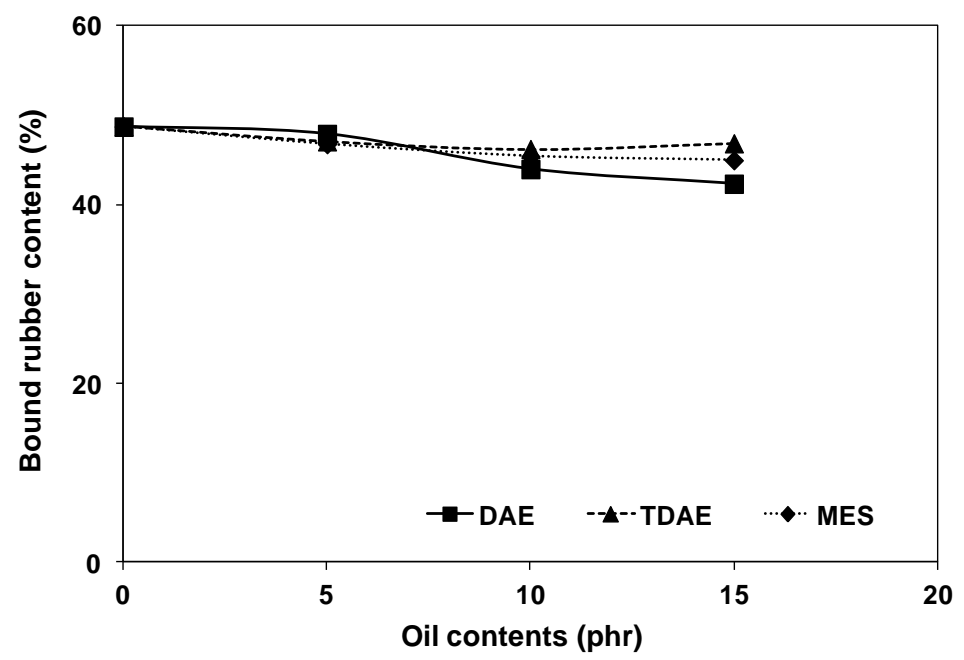

Figure 6.12 Bound rubber content of HAF-filled NR masterbatches with various oil types and amounts.

The influence of oil types and amounts on the carbon black dispersion in NR compounds was also analyzed by means of scanning electron microscopy (SEM) by using the cryogenically fractured surface of the filled NR-vulcanizates. The SEM micrographs are displayed in Figures 6.13 and 6.14. One of the roles of process oils for the filled-rubber compounds is to improve processing. The softening effect of oils leads to an easier filler incorporation and dispersion. Even though all the three oil types show a good solubility in NR as the differences in solubility parameters $(\Delta \bar{\delta})$ are small (Table 4.3 ), their compatibility with the rubber is not the same. At the temperature during mixing, NR and MES oil are less compatible while NR and DAE are best compatible, as interpreted by the $\Delta \delta$ values shown in Table 4.3. The SEM micrographs in Figure 6.13 show that all of the compounds show overall similar micrographs, and carbon black is uniformly dispersed within the rubber matrix. It is well-known that carbon black can easily be dispersed in NR, provided that the mixing conditions are suitable. The high viscosity of NR in the early stage of the mixing cycle generates high shear forces to break up the filler agglomerates, and to disperse the aggregates into the rubber. The similar dispersion level of carbon black in the rubber between the different oil types reflects in a similar level of mechanical properties, which will be further discussed in section 6.3.4. 

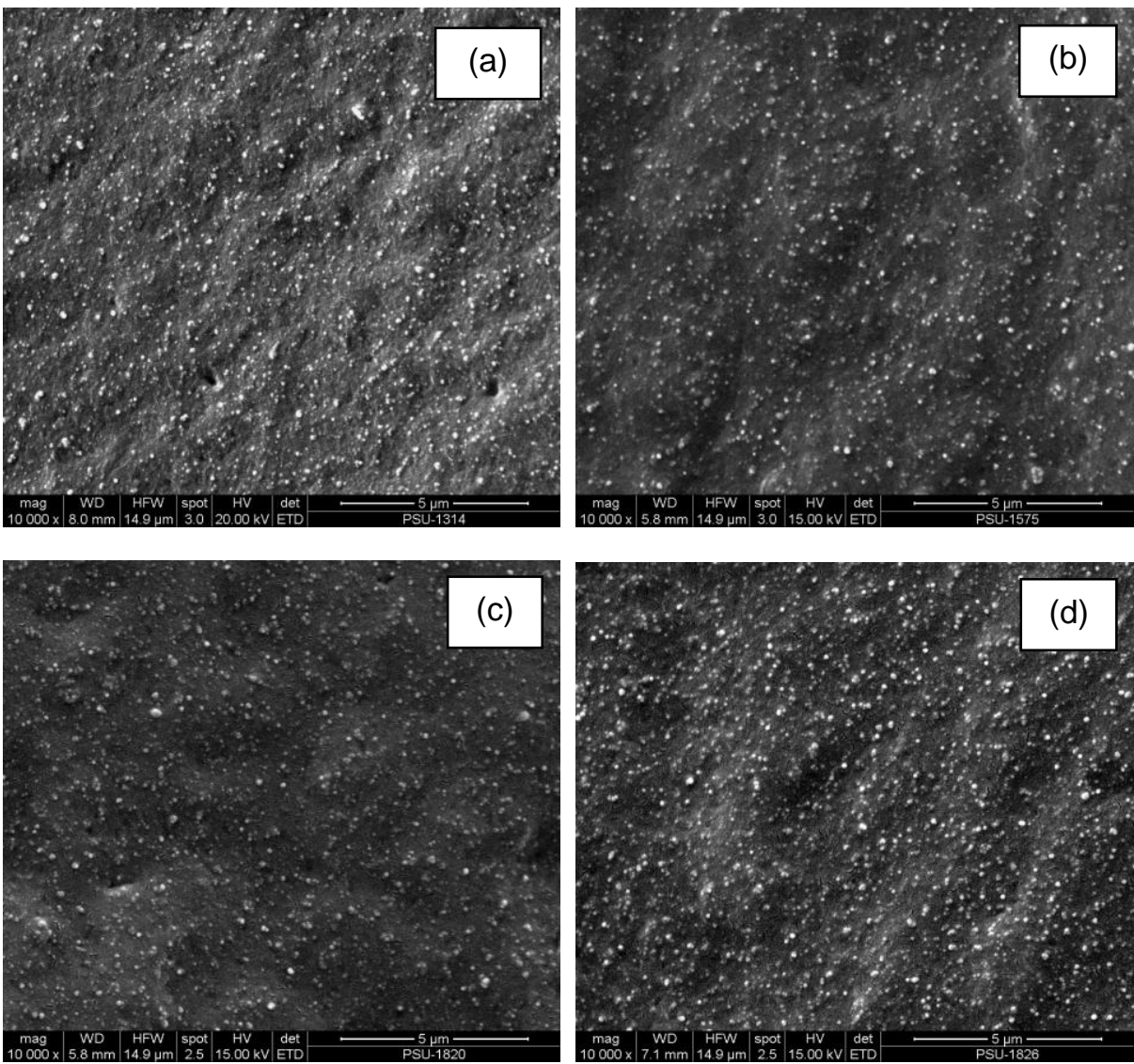

Figure 6.13 SEM images of HAF-filled NR compounds with various oils at 10 phr: (a) without oil; (b) DAE; (c) TDAE and (d) MES.

However, at a closer look in Figure 6.13, the compounds without oil and with MES oil have a very similar morphology wherein aggregates of carbon black can clearly be seen, and seem to have somewhat poorer filler dispersion when compared to the compounds with DAE- and TDAE-oils. Among the four images, the TDAE-plasticized compound shows the best uniformly dispersed carbon black aggregates. The best compatibility between DAE and NR leads to the greatest solvating power in the rubber. This may lead to slightly lower shear forces locally generated during mixing, and so adversely affected on the filler break-up process. The better dispersion of carbon black in the TDAE-containing compound over the DAE-one is in agreement with the results of Payne effect (i.e., filler-filler interaction) and bound rubber content, as shown in Figures 6.11 and 6.12, respectively. The increasing oil contents dilute the filler fraction volume in the compounds, and decrease the filler-filler 
networks which lead to better filler dispersion, as shown in Figure 6.14. The compounds with oil incorporation show a finer morphology, and smaller aggregates can be observed in the compounds with higher oil contents.
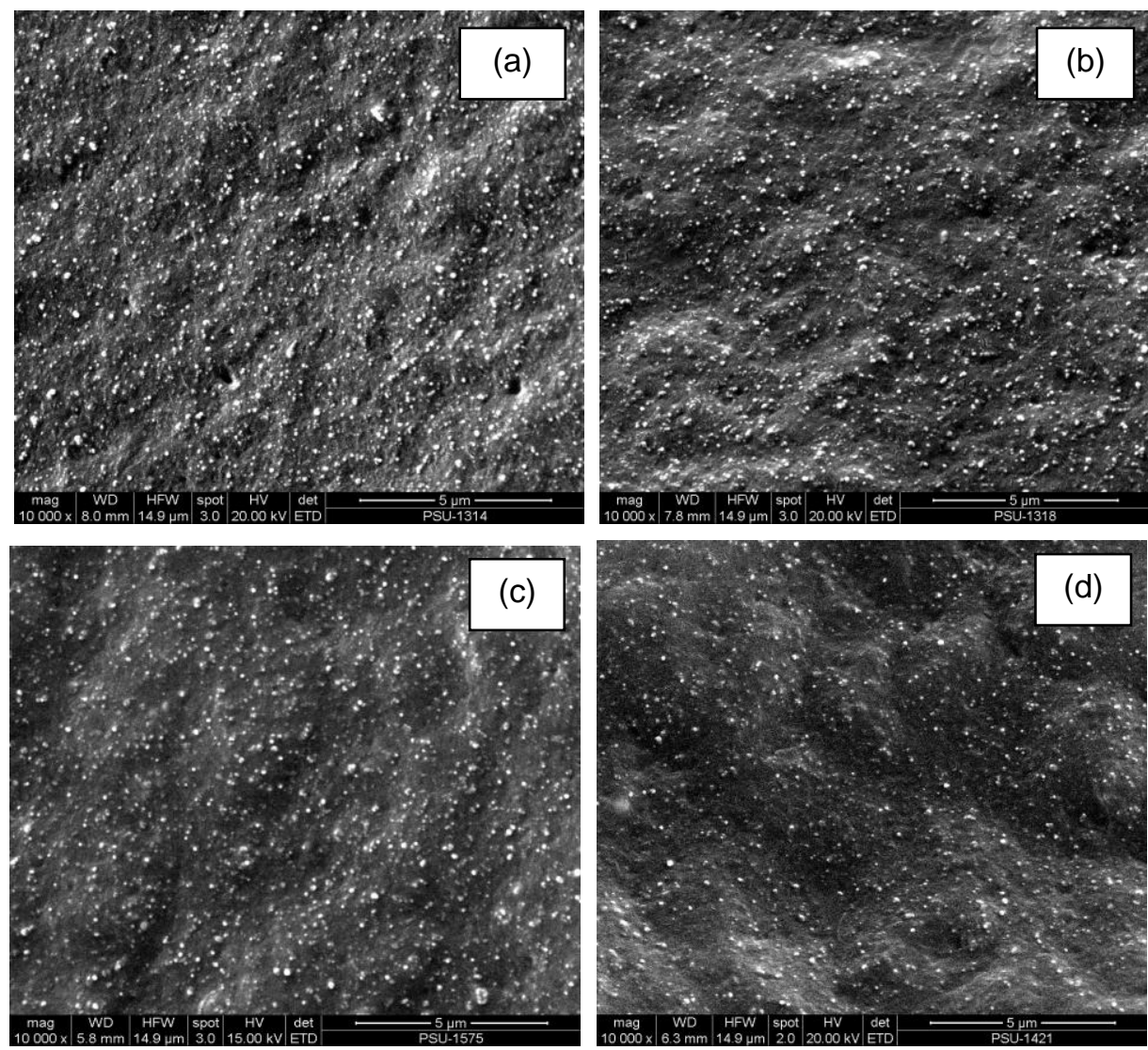

Figure 6.14 SEM images of HAF-filled NR compounds with DAE oil at various contents: (a) without oil; (b) 5 phr; (c) 10 phr and (d) 15 phr.

\subsubsection{Vulcanizate properties}

\subsubsection{Mechanical properties}

The mechanical properties of carbon black filled-NR vulcanizates with different oil types and amounts are shown in Figures 6.15-6.22. Apparently, the change of oil types by replacing DAE- with TDAE- and MES-oils has only minor effects on the mechanical properties of the vulcanizates. The increase of oil loading to 10 and 15 phr results in the same lower hardness, $100 \%$ modulus and tensile strength, but higher elongation at break, as shown in Figures $6.15-6.17$. The rubber vulcanizates that contain 5 phr of oils show the 
same levels of properties when compared to the one without oil. The use of oil at $5 \mathrm{phr}$ should make the process of filler incorporation easier and facilitate the movement of polymer chains as well as filler agglomerates/aggregates. However, this oil content is apparently not high enough to play a significant role as diluent. Increased oil contents especially to $15 \mathrm{phr}$ clearly reduce the hardness, which is in accordance with the lower cure torque difference $\left(\mathrm{M}_{\mathrm{H}}-\mathrm{M} \mathrm{L}\right)$, as shown in Figure 6.7. The decrease of torque difference implies a lower crosslink density either by physical or chemical influences or both. As a consequence, the hardness, modulus and tensile strength decrease, but elongation at break increases. As the mechanical properties of the filled-rubber vulcanizates are further mainly affected by the filler loading and filler dispersion level, in this case, all of the three types of oil must give similar levels of filler dispersion because of their good compatibility with the rubber, as determined by the difference in solubility parameters $(\Delta \delta)$ in Chapter 4 . Basically, a good dispersion of reinforcing fillers improves all fundamental properties of the rubber. Therefore, change of the oil types in carbon black-filled NR compounds causes no significant changes in the mechanical properties, including hardness, modulus, reinforcement index (M300/M100), tensile strength, elongation at break and tear resistance, as displayed in Figures 6.15 to 6.18 , respectively.

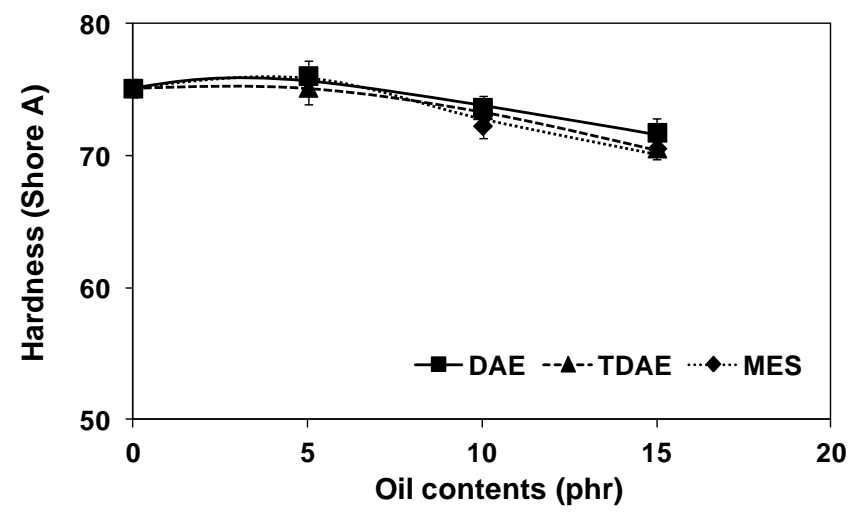

Figure 6.15 Hardness of HAF-filled NR vulcanizates with varying amounts of DAE-, TDAEand MES-oils. 

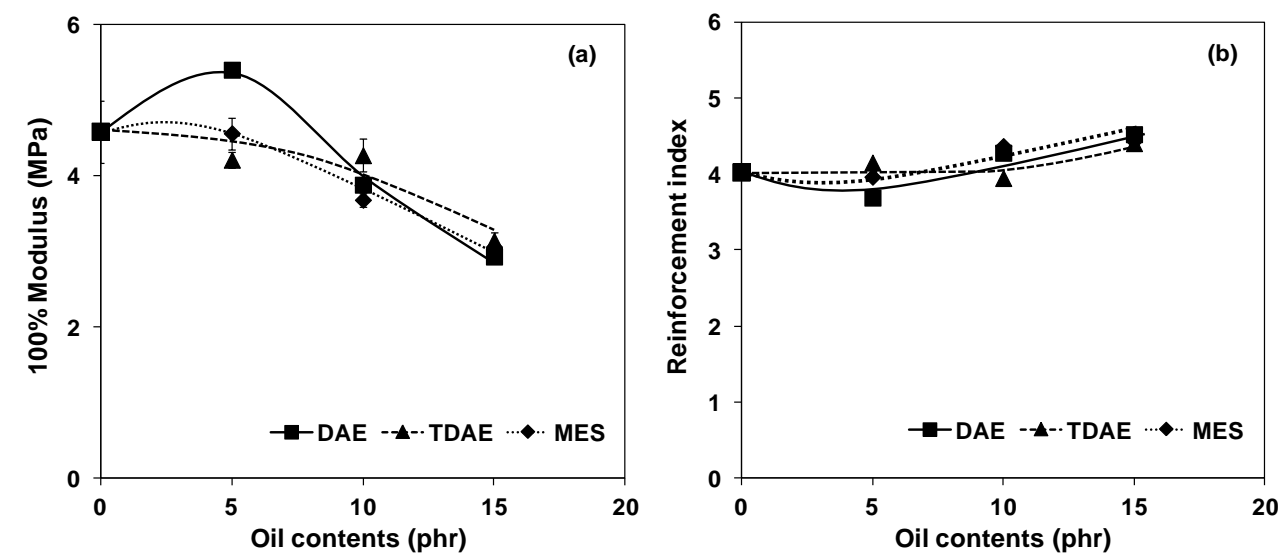

Figure 6.16 Tensile properties of HAF-filled NR vulcanizates with varying amounts of DAE-,

TDAE- and MES-oils: (a) 100\% modulus, and (b) reinforcement index (M300/M100).
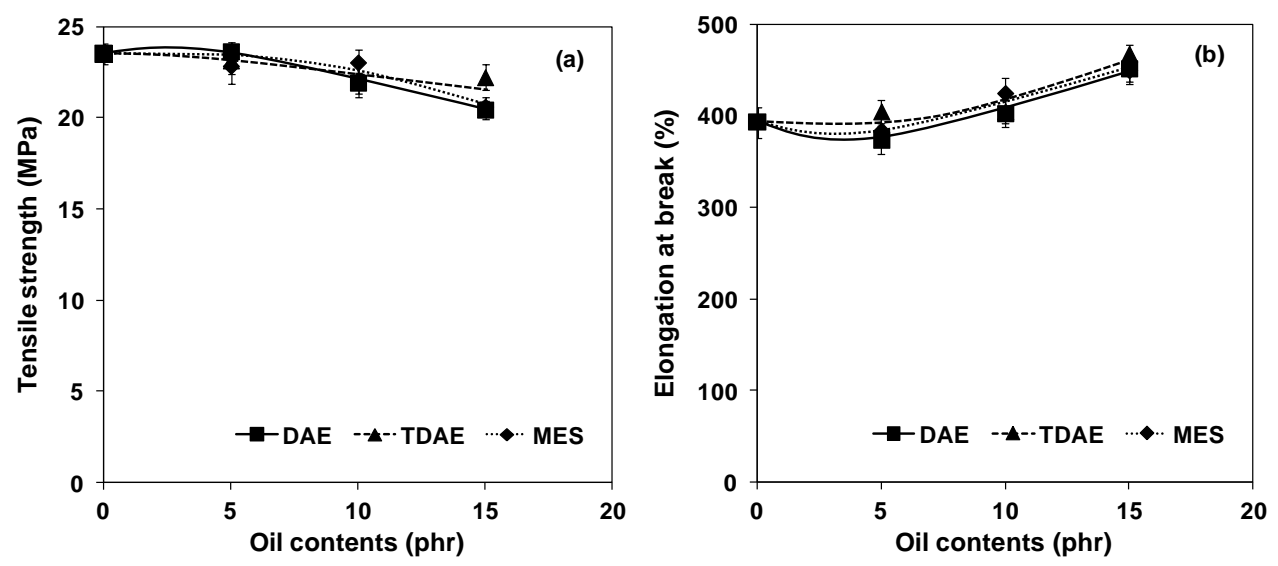

Figure 6.17 Tensile properties of HAF-filled NR vulcanizates with varying amounts of DAE-, TDAE- and MES-oils: (a) tensile strength and (b) elongation at break.

The reinforcement index, i.e. the ratio of modulus at $300 \%$ strain (M300) to the modulus at $100 \%$ strain (M100), as shown in Figure 6.16 (b) tends to increase slightly with increasing oil contents in the NR vulcanizates, which could be related to a better carbon black dispersion and distribution, as previously observed in the lower Payne effect in Figure 6.11. At the same oil content, the reinforcement index of each vulcanizate is very similar, which means that the oil types have no strong influence on the carbon black reinforcement efficiency for these NR vulcanizates. 


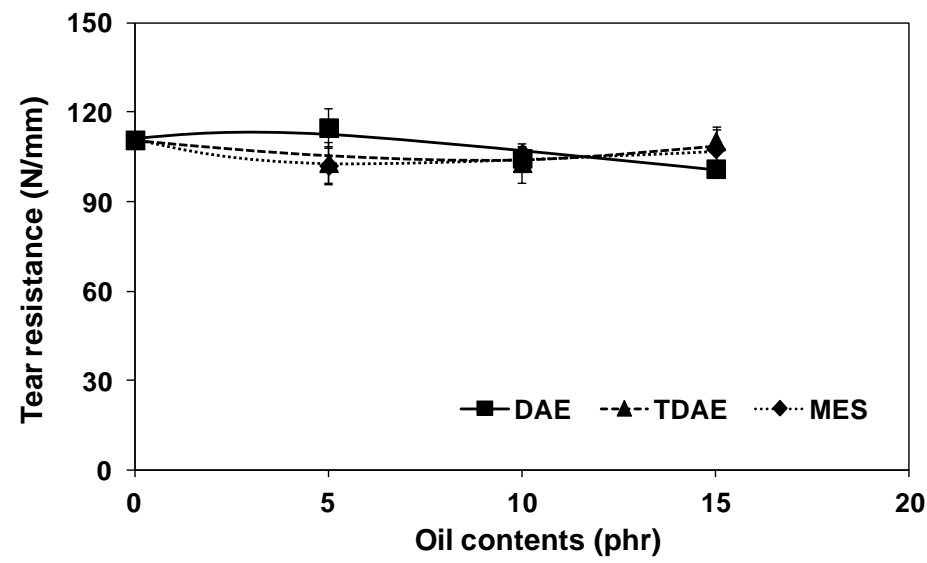

Figure 6.18 Tear resistance of HAF-filled NR vulcanizates with varying amounts of DAE-, TDAE- and MES-oils.

The abrasion resistance of the vulcanizates was tested by measuring the volume loss after abrasion in a DIN abrader, and the results are given in Figure 6.19. The replacement of DAE with MES at every oil content results in an improvement of abrasion resistance, while the use of TDAE oil shows more or less the same level of abrasion resistance compared to the use of DAE oil. Increasing oil content reduces the abrasion resistance of NR vulcanizates, as reflected in an increase of volume loss in Figure 6.19. The presence of oils in between rubber molecules and on the rubber-filler interface reduces the hardness and consequently increases the loss of rubber while being abraded. As presented in Figure 5.7, the addition of oils also affects the glass transition temperature $\left(T_{g}\right)$ of the unfilled-rubber compounds. The use of MES which has the lowest $T_{g}$ among the three types of oils studied, is also expected to result in the lowest $T_{g}$ of the carbon black filled compounds. The change of $\mathrm{T}_{\mathrm{g}}$ does affect the viscoelastic behavior of the materials. The MES containing compounds with the lowest $T_{g}$ therefore show somewhat better elastic properties, as reflected in the better abrasion resistance (Figure 6.19) and also fatigue life (Figure 6.20), when compared to the compound with DAE oil. The influence of $T_{g}$ of the rubber on abrasion resistance has been previously reported ${ }^{24}$, in the sense that a higher $\mathrm{T}_{g}$ resulted in higher DIN abrasion loss. The present results are in agreement with that. Furthermore, the MES-oil contains a high paraffinic portion and waxes, as shown in Table 3.2 and the DSC thermogram in Figure 3.4. The incompatible oil and waxes may migrate to the sample surface and affect the abrasive wear ${ }^{12}$. 


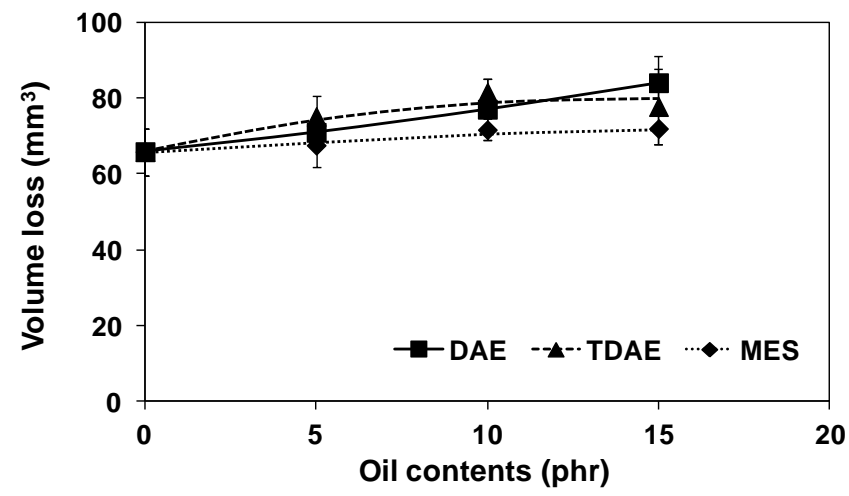

Figure 6.19 DIN abrasion loss of HAF-filled NR vulcanizates with varying amounts of DAE-, TDAE- and MES-oils.

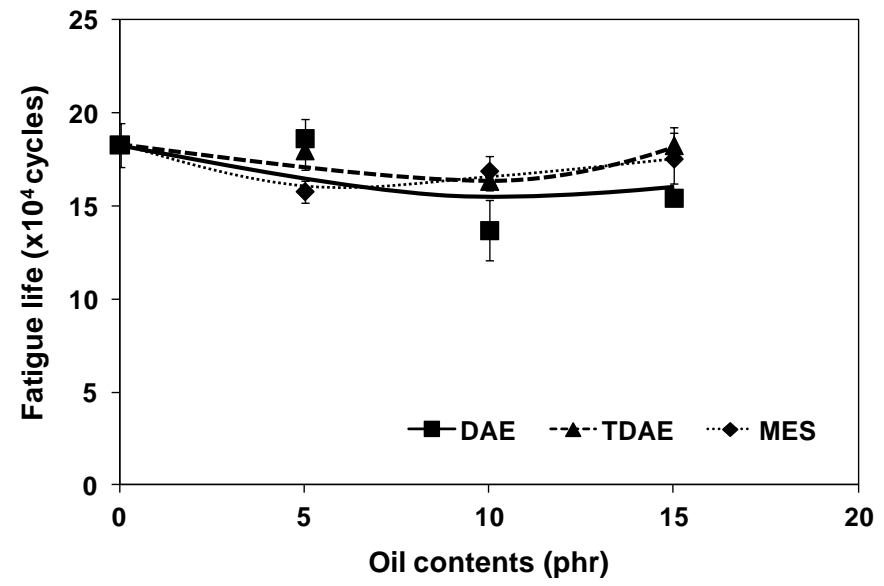

Figure 6.20 Fatigue life of HAF-filled NR vulcanizates with varying amounts of DAE-, TDAEand MES-oils.

The addition of oil to the NR compounds tends to decrease the fatigue-to-failure properties of the vulcanizates especially in the case of DAE oil, as shown by their fatigue life in Figure 6.20. With 10 and 15 phr of oils, the compounds with DAE oil show significantly lower fatigue life when compared to the compounds with TDAE- and MES-oils, which otherwise both show similar results.

Many factors that influence the fatigue life of rubber vulcanizates include the effects of mechanical loading history, environmental effects, rubber formulation and dissipation aspects of the constitutive response of rubber ${ }^{23}$. In the present study, the rubber formulation changed due to the variation of oil types and loadings. The DAE containing NR compounds 
show higher Payne effects and lower bound rubber contents when compared to the other compounds, and the vulcanizates show a little higher hardness which also means higher stiffness. This will have a negative effect on the fatigue life under the displacement controlled test. The highest $T_{g}$ of the DAE oil among the oil types studied will also affect the $T_{g}$ of the filled-rubber vulcanizates to some extent, as previously seen in the unfilled compounds in Figure 5.7. The shift of $\mathrm{T}_{\mathrm{g}}$ to higher temperature also affects the stiffness and hysteresis of the rubber, and thus results in a poorer fatigue life. Furthermore, the smallest difference in solubility parameters ( $\Delta \delta$-value) of DAE and NR makes them most compatible with each other and consequently DAE can swell NR to a greater extent, as described in Chapter 4. The good oil-rubber compatibility will also affect the elastic modulus and dynamically stored energy, and finally have an influence on specimen fracture ${ }^{25}$. A study with ethylene propylene diene rubber (EPDM) by Jerrams et al. $^{25}$. showed that the fatigue life of the rubber decreased in proportion to the degree of swelling. The greater swelling decreased the stiffness of the materials, and consequently increased the dynamically stored energy in the sample, which finally lead to failure.
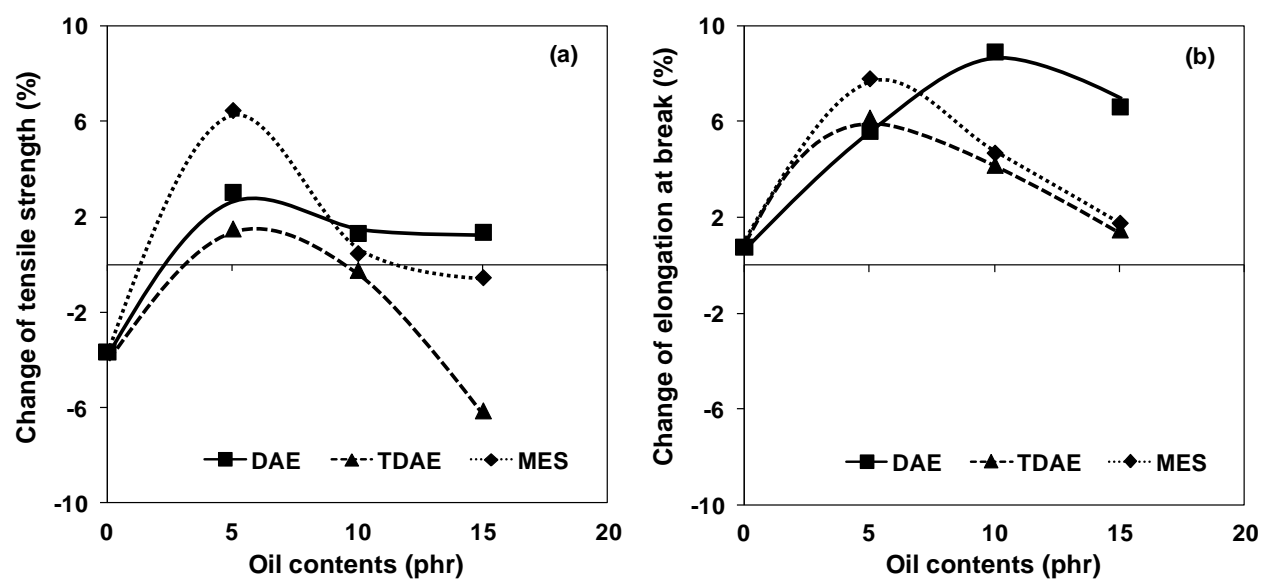

Figure 6.21 Percent changes of properties after aging of HAF-filled NR vulcanizates with varying amounts of DAE-, TDAE- and MES-oils: (a) tensile strength, and (b) elongation at break.

The thermal aging resistance at $70^{\circ} \mathrm{C}$ for 168 hours of the NR vulcanizates was investigated in terms of the percentages of change in tensile strength and elongation at break, as shown in Figures 6.21 (a) and (b), respectively. The vulcanizates with 5 phr of oil of all types show an increase in both tensile strength and elongation at break after aging, but with increasing oil contents to 10 and 15 phrs, the percent change of the properties are 
smaller especially in the case of the rubber compounds with MES- and TDAE-oils. Overall, the changes of tensile strength and elongation at break after aging are small, i.e. $<10 \%$. This is because the rubber formulation contains sufficient amounts of antioxidants, i.e. TMQ and 6PPD.
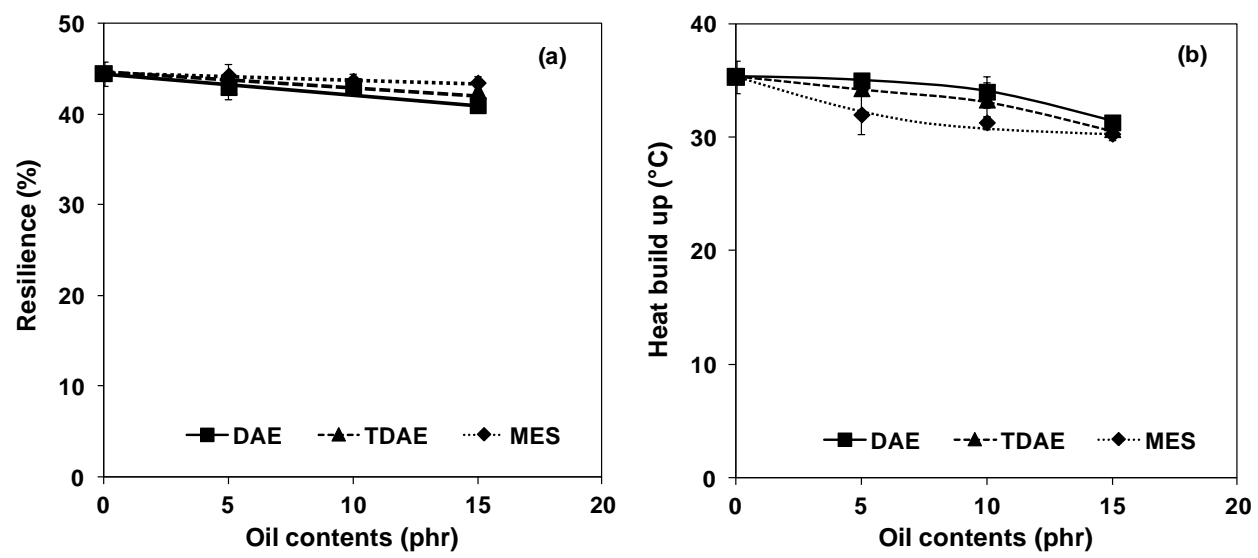

Figure 6.22 Resilience (a) and heat build-up (b) of HAF-filled NR vulcanizates with varying amounts of DAE-, TDAE- and MES-oils.

The influence of DAE-, TDAE- and MES-oils on rebound resilience and heat buildup of the NR vulcanizates are illustrated in Figures 6.22. As expected, the increase of oil contents, which is a viscous component, into the compounds decreases the rebound resilience of the vulcanizates. This indicates a higher loss of energy while being subjected to stress. However, increasing oil content also gives reduction of the heat build-up of the vulcanizates. The addition of carbon black into the NR compound principally increases the heat build-up as a result of the breakage of carbon black structure and viscoelastic loss ${ }^{26}$. The oil molecules that are distributed in the free volume between the rubber molecules and at the filler-rubber interface may help to dissipate the heat and so cause less temperature rise in the rubber vulcanizates. The higher oil loading clearly reduces the heat build-up. The replacement of DAE with TDAE and MES in the NR compounds gives some higher resilience and lower heat build-up, indicating some but little improvement of rubber elasticity. Among the three types of oils, the compounds with MES oil show the best elastic response, as reflected by the highest resilience and lowest heat generated in the rubber. These two properties can be related to the viscoelastic behaviors of the materials which are affected by the glass transition temperatures of the oils. The MES oil has the lowest $T_{g}$ due to its high proportion of paraffin and low aromatic content. The compounds with MES oil should 
therefore have a lower $\mathrm{T}_{g}$ and better elastic properties, compared to the compounds with TDAE- and DAE-oils. The highest resilience of MES containing vulcanizates is therefore in accordance with the lowest heat build-up, while the lowest resilience of the DAE-plasticized NR agrees well with the highest heat build-up, as shown in Figure 6.22.

\subsubsection{Dynamic properties}

Dynamic properties are very important for tire applications, especially for aspects of wet grip and tire rolling resistance. These properties are related to the viscoelastic behavior of the materials. The variation of oil types and amounts shows their influence on the glass transition temperature $\left(\mathrm{T}_{\mathrm{g}}\right)$ and loss tangent of HAF-filled NR vulcanizates, as shown in Figures 6.23 to 6.26 .

The effect of oil types and contents on the glass transition temperature $\left(T_{g}\right)$ of rubbers was previously investigated for unfilled compounds in Chapter 5 . Therein, the $T_{g}$ 's of NR and SBR were shifted according to the $T_{g}$ 's of oils; DAE oil caused a shift of $T_{g}$ of both types of rubbers to higher temperature because of its higher $T_{g}$ compared to the $T_{g}$ of rubbers. For carbon black-filled NR, the $T_{g}$ of the rubber vulcanizate is still affected by the $T_{g}$ of the oil, as displayed in Figures 6.23-6.25, but the shift is smaller than $2^{\circ} \mathrm{C}$ (Figure 6.25) due to the presence of filler at high loading, i.e. $60 \mathrm{phr}$. The typical loss tangent curves of the filled-NR compounds containing 10 phr of different oils are displayed in Figure 6.23. The $T_{g}$ 's of all vulcanizates with varying oil types and contents are presented in Figure 6.24, and the differences of $T_{g}$-values $\left(\Delta T_{g}\right)$ of the plasticized compounds relative to the mix without oil are shown in Figure 6.25. Addition of TDAE and DAE in the NR compounds slightly increases the $T_{g}$ of the vulcanizates when compared to the one without oil, while the use of MES oil results in a similar $\mathrm{T}_{\mathrm{g}}$ or only a marginal change. The increasing oil contents however show no clear influence on $\mathrm{T}_{\mathrm{g}}$ of the vulcanizates. 


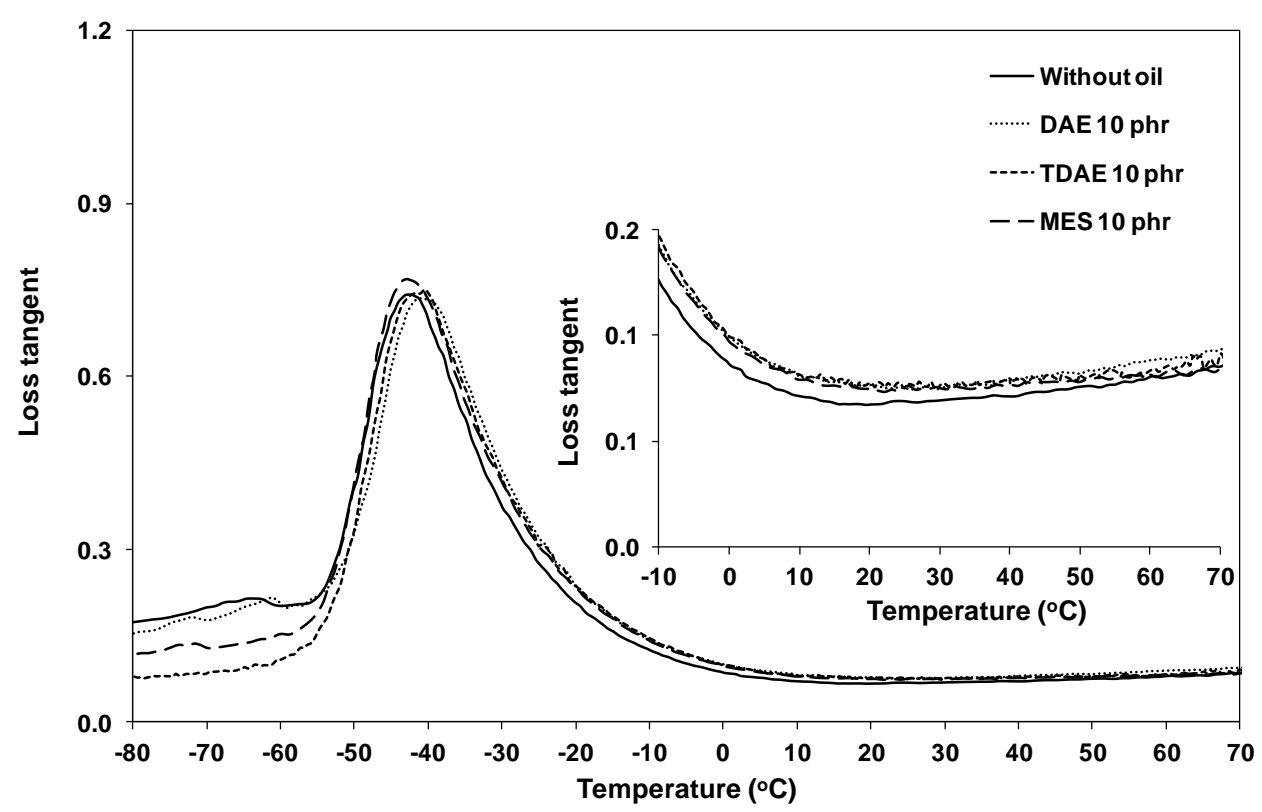

Figure 6.23 Loss tangent curves of HAF-filled NR compounds with DAE-, TDAE- and MESoils at 10 phr.

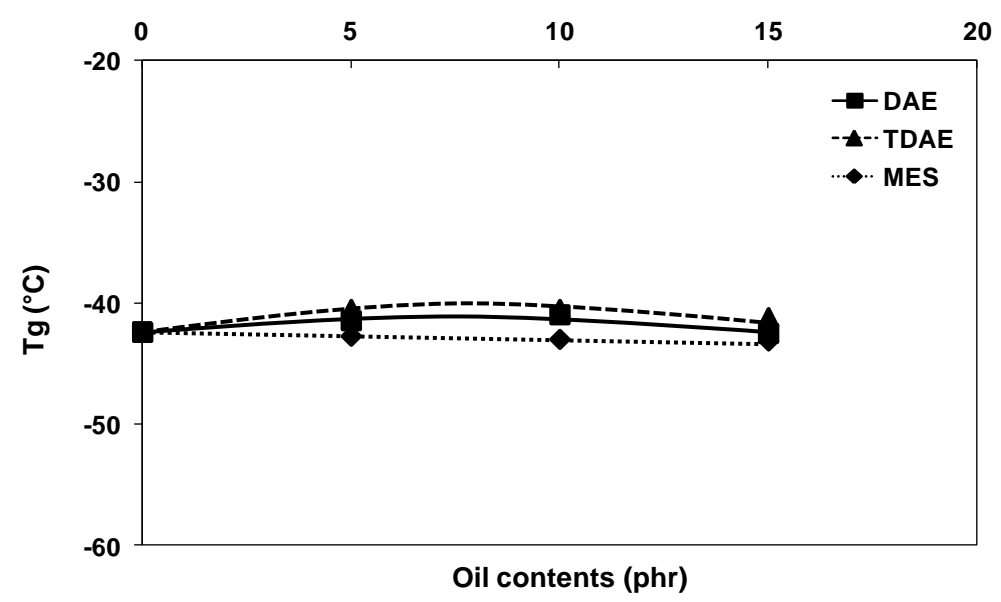

Figure 6.24 Glass transition temperatures of HAF-filled NR vulcanizates with varying amounts of DAE-, TDAE- and MES-oils. 


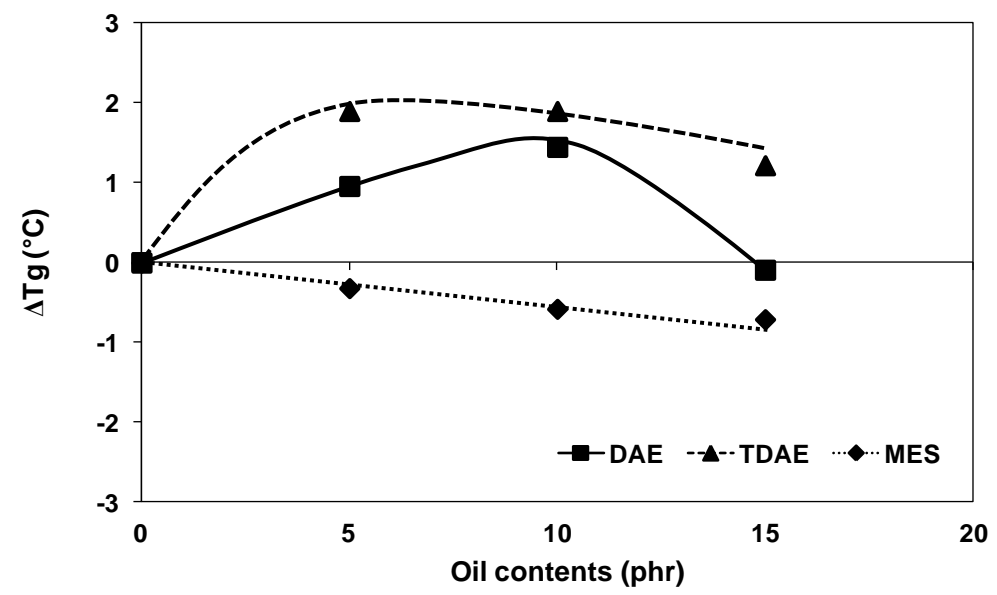

Figure 6.25 Difference of glass transition temperature $\left(\Delta T_{g}\right)$ of HAF-filled NR vulcanizates with varying types and amounts of oils, in relation to the unplasticized compound.

The loss tangent $\left(\tan \delta\right.$ ) values at $0^{\circ} \mathrm{C}$ and $60^{\circ} \mathrm{C}$ of the filled-NR compounds which are commonly used to indicate wet grip and rolling resistance for tires, respectively, are shown in Figure 6.26. The NR-vulcanizates with the three different oil types show almost identical values of loss tangent at $0^{\circ} \mathrm{C}$ which increase with increasing oil contents due to the large viscous contribution from the oils. Therefore, the incorporation of process oil improves the wet grip performance of tires. With regard to the change of the loss tangent at $60^{\circ} \mathrm{C}$, the NR-vulcanizates with DAE oil show a higher tan $\delta$ at $60^{\circ} \mathrm{C}$ when compared to the rubbers with TDAE and MES. This is different from the loss tangents of the unfilled compounds as previously shown in Figure 5.9. For filled-NR vulcanizates there are apparently more factors involved in the energy loss during sinusoidal deformation. These include filler dispersion, filler-rubber and filler-filler interactions. When compared to the compound without oil, the addition of all oil types except for 5 phr loading increases the loss tangent at $60^{\circ} \mathrm{C}$. The highest or poorest loss tangent at $60^{\circ} \mathrm{C}$ for the DAE containing vulcanizates correlates with its highest Payne effect and lowest bound rubber content, as displayed in Figures 6.11 and 6.12 , respectively. Furthermore, the better compatibility between DAE and NR, which shall result in a greater degree of swelling of oil in the rubber, is also expected to increase the energy loss in the rubber during cyclic deformation. The conversely poorest elastic response of the DAE-plasticized HAF-filled-NR compound correlates with the results of rebound resilience and heat build-up, as previously shown in Figure 6.22 . The loss tangents at $60^{\circ} \mathrm{C}$ for the compounds with TDAE- and MES-oils are similar, where the one with MES oil which has the lowest $T_{g}$ shows a little lower value. From these results, it can be concluded that the 
replacement of DAE- with MES- and TDAE-oils indicates a slightly lower rolling resistance if applied in tire treads, while maintaining the wet grip or wet skid resistance. Increased oil contents improve wet grip but deteriorate tire rolling resistance.

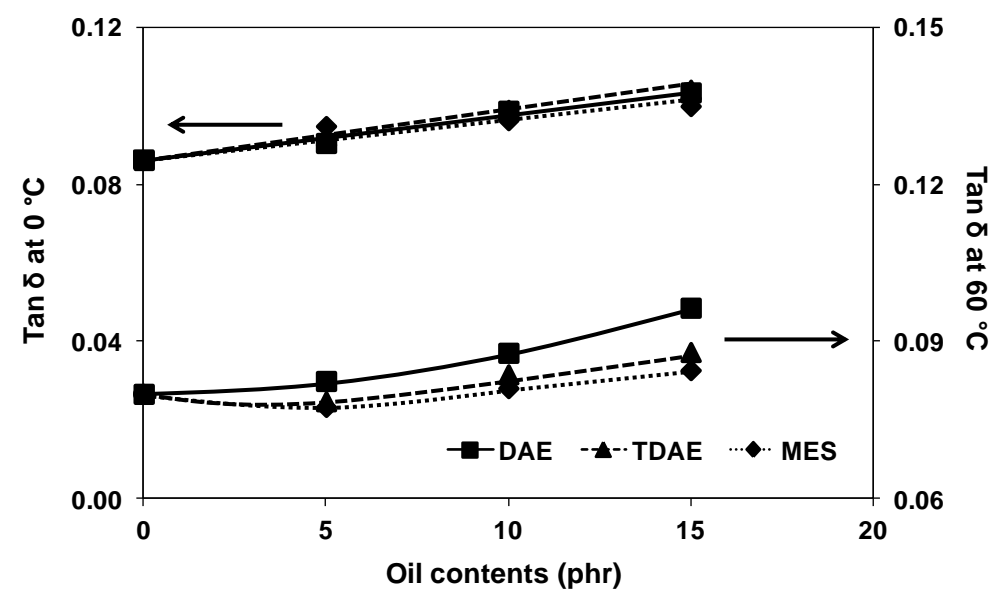

Figure 6.26 Loss tangent at 0 and $60^{\circ} \mathrm{C}$ of HAF-filled NR vulcanizates with varying amounts of DAE-, TDAE- and MES-oils.

\subsection{CONCLUSIONS}

The influence of DAE-, TDAE- and MES-oils at different loadings on the properties of HAF-filled NR compounds was investigated. The compounds show similar mixing torques with all types of oils, but the DAE-containing compounds have lower Mooney viscosities but higher complex viscosities when compared with the mixes with TDAE- and MES-oils. Increasing oil loadings decrease the compound viscosities, except at $5 \mathrm{phr}$ where the values are higher than for the unplasticized compound. The mixing of NR with carbon black without oil is affected by the mastication effect which results in a greater extent of polymer chain break-down. The compounds with different oils show similar cure characteristics. The DAEplasticized compounds show the highest Payne effect and lowest bound rubber content compared to the mixes with TDAE- and MES-oils. The filler-filler and filler-rubber interactions tend to decrease slightly when more oils are included in the compounds, but SEM micrographs reveal that carbon black is finely dispersed in all of the compounds. The use of DAE, TDAE and MES gives vulcanizates with similar mechanical properties (i.e., hardness, tensile and tear strength, and elongation at break), but they differ in properties which are related to the change of the glass transition temperature and viscoelastic behavior. The use of DAE with the highest $T_{g}$ among the three results in lower abrasion resistance, fatigue life, rebound resilience and higher heat build-up, while the use of MES with the lowest $T_{g}$ gives 
the best elastic response. Increasing oil loading increases the loss tangent at both $0^{\circ} \mathrm{C}$ and $60^{\circ} \mathrm{C}$ of the vulcanizates. The loss tangent values at $0^{\circ} \mathrm{C}$ of all the vulcanizates with the same oil loadings are similar, but the loss tangent at $60^{\circ} \mathrm{C}$ of the rubbers with MES and TDAE is lower than that with DAE, respectively. The results clearly reveal that the replacement of DAE- with TDAE- and MES-oils has no significant effect on the mechanical properties, but influences the dynamic mechanical properties which are related to the different $T_{g}$ 's of the oils, which may have an impact on the performance of tires produced with these oils.

\subsection{REFERENCES}

1 A.Y. Coran and J.B. Donnet, Rubber Chem. Technol., 65, 973 (1992).

2 G. Ramorino, D. Vetturi, D. Cambiaghi, A. Pegoretti and T. Ricco, Polym. Test., 22, 681 (2003).

3 J.L. Leblanc, Prog. Polym.Sci., 27, 627 (2002).

4 L. Bokobza and O. Rapoport, J. Appl. Polym.Sci., 85, 2301 (2002).

5 M. Tosaka, S. Murakami, S. Poompradub, Y. Ikeda, S. Toki, I. Sics and B.S. Hsiao, Macromolecules, 37, 3299 (2004).

6 M. Tosaka, K. Senoo and S. Kohjiya, J. Appl. Phys., 101, 084909 (2007).

7 N.M. Mathew, in: Rubber Technologist's Handbook, Chapter 2: Natural Rubber, Eds.: S.K. De and J.R. White, Rapra Technology Limited, Shropshire, 2001.

8 W. Klingensmith and B. Rodgers, in: Rubber Compounding, Chemistry and Applications, Chapter 1: Natural Rubber and Recycled Materials, Eds.: B. Rodgers, Marcel Dekker Inc., New York, 2004.

9 S. Wolff, M. J. Wang and E. H. Tan, Rubber Chem. Technol., 66, 163 (1993).

10 N. Rattanasom and K. Suchiva, J. Appl. Polym. Sci., 98, 456 (2005).

11 G.R.Cotten, Rubber Chem. Technol., 58, 774 (1985).

12 K. Sahakaro and A. Beraheng, Rubber Chem. Technol., 84, 200 (2011).

13 J. Malac, The Open Macromolecules Journal, 3, 41 (2009).

14 J.S. Dick, in: Rubber Technology, Compounding and Testing for Performance, Chapter 2: Compound Processing Characteristics and Testing, Eds.: J. S. Dick, Carl Hanser Verlag, Munich, 2001.

15 R.K.Gupta, "Polymer and Composite Rheology", $2^{\text {nd }}$ edition, Marcel Dekker, New York, 2000.

16 T.G. Mezger, "The Rheology Handbook", $2^{\text {nd }}$ edition, Vincentz Network, Hannover, 2006. 
17 J.S. Dick, C.A.Sumpter and B. Ward, presented at a meeting of the Rubber Division, American Chemical Society (ACS), September 29 - October 2,1998, Nashville, TN, USA.

18 J.S. Dick, C. Harman and A. Vare, Polym. Test., 18, 327 (1999).

19 H. D. Luginsland, J. Fröhlich and A. Wehmeier, Rubber Chem. Technol., 75, 563 (2002).

20 S. Dasgupta, S. L. Agarwal, S. Bandyopadhyay, R. Mukhopadhyay, R. K. Malkani and S.

C. Ameta, Polym. Test., 28, 251 (2009).

21 S. Wolff, Rubber Chem. Technol., 69, 325 (1996).

22 Y. Fukahori, Rubber Chem. Technol., 80, 701 (2007)

23 Y. Fukahori, J. Appl. Polym. Sci., 95, 60 (2005).

24 K.H. Nordsiek, Kautsch. Gummi Kunstst., 39, 599 (1986).

25 S. Jerrams, J. Hanleys, N. Murphy and H. Ali, Rubber Chem. Technol., 81, 638 (2008).

26 D.M. Park, W.H. Hong, S.G. Kim and H.J. Kim, Eur. Polym. J., 36, 2429 (2000). 


\section{EFFECT OF OIL TYPES AND CONTENTS ON THE PROPERTIES OF CARBON BLACK-FILLED NR/SBR BLEND COMPOUNDS}

The present chapter discusses the influence of DAE-, TDAE- and MES-oils on the properties of carbon black-filled NR/SBR blend compounds. The properties of plasticized blends are clearly affected by the oil contents, but less dependent on the oil types. At the same oil content, the compounds show similar mixing torques, dump temperatures and Mooney viscosities which are decreasing with increasing oil contents, but the compounds with DAE show higher complex viscosity than the mixes with TDAE and MES. The differences between the oil types have only a small effect on scorch and cure times, but increased oil loadings prolong the cure and decrease the rheometer torque difference. The compounds with DAE oil show higher Payne effect compared to those with TDAE- and MES-oils, respectively, but all show similar bound rubber contents. Both filler-filler and fillerrubber interactions are reduced with increasing oil contents. SEM micrographs of the blends show that carbon black is finely dispersed in the compounds, although the MES-plasticized blend shows slightly poorer filler dispersion compared to the ones with TDAE and DAE. The vulcanizates with all types of oils show very similar tensile strength and reinforcement index, but the one with DAE has higher hardness than those with TDAE and MES. The blends containing the different oil types show remarkable differences in abrasion resistance. The use of TDAE oil results in the lowest volume loss and highest fatigue life, whereas the use of DAE gives the highest volume loss and lowest fatigue life. The DAE-containing blends also have the lowest rebound resilience and highest heat build-up, whereas the blends with TDAE and MES show better but similar properties. The blends exhibit two glass transition temperatures $\left(T_{g}\right)$ associated with each elastomer blend component. When compared to the blend without oil, the $T_{g}$ of the NR phase is little affected by the incorporation of oils, but that of the SBR phase is clearly shifted to a higher temperature. The presence of the oils clearly increases the loss tangent at $0^{\circ} \mathrm{C}$, but marginally increases the value at $60^{\circ} \mathrm{C}$. Based on the properties that are related to viscoelastic performance, the blends with TDAE show the best overall elastic response. 


\subsection{INTRODUCTION}

Passenger tire treads are generally made of blends from either Natural Rubber (NR) or Butadiene Rubber (BR) and Styrene Butadiene Rubber (SBR). NR and BR are used to provide elastic properties while SBR is needed for damping, e.g. wet skid resistance or wet grip. The use of NR provides better mechanical strength while BR has better abrasion resistance. These two types of rubbers are chosen based on their availability and specific technical requirements. Basically, BR/SBR or NR/SBR blends are used for passenger tire tread formulations. In addition to its damping behavior, SBR provides an excellent abrasion resistance and better crack or cut growth initiation than NR. Moreover, SBR gives better heat aging properties than $\mathrm{NR}^{1}$. SBR is therefore an essential rubber to be used for blending with NR or BR for production of tire treads ${ }^{2,3}$. There are two main types of SBR: emulsion SBR (E-SBR) and solution SBR (S-SBR), which are produced by different polymerization methods. E-SBR commonly has a broader molecular weight distribution which is better for processability $^{4}$, and a fixed polybutadiene, cis, trans, 1,2-vinyl, configuration ratio by the radical polymerization process. S-SBR is prepared by anionic polymerization that can be manipulated in a broader range to provide variable polybutadiene configuration ratios and higher molecular weights. But S-SBR has a narrow molecular weight distribution that makes it more difficult to process. The changes of styrene content and polybutadiene configuration affect the glass transition temperature $\left(T_{g}\right)$. S-SBR is similar to E-SBR in terms of tensile strength, modulus and elongation, but has better flex resistance, lower heat build-up, higher resilience and gives lower rolling resistance if applied in tires ${ }^{1}$. Therefore, S-SBR is preferable for low rolling resistance tires. For carbon black-filled tire treads, E-SBR is still used for its better processing ease and lower price.

For high filler-loaded compounds such as tire tread formulations, process oils are used to control compound viscosity and filler dispersion. Different oil types are used including Distillate Aromatic Extract (DAE) oil, Treated Distillate Aromatic Extract (TDAE) oil, Mild Extracted Solvate (MES) oil, Naphthenic (NAP) oil and natural oils. It has been reported that the use of eco-friendly process oils, such as TDAE, MES and NAP resulted in a narrow range of changes in rheological, physical and mechanical properties of un-aged vulcanizates of NR, SBR, NR/SBR and NR/brominated-isobutylene-isoprene rubber (BIIR) ${ }^{5}$. MES- and TDAE-oils provided similar ageing behavior to DAE for NR compounds, but improved the aging resistance of NR/SBR and NR/BIIR-based vulcanizates. The NR, SBR and NR/SBR compounds plasticized with epoxidized palm oil (EPO) showed comparable cure characteristics and processing properties, as well as mechanical and dynamic mechanical properties of the vulcanizates when compared to compounds with DAE oil ${ }^{6}$. The replacement of DAE by TDAE, MES and NAP in carbon black- and silica-filled tire 
compounds slightly shifted the wet grip performance and improved the rolling resistance, which was most clearly observed in carbon black-filled compounds ${ }^{7}$. Furthermore, some natural oils were reported to give better abrasion resistance in NR, NR/BR and SSBR/NR/BR compounds, compared to the DAE oil ${ }^{8}$.

The previous chapter already highlighted the influence of DAE-, TDAE- and MESoils at different loadings in HAF-filled NR compounds in which the change of oil types from conventional DAE to TDAE- and MES-oils affected the properties which are closely related to the viscoelastic behavior of the materials. NR based tire tread compounds are basically for truck tires, but NR/SBR blends are for passenger tire treads. This present chapter therefore investigates the influence of oil types and contents on processing properties, cure characteristics, filler dispersion, filler-filler interaction, mechanical and dynamic properties of carbon black-filled NR/SBR compounds. For comparison of some properties of the uncured compounds, carbon black-filled SBR compounds of the same formulation are also prepared and tested.

\subsection{EXPERIMENTAL}

\subsubsection{Materials}

Emulsion styrene butadiene rubber (Buna ${ }^{\circledR}$ SB 1502-Schkopau) was obtained from Styron HoldCo B.V., Germany. NR and all other ingredients were the same as described in Chapter 6. All ingredients were used as received.

\subsubsection{Methods}

\subsubsection{Preparation of NR/SBR blend and SBR compounds}

The NR/SBR blend compounds with varying oil types and loadings were prepared by applying the same mixing procedure and conditions, e.g. mixer type, mixer temperature setting of $50^{\circ} \mathrm{C}$, fill factor of 0.7 and rotor speed of $40 \mathrm{rpm}$, as were employed for the NR compounds in Chapter 6. The NR/SBR and SBR compound formulations are displayed in Table 7.1 
Table 7.1 Formulations for the HAF-filled NR/SBR blend and SBR compounds studied.

\begin{tabular}{lcc}
\hline \multirow{2}{*}{ Ingredients } & \multicolumn{2}{c}{ Amount (phr) } \\
\cline { 2 - 3 } & NR/SBR & SBR \\
\hline NR (RSS 3) & 50.0 & - \\
SBR (1502) & 50.0 & 100.0 \\
Carbon black (N330) & 60.0 & 60.0 \\
Oil & Varying types and loadings \\
Zinc oxide & 3.0 & 3.0 \\
Stearic acid & 1.0 & 1.0 \\
6PPD & 1.5 & 1.5 \\
TMQ & 2.0 & 2.0 \\
Microcrystalline wax & 0.5 & 0.5 \\
CBS & 1.2 & 1.2 \\
DPG & 0.3 & 0.3 \\
Sulfur & 1.5 & 1.5 \\
\hline
\end{tabular}

Three different types of process oils, i.e. DAE, TDAE and MES were employed and the oil contents were varied at $0,5,10$ and $15 \mathrm{phr}$. These oils were heated at $60^{\circ} \mathrm{C}$ before being added into the mixer. For the blends, NR was pre-masticated for 3 mins. on a two-roll mill and kept at room temperature overnight prior to the blend preparation. The two-step mixing procedure was started by adding pre-masticated NR and SBR into the internal mixer and mixing for 2 mins. Then, stearic acid, zinc oxide, 6PPD, TMQ, microcrystalline wax and $2 / 3$ of the carbon black were added, and mixed for 3 mins. Afterwards, the remaining carbon black and process oil were added, mixed for another 4 mins., and subsequently the masterbatch was dumped to make a sheet on a two-roll mill. The second mixing step was to add CBS, DPG and sulfur into the masterbatch by using a two-roll mill. The final compounds were sheeted to a thickness of approximately $3 \mathrm{~mm}$.

The SBR compounds were prepared by using a laboratory internal mixer Brabender Plasticoder $350 \mathrm{~S}$ mixer with a chamber volume of 390 milliliters, a mixer temperature setting of $50^{\circ} \mathrm{C}$, a fill factor of 0.70 and a rotor speed of $50 \mathrm{rpm}$. SBR was fed into the internal mixer and homogenized for 2 mins. The mixing was then executed using the same mixing procedure as that of the blend compounds, including the second step of 
curatives addition on the two-roll mill. The rubber compounds were vulcanized to their $90 \%$ optimum cure times by compression molding at $150^{\circ} \mathrm{C}$.

\subsubsection{Properties testing}

The NR/SBR blend compounds were tested for their properties similar to the filled NR- compounds. Mooney viscosity, Mooney stress relaxation rate, complex viscosity, cure characteristics, Payne effect, bound rubber content, filler dispersion, mechanical properties (i.e. hardness, tensile properties, tear strength, abrasion resistance, fatigue-to-failure, rebound resilience, heat build-up), and dynamic mechanical properties were tested following the methods and procedures described in detail in Chapter 6. The filled-SBR compounds were tested for their complex viscosity, cure characteristics, Payne effect and bound rubber content of the uncured compounds only.

\subsection{RESULTS AND DISCUSSION}

It should be noted that due to unexplained erratic behavior of the blend compound with 10 phr of DAE oil, this compound is omitted from this Results and Discussion part.

\subsubsection{Mixing torque}

The mixing torques of the carbon black-filled NR/SBR masterbatches with 5 and 15 phr of the different oil types are shown in Figure 7.1, and with different contents of TDAE and MES in Figure 7.2. In these figures, the mixing torque of the compound without oil is also included for comparison. The mixing curves are divided into three zones according to the mixing procedure employed, as shown in Figure 7.1. In zone I, the pre-masticated NR and SBR were mixed and mixing torques slightly decreased because the break-down of the NR molecules and the results of shear heating. The addition of solid particles of carbon black and other chemicals to the rubber increased the mixing torques in the beginning of zone II, which later decreased as the carbon black was dispersed while the compound temperature was further increased due to the viscous shearing action. Dispersive mixing leads to dispersion of carbon black agglomerates and a reduction in the volume of rubber occluded within the agglomerates. During dispersive mixing, there are several factors that have an effect on the rate of dispersive mixing. At a fixed filler loading, a faster rate is obtained by increased polymer-filler interactions and batch temperature ${ }^{9}$. In the initial stage of carbon black incorporation, agglomerates are encapsulated by the rubber. Then, rubber is forced into the interstices within agglomerates and aggregates. Bound rubber is formed introducing an immobilized rubber layer around the aggregates ${ }^{10}$. In Zone III, the addition of the remaining $1 / 3$ carbon black and oil again increased the mixing torque which later steadily decreased after the dispersion of carbon black and the oil plasticization of the rubber. 

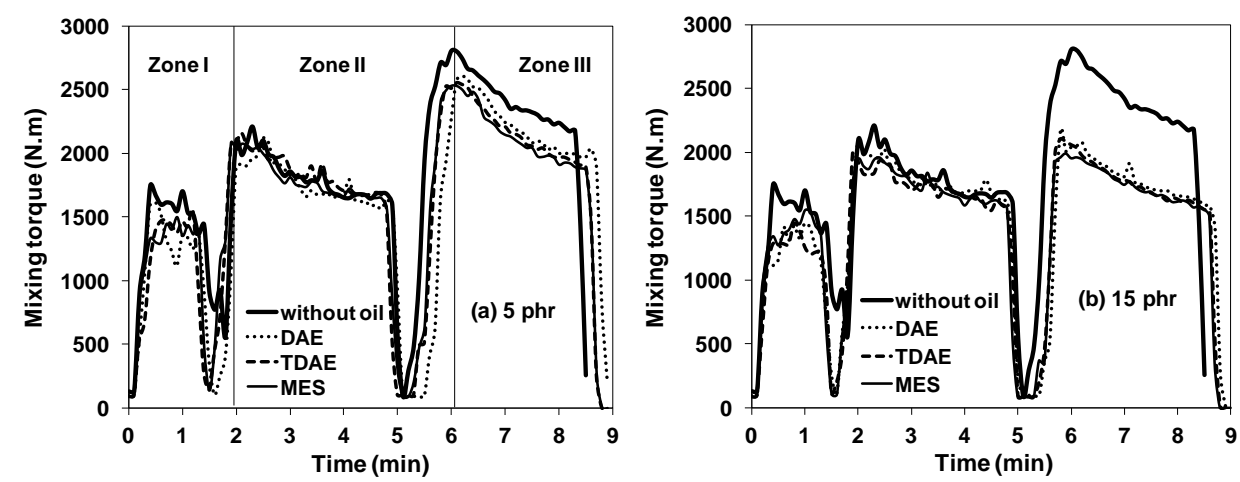

Figure 7.1 Mixing torques of HAF-filled NR/SBR masterbatches with (a) $5 \mathrm{phr}$ and (b) $15 \mathrm{phr}$ of various oil types.
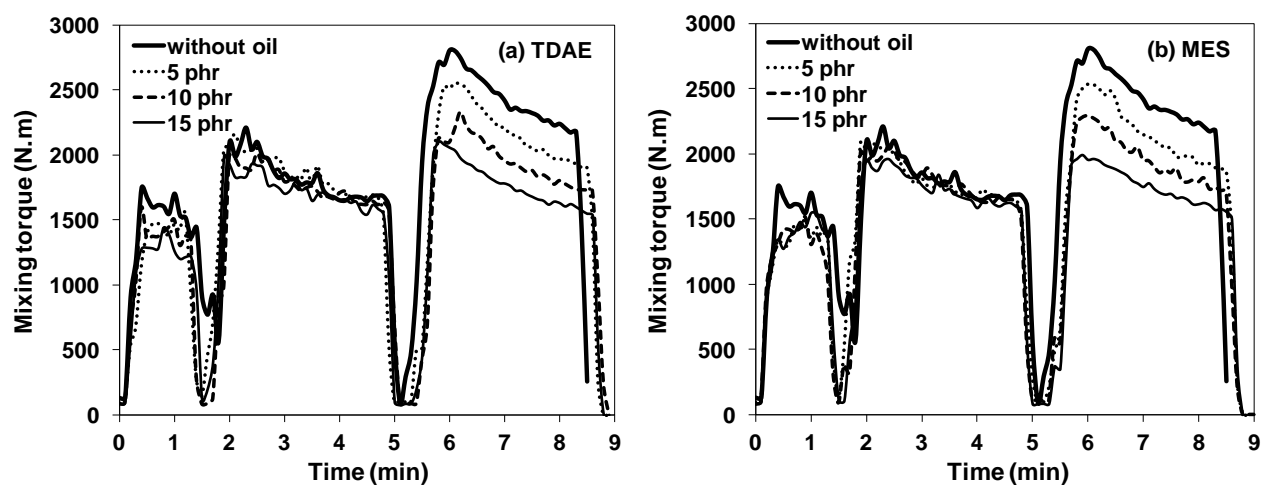

Figure 7.2 Mixing torques of HAF-filled NR/SBR masterbatches with varying contents of (a) TDAE oil and (b) MES oil

At the same oil loading, i.e. 5 phr in Figure 7.1(a) and 15 phr in Figure 7.1(b), the blend compounds with different oil types show very similar mixing torques. When compared with the unplasticized compound, the incorporation of oil in Zone III clearly decreases the mixing torque and the difference is obviously larger when the oil loading is increased. The blend masterbatches show a decrease of mixing toques consecutive with increasing oil loading, as observed in Zone III in Figure 7.2.

The dump temperatures of the blend masterbatches are summarized in Table 7.2. The mixing of rubber with filler but without oil leads to the highest batch temperature as a result of viscous heating. The dump temperatures of the masterbatches were reduced by the addition of oil and increasing oil loading due to the plasticization effect, which caused lower viscosities, thus lower shearing forces and heat generation. At the same oil loading, the 
masterbatches with different oil types show very similar dump temperatures in which the mixes with DAE oil are $1-2^{\circ} \mathrm{C}$ higher than the compounds with TDAE and MES.

Table 7.2 Dump temperatures of NR/SBR blend masterbatches.

\begin{tabular}{ccccc}
\hline \multirow{2}{*}{$\begin{array}{c}\text { Oil contents } \\
(\text { phr })\end{array}$} & without oil & DAE & TDAE & MES \\
\cline { 2 - 5 } & 158 & - & - & - \\
5 & - & 153 & 152 & 150 \\
10 & - & 144 & 143 & 143 \\
15 & - & 137 & 137 & 136 \\
\hline
\end{tabular}

\subsubsection{Viscosities and cure characteristics of the compounds}

Change of oil contents has a larger effect on the Mooney viscosities of the NR/SBR compounds than change of oil types, as displayed in Figure 7.3. Increasing the oil loadings to 10 and $15 \mathrm{phr}$ clearly reduces the Mooney viscosities of the compounds due to plasticization and lubrication effects, whereas the masterbatches with 5 phr of DAE- and TDAE-oils show similar Mooney viscosities and the one with MES-oil shows a higher value when compared with the compound without oil. As mentioned in Chapter 6, the difference in compound viscosities may be related to the level of filler dispersion, interactions between filler and rubber, and the relative solubility between oils and rubber. Better rubber-oil compatibility and filler dispersion results in lower compound viscosities ${ }^{6}$. For the rubber-oil combinations studied, DAE-oil has a better compatibility with both NR and SBR rubbers than the TDAE- and MES-oils, as evidenced by the smallest difference in solubility parameter $(\Delta \delta)$ between rubber and oils at high temperature $\left(\geq 100^{\circ} \mathrm{C}\right)$ : Table 4.3. Therefore, the use of DAE-oil should give better filler dispersion and lower compound viscosity than the use of TDAE and MES, respectively. The phenomenon of increased Mooney viscosity at 5 phr oil loading is similar to what was observed for the HAF-filled NR compounds, in Chapter 6, but the differences of Mooney viscosities of the compounds without oil and with 5 phr of oil are smaller in the blend that has SBR as a component. SBR is not sensitive to mastication unlike NR. In the absence of plasticizing oil, NR was masticated under high shearing forces into shorter polymer chains. The incorporation of $5 \mathrm{phr}$ of oil facilitates chain flexibility and reduces the break-down of the NR molecules. The possible difference in molecular weight of NR in the blends without oil and with oil therefore has an effect on compound viscosity. At higher oil loadings, the dilution effect prevails and the compound viscosities are substantially reduced. 


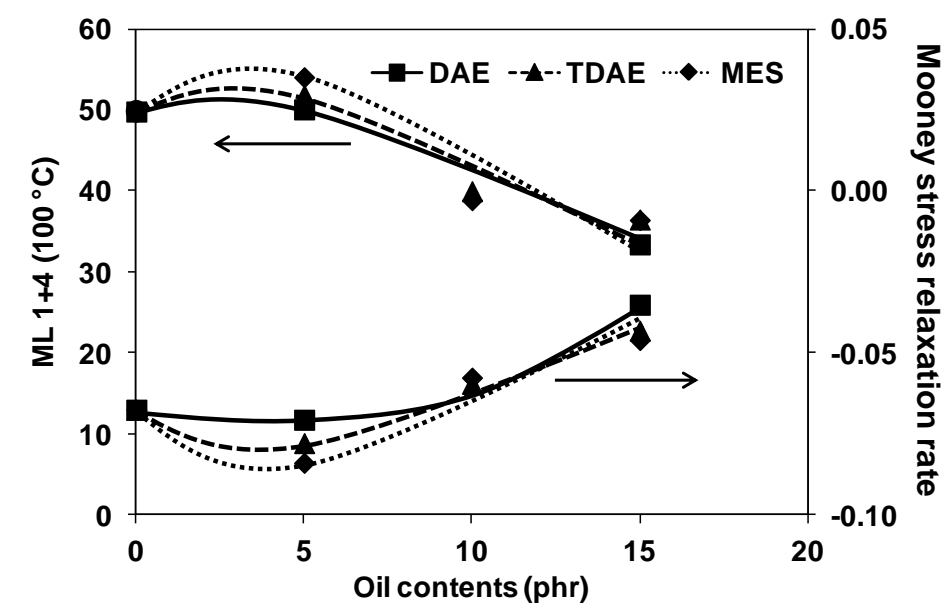

Figure 7.3 Mooney viscosities and Mooney stress relaxation rate of HAF-filled NR/SBR compounds with varying amounts of DAE-, TDAE- and MES-oils.

The Mooney stress relaxation rate can be used to describe the elastic vs. viscous response in the uncured compounds. A higher decay rate means a higher ratio of the viscous over elastic response and a lower uncured rubber elasticity ${ }^{11,12}$. The NR/SBR blends consisting of different oil types and loadings show the same trends of Mooney stress relaxation rate as those of the filled-NR compounds: Figures 7.3 vs. 6.3. Carbon black filled NR/SBR compounds with DAE-oil tend to have a lower rate of decay especially at $5 \mathrm{phr}$, where the decay rate may be ranked according to the oil types as follows: MES > TDAE > DAE. This difference is again due to the rubber/oil compatibilities. DAE-oil is more compatible with both of NR and SBR rubbers than the other two oils, so the wetting by oil of the rubber molecules is better and the rubber chains move easier. So, the use of DAE-oil provides a larger elastic/viscous ratio of the uncured compounds. Increasing oil contents tend to give lower stress relaxation rates of the NR/SBR compounds, indicating increased uncured elasticity in the presence of the oils. A faster rate of decay of the compounds with 5 phr of oil is observed, when compared with the unplasticized compound. As discussed previously for the Mooney viscosity itself, the same mechanistic arguments apply.

The complex viscosity $\eta^{*}$ versus oscillating frequency of the NR/SBR-filled compounds with 15 phr of oils is shown in Figure 7.4 (a) as a typical example. The complex viscosities of all the blend compounds are decreased with increasing frequency, indicating the large shear-thinning behavior of the materials. When compared with the compound without oil, the presence of the oils at $15 \mathrm{phr}$ clearly reduces the complex viscosity of the NR/SBR compounds, and all the oil types show similar behavior. At $0.5 \mathrm{~Hz}$, the compounds 
with DAE have a higher complex viscosity than that of the compounds with TDAE and MES: Figure 7.4 (b), which show more or less the same values. The increasing oil contents reduce the complex viscosities of these blend compounds much like for the filled-NR. Moreover, the shapes of the complex viscosity curves at different oil loadings look similar to the Mooney viscosity curves in Figure 7.3. The compounds with DAE have the highest complex viscosity but the lowest Mooney viscosity. The different trend of Mooney viscosity and complex viscosity might be attributed to their totally different range of shear rate applied during the tests and their different deformation levels, as previously discussed in Section 6.3.2.

The complex viscosity curves at varying frequencies and at different oil loadings of the NR/SBR compounds show similar patterns as those of the filled pure SBR compounds: Figure 7.5, and quite different from those of the filled-NR compounds: Figure 6.4. With 15 phr of the oils, the complex viscosities of the filled-NR/SBR and filled-SBR compounds are reduced to a greater extent compared with the filled-NR compounds.
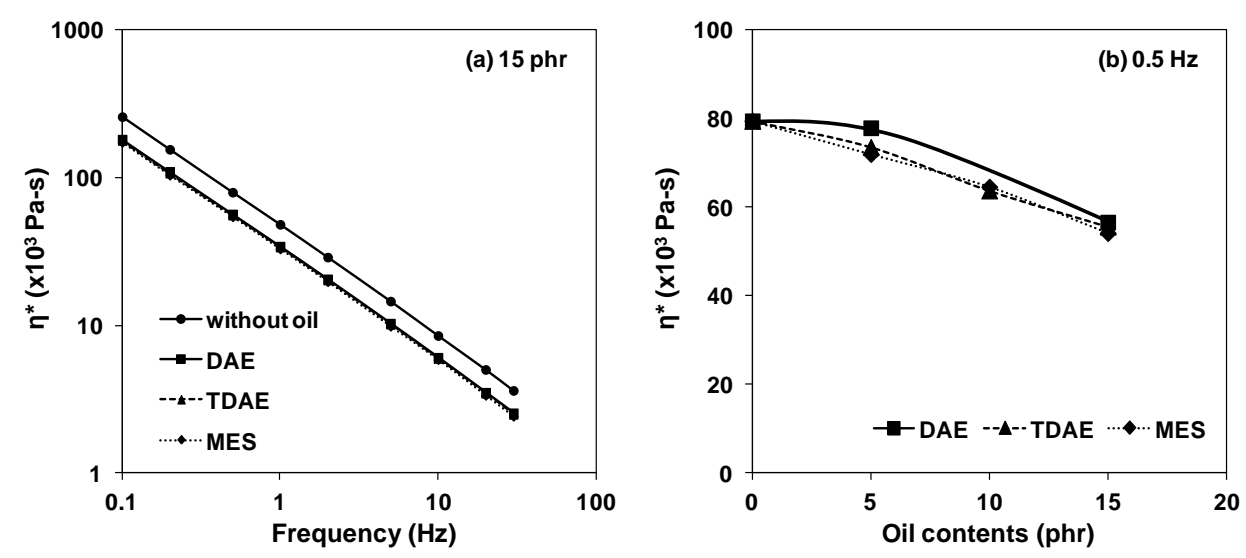

Figure 7.4 Complex viscosities of HAF-filled NR/SBR compounds with different oil types: (a) at varying frequencies with $15 \mathrm{phr}$ of oil; (b) with different oil contents at $0.5 \mathrm{~Hz}$, both at $7 \%$ strain and $100^{\circ} \mathrm{C}$. 

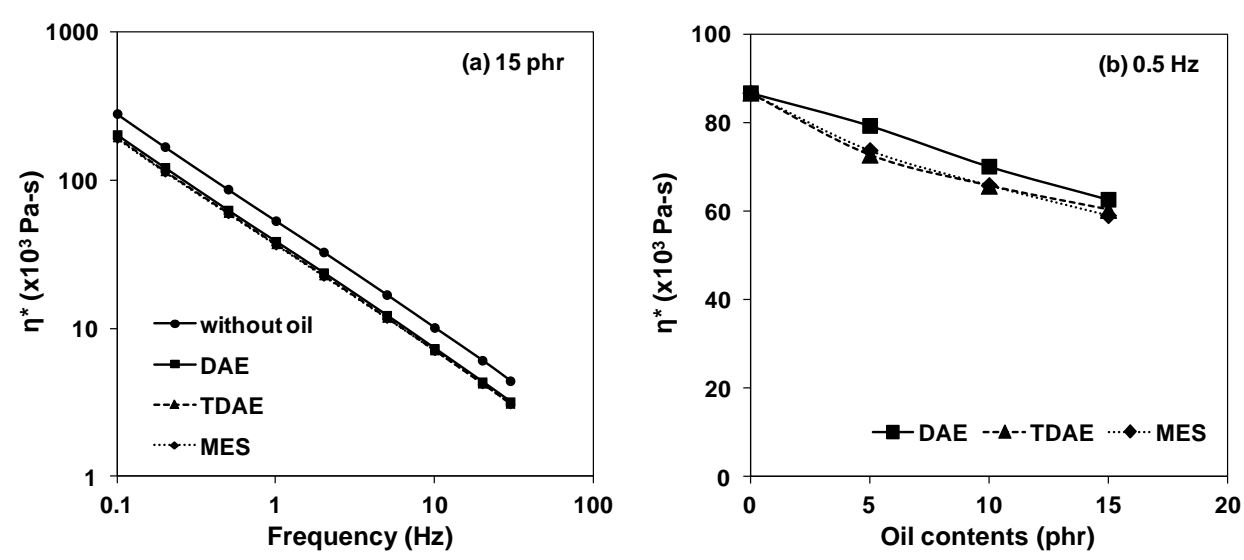

Figure 7.5 Complex viscosities of HAF-filled SBR compounds with different oil types: (a) at varying frequencies with $15 \mathrm{phr}$ of oil; (b) with different oil contents at $0.5 \mathrm{~Hz}$, both at $7 \%$ strain and $100^{\circ} \mathrm{C}$.
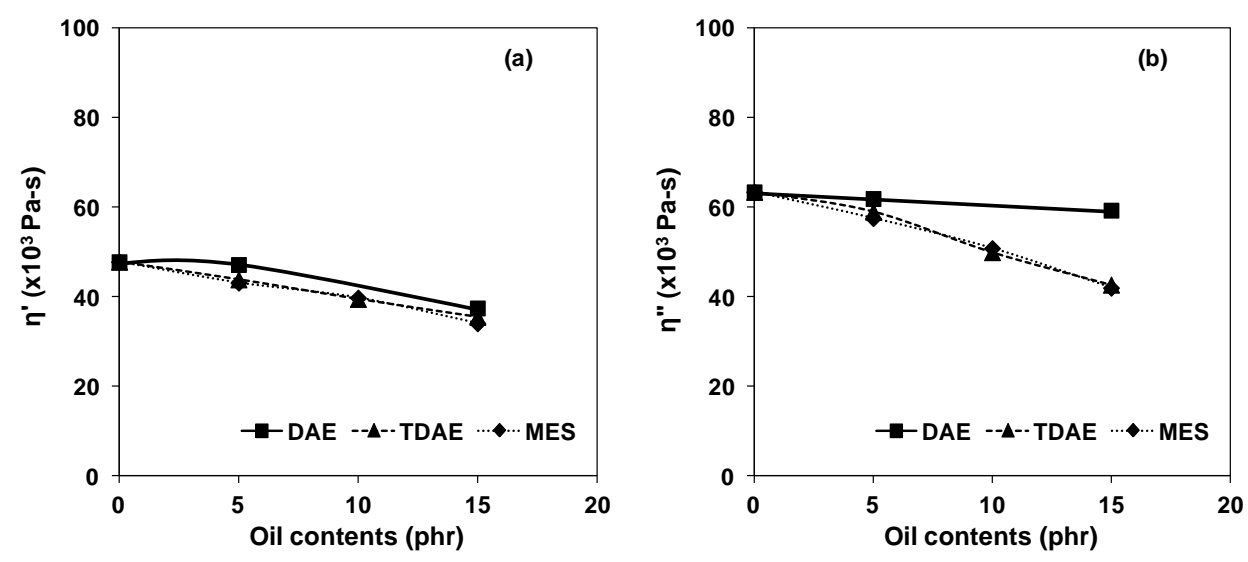

Figure 7.6 Real (a) and imaginary (b) parts of complex viscosities at $0.5 \mathrm{~Hz}$ of HAF-filled NR/SBR blend compounds with different oil types and contents.

As previously discussed in Chapter 6 that the complex viscosity of the materials consists of the real $\left(\eta^{\prime}\right)$ and imaginary $\left(\eta^{\prime \prime}\right)$ parts, in which the real component relates to the rate of energy dissipation and the imaginary part indicates the elastic behavior, it is clearly seen in Figure 7.6 that the addition of oils into the blend compounds again contributes more to the elastic component like in the case of the filled NR-compounds. A significantly higher $\eta "$ of the blend with DAE-oil compared to the ones with TDAE and MES indicates a stronger elastic response of this blend in the uncured state. The stronger elasticity of the uncured DAE-plasticized NR/SBR compounds is in accordance with the result of Mooney stress 
relaxation which is also a property triggered more by the elastic than the viscous component of the viscoelastic spectrum of the material: Figure 7.3.

The differences in the complex viscosities $\left(\Delta \eta^{*}\right)$ at 0.5 and $30 \mathrm{~Hz}$ of the plasticized NR/SBR-filled compounds compared with the unplasticized one are shown in Figure 7.7. All the compounds show a decrease of the complex viscosities compared to the one without oil at both frequencies due to the increase of chain mobility and free volume between the rubber molecules. The change of $\Delta \eta^{*}$ with oil loadings of the filled-NR/SBR compounds is quite different from what was previously observed for the filled-NR compounds: Figure 6.6, but more resemble the behavior of filled-SBR compounds as displayed in Figure 7.8. This difference underlines the mastication effect in the NR compounds that plays a role in processing properties, while the NR/SBR (50/50 weight ratio) and SBR compounds are much less or not sensitive to mastication. In relation to the compound without oil, the mixes with DAE-oil show the smallest reduction in complex viscosities, whereas the TDAE- and MES-oils give very similar $\Delta \eta^{*}$. DAE-oil has a better compatibility with NR and SBR than the TDAE- and MES-oils. Carbon black dispersion is also expected to be best in the presence of DAE-oil. Under dynamic deformation, the compounds with DAE therefore exhibit a higher elastic response from interactions between the various components. The TDAE- and MESoils that have a lower rubber-oil compatibility exhibit more a viscous nature of the oils and the compounds therefore show a larger reduction in complex viscosity. At higher frequency, the $\Delta \eta^{*}$ is much smaller due to the shear thinning of the rubber compounds.
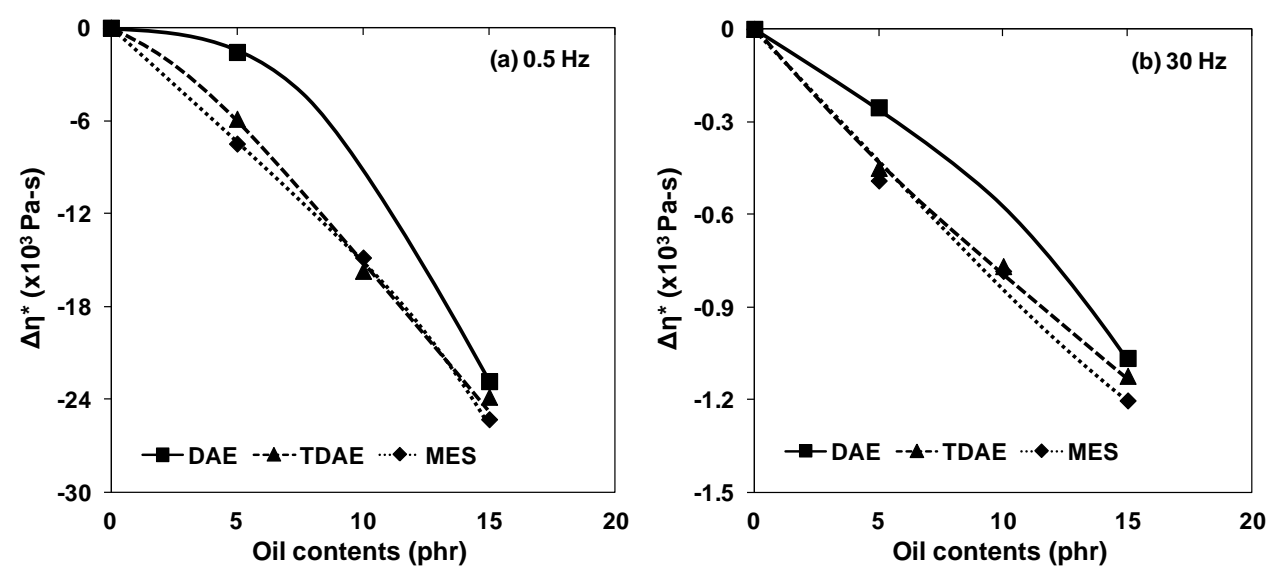

Figure 7.7 Differential complex viscosities as functions of oil contents of HAF-filled NR/SBR compounds with different oil types at (a) $0.5 \mathrm{~Hz}$ and (b) $30 \mathrm{~Hz}$, at $7 \%$ strain and $100^{\circ} \mathrm{C}$. 

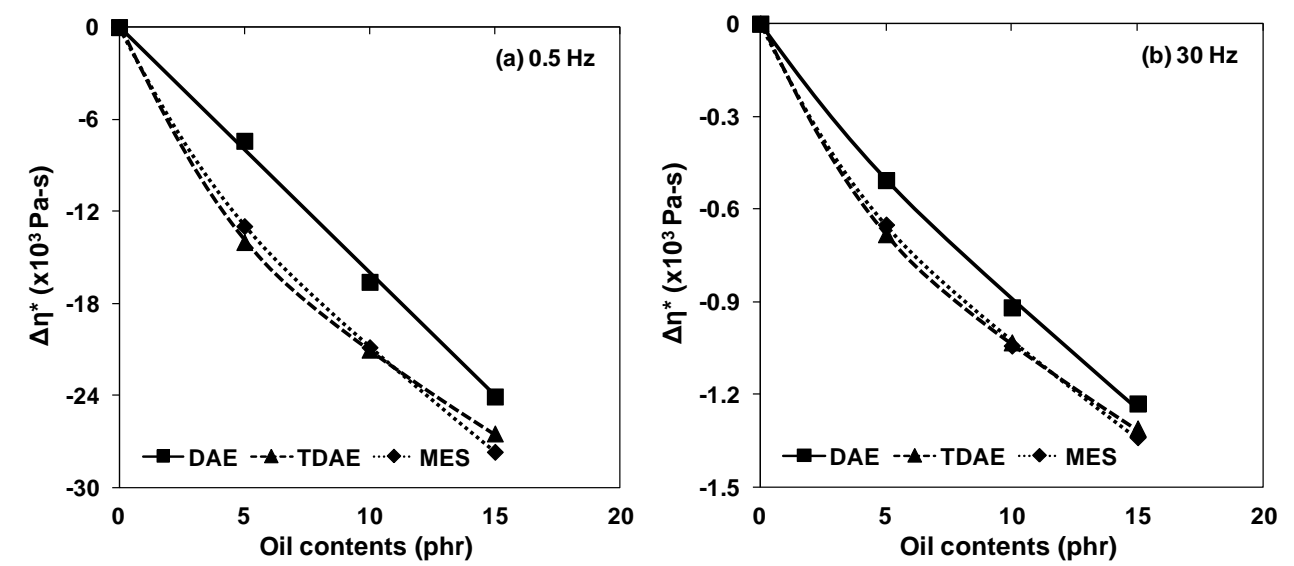

Figure 7.8 Differential complex viscosities as functions of oil contents of HAF-filled SBR compounds with different oil types at (a) $0.5 \mathrm{~Hz}$ and (b) $30 \mathrm{~Hz}$, at $7 \%$ strain and $100^{\circ} \mathrm{C}$.

Figure 7.9 shows the minimum cure torque $M_{L}$ and the torque difference $\left(M_{H}-M_{L}\right)$ of the NR/SBR-filled compounds as functions of oil loadings. Minimum cure torques may be taken as indicative for the viscosities of the blend compounds with different oil types and loadings, and are best in agreement with the results of complex viscosity: Figure 7.4 (b), as previously discussed. The torque difference, that can be related to the level of cure or crosslink density, decreases with increasing oil contents because of the dilution and plasticization effects of the oils on the rubber and the compounding ingredients ${ }^{6}$. Among the three oil types studied, the compounds with DAE show the highest torque difference while TDAE and MES give more or less the same values. The better compatibility of DAE and rubbers leads to better carbon black dispersion and interactions between the phases. Furthermore, DAE oil contains nitrogen-and sulfur-heterocyclic compounds that can additionally accelerate the cure, as previously discussed in Chapter 5, Section 5.3.1. Therefore, the DAE-containing filled-blend compounds show the highest torque increase. 


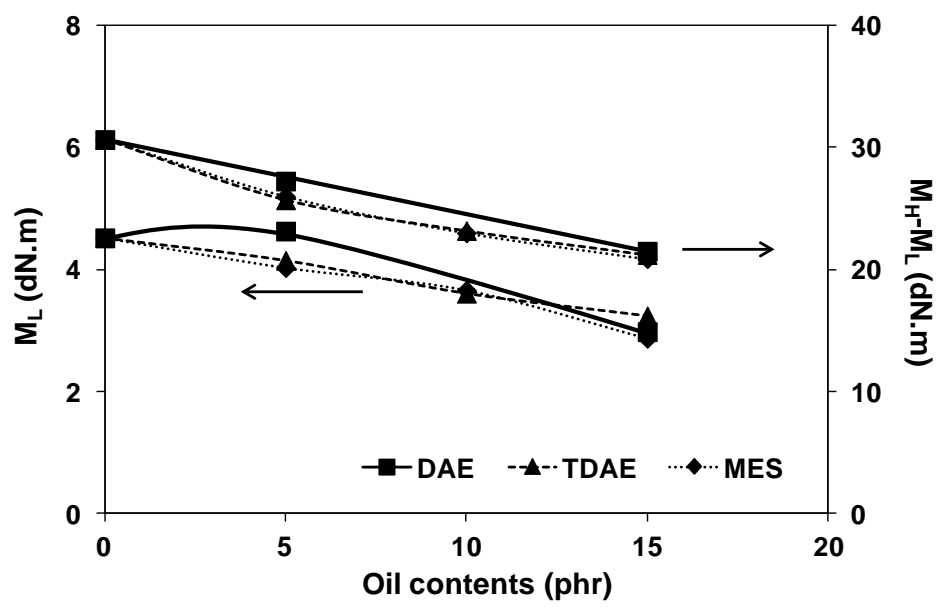

Figure 7.9 Minimum torque and torque difference of HAF-filled NR/SBR compounds with varying amounts of DAE-, TDAE- and MES-oils.

Typical cure curves of the NR/SBR-filled compounds with 5 and 15 phr of oils are shown in Figure 7.10, and their cure rate indices at varying oil loadings are shown in Figure 7.11. The incorporation of oils in the filled-blend compounds even at low oil content, i.e. 5 phr, clearly reduces the cure maximum torques $\left(\mathrm{M}_{\mathrm{H}}\right)$ which is quite different from the results observed in filled-NR compounds: Figure 6.8. Scorch and cure times of the filled-blend compounds are prolonged with increasing oil loadings, as shown in Figure 7.10, while the cure rate indices of these compounds are slightly reduced as displayed in Figure 7.11. This is owing to the dilution effect of the oils. The DAE added compounds show slightly higher $\mathrm{M}_{\mathrm{H}}$ in the cure curves at both 5 and 15 phr in accordance with the torques differences in Figure 7.9. However, the different oil types result in insignificant difference in the cure rate indices.

The dilution effect of the oils on cure characteristics without interference from the mastication effect of NR can best be seen from the cure properties of HAF-filled pure SBR compounds in Figures 7.12 and 7.13. The addition of oil into pure SBR-filled compounds clearly results in reduction of minimum cure torque and torque difference as shown in Figures 7.12 (a) and Figure 7.13, respectively. There is no significant difference of cure behaviors between the oil types. The use of oils to plasticize SBR-filled compounds also causes very little change in the cure rate indices, as shown in Figure 7.12(b), due to the lower reactivity of SBR towards the nitrogen- and sulfur-containing heterocyclic compounds in the DAE oil as previously seen in Figure 5.6 for unfilled NR compounds and Figure 6.9 for HAF-filled NR compounds. The retardation of cure by the presence of oils and increased oil 
contents is also clearly seen in Figure 7.13, like the case of NR/SBR compounds: Figure 7.10 .
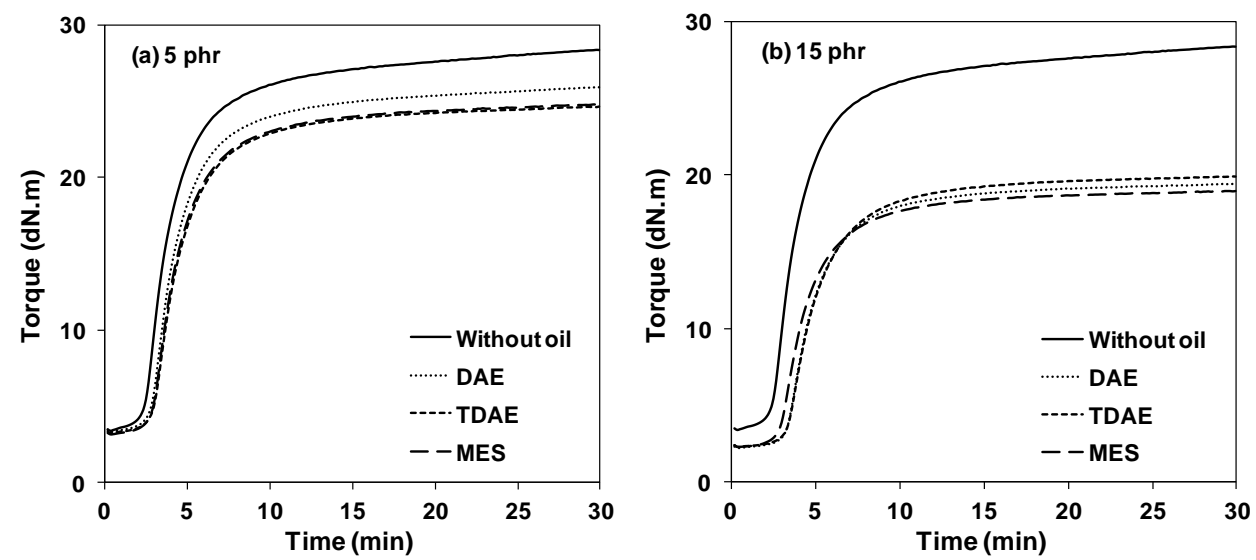

Figure 7.10 Typical cure curves of HAF-filled NR/SBR compounds with DAE-, TDAE- and MES-oils at (a) 5 phr, and (b) 15 phr.

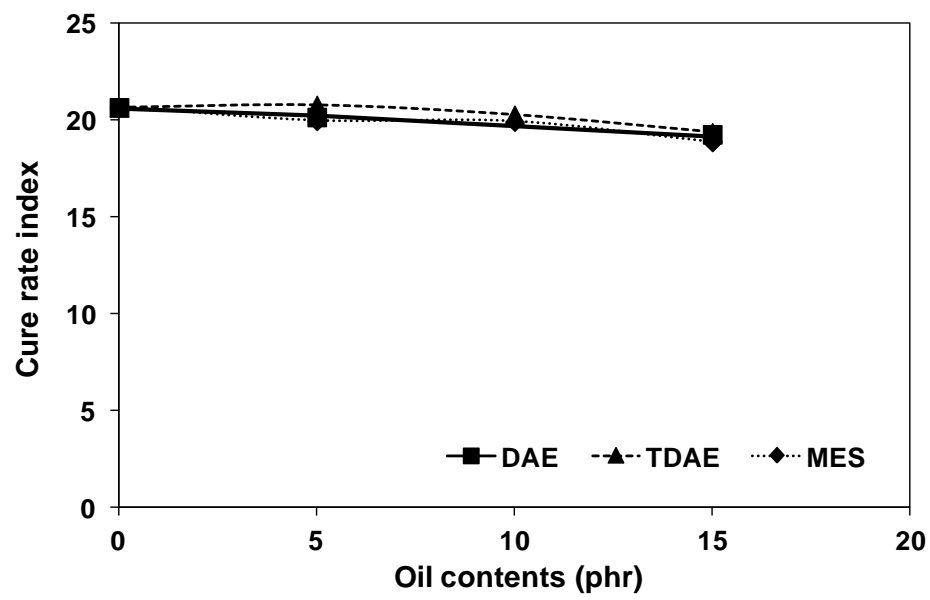

Figure 7.11 Cure rate indices of HAF-filled NR/SBR compounds with varying amounts of DAE-, TDAE- and MES-oils. 

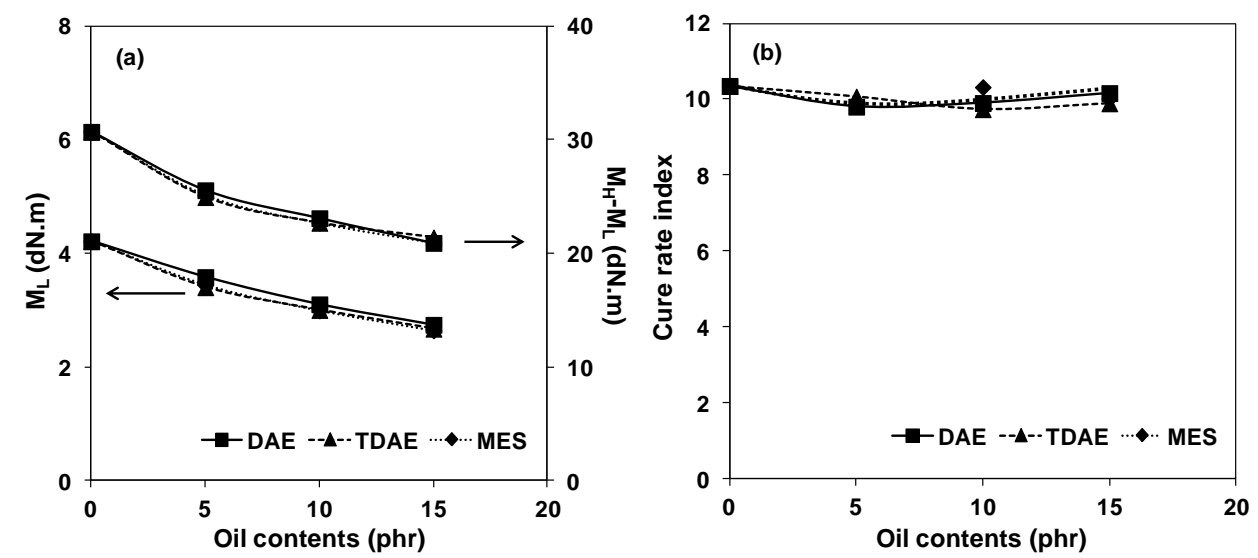

Figure 7.12 Cure characteristics of HAF-filled SBR compounds with varying amounts of

DAE-, TDAE- and MES-oils: (a) Minimum torque and torque different, and (b) cure rate indices.
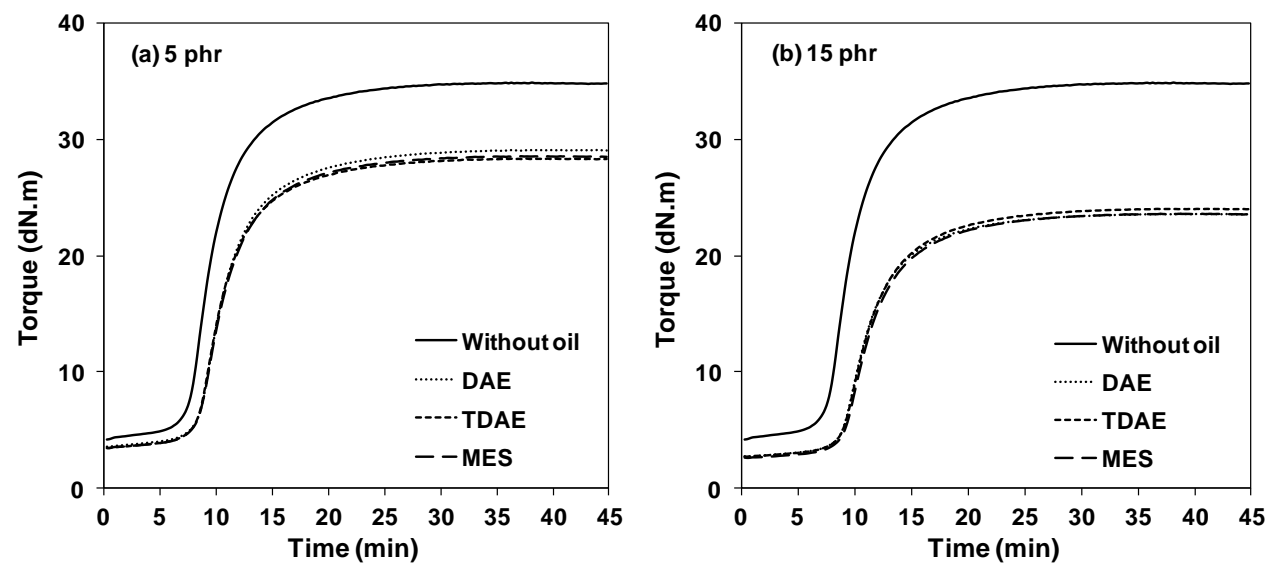

Figure 7.13 Typical cure curves of HAF-filled SBR compounds with DAE-, TDAE- and MESoils at (a) $5 \mathrm{phr}$, and (b) $15 \mathrm{phr}$.

\subsubsection{Filler - filler interaction, bound rubber and filler dispersion}

The influence of oil types and contents on the reduction of storage modulus G' with increasing strain of the filled-NR/SBR masterbatches, without curatives is shown in Figure 7.14 , in comparison with that of the masterbatch without oil. The addition of 5 phr of oil into the filled-blend masterbatches clearly introduces a softening effect with growing influence when the oil content is increased, as observed by a large decrease of the storage modulus of the masterbatches with 15 phr of oils in Figure 7.14 (b). The filled masterbatches with 
DAE-oil show a higher storage modulus at low strain compared with the mixes with TDAE and MES. This is in agreement with the difference in storage moduli $\Delta G^{\prime}$ at low and high strains, i.e. $G^{\prime}(0.56 \%)-G^{\prime}(100 \%)$ of the masterbatches with various oil loadings, as shown in Figure 7.15. The results show that DAE-oil gives the highest Payne effect, i.e. filler-filler interactions, followed by TDAE- and MES-oils, respectively. The Payne effects of these masterbatches are decreased with increasing oil content, indicating a decrease of filler-filler interactions due to the presence of the oils between the rubber molecules and carbon black particles/aggregates. However, the absolute differences in Payne effect between the three oil types increases with larger oil loadings. As determined by the difference in solubility parameters of rubber and oils, $\Delta \delta$ in Table 4.3, DAE-oil has a better compatibility with both NR and SBR rubbers in the mixing temperature range than the TDAE- and MES-oils. Therefore, DAE-oil can diffuse in between the rubber molecules and swell the rubber to a greater extent, leaving less oil located in the rubber-filler interface and between the filler aggregates. The filler-filler interaction is therefore higher in the case of DAE-plasticized masterbatches. Moreover, the DAE-oil that can dissolve and swell the rubber to the greater extent than the other oils results in lower Mooney viscosity: Figure 7.3 and lower shearing forces during mixing, causing less disruption of the filler-filler interactions. MES-oil which has the lowest compatibility with the rubbers moves to interstices in between the filler particles/aggregates, facilitates the filler dispersion, reduces the interactions between the filler aggregates/agglomerates, and so lowers the storage modulus especially at low strain.

Increasing oil contents decrease the contact between filler aggregates / agglomerates and so leaves less interactions between them. The reduction of the Payne effect with increasing oil content in the NR/SBR-filled compounds is sharper when compared to that of the NR-filled compounds, as seen in the previous chapter. This difference may be related to their rubber-oil compatibility levels. As shown in Table 4.6, at the temperatures of $100^{\circ} \mathrm{C}$ and $140^{\circ} \mathrm{C}, \mathrm{SBR}$ has a larger $\Delta \bar{\delta}$, i.e. is less compatible with the oils. To elucidate the effect of rubber-oil compatibility on filler-filler interactions, the Payne effects of filled pureSBR masterbatches were also studied and the results are shown in Figure 7.16. DAE-oil again gives the highest Payne effect at every oil contents, while the TDAE- and MES-oils show similar levels. The increasing oil content decreases the Payne effect of the masterbatches as a result of the dilution effect. On comparing the values of the Payne effect over the entire range of oil contents studied, the filled-SBR compounds show the lowest values of $\Delta G^{\prime}$, followed by the filled NR/SBR blends and filled-NR compounds, respectively. 

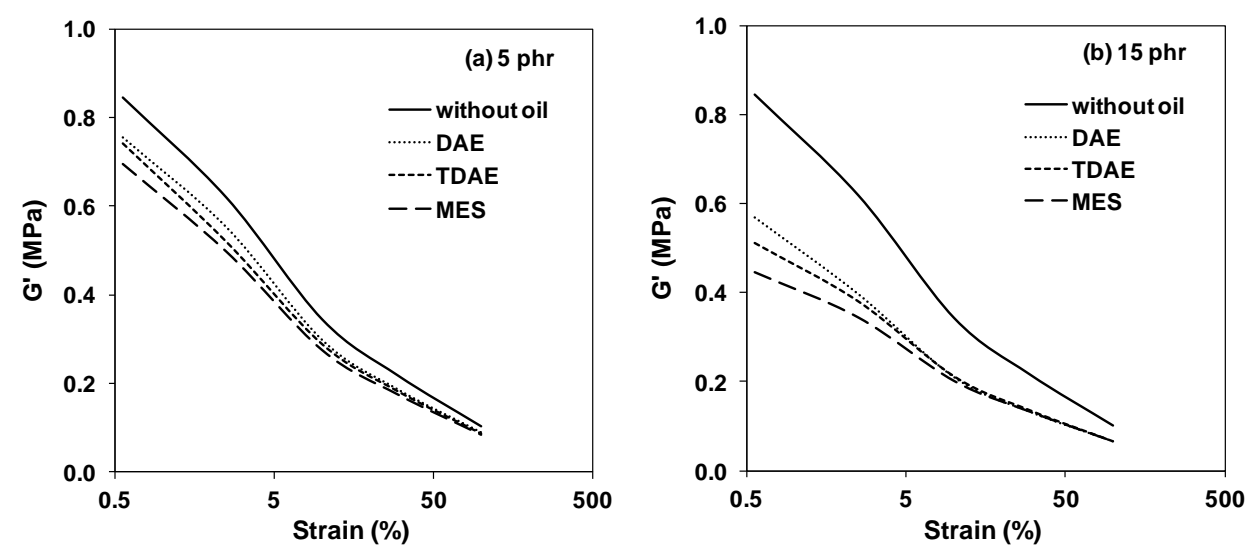

Figure 7.14 Storage moduli as a function of strain of HAF-filled NR/SBR masterbatches with (a) 5 phr, and (b) 15 phr of various oil types.

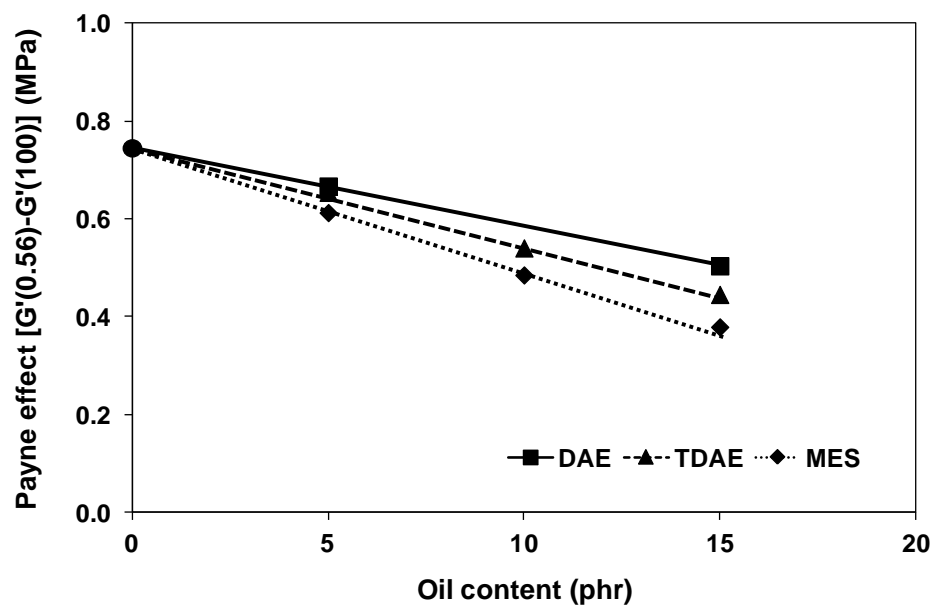

Figure 7.15 Payne effects of HAF-filled NR/SBR compounds with various oil types and amounts. 


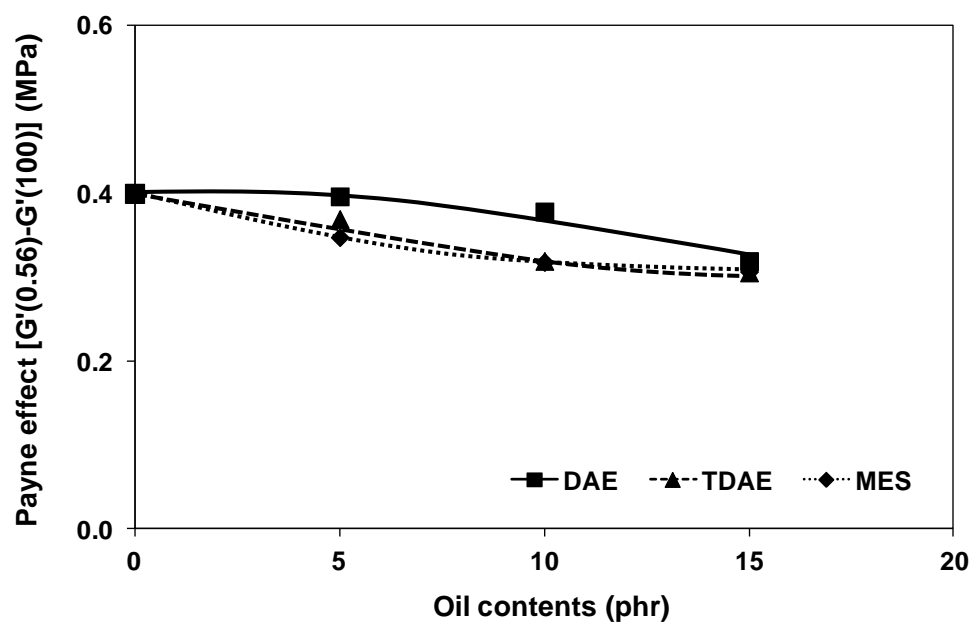

Figure 7.16 Payne effects of HAF-filled SBR compounds with various oil types and amounts.

Bound rubber content is a commonly used parameter for determining the fillerrubber interaction ${ }^{13-15}$. The bound rubber contents of the uncured filled-NR/SBR compounds as functions of oil loadings are displayed in Figure 7.17. Increasing of oil loading gradually reduces the bound rubber contents of the compounds, but the bound rubber content is insignificantly influenced by the types of oils. When comparing the bound rubber contents of filled-NR and filled-SBR compounds, as shown in Figure 7.18, the filled-SBR compounds clearly have lower bound rubber contents, i.e. lower filler-rubber interactions, than the filledNR compounds. The values of the blend compounds lie in between those of the filled-NR and -SBR individual counterparts, where the results of the blends are closer to the properties of the filled-SBR compounds. The bound rubber content is shown to depend on the degree of unsaturation in the rubbers, in which more saturated rubber shows less bonding to the same type of carbon black than unsaturated rubber ${ }^{16-18}$. As seen in Figure 7.18, NR that possesses a higher unsaturation than SBR shows a higher bound rubber content than SBR at a given carbon black loading. When compared with the unplasticized compound, the addition of oils remarkably decreases the bound rubber content for the filledSBR compounds, whereas the filled-NR and NR/SBR compounds show a narrower range of reduction in bound rubber content with increasing oil loading. This indicates a different level of interaction strength in NR and SBR because of their difference in chemical structure. In addition to their different unsaturation levels, the chain break-down of NR during mixing generates free radicals which may lead to strong interactions with the filler surface. The 
dependence of bound rubber content on the actual oil types shows a clear influence for filled-NR compounds only at high oil loadings, i.e. at 10 and 15 phrs: Figure 7.18 (a).

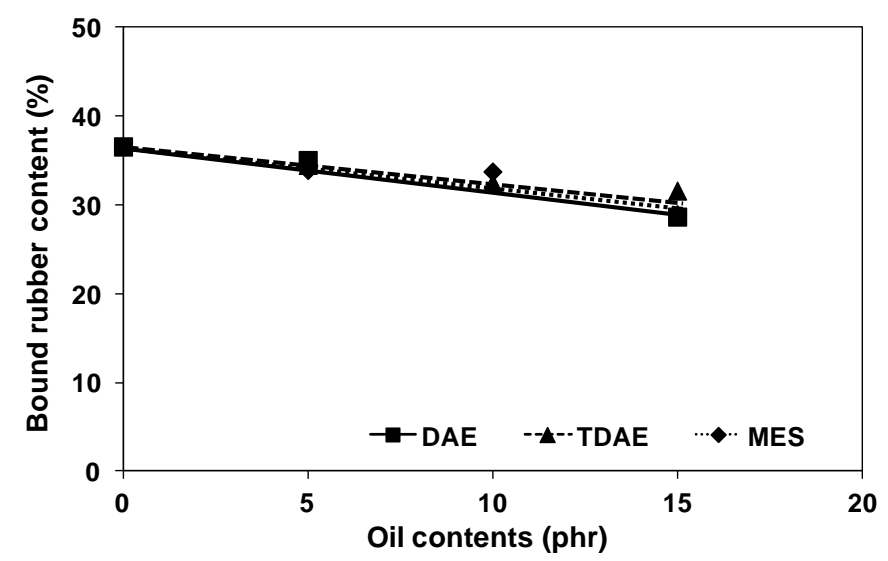

Figure 7.17 Bound rubber contents of HAF-filled NR/SBR masterbatches with various oil types and amounts.
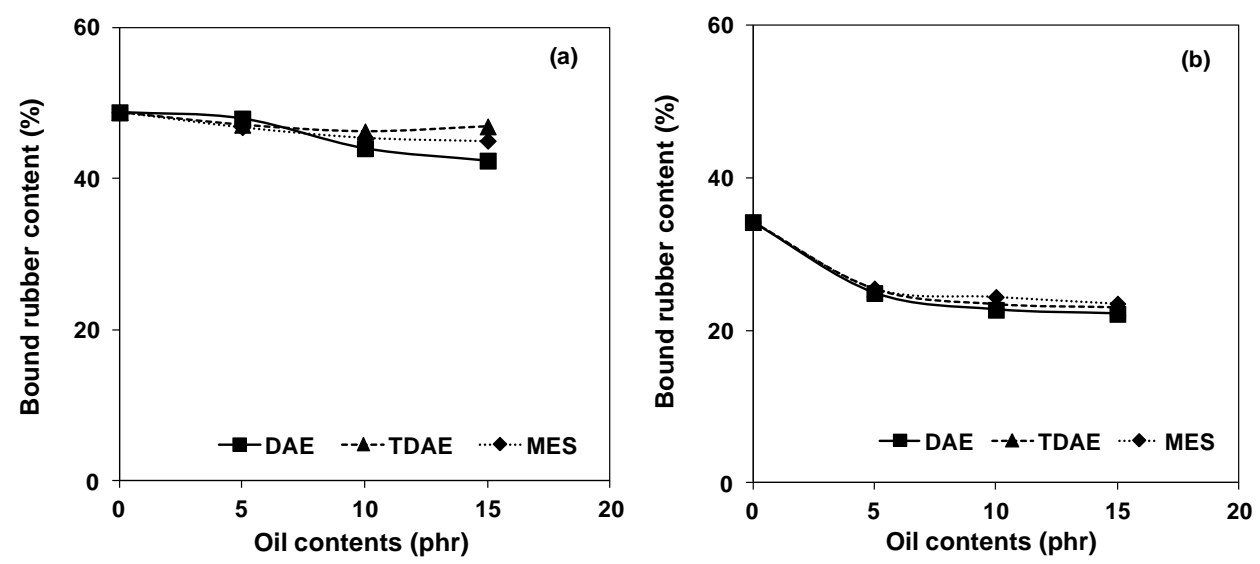

Figure 7.18 Bound rubber contents of HAF-filled NR (a) and SBR (b) compounds with various oil types and amounts.

The carbon black dispersion in filled-NR/SBR compounds was investigated by scanning electron microscopy (SEM); the SEM micrographs are presented in Figures 7.19 and 7.20. The addition of carbon black to the heterogeneous rubber blends encounters a difference in filler affinity in each rubber phase. It has been reported that NR/SBR is a heterogeneous blend and that the addition of carbon black to pre-blended rubbers leads to a higher concentration of black in the SBR phase, where SBR is the continuous phase in $50 / 50$ blends of NR/SBR ${ }^{19}$. The higher filler affinity of carbon black towards SBR over NR in 
blends of NR/SBR has been reported already in a number of works ${ }^{16,20-21}$. In addition to the uneven carbon black distribution in the NR and SBR phases, the diffusion of oil into each phase can be also different due to the difference in the compatibility between oils and rubbers. Even though the two phases cannot be seen in the SEM micrographs, it is observed that the carbon black is not homogeneously dispersed in the rubber matrix like in the case of NR: Figure 6.13. The area with higher concentration of carbon black may be implied to be the SBR phase. Considering the SEM micrographs of the blends with the same oil loadings of 15 phr in Figure 7.19, all of the compounds show a similar morphology except the one with MES-oil that shows clusters of aggregates and poorer carbon black dispersion. This is attributed to the lower compatibility of MES-oil with NR and SBR compared to the other two oil types.

The blends that contain MES at different oil contents also show slightly increasing inferior carbon black dispersions compared with the blend compound without oil, as shown in Figure 7.20. With increasing oil content, the dilution effect causes a reduction in filler fraction volume and filler-filler interactions between the aggregates/agglomerates, which is in accordance with a decrease of the Payne effect: Figure 7.15. For the MES-plasticized blend, the clusters of filler become clearer with increasing oil content. 

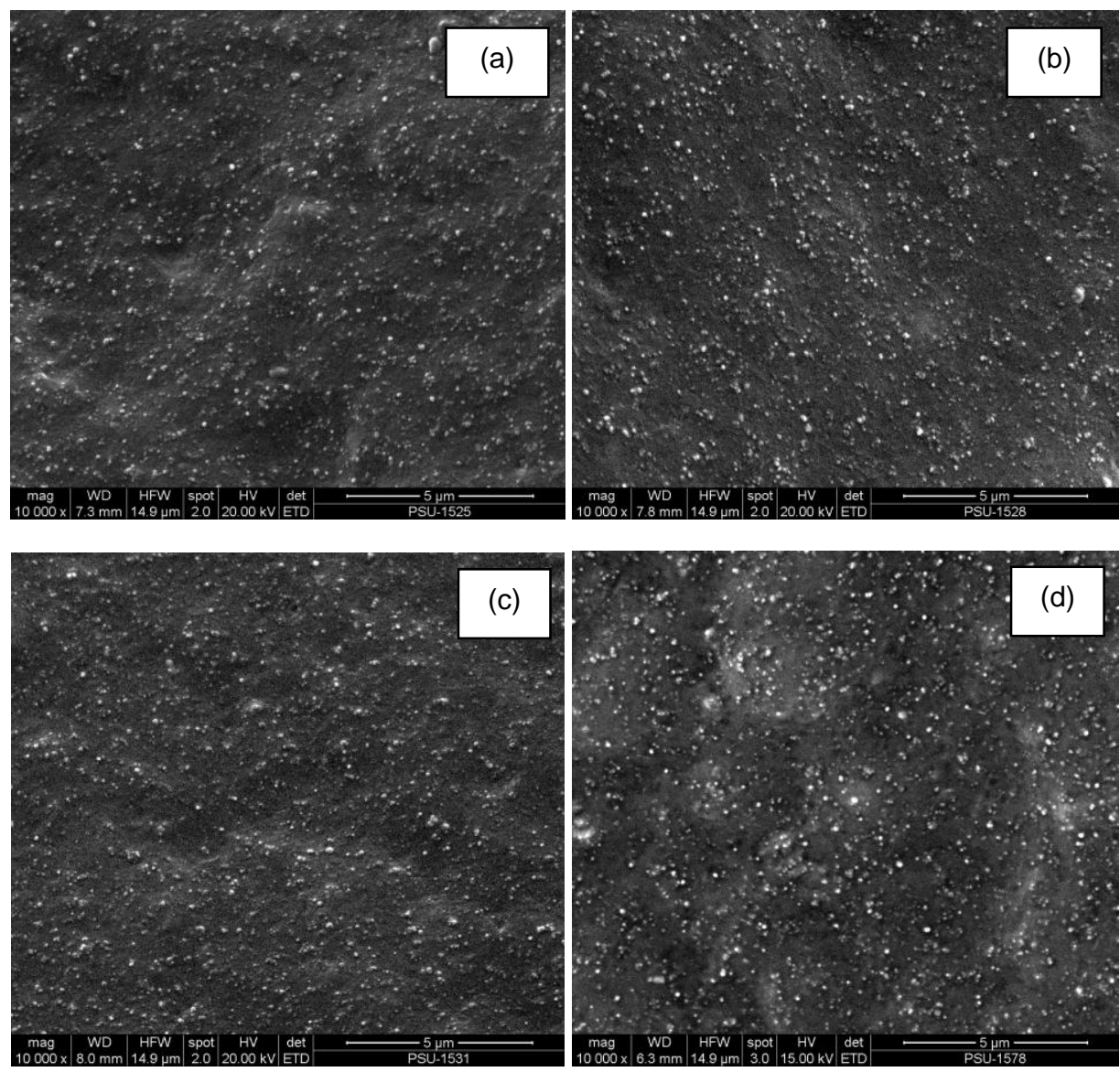

Figure 7.19 SEM images of HAF-filled NR/SBR compounds with various oils at 15 phr: (a) without oil; (b) DAE; (c) TDAE and (d) MES. 

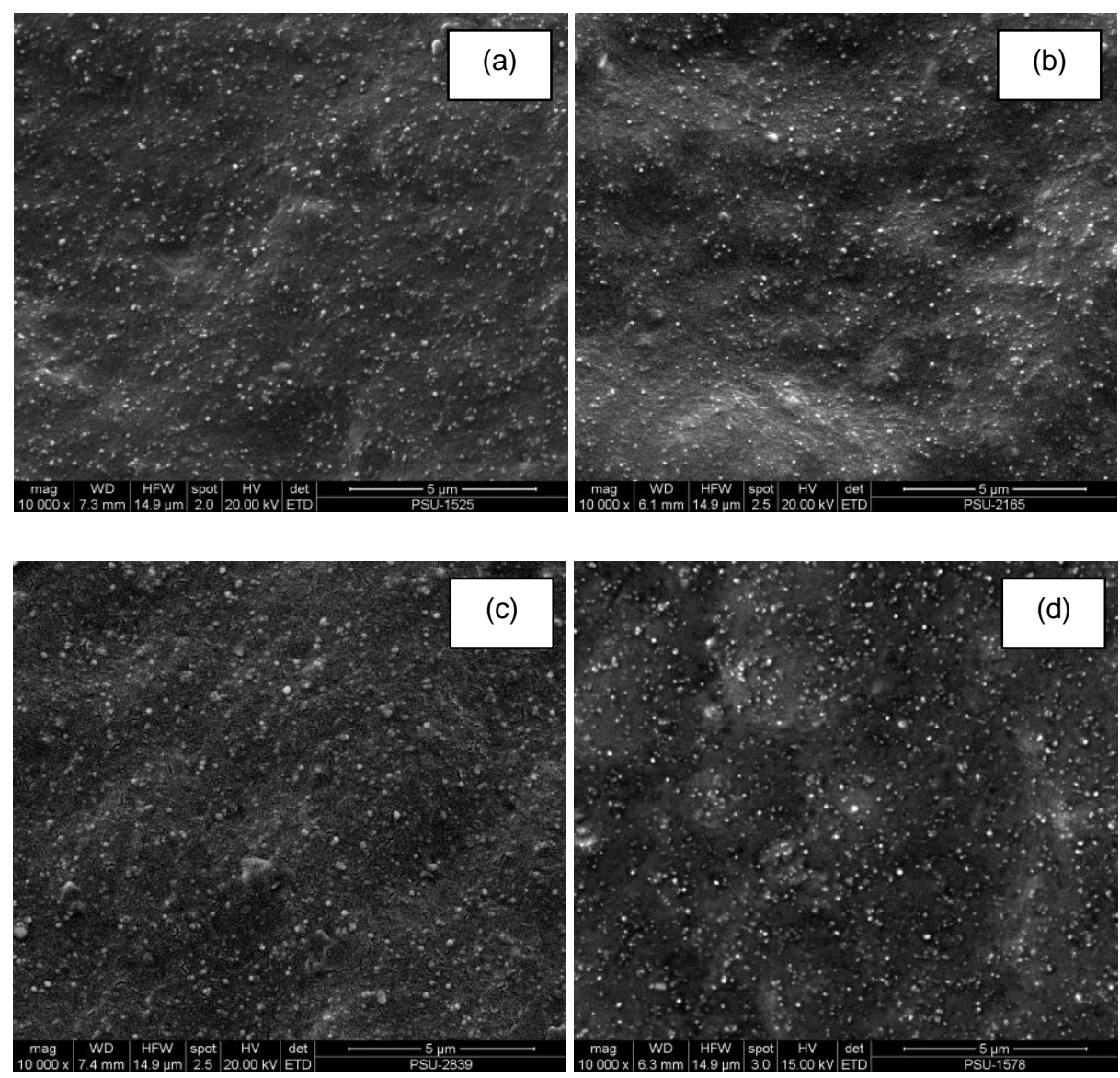

Figure 7.20 SEM images of HAF-filled NR/SBR compounds with MES oil at various contents: (a) without oil; (b) 5 phr; (c) 10 phr and (d) 15 phr.

\subsubsection{Vulcanizate properties}

\subsubsection{Mechanical properties}

The influences of the various oil types and contents on the mechanical properties of the carbon black filled-NR/SBR vulcanizates are shown in Figures 7.21 - 7.28. Hardness, $100 \%$ modulus and tensile strength, as displayed in Figures 7.21, 7.22 (a) and 7.23 (a) respectively, are gradually reduced by the increase of oil contents. Different oil types give more or less the same values of tensile strength at a given oil content, but result in some differences in hardness and $100 \%$ modulus. On the other hand, the reinforcement index and elongation at break of the blend vulcanizates tend to increase with increasing oil loadings, as shown in Figure 7.22(b) and 7.23(b). The presence of oils facilitates filler incorporation and filler dispersion as well as increases the rubber chain mobility. The addition of higher oil 
contents softens the vulcanizates and dilutes the contact points between polymer chains and filler aggregates, resulting in less resistance to deformation: i.e. lower hardness, modulus and strength, but higher ultimate strain. The results of hardness are in accordance with the reduction of rheometer torque differences with increasing oil contents as shown in Figure 7.9. Figure 7.21 shows that the hardness of filled-NR/SBR vulcanizates with DAE-oil is slightly higher than that of the vulcanizates with TDAE- and MES-oils. But, these DAEplasticized blend vulcanizates surprisingly show the lowest $100 \%$ modulus. The controversy of hardness and $100 \%$ modulus values of the DAE-containing compounds in relation to the oil types may relate to their different levels of deformation during the tests. For hardness tests, the specimens are deformed a little and so the filler networks as well as interactions are not much destroyed. The blend with DAE that has the highest Payne effect therefore shows the highest hardness. On the other hand, the elongated specimens at $100 \%$ strain where the filler network and physical interactions are practically totally disrupted, the DAE-oil that dissolves more in the rubber, can ease the movement of rubber chains resulting in a lower stress while being stretched. This also results in higher elongation at break of the DAE-containing compounds. The use of TDAE- and MES-oils gives blend vulcanizates of similar tensile properties.

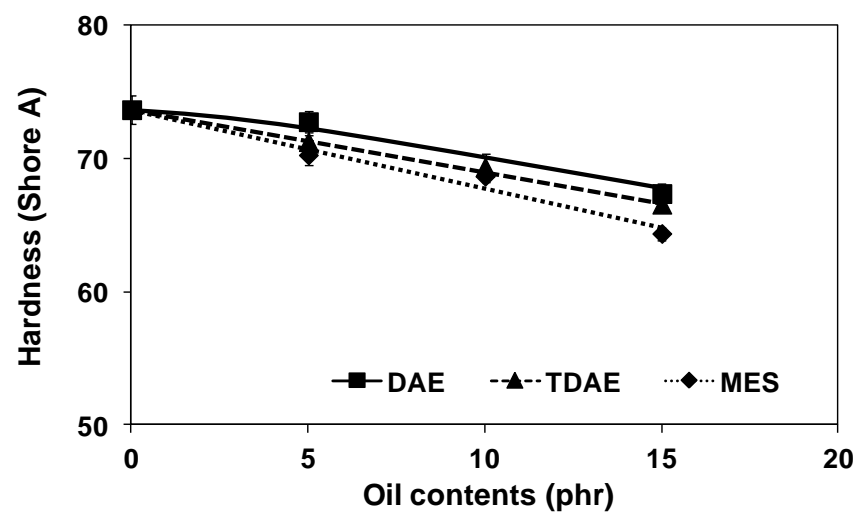

Figure 7.21 Hardness of HAF-filled NR/SBR vulcanizates with varying amounts of DAE-, TDAE- and MES-oils. 

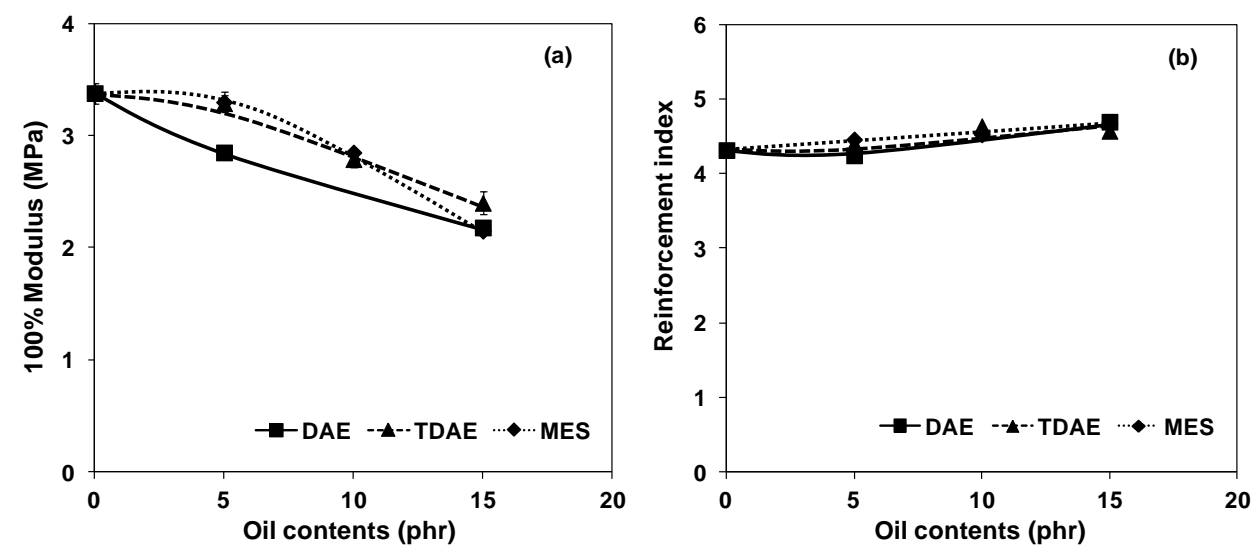

Figure 7.22 Tensile properties of HAF-filled NR/SBR vulcanizates with varying amounts of DAE-, TDAE- and MES-oils: (a) 100\%modulus, and (b) reinforcement index (M300/M100).
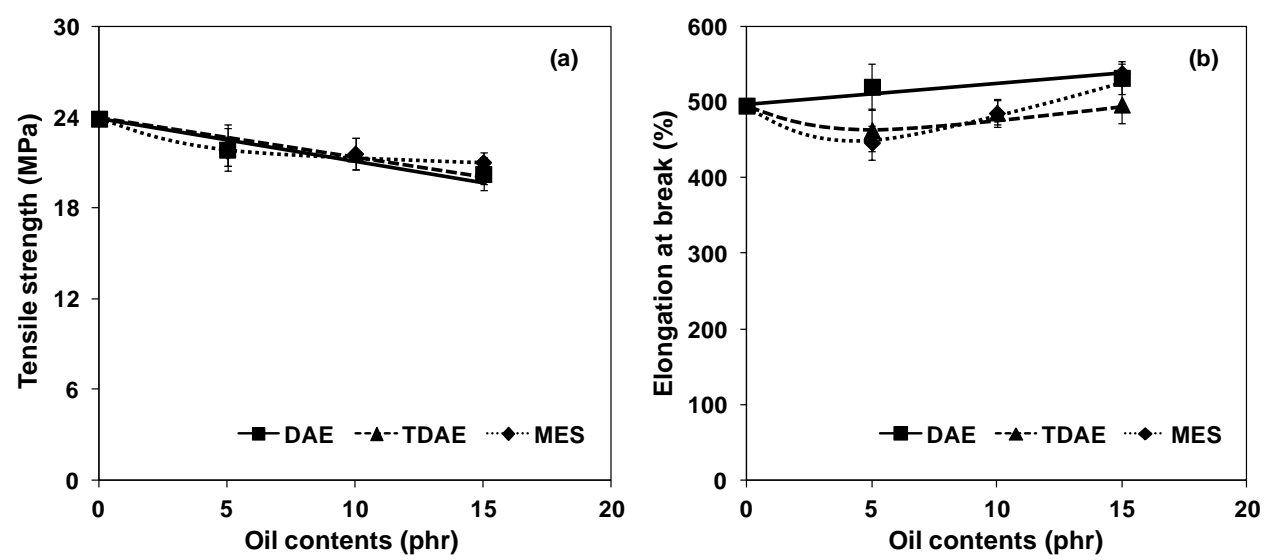

Figure 7.23 Tensile properties of HAF-filled NR/SBR vulcanizates with varying amounts of DAE-, TDAE- and MES-oils: (a) tensile strength and (b) elongation at break.

Tear resistance of the blend vulcanizates with oil contents up to $10 \mathrm{phr}$ of all types show similar values. But the increase of DAE- and TDAE-oil content to 15 phr anomalously enhances the tear resistance of the vulcanizates, while the increase of MES-oil content has no effect on this property. When compared with the tear resistance of filled-NR vulcanizates: Figure 6.18, that also does not change significantly with oil types and contents, the filledNR/SBR blends have a much lower tear resistance due to the heterogeneous blend system and the inferior tear property of SBR relative to NR by lack of strain-induced crystallization. The sharp increase of the tear resistance of the blends with DAE- and TDAE-oils at $15 \mathrm{phr}$ 
may have been caused by a better homogeneity of the swollen rubbers in the presence of high amounts of oils that have a better compatibility with the rubbers than MES.

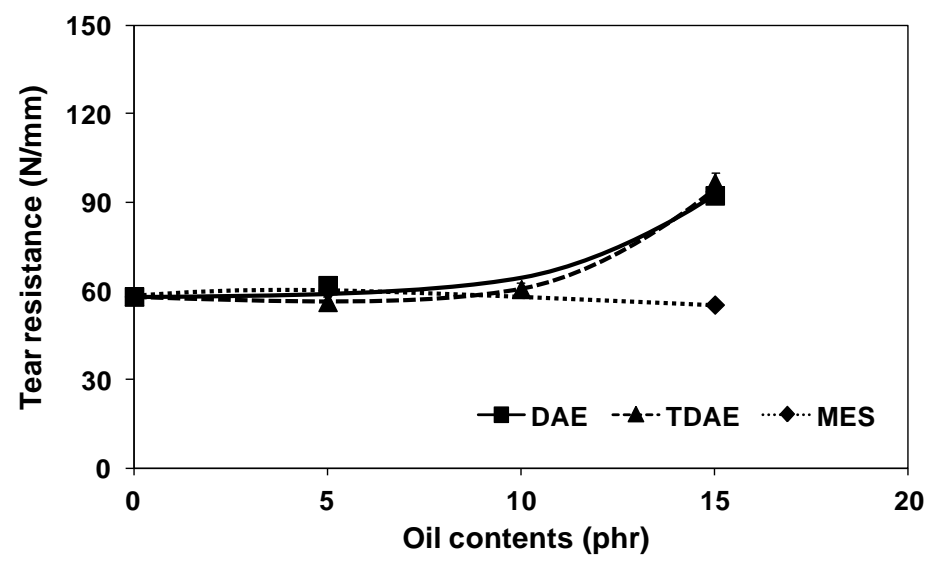

Figure 7.24 Tear resistance of HAF-filled NR/SBR vulcanizates with varying amounts of DAE-, TDAE- and MES-oils.

The results of DIN abrasion loss for the filled-NR/SBR vulcanizates are given in Figure 7.25. The addition of oils in filled-NR/SBR compounds improves the abrasion resistance of these vulcanizates as observed by the lower volume loss of the abraded specimens. The lowest volume loss is observed when $5 \mathrm{phr}$ of oil was added for all oils. Increasing oil contents to 10 and $15 \mathrm{phr}$ deteriorate the abrasion resistance of the vulcanizates. When compared to the use of DAE-oil, the blend vulcanizates with MES-oil show only a slightly better abrasion resistance, but the use of TDAE-oil drastically reduces the volume loss of the blend vulcanizates at every oil content. The results are totally different from the abrasion resistance of filled-NR vulcanizates in Figure 6.19. Therein the incorporation of oils at every oil loading increases the volume loss and the MES-plasticized NR shows the best abrasion resistance.

The improvement of abrasion resistance of the blend in the presence of small amounts of oils when compared to the unplasticized one, may be attributed to a better homogeneity in the materials and a better flexibility of the polymer chains. However, further increasing the oil loadings softens the materials causing the volume loss of rubber to increase again. Abrasion loss is a very complex behavior of materials that is affected by a great variety of factors and is closely related to the viscoelastic properties. In the present case, the situation is even more complicated due to the presence of binary rubber phases in which each phase has a different filler affinity and oil compatibility. As shown in Figure 5.7 
for unfilled NR and SBR compounds, the addition of DAE-oil increases the $T_{g}$ 's of both rubbers. The use of TDAE increases the $T_{g}$ of NR but slightly decreases the $T_{g}$ of SBR, whereas the addition of MES has almost no effect on the $T_{g}$ of NR but reduces the $T_{g}$ of SBR. The changes of $T_{g}$ 's affect the viscoelastic propertie. Generally, a rubber with lower $T_{g}$ has a better elastic deformation behavior which leads to a better resistance to wear when it is in contact with abrasive surfaces ${ }^{22}$. In the NR/SBR blend, the use of MES-oil should lower the $T_{g}$ of $S B R$ and improves this property better than the other two types of oils. However, due to the poorer dispersion of filler in the blends with MES-oil, as observed in the SEM images in Figure 7.19 and Payne effects in Figure 7.15, the blends with TDAE-oil provide a better balance between good filler dispersion and a small change in $T_{g}$-value of the SBR phase, that provides the better abrasion resistance than NR.

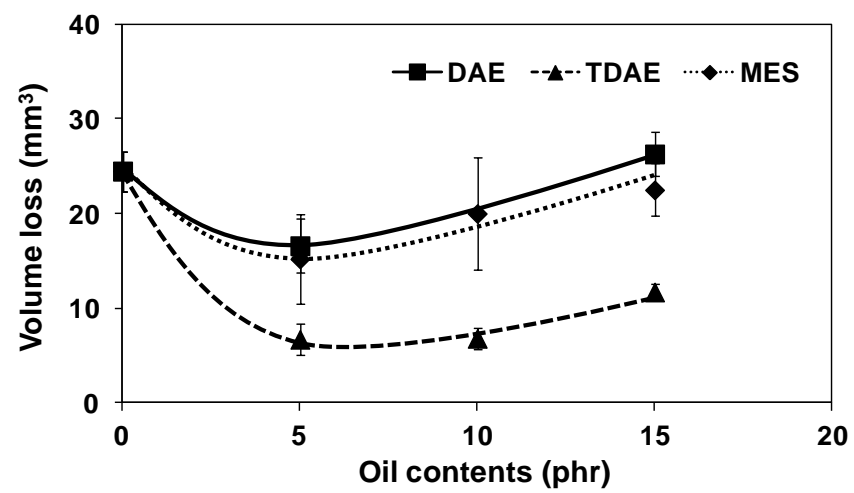

Figure 7.25 DIN abrasion loss of HAF-filled NR/SBR vulcanizates with varying amounts of DAE-, TDAE- and MES-oils.

In contrast to the results of filled-NR vulcanizates presented in Figure 6.20, the fatigue life of filled-NR/SBR vulcanizates as depicted in Figure 7.26 shows an increase of fatigue life with increasing oil contents in the blends. The use of DAE-oil with the highest $T_{g}$ results in the lowest fatigue life, while the use of TDAE gives a slightly better fatigue life compared with the use of MES. The difference between oil types is larger at higher oil loadings. The fatigue life of rubber vulcanizates depends again on many factors, as elaborated in Chapter 6 . In the present case, the presence of two rubber phases in the blend introduces an additional complication again. For SBR-rubber that has bulky phenyl groups in the styrene part of its composition, to hinder the rotation of the polymer backbone ${ }^{23}$, the presence of this styrene moiety gives a high viscoelastic energy dissipation during deformation and positively affects the fatigue life. The poorest fatigue life of the DAE- 
plasticized blends is a result of several contributions including its highest filler-filler interactions: Figure 7.15, the highest hardness: Figure 7.21, and the shift of $\mathrm{T}_{\mathrm{g}}$ 's of both rubbers to higher temperatures. In addition, the greater swelling by DAE of the rubbers causes a decrease of material stiffness and increase of the dynamically stored energy during cyclic deformation, leading to faster failure ${ }^{24}$. The increase of fatigue life of the blend after the addition of oils and with increasing oil contents, can be ascribed by the better homogeneity of the blend and better filler dispersion. The lowest $T_{g}$ of MES-oil, which shall impart a better elasticity to the material, is impeded by its poorest dispersion of carbon black in the blend. Therefore, the blends with TDAE-oil show the best fatigue life.

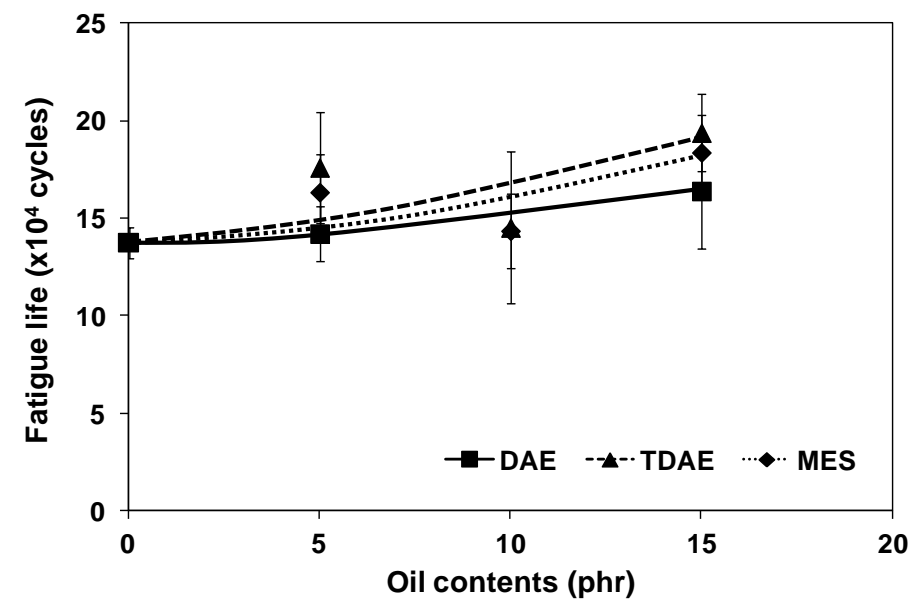

Figure 7.26 Fatigue life of HAF-filled NR/SBR vulcanizates with varying amounts of DAE-, TDAE- and MES-oils.

Figure 7.27 displays the percent changes of tensile strength and elongation at break after aging at $70^{\circ} \mathrm{C}$ for 168 hours. The changes of tensile strength are in a narrow range of less than $10 \%$. The vulcanizates with DAE- and MES-oils show a slight increase of tensile strength, while the addition of TDAE-oil at $5 \mathrm{phr}$ decreases the tensile strength after aging but later increases when 15 phr of TDAE is used. All three oil types show a decrease of elongation at break after aging but the change is smaller when the oil loading is increased. Among the different oil types, the blend vulcanizates with MES-oil show the smallest change of properties, i.e. the best aging resistance due to the highly saturated structure of MES. But overall the effects are minimal. 

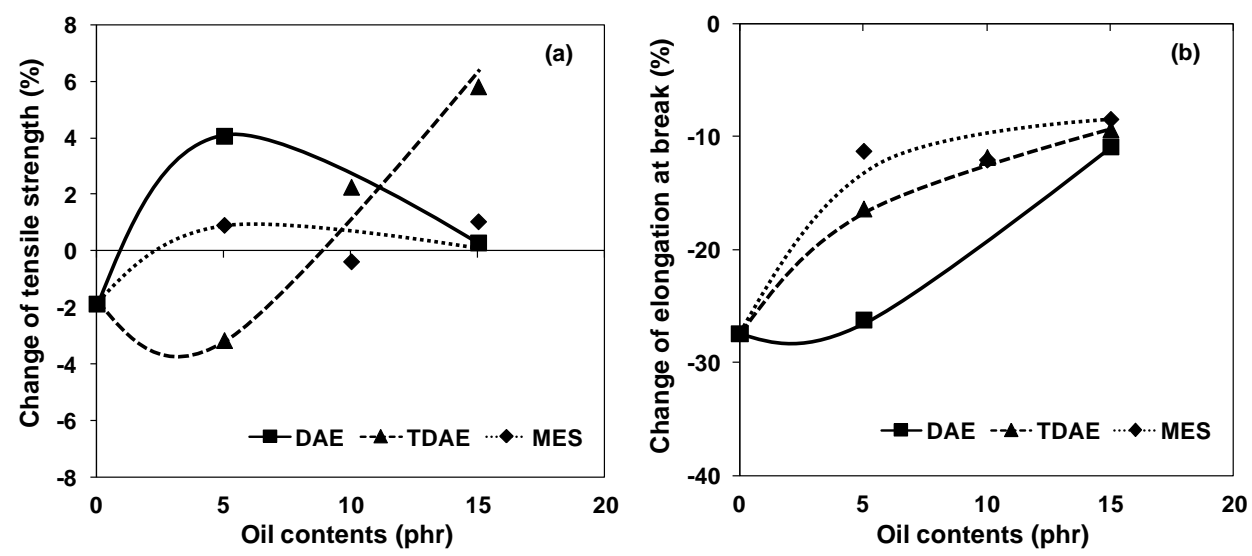

Figure 7.27 Percent changes of properties after aging at $70^{\circ} \mathrm{C}$ for 168 hours of HAF-filled NR/SBR vulcanizates with varying amounts of DAE-, TDAE- and MES-oils: (a) tensile strength, and (b) elongation at break.

The rebound resilience and heat build-up of the NR/SBR blend vulcanizates containing various oil types and contents are shown in Figure 7.28. These two properties are known to correlate with the viscoelastic behavior of the materials. The addition of oils introduces viscous components to the compounds and so reduces the elasticity. The $T_{g}$ of the oils also affects the $T_{g}$ of the rubber vulcanizates. The change of rebound resilience and heat build-up as functions of oil contents and types for the NR/SBR blends are similar to the case of filled-NR vulcanizates. That is, increasing oil contents reduce both rebound resilience and heat build-up. The presence of higher oil contents leads to higher energy losses resulting in lower rebound resilience, but the oils in the rubber can dissipate the heat and reduce the rising temperature caused by the lower heat build-up. The vulcanizates with TDAE and MES show a higher rebound resilience and lower heat build-up when compared to the one with DAE-oil. This is attributed to the lower $T_{g}$ 's of the MES- and TDAE-oils compared with that of DAE-oil, which also has an effect on the $T_{g}$ 's of the vulcanizates. The ones with DAE-oil are therefore less elastic. The higher rebound resilience of the vulcanizates with TDAE and MES is in accordance with the lower heat build-up. The results of the blends again indicate that the replacement of DAE with these two types of safe process oils improves the rubber elasticity. 

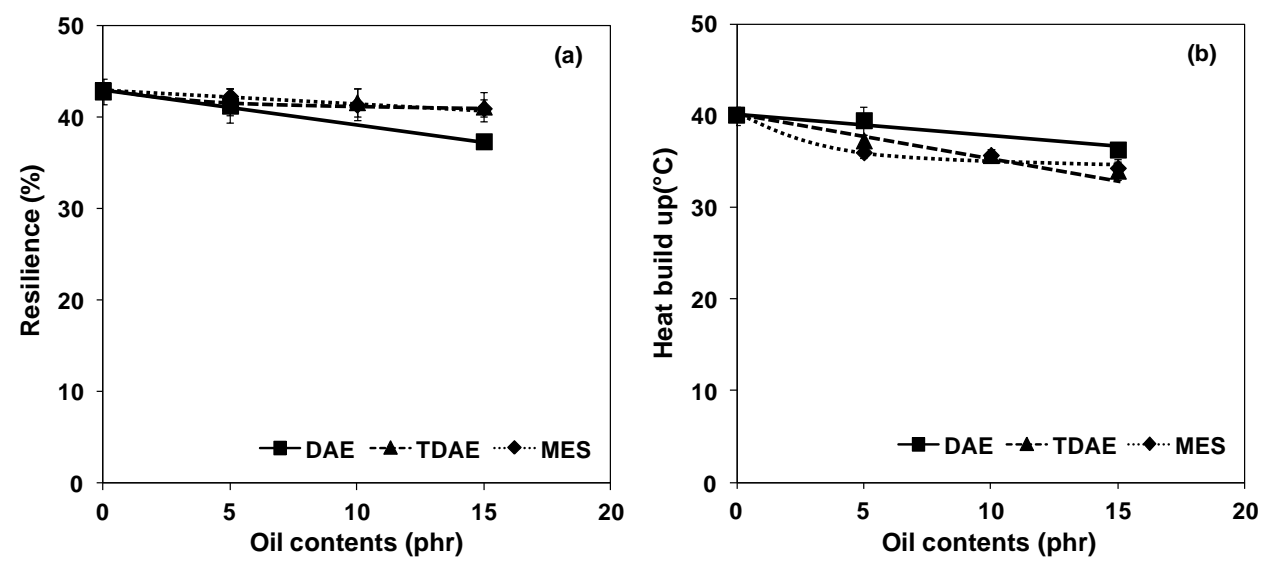

Figure 7.28 Resilience (a) and heat build-up (b) of HAF-filled NR/SBR vulcanizates with varying amounts of DAE-, TDAE- and MES-oils.

\subsubsection{Dynamic properties}

The filled NR/SBR blend vulcanizates were analyzed with a dynamic mechanical analyzer for their loss tangent curves as functions of temperature in order to assess their two key properties that are related to tire performance; i.e. wet grip and rolling resistance. Typical loss tangent curves of the vulcanizates with $15 \mathrm{phr}$ of oils are displayed in Figure 7.29. The curves clearly display a main peak associated with the $T_{g}$ of the SBR phase and a shoulder peak at a lower temperature which is associated with the $T_{g}$ of NR. SBR has a styrene moiety that gives damping properties and so exhibits the large peak of the loss tangent, even though the blend consists of 50/50 \% by weight of NR/SBR. By taking the temperatures at the loss tangent peaks of each phase, the $T_{g}$ 's of NR and SBR in the blends with various oil types and contents are plotted in Figure 7.30. It is observed that the addition of the oils results in almost no change in $T_{g}$ of the NR but shifts the $T_{g}$ of SBR to higher temperatures. The presence of oils raises the peak loss tangent values also a little in the rubbery region due to the viscous nature of the oils that influences the viscoelastic behavior of the rubbers. 


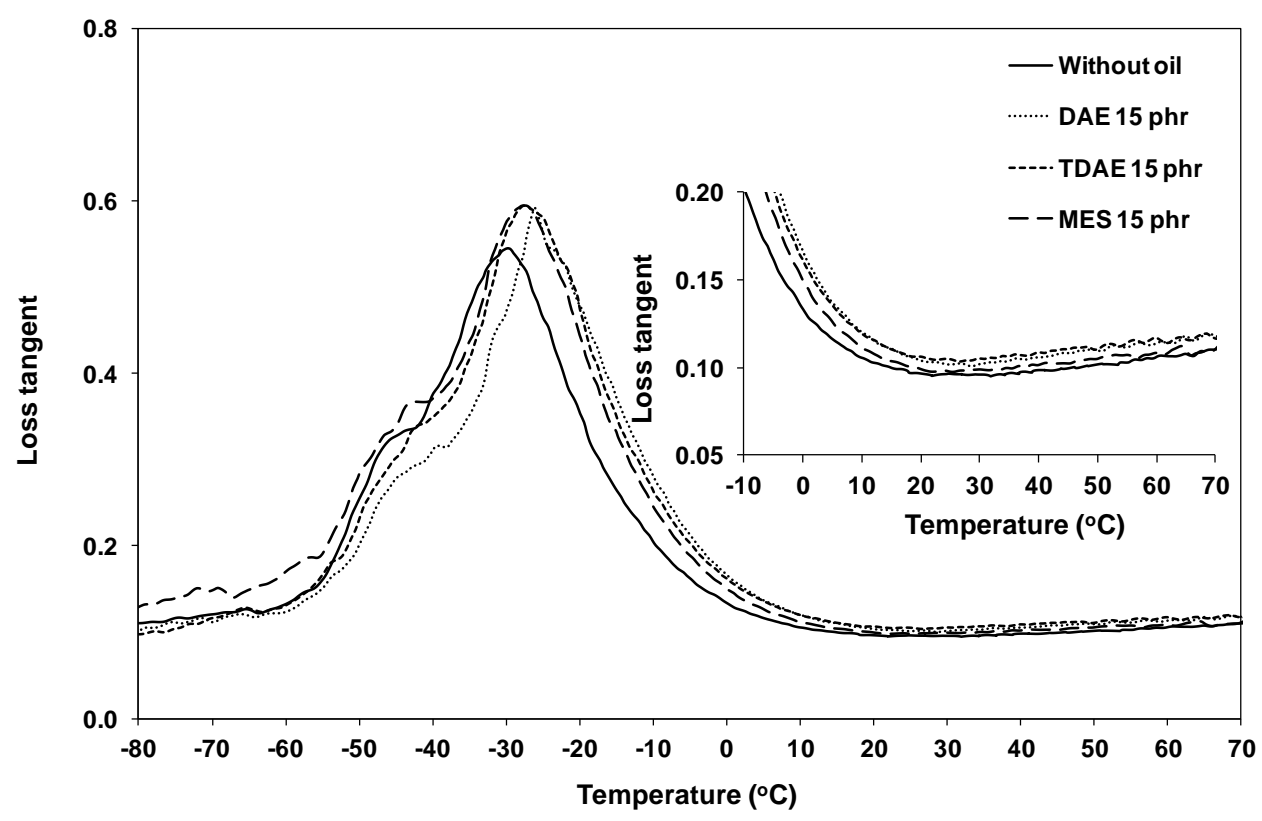

Figure 7.29 Loss tangent curves of HAF-filled NR/SBR compounds with DAE-, TDAE- and MES-oils at 15 phr.

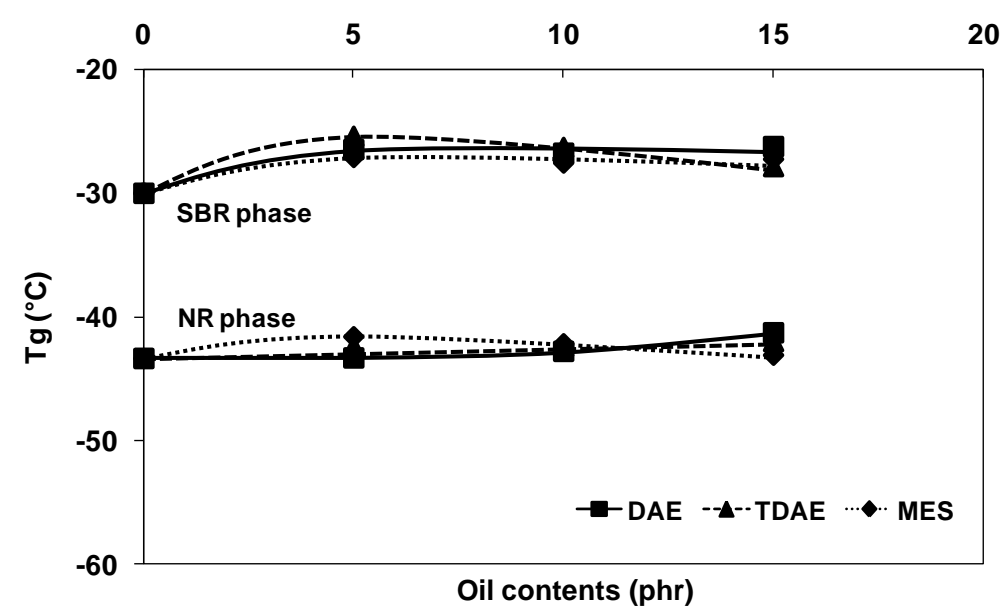

Figure 7.30 Glass transition temperatures of the HAF-filled NR/SBR compounds with varying amounts of DAE-, TDAE- and MES-oils.

By taking the $T_{g}$ of each phase in the blend without oil as reference, the differences of $T_{g}$ values: $\Delta T_{g}$, of all the vulcanizates with varying oil types and contents were calculated and are shown in Figure 7.31. The addition of all oil types results in higher $\mathrm{T}_{\mathrm{g}}$ 's of both the 
NR and SBR phases when compared to the $T_{g}$ 's in the rubber without oil. However, the extent of changes is different. A narrower range of $T_{g}$-shift in NR is observed and there is no clear trend of changes with oil contents and types. The shift of $T_{g}$ of the SBR-phase is larger, as shown in Figure 7.31 (b). This $T_{g}$-shift can be a combination of uneven carbon black distribution as it prefers the SBR phase ${ }^{20-21}$, and the influence of the $T_{g}$ of the oil. As shown in Table 3.2, DAE-oil has a higher $\mathrm{T}_{\mathrm{g}}$ than TDAE and MES. At $15 \mathrm{phr}$ of these oils, the rubbers with DAE clearly show a higher $T_{g}$ than the rubbers with MES, but the results of TDAE-plasticized rubber show a bit inconsistency. Based on the $T_{g}$-shift in the NR and SBR phases, it may be implied that the oils are preferentially located in the SBR- over the NRphase. A study of oil distribution in blends of NR/SBR by Naito et al. ${ }^{25}$. also showed that aromatic oil was preferentially distributed towards the SBR-phase.
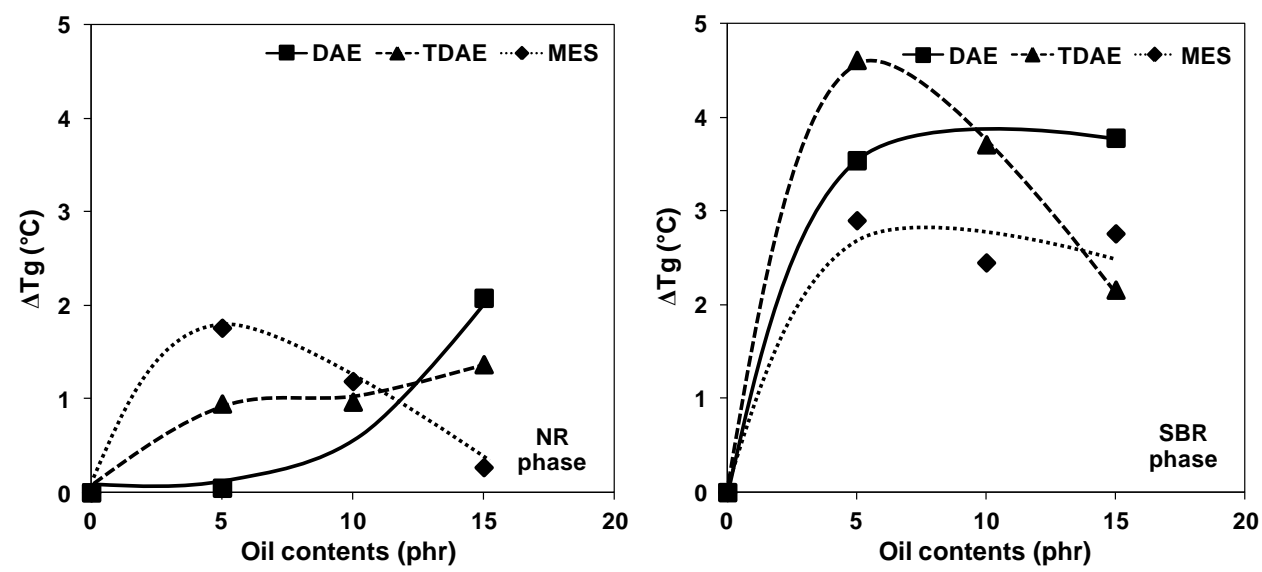

Figure 7.31 Difference of glass transition temperature $\Delta T_{g}$ of NR- and SBR-phases in the HAF-filled NR/SBR vulcanizates with varying types and amounts of oils, in relation to the unplasticized compound.

The influence of oil types and contents on the loss tangent: $\tan \delta$ values at $0^{\circ} \mathrm{C}$ and $60^{\circ} \mathrm{C}$ of the filled-NR/SBR vulcanizates as indication parameters for tire wet grip and rolling resistance, respectively, are displayed in Figure 7.32. The use of all oil types results in an increase of $\tan \delta$ at both $0^{\circ} \mathrm{C}$ and $60^{\circ} \mathrm{C}$, and the values increase with growing oil contents. This may be taken as an indication for enhanced wet grip performance of tires by the incorporation of oils. The blends with DAE and TDAE show almost identical tan $\delta$ values at $0^{\circ} \mathrm{C}$, which are higher than for the MES-plasticized vulcanizates. So, among the three types of oils studied, MES-oil gives the poorest wet grip. When compared to the tan $\delta$ values at 
$0^{\circ} \mathrm{C}$ of NR: Figure 6.26 , the NR/SBR blend shows a significantly higher tan $\delta$ due to the damping behavior of the styrene part in the SBR blend component.

When considering the tan $\delta$ at $60^{\circ} \mathrm{C}$, the vulcanizates with DAE-oil show marginally higher values than those of the mixes with TDAE and MES, due to its $T_{g}$-influence. This higher loss tangent at $60^{\circ} \mathrm{C}$ is in accordance with the results of rebound resilience: Figure 7.28 (a) and heat build-up: Figure 7.28 (b), in which the blend vulcanizates containing DAEoil have lower rebound resilience and higher heat build-up, compared with the more elastic TDAE- and MES-plasticized blends. The replacement of DAE with TDAE and MES will therefore give slightly lower rolling resistance of tires. Based on these dynamic mechanical properties, the use of TDAE-oil provides the best balance of wet grip and rolling resistance for tire treads.

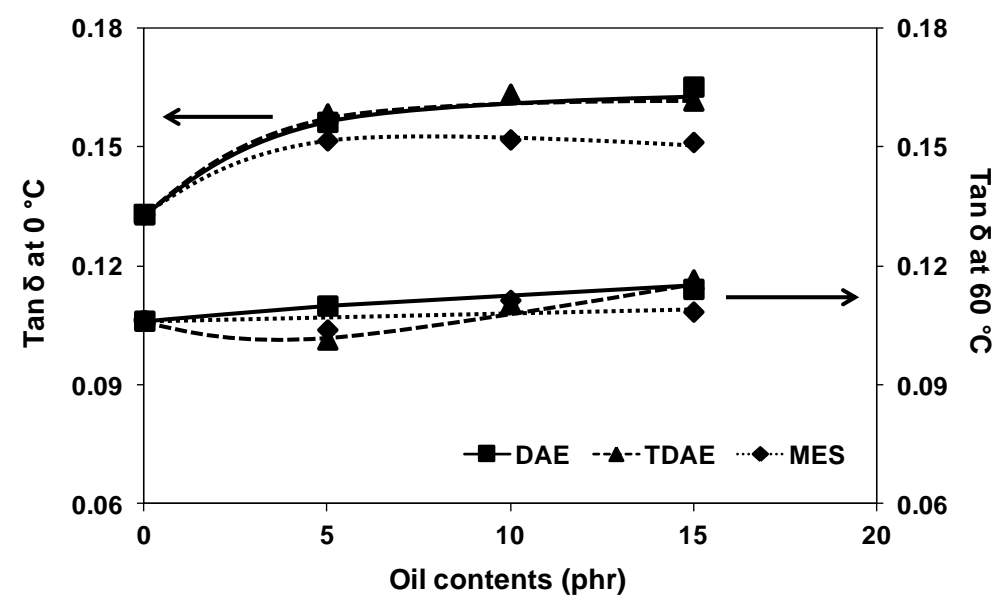

Figure 7.32 Loss tangent at 0 and $60^{\circ} \mathrm{C}$ of the HAF-filled NR/SBR compounds with varying amounts of DAE-, TDAE- and MES-oils.

\subsection{CONCLUSIONS}

The increase of oil loadings and change of oil types in carbon black-filled 50/50\% NR/SBR blend compounds affect both processing and vulcanizates properties. The compounds with DAE-oil show lower Mooney viscosities but higher complex viscosities compared with the ones with TDAE- and MES-oils. The viscosities are decreased with increasing oil contents. The different oil types and loadings have little effect on cure rate index but increasing oil contents prolong scorch and cure times and lower the rheometer torque difference $\left(\mathrm{M}_{\mathrm{H}}-\mathrm{M}_{\mathrm{L}}\right)$. The DAE-plasticized blends show a higher rheometer torque difference than the compounds with the other types of oils. The use of DAE results in higher Payne effect in the filled-blend compounds when compared to TDAE and MES, respectively, 
but the different oil types do not affect the bound rubber content of the filled-NR/SBR and filled-SBR compounds. Increasing oil contents reduce both the Payne effect and bound rubber contents in the uncured compounds. SEM micrographs of the vulcanizates without oil, and with DAE- and TDAE-oils show that carbon black is rather homogeneously dispersed and has a better dispersion overall than that of the mix with MES-oil. The mechanical properties of the vulcanizates change according to the increased oil contents due to the dilution effect. Increasing oil contents decrease hardness, modulus, tensile strength, but increase elongation at break. The DAE-containing vulcanizates show the lowest $100 \%$ modulus, abrasion resistance, fatigue life, rebound resilience, but the highest heat build-up. The use of TDAE-oil gives superior abrasion resistance and fatigue life compared with the use of MES and DAE. The replacement of DAE with TDAE and MES improves the elastic properties of the filled NR/SBR blends as indicated by an increased rebound resilience, decreased heat build-up and lowered loss tangent at $60^{\circ} \mathrm{C}$. The addition of oil causes a larger shift of the glass transition temperature $T_{g}$ of the SBR-phase compared to the shift of $\mathrm{T}_{\mathrm{g}}$ of the NR phase, indicating that the oils are preferentially distributed towards the SBR-phase. Increasing oil contents increase the loss tangent at $0^{\circ} \mathrm{C}$ and $60^{\circ} \mathrm{C}$. The use of MES-oil gives the lowest loss tangent at $0^{\circ} \mathrm{C}$ while DAE-oil gives the highest loss tangent at $60^{\circ} \mathrm{C}$. So, the use of TDAE indicates the best balance of wet grip and rolling resistance for the HAF-filled NR/SBR compounds.

\subsection{REFERENCES}

1 S. Datta, in: Rubber Technologist's Handbook, Chapter 3: Synthetic Elastomers, Eds.: J.R. White and S.K. De, Rapra Technology Limited, Shropshire, 2001.

2 R.M. Scriver, T.S. Mroczkowski and S.D. Patkar (To Pirelli Armstrong Tire Corporation), U.S. Patent 5219944, June 15, 1993.

3 O. Beckmann, J. Bertrand and R.Teves (To Semperit Reifen AG), U.S. Patent 5717022 , February 10, 1998.

4 B. Kastein, in: Basic Elastomer Technology, Chapter 9: General Purpose Elastomers B. Styrene Butadiene Rubbers (SBR), Eds.: K.C. Baranwal and H.L. Stephens, The Rubber Division American Chemical Society, Akron, 2001.

5 M. Öter and B. Karaağaç, Kautsch. Gummi Kunstst., 65, 48 (2011).

6 K. Sahakaro and A. Beraheng, Rubber Chem. Technol., 84, 200 (2011).

7 V. Null, Kautsch. Gummi Kunstst., 52, 799 (1999).

8 S. Dasgupta, S. L. Agarwal, S. Bandyopadhyay, R. Mukhopadhyay, R. K. Malkani and S. C. Ameta, Polym. Test., 28, 251 (2009).

9 G.R. Cotten, Rubber Chem. Technol., 57, 118 (1984). 
10 G.R. Cotten, Rubber Chem. Technol., 58, 774 (1985).

11 J. Malac, The Open Macromolecules Journal, 3, 41 (2009).

12 J.S. Dick, in: Rubber Technology Compounding and Testing for Performance, Chapter 2: Compound Processing Characteristics and Testing, Eds.: J. S. Dick, Carl Hanser Verlag, Münich, 2001.

13 S. Wolff, M. J. Wang and E. H. Tan, Rubber Chem. Technol., 66, 163 (1993).

14 S. Wolff, Rubber Chem. Technol., 69, 325 (1996).

15 J.L. Leblanc, Prog. Polym.Sci., 27, 627 (2002).

16 G.R. Cotten and L.J. Murphy, Rubber Chem. Technol., 61, 609 (1988).

17 A.K. Sirkar and A. Voet, Rubber Chem. Technol., 43, 973 (1970).

18 S.S. Choi, J. Appl. Polym. Sci., 93, 1001 (2004).

19 W.M. Hess and V.E. Chirico, Rubber Chem. Technol., 50, 301 (1977).

20 J.E. Callan, W.M. Hess and C.E. Scott, Rubber Chem. Technol., 44, 814 (1971).

21 M. Klüppel, R.H. Schuster and J. Schaper, Rubber Chem. Technol., 72, 91 (1999).

22 K.H. Nordsiek, Kautsch. Gummi Kunstst., 38, 178 (1985).

23 J. Zhao and G.N. Ghebremeskel, Rubber Chem. Technol., 74, 409 (2001).

24 S. Jerrams, J. Hanleys, N. Murphy and H. Ali, Rubber Chem. Technol., 81, 638 (2008).

25 K. Naito, N. Wada, S. Inoue and T. Nishi, J. Appl. Polym. Sci., 61,755 (1996). 


\section{SUMMARY}

The generally used process oils in rubber compounds are mineral oils which are categorized into three types: aromatic-, naphthenic- and paraffinic-oils. The oils are added to rubber compounds to improve processing properties, low temperature flexibility, dispersion of fillers, and to reduce costs: commonly called "extension". Aromatic oil is conventionally most widely used in tire compounds because it is not only good compatible with Natural rubber (NR) and most synthetic rubbers like Styrene Butadiene Rubber (SBR) used in tires, but it is also inexpensive. However, aromatic oil which is also referred to as Distillate Aromatic Extract (DAE), contains a high content of Polycyclic Aromatic Hydrocarbons (PAHs) or also called Polynuclear aromatics (PNAs). Eight types of PAHs are identified as carcinogens, to include Benzo[a]pyrene (BaP), Benzo[e]pyrene (BeP), Benzo[a]anthracene $(\mathrm{BaA})$, Benzo[b]fluoranthene (BaFA), Benzo[j]fluoranthene (BjFA), Benzo[k]fluoranthene (BkFA), Dibenzo[a,h]anthracene (DBahA) and Chrysene (CHR). PAHs that can be released from tires by tire wear are harmful to health and environment. As a consequence, noncarcinogenic oils were developed to replace aromatic oil in tire compounds. The noncarcinogenic oils which have been proposed to be used in tire compounds are such as Treated Distillate Aromatic Extract (TDAE), Mildly Extracted Solvate (MES), Naphthenic oils (NAP) and natural oils. The present thesis comparatively studies the influence of petroleumbased safe process oils, i.e. TDAE and MES, versus the conventional aromatic oil on the properties of NR-based truck tire tread compounds and NR/SBR-based passenger tire tread compounds. Oil characterization data are analyzed, and the influence of the oils on the properties of unfilled compounds is also elucidated.

A general introduction, aims of this research and structure of the thesis are elaborated in Chapter 1. The research background and an overview of process oils employed for extension of rubber are described in Chapter 2. This chapter provides some key fundamentals of process oils, covering the purposes of use of process oils in rubber compounds, types, manufacturing, oil characterizations, plastization mechanism and the non-carcinogenic process oils developed mainly for tire purposes. A literature overview based on the use of safe process oils in rubber compounds is also given.

Each of the oil types has different characteristics, so the oils characteristic properties are analyzed and discussed in Chapter 3. The physico-chemical characteristics of the DAE, TDAE and MES, e.g. density, refractive index, kinematic viscosity, viscosity gravity constant (VGC), aniline point, PAHs content, carbon type and glass transition 
temperature, are covered. The thermal properties of the process oils are characterized by Differential Scanning Calorimetry (DSC) and their chemical structures analyzed by Fourier Transform Infrared Spectroscopy (FT-IR) and proton Nuclear Magnetic Resonance Spectroscopy $\left({ }^{1} \mathrm{H}-\mathrm{NMR}\right)$. The higher aromatic content of DAE over that of TDAE and MES, is clearly indicated by its viscosity gravity constant (VGC), aniline point, carbon distribution and DMSO extract, as also evidenced in the FT-IR and ${ }^{1} \mathrm{H}-\mathrm{NMR}$ spectra. The higher aromatic carbon $\left(\mathrm{C}_{A}\right)$ content results in higher density, refractive index, kinematic viscosity and glass transition temperature $\left(T_{g}\right)$ of DAE. The $T_{g}$ 's of the oils are ranked as DAE > TDAE > MES, as also proved by DSC analysis and theoretical prediction. The highest aniline point of MES implies the lowest compatibility of oil with rubber. The infrared absorption peaks of MES oil clearly show weaker characteristic peaks of aromatic structures compared to those of TDAE and DAE, in accordance with the ${ }^{1} \mathrm{H}$ NMR spectra. The ${ }^{1} \mathrm{H}-\mathrm{NMR}$ spectrum of DAE oil not only shows a substantially high aromatic content, as reflected by absorption bands of aromatic protons that are attached to ring structures, but also displays peaks between 8.3 to $9.2 \mathrm{ppm}$ which are assigned to bay region protons in $\mathrm{PAH}$-molecules, of which some are classified as carcinogenic substances.

The oil characteristics have an influence on the compatibility and mutual solubility of oils and rubbers, so the solubility parameters of oils and rubbers are theoretical derived and discussed in Chapter 4. The compatibility of NR, SBR and their 50/50 blend with the three types of oils is studied by a theoretical prediction based on the difference in solubility parameters $(\Delta \delta)$ and by an experimental swelling study. The solubility parameters $(\delta)$ are calculated based on the group contribution method that uses molar attraction constants, and the $\Delta \delta$ values between oils and rubbers are correlated with the mass swelling of lightly crosslinked NR and SBR at different temperatures. The results reveal that all of the three oils have a good solubility in both NR and SBR as the $\Delta \delta$ are small $\left(\leq 5 \mathrm{~J}^{1 / 2} / \mathrm{cm}^{3 / 2}\right)$. A smaller $\Delta \delta$ means better solubility of oil in the rubber which is confirmed by the higher level of oil uptake in the rubber. Nevertheless, at high temperature in the range of rubber mixing temperatures, MES oil shows less compatibility with NR and SBR compared to TDAE and DAE, respectively. The theoretical predictions correlate with the results of swelling.

Chapter 5 describes the results of a preliminary study which was designed to investigate the effect of oil types and contents on the properties of unfilled compounds. The investigation with unfilled NR, SBR and the NR/SBR blend at 50/50 weight ratio using DAE oil, and TDAE and MES as alternative safe process oils reveals that the oil-types have only minor effects on Mooney viscosity and cure rate of all the compound types, except for the 
NR-compounds in which DAE- and TDAE-oils give a higher cure rate index compared to MES. The different $T_{g}$ 's of the process oils affect the $T_{g}$ 's of the rubber compounds. The incorporation of DAE which has a higher $T_{g}$ than the oil-free rubbers, increases the $T_{g}$ of the rubber compounds, while the use of MES oil with the lowest $T_{g}$ has no effect on the $T_{g}$ of NR but decreases the $T_{g}$ of SBR slightly. The SBR with MES oil shows lower loss tangent values at both 0 and $60^{\circ} \mathrm{C}$, while the use of MES oil in NR results in higher loss tangent at $60^{\circ} \mathrm{C}$, compared to that of DAE and TDAE. The replacement of DAE with TDAE and MES in unfilled SBR and in the NR/SBR blend shows only small changes in their mechanical properties, but the use of MES in NR results in lower hardness, 100\% modulus and tensile strength when compared with TDAE or DAE. When considering the overall changes in properties, NR is most sensitive to the change of oil type.

Practical carbon black-filled NR truck tire tread compounds with varying oil types and amounts were thereafter investigated and their properties of both unvulcanized compounds and vulcanizates are discussed in Chapter 6. The compounds show similar mixing torques for the same oil contents of all types. The ones with DAE oil have lower Mooney viscosities but higher complex viscosities when compared to the mixes with TDAEand MES-oils. Increasing oil loadings decrease the compound viscosities, except at $5 \mathrm{phr}$ where the values are slightly higher than for the unplasticized compound. The mixing of NR with carbon black without oil is affected by the mastication effect which results in a greater extent of polymer chain break-down. The compounds with different oils show similar cure characteristics. The DAE-extended compounds show the highest Payne effect and lowest bound rubber content compared with the mixes with TDAE- and MES-oils. The filler-filler and filler-rubber interactions tend to decrease slightly when more oils are included in the compounds. SEM micrographs of the vulcanizates show that the carbon black is finely dispersed in all of the compounds. The use of DAE, TDAE and MES gives vulcanizates with similar mechanical properties (i.e., hardness, tensile and tear strength, and elongation at break), but different in those properties which are related to the change of the $T_{g}$ and viscoelastic behavior. The use of DAE with the highest $T_{g}$ results in lower abrasion resistance, fatigue life, rebound resilience and higher heat build-up, while the use of MES with the lowest $T_{g}$ gives the best elastic response. The incorporation of oil increases the loss tangent at both $0^{\circ} \mathrm{C}$ and $60^{\circ} \mathrm{C}$ of the filled-NR vulcanizates. The loss tangent values at $0^{\circ} \mathrm{C}$ of all the vulcanizates with the same oil loadings are similar, but the loss tangent at $60^{\circ} \mathrm{C}$ of the rubbers with MES and TDAE is lower than for those with DAE. The results clearly show that the replacement of DAE with TDAE and MES-oils has little effect on the mechanical properties, but does influence the dynamic mechanical properties related to the different $T_{g}$ 's 
of the oils, which may have an impact on the overall performance of tires produced with these oils.

The properties of carbon black-filled NR/SBR passenger tire tread compounds are also affected by the change of oil types and contents, as reported in Chapter 7 . The various oil types differ insignificantly with respect to their influence on the mixing torque which is decreased with increasing oil contents. The compounds with DAE oil show lower Mooney viscosity but higher complex viscosity compared with the mixes with TDAE and MES, and the viscosities are decreased with increasing oil contents. The DAE-extended filled SBR compounds also show the highest complex viscosity among the three types of oils studied. The scorch and cure times of filled-NR/SBR and filled-SBR compounds are not affected by the change of oil types but prolonged with increasing oil contents. The blend compounds with DAE oil show higher Payne effects when compared to the ones with TDAE and MES, respectively. However, the oil types do not show an effect on bound rubber content in NR/SBR as well as in SBR compounds. Increasing oil contents reduce both the Payne effect and bound rubber contents for all compounds. SEM micrographs show that carbon black is finely dispersed in all compounds, although the one with MES shows a slightly poorer filler dispersion. The NR/SBR blends with DAE oil have the lowest $100 \%$ modulus, abrasion resistance, fatigue life, rebound resilience, but the highest heat build-up compared with the compounds containing TDAE and MES oils. But the different oil types have no significant influence on tensile strength and reinforcement index. TDAE oil gives superior abrasion resistance and fatigue life of the blend vulcanizates compared to MES and DAE. Increasing oil contents reduce hardness, $100 \%$ modulus, tensile strength, rebound resilience, heat build-up, but increase the loss tangent at both $0^{\circ} \mathrm{C}$ and $60^{\circ} \mathrm{C}$, as expected. The $\mathrm{T}_{\mathrm{g}}$ 's of the blend vulcanizates are affected by the $T_{g}$ 's of the oils. The SBR phase shows a larger shift of $T_{g}$ compared to the NR phase, indicating that the oils are preferentially located in the SBR phase. The use of MES oil gives the lowest loss tangent at $0^{\circ} \mathrm{C}$, while DAE results in the highest loss tangent at $60^{\circ} \mathrm{C}$. Therefore, TDAE oil provides the best balance of loss tangent at $0^{\circ} \mathrm{C}$ and $60^{\circ} \mathrm{C}$, which may be taken as indicative for the wet grip and rolling resistance of tires.

Overall, the different chemical structures and compositions of DAE-, TDAE- and MES-oils that affect on their characteristics, have influences on their compatibility with rubbers and the properties of the corresponding rubber compounds. The theoretical predictions based on differences in solubility parameters $(\Delta \bar{\delta})$ and the experimental swelling study agree well in that MES is less compatible with NR and SBR compared with TDAE and 
DAE. The difference of cure characteristics, due to the presence of nitrogen-and sulfurheterocyclic species in DAE oil, as observed in unfilled compounds, is diminished in the carbon black-filled compounds. The mechanical properties of both unfilled and carbon black filled compounds are little influenced by the change of oil types, but the properties are changed according to the oil loadings, basically due to the dilution effect. The different glass transition temperatures $\left(T_{g}\right)$ of the oils affect the $T_{g}$ 's of the rubber vulcanizates and hence the viscoelastic-related properties, i.e. abrasion resistance, rebound resilience, heat build-up and loss tangent. The replacement of toxic DAE by safe TDAE and MES enhances the elastic response of the materials. Based on the processing properties of the uncured compounds and mechanical as well as dynamic properties of the vulcanizates, TDAE oil provides better overall properties as replacement for DAE oil than MES. For tire tread compounds, the change from DAE to TDAE or MES positively influences the key tire tread performance characteristics, i.e. abrasion resistance, wet grip and rolling resistance. 


\section{SAMENVATTING}

De algemeen gebruikelijke proces-oliën in rubber compounds zijn minerale oliën, onderverdeeld in drie types: aromatische, nafthenische en paraffinische oliën. Zij worden toegevoegd aan rubber mengsels om de verwerkings-eigenschappen te verbeteren, de lage temperatuur flexibiliteit, de verdeling van vulstoffen, en om de kosten te verlagen: in het Engels gewoonlijk aangeduid met "extension". Aromatische olie wordt van oudsher het meest gebruikt in banden compounds, niet alleen omdat het goed verdraagzaam is met NatuurRubber (NR) en de meeste synthetische rubbers zoals Styreen Butadiëen Rubber (SBR) gebruikt in banden, maar het is ook goedkoop. Echter, aromatische olie ook wel aangeduid als Distillate Aromatic Extract (DAE), bevat een hoog gehalte Polycyclisch Aromatische Koolwaterstoffen (PAKs) of ook wel Polycyclische Aromaten genoemd (PCAs). Acht typen PAKs worden als carcinogeen aangemerkt: Benzo[a]pyreen (BaP), Benzo[e]pyreen ((BeP), Benzo[a]anthraceen (BaA), Benzo[b]fluoranteen (BaFA), Benzo[j]fluoranteen (BjFA), Benbzo[k]fluoranteen (BkFA), Dibenzo[a,h]antraceen (DBahA) en Chryseen (CHR). PAKs die kunnen vrijkomen uit banden door slijtage zijn schadelijk voor de gezondheid en het milieu. Daarom zijn niet-carcinogene oliën ontwikkeld om de aromatische oliën in banden-compounds te vervangen. De niet-carcinogene oliën die worden aanbevolen voor gebruik in banden-compounds zijn Treated Distillate Aromatic Extract (TDAE), Mildly Extracted Solvate (MES), Nafthenische oliën (NAP) en natuurlijke oliën. Het onderhavige proefschrift bestudeert vergelijkenderwijs de invloed van op aardolie gebaseerde veilige proces-oliën, t.w. TDAE en MES, ten opzichte van conventionele aromatische olie, op de eigenschappen van op NR gebaseerde vrachtwagen- banden loopvlak compoundS, en op een mengsel van NR en SBR gebaseerde personenwagenbanden loopvlak compounds. Olie karakteriserings-gegevens worden geanalyseerd, en de invloed van de oliën op de eigenschappen van ongevulde, niet versterkte compounds wordt eveneens opgehelderd.

In Hoofdstuk 1 wordt een algemene inleiding gegeven, en de doelstellingen van dit onderzoek en de opzet van het proefschrift uitgewerkt. De research achtergrond en een overzicht van de proces oliën gebruikt voor rubber-extension worden beschreven in Hoofdstuk 2. Dit hoofdstuk geeft enkele fundamentele hoofdzaken van de proces-oliën, met name de redenen voor het gebruik van proces-oliën in rubber compounds, de soorten, de productie, olie karakteriseringen, het mechanisme van plasticering en de niet-carcinogene 
proces-oliën voornamelijk ontwikkeld voor banden doeleinden. Een literatuur overzicht op basis van het gebruik van veilige proces-oliën in rubber compounds wordt ook gegeven.

Elk van de olie-types heeft verschillende karakteristieken, derhalve worden de karakteristieke eigenschappen van de oliën geanalyseerd en besproken in Hoofdstuk 3. De fysisch-chemische eigenschappen van DAE, TDAE en MES, m.n. dichtheid, brekingsindex, kinematische viscositeit, viscosity gravity constant (VGC), aniline punt, gehalte PAKs, koolstof- soort en glasovergangstemperatuur worden besproken. De thermische eigenschappen van de proces-oliën worden gekarakteriseerd met behulp van Differential Scanning Calorimetrie (DSC) en hun chemische structuren geanalyseerd met FourierTransform Infrarood Spectroscopie (FT-IR) en Proton Nuclear Magnetic Resonance Spectroscopie ( $\left.{ }^{1} \mathrm{H}-\mathrm{NMR}\right)$. Het hogere aromatisch gehalte van DAE t.o.v. TDAE en MES blijkt duidelijk uit z'n viscosity gravity constant (VGC), aniline punt, koolstof-soort verdeling en DMSO extract, zoals ook blijkt uit de FT-IR en ${ }^{1} \mathrm{H}$-NMR spectra. Het hogere aromatische koolstof-gehalte $\left(\mathrm{C}_{\mathrm{A}}\right)$ resulteert in een hogere dichtheid, hogere brekingsindex, kinematische viscositeit en glasovergangs-temperatuur $\left(T_{g}\right)$ van DAE. De $T_{g}$ 's van de oliën verhouden zich als DAE > TDAE > MES, zoals blijkt uit DSC-analyse en op basis van theoretische voorspelling. Het hoogste aniline-punt van MES impliceert de laagste verdraagzaamheid van deze olie met rubber. Het infrarood spectrum van MES olie vertoont duidelijk zwakkere karakteristieke pieken van aromatische structuren vergeleken met die van TDAE en DAE, in overeenkomst met de ${ }^{1} \mathrm{H}-\mathrm{NMR}$ spectra. Het ${ }^{1} \mathrm{H}-\mathrm{NMR}$ spectrum van DAE olie vertoont niet alleen een aanzienlijk hoog aromatisch gehalte, zoals blijkt uit adsorptiebanden van aromatische protonen gebonden aan ring-structuren, maar vertoont ook pieken tussen 8,3 en 9,2 ppm, welke worden togewezen aan "bay-region" protonen in PAK-moleculen, waarvan enkele geclassificeerd zijn als kankerverwekkend.

De olie-karakteristieken hebben een invloed op de verdraagzaamheid en onderlinge oplosbaarheid van oliën en rubbers, derhalve worden de oplosbaarheidsparameters van de oliën en rubbers theoretische afgeleid en bediscussieerd in Hoofdstuk 4. De verdraagzaamheid van NR, SBR en hun 50/50 mengsel met de drie types olie wordt bestudeerd aan de hand van een theoretische voorspelling op basis van het verschil in oplosbaarheidsparameters $(\Delta \delta)$ en een experimenteel zwellings-onderzoek. De oplosbaarheidsparameters $(\delta)$ worden berekend met gebruikmaking van de "group contribution method" welke molaire aantrekkings-constanten hanteert, en de $\Delta \delta$-waardes tussen oliën en rubbers worden gecorreleerd met de massa-zwellingen van lichtgecrosslinkte NR en SBR bij verschillende temperaturen. De resultaten laten zien dat alle 
drie oliën goed oplossen in zowel NR als SBR aangezien de $\Delta \delta$ 's klein zijn $\left(\leq 5 \mathrm{~J}^{1 / 2} / \mathrm{cm}^{3 / 2}\right)$. Een kleinere $\Delta \delta$ betekent een betere oplosbaarheid van olie in de rubber, hetgeen wordt bevestigt door een hogere mate van olie-opname in de rubber. Desalniettemin vertoont MES-olie bij hoge temperaturen optredend bij rubber mengen een geringere verdraagzaamheid met $\mathrm{NR}$ en SBR vergeleken met TDAE en DAE. De theoretische voorspellingen correleren met de zwel-resultaten.

Hoofdstuk 5 beschrijft de resultaten van een voorlopige studie bedoeld om de effecten van de olie-types en -hoeveelheden te onderzoeken op de eigenschappen van ongevulde (niet versterkte) compounds. Het onderzoek met ongevulde NR, SBR en het NR/SBR mengsel met 50/50 gewichtsverhouding en met gebruikmaking van DAE, resp. TDAE en MES als alternatieve veilige extenderoliën laat zien dat de olie-types slechts een geringe invloed hebben op Mooney viscositeit en vulkanisatiesnelheid van alle compoundsoorten, behalve voor de NR-compounds, waarin DAE en TDAE een hogere vulkanisatiesnelheid opleveren in vergelijking met MES. De verschillende $T_{g}$ 's van de extender-oliën beïnvloeden de $T_{g}$ 's van de rubber compounds. Gebruik van DAE met een hogere $T_{g}$ dan de olie-vrije rubbers verhoogt de $T_{g}$ van de rubber compounds, terwijl gebruik van MES-olie met de laagste $T_{g}$ geen invloed heeft op de $T_{g}$ van $N R$ en die van $S B R$ lichtelijk verlaagt. De SBR met MES-olie vertoont lagere verlies-hoek waardes bij 0 en $60^{\circ} \mathrm{C}$, terwijl gebruik van MES-olie in NR resulteert in een hogere verlieshoek bij $60^{\circ} \mathrm{C}$ vergeleken met die van DAE en TDAE. De vervanging van DAE door TDAE en MES in ongevulde SBR en in het NR/SBR mengsel laat slechts kleine veranderingen zien in hun mechanische eigenschappen, ofschoon gebruik van MES in NR resulteert in lagere hardheid, 100\% modulus en treksterkte in vergelijking met TDAE en DAE. Betreffende de overall veranderingen in eigenschappen is NR het meest gevoelig voor verandering van olie-type.

Practische roet-gevulde NR vrachtwagenbanden loopvlak compounds met variërende olie-types en -hoeveelheden zijn vervolgens onderzocht en de eigenschappen in zowel ongevulkaniseerde als gevulkansieerde vorm worden besproken in Hoofdstuk 6. De compounds vertonen vergelijkbare meng-koppels voor dezelfde olie-gehaltes voor alle types. De compounds met DAE-olie hebben lagere Mooney viscositeiten, maar hogere complexe viscositeiten, in vergelijking met de mengsels op basis van TDAE- en MES-oliën. Hogere olie-gehaltes verlagen de compound viscositeiten, behalve voor 5 phr waarvoor de waardes lichtelijk hoger liggen dan voor de ongeplasticeerde compound. Het mengen van NR met roet in afwezigheid van olie wordt beïnvloed door het masticeer effect, wat resulteert in een groter mate van afbraak van de polymeer-ketens. De compounds met verschillende 
oliën vertonen vergelijkbare vulkansatie-karakteristieken. De DAE-gevulde compounds vertonen het hoogste Payne-effect en laagste Bound Rubber gehalte vergeleken met de mengsels met TDAE- en MES-oliën. De vulstof-vulstof en vulstof-rubber interacties neigen lichtelijk naar vermindering, wanneer meer olie wordt gebruikt in de compounds. SEMmicroscopische opnamen van de vulcanisaten laten zien, dat de roet fijn verdeeld is in alle compounds. Gebruik van DAE, TDAE en MES geeft vulcanisaten met vergelijkbare mechanische eigenschappen (hardheid, trek- en scheur-sterkte, en breukrek), maar verschillend in die eigenschappen gerelateerd aan verandering van $T_{g}$ en het viscoelastich gedrag. Gebruik van DAE met de hoogste $T_{g}$ resulteert in lagere slijtweerstand, vermoeiings-bestendigheid, terugveer-elasticiteit en hogere warmteopbouw, terwij het gebruik van MES met de laagste $\mathrm{T}_{\mathrm{g}}$ de beste elastische eigenschappen oplevert. Het inmengen van olie verhoogt de verlies-hoek bij zowel $0^{\circ} \mathrm{C}$ als bij $60^{\circ} \mathrm{C}$ van de gevulde NRvulcanisaten. De verlieshoek-waardes bij $0^{\circ} \mathrm{C}$ van alle vulcanisaten zijn vergelijkbaar bij gelijke olie-doseringen, maar de verlieshoek bij $60^{\circ} \mathrm{C}$ van de rubbers met MES en TDAE is lager dan voor DAE. De resultaten laten duidelijk zien, dat de vervanging van DAE door TDAE- en MES-oliën weinig effect heeft op de mechanische eigenschappen, maar dat de dynamische mechanische eigenschappen gerelateerd aan de verschillende $T_{g}$ 's van de oliën wel worden beïnvloed, hetgeen weer van invloed is op het overall functioneren van banden geproduceerd met deze oliën.

De eigenschappen van roet-gevulde NR/SBR personenwagen loopvlak compounds worden eveneens beïnvloed door verandering in olie-types en -hoeveelheden, zoals gerapporteerd in Hoofdstuk 7. De onderscheiden olie-types verschillen niet significant met betrekking tot hun invloed op het meng-koppel, dat afneemt met toenemende olie-gehaltes. De compounds met DAE-olie vertonen een lagere Mooney-viscositeit maar hogere complexe viscositeit vergeleken met de mengsels met TDAE en MES, en de viscositeiten gaan omlaag met toenemende olie-gehaltes. Gevulde SBR-compounds (zonder NR) met DAE vertonen eveneens de hoogste complexe viscositeit onder de drie types olie. De scorch- en vulcanisatie-tijden van roet-gevulde NR/SBR en gevulde SBR-compounds worden niet beïnvloed door verandering van de olie-types, maar nemen wel toe met hogere olie-hoeveelheden. De mengsel-compounds met DAE-olie vertonen hogere Payne-effecten in vergelijking met respectievelijk TDAE en MES. Evenwel, de olie-types vertonen geen effect op het Bound Rubber gehalte in zowel NR/SBR- als SBR-compounds. Verhoging van de olie-gehaltes reduceert zowel het Payne-effect als het Bound Rubber gehalte voor alle compounds. SEM-microscopische opnamen laten zien dat de roet fijn verdeeld is in alle compounds, ofschoon degene met MES een iets slechtere vulstof-dispersie vertoont. De 
NR/SBR-mengsels met DAE-olie hebben de laagste 100\% modulus, slijtage weerstand, vermoeidheids-bestendigheid en terugveer-elasticiteit, maar de hoogste warmte-opbouw vergeleken met de compounds op basis van TDAE- en MES-oliën. De verschillende olietypes hebben geen significante invloed op de treksterkte en de versterkings-index (reinforcement-index). TDAE geeft superieure slijtweerstand en vermoeiingsbestendigheid van de mengsel-vulcanisaten vergeleken met MES en DAE. Verhogen van de olie-gehaltes vermindert de hardheid, de 100\% modulus, treksterkte, terugveer-elasticiteit, warmteopbouw, maar laat de verlieshoek bij zowel $0^{\circ} \mathrm{C}$ als $60^{\circ} \mathrm{C}$ toenemen, zoals verwacht. De $\mathrm{T}_{\mathrm{g}}$ 's van de mengsel-vulcanisaten worden beïnvloed door de $T_{g}$ 's van de oliën. De SBR-fase vertoont een grotere $T_{\mathrm{g}}$-verschuiving vergeleken met de NR-fase, hetgeen aangeeft dat de oliën preferent worden opgenomen door de SBR-fase. Gebruik van MES-olie geeft de laagste verlieshoek bij $0^{\circ} \mathrm{C}$, terwijl DAE resulteert in de hoogste verlieshoek bij $60^{\circ} \mathrm{C}$. Derhalve geeft TDAE de beste balans tussen de verlieshoeken bij $0^{\circ} \mathrm{C}$ en $60^{\circ} \mathrm{C}$, indicatief voor de natte- slip- en rol-weerstand van banden.

Over het geheel genomen hebben de chemische structuren en samenstelling van DAE-, TDAE- en MES-oliën, die hun karakteristieke beïnvloeden, een uitwerking op hun verdraagzaamheid met rubbers en de eigenschappen van de corresponderende rubber compounds. De theoretische voorspellingen gebaseerd op verschillen in oplosbaarheidsparameters $(\Delta \delta)$ en de experimentele zwelling-studie komen goed overeen in de zin dat MES minder verdraagzaam is met NR en SBR vergeleken met TDAE en DAE. Het verschil in vulcanisatie-karakteristieken ten gevolge van de aanwezigheid van stikstof- en zwavelhoudende heterocyclische verbindingen in DAE-olie, zoals waargenomen in ongevulde (nietversterkte) compounds, vermindert in geval van roet-gevulde compounds. De mechanische eigenschappen van zowel ongevulde als roet-gevulde compounds worden weinig beïnvloed door verandering van de olie-types, maar de eigenschappen veranderen wel met de oiliedosering, voornamelijk door het verdunnings-effect. De verschillende glasovergangstemperaturen $\left(T_{g}\right)$ van de oliën beïnvloeden de $T_{g}$ 's van de rubber vulcanisaten en dientengevolge de eigenschappen gerelateerd aan de viscoelasticiteit, zoals de slijtweerstand, de terugveer-elasticiteit, warmte-opbouw en verlies-hoek. De vervanging van toxisch DAE door veilige TDAE en MES verbetert de elastische respons van de materialen. Op basis van de verwerkings-eigenschappen van de ongevulcaniseerde compounds zowel als de mechanische en dynamische eigenschappen van de vulcanisaten, geeft TDAE-olie betere overall eigenschappen als vervanging van DAE-olie dan MES. Voor banden loopvlakken beïnvloedt de overgang van DAE naar TDAE en MES op positieve 
wijze de voornaamste banden loopvlak karakteristieken, met name slijtweerstand, natte slipen rol-weerstand. 


\section{SYMBOLS AND ABBREVIATIONS}

\section{SYMBOLS}

$\alpha$

Y

$\delta$

$\Delta \delta$

$\delta_{\mathrm{A}}$

$\delta_{N}$

$\delta_{\mathrm{p}}$

$\delta_{d}$

$\delta_{p}$

$\delta_{\mathrm{H}}$

$\eta$

$\eta^{*}$

$\Delta \eta^{*}$

$\eta^{\prime}$

$\eta "$

Prubber

$\rho_{\text {oil }}$

${ }^{\circ} \mathrm{C}$

$\mathrm{C}_{\mathrm{A}}$

$\mathrm{C}_{\mathrm{N}}$

$\mathrm{C}_{\mathrm{P}}$

d

$E_{\text {coh }}$

$\mathrm{F}$

G'

$\Delta G^{\prime}$

$G^{*}$

$\mathrm{H}_{\text {Bay }}$

M300/M100

$\mathrm{m}_{0}$

$\mathrm{m}_{\mathrm{s}}$

\section{DESCRIPTION}

Coefficient of linear thermal expansion

Shear rate

Solubility parameter

The difference in solubility parameter

Solubility parameter of the aromatic structure

Solubility parameter of the naphthenic structure

Solubility parameter of the paraffic structure

The energy from dispersive forces

The energy from intermolecular forces

The energy from hydrogen bond between molecules

Shear viscosity

Complex viscosity

Difference in complex viscosity

Real part of complex viscosity

Imaginary part of complex viscosity

Density of the rubber

Density of the oil

Degrees Celsius

Aromatic carbon atom

Naphthenic carbon atom

Paraffinic carbon atom

Density

Cohesive energy

Molar attraction constant

Elastic or storage modulus

Difference in storage moduli

Dynamic modulus

Bay region protons

Reinforcement index

Mass of the crosslinked rubber before swelling

Mass of the crosslinked rubber at equilibrium swelling 
$\mathrm{M}_{\mathrm{H}}$

$\mathrm{M}_{\mathrm{L}}$

$\mathrm{M}_{\mathrm{H}}-\mathrm{M}_{\mathrm{L}}$

$\mathrm{ML}(1+4)$

SUS

$\mathrm{N}_{\mathrm{D}}^{20}$

Q

$\tan \delta$

$\mathrm{W}_{0}$

$\mathrm{W}_{1}$

$\mathrm{W}_{\mathrm{A}}$

$W_{N}$

$W_{P}$

\section{ABBREVIATIONS} 6PPD

ASTM

$\mathrm{BaA}$

BaFA

$\mathrm{BaP}$

BeP

BjFA

BkFA

BR

BIIR

BIT

BRC

CBS

$\mathrm{CDCl}_{3}$

CED

$\mathrm{CHR}$

DAE

DBahA

DCP
Maximum torque

Minimum torque

Torque difference

Mooney viscosity after 1 minute of preheating and 4 minutes of measuring, measured with a large rotor Saybolt Universal Seconds

Refractive index at $20^{\circ} \mathrm{C}$

Equilibrium swelling ratio

Loss tangent

Weights of dried samples

Weights of swollen samples

Mole percentage of aromatic structure

Mole percentage of naphthenic structure

Mole percentage of paraffinic structure

\section{DESCRIPTION}

$\mathrm{N}$-(1,3-dimethylbutyl)-N'-phenyl-p-phenylenediamine American Society for Testing and Materials

Benzo[a]anthracene

Benzo[b]fluoranthene

Benzo[a]pyrene

Benzo[e]pyrene

Benzo[j]fluoranthene

Benzo[k]fluoranthene

Butadiene rubber

Brominated isobutylene isoprene rubber

Black incorporation time

Bound rubber content

$\mathrm{N}$-cyclohexyl-2-benzothiazolesulfenamide

Deuterated chloroform

Cohesive energy density

Chrysene

Distillate aromatic extract

Dibenzo[a,h]anthracene

Dicumyl peroxide 
DMSO

DMTA

DPG

DSC

EPDM

EPO

E-SBR

ESBO

EU

FT-IR

$\mathrm{GC}$

GC-MS

$\mathrm{HA}$

HAF

HBU

${ }^{1} \mathrm{H}-\mathrm{NMR}$

HPLC

HSP

$\mathrm{Hz}$

IARC

ISO

LC-GC

MES

$\mathrm{MPa}$

NAP

NR

$\mathrm{PAH}$

PASHs

PCA

phr

PNA

RAE

RI

RPA

rpm

RSS
Dimethyl sulfoxide

Dynamic mechanical thermal analysis

Diphenylguanidine

Differential scanning calorimetry

Ethylene propylene diene rubber

Epoxidized palm oil

Emulsion styrene butadiene rubber

Epoxidized soybean oil

European Community

Fourier-transform infrared spectroscopy

Gas chromatography

Gas chromatography - mass spectrometry

Highly aromatic oil

High abrasion furnace black

Heat build-up

Proton nuclear magnetic resonance spectroscopy

High performance liquid chromatography

Hansen solubility parameter

Hertz

The International Agency for Research on Cancer

International Organization for Standardization

Liquid chromatography - gas chromatography

Mild extracted solvate

Megapascal

Naphthenic oil

Natural rubber

Polycyclic aromatic hydrocarbon

Polycyclic aromatic sulfurated hydrocarbons

Polycyclic aromatic

Parts per hundred parts of rubber

Polynuclear aromatic

Residual aromatic extract

Refractive index

Rubber Process Analyzer

Rounds per minute

Ribbed smoked sheet 
SBR

SEM

S-SBR

TDAE

$T_{g}$

TMQ

VGC

$\mathrm{ZnO}$
Styrene butadiene rubber

Scanning electron microscopy

Solution styrene butadiene rubber

Treated distillate aromatic extract

Glass transition temperature

Polymerized 2,2,4-trimethyl 1,2dihydroquinoline

Viscosity gravity constant

Zinc oxide 


\section{BIBLIOGRAPHY}

\section{Journal Articles}

1. A. Petchkaew, K. Sahakaro and J.W.M. Noordermeer, Petroleum-based safe process oils in NR, SBR and their blends: Study on unfilled compounds. Part I. Oil characteristics and solubility aspects, Kautschuk Gummi Kunststoffe, 66 (4), 43-47 (2013).

2. A. Petchkaew, K. Sahakaro and J.W.M. Noordermeer, Petroleum-based safe process oils in NR, SBR and their blends: Study on unfilled compounds. Part II. Properties, Kautschuk Gummi Kunststoffe, 66 (5), 21-27 (2013).

3. A. Petchkaew, K. Sahakaro and J.W.M. Noordermeer, Petroleum-based safe process oils: Solubility aspect and their influence on the properties of unfilled NR, SR and their blends, Indian International Rubber Journal, May-June (2013), 66-69.

4. A. Petchkaew, K. Sahakaro and J.W.M. Noordermeer, Effects of petroleum-based safe process oil types and contents on the properties of carbon black filled NR and NR/SBR blends, Polymer Testing, in preparation.

\section{Presentations}

1. A. Petchkaew, K. Sahakaro and J.W.M. Noordermeer, Petroleum-based PAH-safe process oils in NR, SBR, and their blends: Study on unfilled compounds, Fall $178^{\text {th }}$ Technical Meeting of the Rubber Division, ACS, Milwaukee, Wisconsin, US, paper no.81, 12-14 October 2010.

2. A. Petchkaew, K. Sahakaro and J.W.M. Noordermeer, Implications of PAH-free aromatic extender oils in NR and NR/SBR tire compounds, Dutch Polymer Day 2013, De Werelt Conference Centre, Lunteren, the Netherlands, 18-19 March 2013. 


\section{ACKNOWLEDGEMENTS}

From the beginning of my $\mathrm{PhD}$ study until the dissertation was finished, a lot of things were coming to my life. I have obtained the opportunity to find many people, to know a lot of new lessons and to go to many places. I have fortunately received the assistance from several kind people to get the achievement on my thesis when I studied and worked in Department of Rubber Technology and Polymer Science (PSU) and in Department of Elastomer Technology and Engineering (UT).

First of all, I am sincerely thankful to my promoter, Prof. Dr. J.W.M. Noordermeer for giving me the opportunity to be a PhD student in the group of Elastomer Technology and Engineering (ETE). During my PhD study period he has not only given me the knowledge concerning my work but also advised me how to develop my personality. He has tried to hearten me when I got the trouble on my life. Dear Prof. Noordermeer, thank you for your guidance to improve my dissertation and all your supports during this period.

I am especially grateful to my advisor Dr. Kannika for accepting me to be a student and all assistances on my PhD study. Dear Aj. Kannika, my dissertation could not have moved on and done without your support. During this time, you have always suggested me how to develop my experiments and my personal skills. I have gotten a lot of helps on my $\mathrm{PhD}$ thesis from you. Thank you very much for all your advices to push on me in order to reach the successful of this thesis.

Next, I would like to acknowledge the Dutch Natural Rubber Foundation and Hansen \& Rosenthal KG (Germany) for giving me the financial support of this thesis. By your supports, I could do my thesis without any obstacles and I have gotten the chance to know a new lesson about the process oils. I am also thankful to Mr. Jürgen Trimbach and Dr. Cristina Bergmann who took care of me when I visited H\&R in Hamburg and gave me the comments and suggestions on my work. Thank you for all of your helps and fruitful discussions. I would also like to thank Mr.Wil Aben for his advice and comments for this work.

Dear Wilma, you always open the door for all kind of matters that came during I worked in ETE group and you have always been nice to me since the first time we met each other. I would like to thank for all of your supports. 
I am grateful to Prof. Dewulf, Prof. Akkerman, Prof. Engbersen, Prof. Kummerlöwe and Prof. Busfield for being members of my graduation committee. Your thesis evaluation and comments for the completion of this thesis are appreciated.

Dear Jacob, I am impressively thankful for all of your helps. You have always supported me not only on my experiment in the lab but also on my private life. You always cheer on me when I depressed, thank you very much.

I wish to thank to all the teaching and non-teaching staff in the Department of Rubber Technology and Polymer Science, PSU. P-Absorn, P-Somkid and other technicians, thanks for your nice cooperation.

I would like to thank my ETE members for their help, kindness and friendship. To my ETE members: Nadia, Ernest, Salina, Andre, Somayeh, Morteza, Gerda, Ceciel and Yvonne. I had a great time with all of you during working in ETE group. I also appreciate all the nice times we spent together for all group activities. My special thanks to Nadia for being my paranimph and preparing my draft thesis for the committee members. Ceciel, thanks for all of your helps about my PhD promotion and others.

Living overseas would be complicated for my life if I were without all Thai friends in Enschede. I am thankful to my friends: Siti \& P-Nu, P-May \& P-Tom, N-Pipe, N-Gift, N-Rex, Wisut, N-Neung, Waew, Linda, N-Ham, N-Wa, N-May. My special thanks to Siti \& P-Nu for all helps on my work and my private life. All of you not only being my friends but also supporting me for all activities such as cooking, eating, shopping and travelling. Dear N-Gift, thanks for being my paranimph and supporting me about the accommodation.

I want to thank my friends in Thailand. During my PhD study, I have received a lot of assistance and enjoyment from my friends. Dear friends in Polymer Science 7, thanks for your supports and cares. Dear my colleagues and friends in Department of Rubber Technology and Polymer Science, PSU: N-Pui, N-Alif, N-Knot, N-Karnda, N-Da, N-Na, NTah, N-Fon Chalao, N-Dee, N-Kui, N-Peung, N-Akim, N-Subhan, N-Big, N-Ball, N-Dream, and others who have become my good friends, thanks for all of your helps. Special thanks to $\mathrm{N}-\mathrm{Subhan}$ for a nice thesis cover design.

Finally, I would like to express my sincere gratitude to my mom and dad for their unconditional support and love. Dear Dad, I always miss you and pray for you. I owe my deepest thank to my sister and brother, brother- and sister-in-law for your love and supports. To all my family, thank you for all your supports. 


\section{CURRICULUM VITAE}

Anida Petchkaew was born in Narathiwat (Thailand) on October $11^{\text {th }}, 1977$. She studied Polymer Science at Prince of Songkla University, Thailand and received B.Sc. degree in 2000. After that, she worked in the natural rubber glove company prior to resuming her study for M.Sc. degree at the same university in 2003. The topic of her master thesis was "Preparation and mechanical properties of natural rubber blended with chlorosulfonated polyethylene". After completing her M.Sc. study in 2006, she worked in the rubber parts industry. In May 2009, she joined the joint Ph.D. degree program between Prince of Songkla University and University of Twente and worked on the topic of "Implication of PNA-free aromatic/naphthenic extender oil in NR-based tire treads" under the financial support by the Netherlands Natural Rubber Foundation and Hansel \& Rosenthal KG. 
"Don't need to fly as high as others

Fly where you can

The flying style no need to copy others

Just fly to reach your dream"

"DhamINDDy" 